Review

\title{
Porous Carbon-Based Supercapacitors Directly Derived from Metal-Organic Frameworks
}

\author{
Hyun-Chul Kim and Seong Huh * (D) \\ Department of Chemistry and Protein Research Center for Bio-Industry, Hankuk University of Foreign Studies, \\ Yongin 17035, Korea; mdkop@naver.com \\ * Correspondence: shuh@hufs.ac.kr; Tel.: +82-31-330-4522
}

Received: 4 August 2020; Accepted: 21 September 2020; Published: 22 September 2020

check for updates

\begin{abstract}
Numerously different porous carbons have been prepared and used in a wide range of practical applications. Porous carbons are also ideal electrode materials for efficient energy storage devices due to their large surface areas, capacious pore spaces, and superior chemical stability compared to other porous materials. Not only the electrical double-layer capacitance (EDLC)-based charge storage but also the pseudocapacitance driven by various dopants in the carbon matrix plays a significant role in enhancing the electrochemical supercapacitive performance of porous carbons. Since the electrochemical capacitive activities are primarily based on EDLC and further enhanced by pseudocapacitance, high-surface carbons are desirable for these applications. The porosity of carbons plays a crucial role in enhancing the performance as well. We have recently witnessed that metal-organic frameworks (MOFs) could be very effective self-sacrificing templates, or precursors, for new high-surface carbons for supercapacitors, or ultracapacitors. Many MOFs can be self-sacrificing precursors for carbonaceous porous materials in a simple yet effective direct carbonization to produce porous carbons. The constituent metal ions can be either completely removed during the carbonization or transformed into valuable redox-active centers for additional faradaic reactions to enhance the electrochemical performance of carbon electrodes. Some heteroatoms of the bridging ligands and solvate molecules can be easily incorporated into carbon matrices to generate heteroatom-doped carbons with pseudocapacitive behavior and good surface wettability. We categorized these MOF-derived porous carbons into three main types: (i) pure and heteroatom-doped carbons, (ii) metallic nanoparticle-containing carbons, and (iii) carbon-based composites with other carbon-based materials or redox-active metal species. Based on these cases summarized in this review, new MOF-derived porous carbons with much enhanced capacitive performance and stability will be envisioned.
\end{abstract}

Keywords: Metal-Organic Frameworks (MOFs); carbonization; pyrolysis; porous carbons; supercapacitors; ultracapacitors; symmetric supercapacitors; asymmetric supercapacitors; pseudocapacitors; hybrid electrochemical capacitors; heteroatom-doped carbons; carbon composites; capacitance

\section{Introduction}

The development of efficient electrochemical energy storage materials is an urgent issue for modern scientific society [1,2]. Many electricity-driven devices ranging from small portable electronics to electric vehicles (EVs) absolutely require high performance rechargeable energy storage devices as a primary component [3]. In this sense, high-capacity lithium-ion batteries (LIBs) have been being studied intensively for better performance [4,5]. The impact of LIBs on modern technology is enormous. Meanwhile, there is a growing interest in supercapacitors, or ultracapacitors, as a means of alternative energy storage devices with high power [6]. Generally, LIBs outperform supercapacitors due to their 
high energy density. Nevertheless, chemically stable supercapacitors are especially useful for various cutting-edge applications [7]. Furthermore, fabrication of supercapacitors is simple and their raw materials are usually cost-effective. In this regard, research towards high performance supercapacitors is continuously growing.

There are previous excellent review articles well covering supercapacitors [6-13]. Therefore, we mostly focus on the supercapacitors directly derived from various metal-organic frameworks (MOFs). Most MOFs are made of two key components, metal ions and bridging organic-based linkers [14-16]. In some cases, solvate molecules or counterions can be present. Therefore, it is possible to obtain carbon-based materials through simple pyrolysis of MOFs under inert atmosphere. The numerously different types of organic-based bridging linkers can act as very good carbon precursors. Since the properties of carbon materials are mainly related to their precursors, one can prepare many different types of carbons by choosing different MOFs. MOF-derived supercapacitor electrode materials can be classified into three main types based on their chemical compositions of the resulting porous carbons upon pyrolysis of MOFs under inert atmosphere: (i) pure and heteroatom-doped carbons, (ii) metallic nanoparticle (NP)-containing carbons, and (iii) other carbon-based composites as illustrated in Scheme 1. Simple pyrolysis process of certain MOFs affords almost pure carbonaceous materials with good porosity. In this case, volatile metallic elements are effectively lost during high-temperature pyrolysis conditions [17]. Contrarily, some heteroatoms such as N, S, O, and P can be incorporated into the carbon matrix. These heteroatoms are originated from the organic-based linkers or counterions [18-23]. Incomplete removal of metal ions often produces metallic NP-containing carbons and carbon-based composite materials [24,25]. All these porous materials are good candidates for supercapacitor applications under various working conditions. Pure carbonaceous materials can behave as supercapacitors mainly based on electrical double-layer capacitance (EDLC). The charge can be stored in a sandwich-type porous carbon-based electrode is separated by a porous membrane (Scheme 2). When the voltage is applied to two porous carbon electrodes, charges are stored mostly on the surfaces of the electrodes through the formation of EDL. Not only the types of metal ions but also the types of bridging ligands may play a crucial role in determining the structures of MOFs. Generally, the bridging ligands with small physical dimensions tend to form MOFs with low porosity. Carbons prepared from these MOFs are likely to show less developed porosity with decreased capacitive performance. Additional pseudocapacitances apply for both heteroatom-doped carbons and carbon composites due to the redox-active components. Now that there is promising progress using these materials as supercapacitor electrodes, we would like to review this interesting area for electrochemical energy storage.

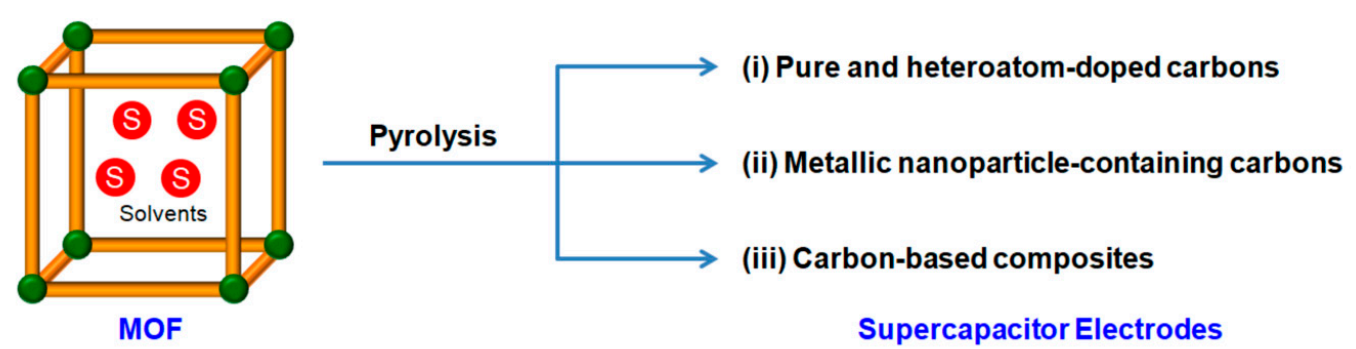

Scheme 1. A schematic illustration of the three main types of porous carbons directly derived from MOFs, and which can be used as supercapacitor electrode materials. 


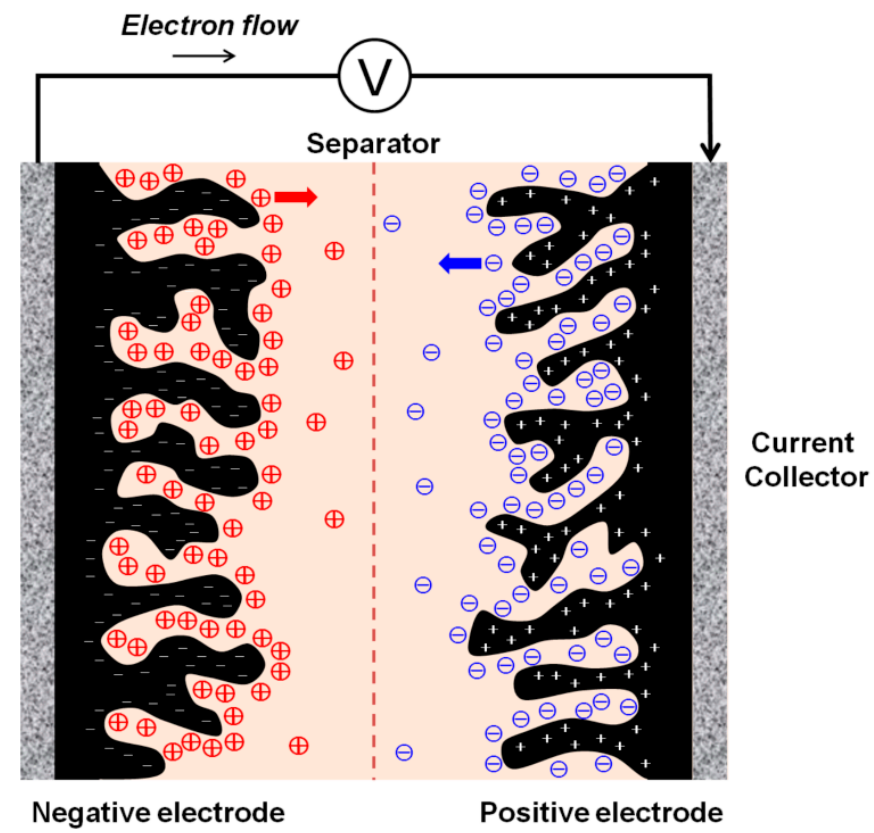

Scheme 2. A simplified view of the porous carbon-based supercapacitor to show operating principle of energy storage.

The performances of supercapacitors are evaluated by several key parameters [26]: gravimetric specific capacitance $\left(C, \mathrm{~F} \mathrm{~g}^{-1}\right)$, specific energy $\left(E, \mathrm{~W} \mathrm{~h} \mathrm{~kg}{ }^{-1}\right)$, specific power $\left(P, \mathrm{~W} \mathrm{~kg} \mathrm{~kg}^{-1}\right)$, and charge/discharge recyclability. The relevant basic equations are shown below:

$$
\begin{gathered}
C=\frac{I \Delta t}{m \Delta V} \\
E=\frac{1}{7.2} C(\Delta V)^{2} \\
P=3600 \frac{E}{\Delta t}
\end{gathered}
$$

where, I: charge/discharge current in A, $\Delta t$ : discharge time in s, $m$ : mass of the active electrode material in $\mathrm{g}, \Delta V$ : voltage window in $\mathrm{V}$.

\section{Pure and Heteroatom-Doped Carbons}

\subsection{Zn-MOF-Derived Carbons}

The most well investigated MOF precursors for porous carbons are Zn-based MOF systems. $\mathrm{Zn}-\mathrm{MOF}$ can be easily assembled from divalent $\mathrm{Zn}^{2+}$ ion and various carboxylate-based bridging ligands. There are fairly many reports relevant this case as summarized in Table 1 . The volatile $\mathrm{Zn}$ species tend to be simultaneously removed during high-temperature carbonization. Therefore, we analyze this system first. 
Table 1. The electrochemical capacitive performances of porous carbons derived from MOF-5 and other non-ZIF-based Zn-MOFs.

\begin{tabular}{|c|c|c|c|c|c|c|}
\hline Samples & $S_{\text {BET }}\left(\mathrm{m}^{2} \mathrm{~g}^{-1}\right)$ & $C_{\max }\left(\mathrm{F} \mathrm{g}^{-1}\right)$ & $E_{\max }\left(\mathrm{Wh} \mathrm{kg}^{-1}\right)$ & $P_{\max }\left(\mathrm{W} \mathrm{kg}^{-1}\right)$ & System & Ref. \\
\hline NPC & 2872 & 312 & - & - & $2 \mathrm{E}$ & 27 \\
\hline NPC530 & 3040 & 158 & - & - & $2 \mathrm{E}$ & 28 \\
\hline NPC650 & 1521 & 222 & - & - & $2 \mathrm{E}$ & 28 \\
\hline NPC800 & 1141 & 151 & - & - & $2 \mathrm{E}$ & 28 \\
\hline NPC900 & 1647 & 148 & - & - & $2 \mathrm{E}$ & 28 \\
\hline NPC1000 & 2524 & 149 & - & - & $2 \mathrm{E}$ & 28 \\
\hline $\mathrm{MC}$ & 1812 & 172 & 23.6 & - & $3 \mathrm{E} / 2 \mathrm{E}$ & 29 \\
\hline MPC & 1543 & 193 & 24.6 & - & $3 \mathrm{E} / 2 \mathrm{E}$ & 29 \\
\hline MAC & 384 & 104 & 3.6 & - & $3 \mathrm{E} / 2 \mathrm{E}$ & 29 \\
\hline MC-A & 1673 & 222 & 27.4 & - & $3 \mathrm{E} / 2 \mathrm{E}$ & 29 \\
\hline MPC-A & 1271 & 196 & 27.6 & - & $3 \mathrm{E} / 2 \mathrm{E}$ & 29 \\
\hline MAC-A & 2222 & 274 & 31.2 & - & $3 \mathrm{E} / 2 \mathrm{E}$ & 29 \\
\hline $\begin{array}{l}\text { 3D hierarchical porous } \\
\text { carbon }\end{array}$ & 1600 & 175 & - & - & $2 \mathrm{E}$ & 30 \\
\hline MDC-D & 2980 & - & - & - & $3 \mathrm{E}$ & 31 \\
\hline IPC3-M & 1515 & 212 & - & - & $2 \mathrm{E}$ & 32 \\
\hline MOF-5-C 850 & 609 & 244 & - & - & $3 \mathrm{E}$ & 33 \\
\hline MOF-5/AC-C nsp 850 & 677 & 300 & - & - & $3 \mathrm{E}$ & 33 \\
\hline IMCS4-8-6 & 860 & 242 & 8.41 & 9907 & $2 \mathrm{E}$ & 34 \\
\hline Porous carbon & 2619 & 148.8 & 17.37 & $13,516.4$ & $3 \mathrm{E} / 2 \mathrm{E}$ & 35 \\
\hline PVDF/CMOF-5 & 847 & 218 & - & - & $2 \mathrm{E}$ & 36 \\
\hline Laminated HPC & 2368 & 234 & - & - & $3 \mathrm{E}$ & 37 \\
\hline C-MOF-5 & 2184 & 150 & - & - & $2 \mathrm{E}$ & 38 \\
\hline C-MOF-2 & 1378 & 170 & - & - & $2 \mathrm{E}$ & 38 \\
\hline C-Zn-BTC & 1326 & 134 & - & - & $2 \mathrm{E}$ & 38 \\
\hline C-Zn-NDC & 920 & 114 & - & - & $2 \mathrm{E}$ & 38 \\
\hline C-Zn-PAA & 495 & 110 & - & - & $2 \mathrm{E}$ & 38 \\
\hline C-Zn-ADA & 513 & 95 & - & - & $2 \mathrm{E}$ & 38 \\
\hline CIRMOF-3-950 & 553 & 239 & - & - & $2 \mathrm{E}$ & 39 \\
\hline CIRMOF-3-800 & 402 & 153 & - & - & $2 \mathrm{E}$ & 39 \\
\hline CIRMOF-3-700 & 454 & 54 & - & - & $2 \mathrm{E}$ & 39 \\
\hline CIRMOF-3-600 & 391 & 0.9 & - & - & $2 \mathrm{E}$ & 39 \\
\hline CMOF-5-950 & 572 & 24 & - & - & $2 \mathrm{E}$ & 39 \\
\hline GNRib & 1492 & 273 & - & - & $2 \mathrm{E}$ & 40 \\
\hline CNRod & 1559 & 187 & - & - & $2 \mathrm{E}$ & 40 \\
\hline $\mathrm{MPC}$ & 1286 & 120 & - & - & $2 \mathrm{E}$ & 40 \\
\hline C-S-800 & 319 & 61 & - & - & $2 \mathrm{E}$ & 41 \\
\hline C-S-900 & 1356 & 369 & 12.5 & 7200 & $2 \mathrm{E}$ & 41 \\
\hline C-S-1000 & 1122 & 248 & - & - & $2 \mathrm{E}$ & 41 \\
\hline C-B-800 & 191 & 35 & - & - & $2 \mathrm{E}$ & 41 \\
\hline C-B-900 & 543 & 116 & - & - & $2 \mathrm{E}$ & 41 \\
\hline C-B-1000 & 528 & 148 & - & - & $2 \mathrm{E}$ & 41 \\
\hline BM-700 & 682 & 192 & - & - & $3 \mathrm{E}$ & 42 \\
\hline BM-800 & 823 & 175 & - & - & $3 \mathrm{E}$ & 42 \\
\hline BM-900 & 1115 & 188 & - & - & $3 \mathrm{E}$ & 42 \\
\hline BM-1000 & 1241 & 179 & - & - & $3 \mathrm{E}$ & 42 \\
\hline КВM-700 & 1129 & 230 & - & - & $3 \mathrm{E}$ & 42 \\
\hline KBM-800 & 1059 & 225 & - & - & $3 \mathrm{E}$ & 42 \\
\hline KBM-900 & 959 & 176 & - & - & $3 \mathrm{E}$ & 42 \\
\hline KBM-1000 & 909 & 154 & - & - & $3 \mathrm{E}$ & 42 \\
\hline MPC-950 & 1455 & 471 & - & - & $3 \mathrm{E}$ & 43 \\
\hline MPC-850 & 746 & 437 & - & - & $3 \mathrm{E}$ & 43 \\
\hline MPC-750 & 589 & 401 & - & - & $3 \mathrm{E}$ & 43 \\
\hline MPC-650 & 518 & 377 & - & - & $3 \mathrm{E}$ & 43 \\
\hline S800 & 774 & 418 & - & - & $3 \mathrm{E}$ & 44 \\
\hline S800 & 774 & 73 & - & - & $3 \mathrm{E}$ & 45 \\
\hline S900 & 828 & 318 & - & - & $3 \mathrm{E}$ & 45 \\
\hline S1000 & 903 & 284 & - & - & $3 \mathrm{E}$ & 45 \\
\hline CNFs & 1725 & 280 & - & - & $3 \mathrm{E}$ & 46 \\
\hline NPC800 & 562 & 269.3 & - & - & $3 \mathrm{E}$ & 47 \\
\hline NPC1000 & 546 & 164.3 & - & - & $3 \mathrm{E}$ & 47 \\
\hline ZBDh-D10-900 & 1490 & $\sim 80$ & - & - & $2 \mathrm{E}$ & 48 \\
\hline ZBDt-M10-900 & 1230 & $\sim 80$ & - & - & $2 \mathrm{E}$ & 48 \\
\hline
\end{tabular}


Table 1. Cont.

\begin{tabular}{ccccccc}
\hline Samples & $S_{\text {BET }}\left(\mathbf{m}^{\mathbf{2}} \mathbf{g}^{-\mathbf{1}}\right)$ & $C_{\max }\left(\mathbf{F} \mathbf{g}^{-\mathbf{1}}\right)$ & $E_{\max }\left(\mathbf{W} \mathbf{~ h ~} \mathbf{~ g}^{-\mathbf{1}}\right)$ & $\boldsymbol{P}_{\max }\left(\mathbf{W ~} \mathbf{~ g g}^{-\mathbf{1}}\right)$ & System & Ref. \\
\hline HPC & 1391 & 166 & - & - & $3 \mathrm{E}$ & 87 \\
HPCs-0 & 1796 & 185 & - & - & $3 \mathrm{E}$ & 87 \\
MC-Zn & 420 & 121.3 & - & - & $3 \mathrm{E}$ & 88 \\
PC-Zn & 1558 & 138 & - & - & $3 \mathrm{E}$ & 89 \\
MOF-DC & 2714 & - & $\sim 20$ & - & $2 \mathrm{E}$ & 90 \\
CMOF-5 & 2489 & 206 & - & - & $3 \mathrm{E}$ & 112 \\
C-MOF & 1117 & 225 & - & - & $3 \mathrm{E}$ & 113 \\
\hline
\end{tabular}

\subsubsection{MOF-5-Derived Carbons}

$\mathrm{Xu}$ et al. reported the unprecedented example of MOF-derived nanoporous carbon (NPC) as an electrode material for EDLC capacitor [27]. A furfuryl alcohol (FA) vapor as a carbon source was infiltrated into the pores of MOF-5 ( $\left[\mathrm{Zn}_{4} \mathrm{O}(\mathrm{bdc})_{3}\right]$, bdc $=1,4$-benzenedicarboxylate) template. Polymerization of the infiltrated FA was performed to construct PFA/MOF-5 composite $(\mathrm{PFA}=$ poly (furfuryl alcohol)), and this composite was transformed into the NPC via one-step carbonization at $1000{ }^{\circ} \mathrm{C}(8 \mathrm{~h}$, Ar flow). Without any additional purification process, the resulting NPC contained ultra-high Brunauer-Emmett-Teller surface area $\left(\mathrm{S}_{\mathrm{BET}}\right)$ as well as large total pore volume $\left(\mathrm{V}_{\text {total }}=2.06 \mathrm{~cm}^{3} \mathrm{~g}^{-1}\right)$. The NPC with hierarchical porosity had good electrochemical performance for symmetric EDLC-type supercapacitor electrode operating in $1 \mathrm{M} \mathrm{H}_{2} \mathrm{SO}_{4}$ electrolyte. It showed a good gravimetric capacitance of $312 \mathrm{~F} \mathrm{~g}^{-1}$ at a scan rate of $1 \mathrm{mV} \mathrm{s}^{-1}$ and $159 \mathrm{~F} \mathrm{~g}^{-1}$ at $50 \mathrm{mV} \mathrm{s}^{-1}$. The same group applied incipient wetness method to insert FA into MOF- 5 for the synthesis of NPCs [28]. The as-prepared NPCs (as-NPC 530 , as- $\mathrm{NPC}_{650}$, as-NPC $\mathrm{NP00}_{8}, \mathrm{NPC}_{900}$ and $\mathrm{NPC}_{1000}$ ) were prepared from the carbonization ( $8 \mathrm{~h}$, Ar flow) of the PFA/MOF- 5 composite. Three NPCs $\left(\mathrm{NPC}_{530}, \mathrm{NPC}_{650}\right.$ and $\left.\mathrm{NPC}_{800}\right)$ were generated by $\mathrm{HCl}(0.1 \mathrm{M})$ treatment of the as-prepared NPCs. Carbonization temperature-dependent properties of the nanoporous carbons (NPCs) such as $\mathrm{S}_{\mathrm{BET}}$, pore size distribution, and electrical conductivity had great influence on the electrochemical performance of symmetric NPC supercapacitor at $1 \mathrm{M} \mathrm{H}_{2} \mathrm{SO}_{4}$ electrolyte. Because of their fine mesoporosities combined with superior electric conductivity, the NPC electrodes except for $\mathrm{NPC}_{530}$ showed ideal capacitive behavior as well as good rate capability.

MOF- 5 as a single-carbon source or MOF- 5 with other secondary carbon sources (phenolic resin or carbon tetrachloride and ethylenediamine) was employed to prepare MOF-5-derived carbons [29]. Without or with secondary carbon precursors, three kinds of porous carbons (MC, MPC and MAC) were synthesized from MOF- 5 at $900{ }^{\circ} \mathrm{C}\left(\mathrm{N}_{2}\right.$ flow). Subsequent potassium hydroxide $(\mathrm{KOH})$ activation $\left(700{ }^{\circ} \mathrm{C}, 3 \mathrm{~h}\right.$, the mass ratio of $\mathrm{KOH} /$ carbon $\left.=5 / 1\right)$ of each carbon generated corresponding three activated samples (MC-A, MPC-A, and MAC-A). Electrochemical performances of the obtained carbon electrodes were investigated under both $6 \mathrm{M} \mathrm{KOH}$ electrolytic three-electrode (3E) system and $1.5 \mathrm{M}$ $\mathrm{NEt}_{4} \mathrm{BF}_{4}$ electrolytic two-electrode (2E) system in acetonitrile. The maximum gravimetric energy densities of 9.4 and $31.2 \mathrm{~W} \mathrm{~h} \mathrm{~kg}^{-1}$ could be obtained for MAC-A in $6 \mathrm{M} \mathrm{KOH}$ and $1.5 \mathrm{M} \mathrm{NEt}_{4} \mathrm{BF}_{4} / \mathrm{AN}$ electrolytes, respectively. Because of high packing density of $0.93 \mathrm{~g} \mathrm{~cm}^{-3}$, MAC-A also delivered high volumetric energy density of $8.8 \mathrm{~W} \mathrm{~h} \mathrm{~L}^{-1}$ at aqueous electrolyte and $29.0 \mathrm{~W} \mathrm{~h} \mathrm{~L}^{-1}$ at organic electrolyte. Facile ionic transport due to hierarchical porosity also led to superior energy density rate capabilities for MC, MC-A, MPC, and MPC-A. For MAC-A at a discharge time of $10 \mathrm{~s}$, the largest volumetric energy density and power density of $6.6 \mathrm{~W} \mathrm{~h} \mathrm{~L}^{-1}$ and $2.4 \mathrm{~kW} \mathrm{~L}^{-1}$ were shown in an aqueous electrolyte.

Glucose was employed as a secondary carbon source for the MOF-5-based three-dimensional (3D) hierarchical porous carbon [30]. A green and effective synthetic method of the 3D hierarchical porous carbon from MOF-5/glucose composite was accomplished via solvothermal reaction and a single-step carbonization. Primary construction of 3D structure of MOF-5 sacrificial template and subsequent infiltration and polymerization of glucose carbon source were performed at solvothermal condition $\left(160^{\circ} \mathrm{C}\right)$. Direct carbonization of optimally synthesized composite (solvothermal reaction time $=25 \mathrm{~h})$ at $950{ }^{\circ} \mathrm{C}(4.5 \mathrm{~h})$ could form $3 \mathrm{D}$ coral-like porous carbon with hierarchical porosity. As an 
active electrode material for a symmetric supercapacitor (SSC) in $1 \mathrm{M} \mathrm{NEt}_{4} \mathrm{BF}_{4} /$ propylene carbonate electrolyte, this carbon exhibited capacitances of $175 \mathrm{~F} \mathrm{~g}^{-1}$ at $0.6 \mathrm{~A} \mathrm{~g}^{-1}$ and $165 \mathrm{~F} \mathrm{~g}^{-1}$ at $12 \mathrm{~A} \mathrm{~g}^{-1}$. These good electrochemical results were assignable to its micro-/meso-/macroporous hierarchical structure. The roles of macropores, mesopores, and micropores are efficient ion-buffering storage, generation of ionic transport pathway, and providing ionic diffusion space, respectively. Another 3D hierarchically porous carbon with controlled large-scale meso-/macroporosity was synthesized from a facile solvent evaporation strategy during the carbonization of MOF- 5 without the requirement of templating and replication process $\left(900^{\circ} \mathrm{C}, 3 \mathrm{~h}, \mathrm{~N}_{2}\right.$ flow) [31]. A direct pyrolytic evaporation of non-volatile $\mathrm{N}, \mathrm{N}$-dimethylformamide (DMF) solvent molecules captured in MOF- 5 micropores was performed to reorganize the MOF template for the construction of ultra-highly porous MOF-derived carbon, MDC-D. The resulting MDC-D exhibited an interconnected macropore structure with 3D wormhole-like shape, high $S_{\mathrm{BET}}$, hierarchical porosity, and exceptionally high $\mathrm{V}_{\text {total }}$ of $5.45 \mathrm{~cm}^{3} \mathrm{~g}^{-1}$. The electrochemical function of micropores was thought to be an ionic reservoir, and the mesopores and macropores were considered to be pathways of ionic transport. As a result, the MDC-D working electrode of 3E system operating in $1 \mathrm{M} \mathrm{NaCl}$ showed high rate capacities in $\mathrm{CV}$ and electrochemical impedance spectroscopy (EIS).

MOF-5-derived 3D interconnected porous carbons (IPCs) were also synthesized through sonochemical $\mathrm{KOH}$ activation $(600 \mathrm{~W}, 20 \mathrm{~min})$ combined with acid washing $(2 \mathrm{M} \mathrm{HCl})$ [32]. The obtained carbon samples known as $\mathrm{IPC}_{\mathrm{x}-\mathrm{M}}$ (x: the mass ratio of MOF-5/KOH, M: microwave heating) showed a unique structure and better electrochemical performance compared to the control sample of $\mathrm{IPC}_{2-\mathrm{C}}$ (C: conventional heating at $850{ }^{\circ} \mathrm{C}$ ). Very thin wall structure provided short pathway for fast ionic transport. Ion accessible porosity was also beneficial for ionic storage. The interconnected framework improved electron conduction. Among them, IPC $3-\mathrm{M}$ was the best electrode material for SSC in $6 \mathrm{M} \mathrm{KOH}$ electrolyte. Mesoporous carbons derived from MOF-5-based carbon composites were reported [33,34]. A soft templating/carbonization strategy was applied to the synthesis of carbon nanospheres (CNSs) from MOF-5/AC composite (AC stands for activated carbon) [33]. AC was used as a nucleation mediator for the crystallization of MOF- 5 at mild room temperature. Thus, AC acted as a soft template for the preparation of MOF-5/AC. Subsequently, MOF-5/AC-C nsp 850 was obtained via carbonization of the composite at $850{ }^{\circ} \mathrm{C}(6 \mathrm{~h}$, Ar flow $)$ and subsequent $1 \mathrm{M}$ hydrofluoric acid (HF) treatment. Compared to the fragmented porous carbon (MOF-5-C 850) directly derived from the as-prepared MOF-5, the obtained MOF-5/AC-C nsp 850 exhibited well-defined and spherical particle morphology with improved mechanical strength. In addition, it also possessed better porosity than the MOF-5-C 850. Therefore, enhanced electrochemical capacitive performance for the 3E system with $6 \mathrm{M} \mathrm{KOH}$ could be seen in the MOF-5/AC-C nsp 850 electrode.

The $\mathrm{KOH}$ activation combined with one-step carbonization of MOF-5/coal tar pitch composites was introduced to simply fabricate the interconnected mesoporous carbon sheets (IMCSs) [34]. KOH-mixed $\mathrm{KOH} / \mathrm{coal}$ tar pitch composites were prepared from cheap high yielded carbon precursor, i.e., coal tar pitch, and room temperature synthesized MOF- 5 as both a template and additional carbon precursor. $\mathrm{KOH}$-mixed $\mathrm{KOH} / \mathrm{coal}$ tar pitch composites were carbonized at $850{ }^{\circ} \mathrm{C}\left(1 \mathrm{~h}, \mathrm{~N}_{2}\right.$ flow $)$ and then neutralized with $2 \mathrm{M} \mathrm{HCl}$ to form $\operatorname{IMCS}_{\mathrm{x}-\mathrm{y}-\mathrm{z}}$ (mass of coal tar pitch (x), MOF-5 (y), and $\mathrm{KOH}(\mathrm{z})$ ). Among the samples, the $\mathrm{IMCS}_{4-8-6}$-based carbon electrode showed superior SSC performance in $6 \mathrm{M}$ $\mathrm{KOH}$ electrolyte. Highest specific capacitance of the $\mathrm{IMCS}_{4-8-6}$ at $0.05 \mathrm{~A} \mathrm{~g}^{-1}$ was $242 \mathrm{~F} \mathrm{~g}^{-1}$, and it retained to $80.2 \%\left(194 \mathrm{~F} \mathrm{~g}^{-1}\right)$ up to $20 \mathrm{~A} \mathrm{~g}^{-1}$. MOF-5-derived electrode for symmetric all-solid-phase supercapacitor was reported [35]. Porous carbon materials with high purity as well as an ultra-large $\mathrm{S}_{\mathrm{BET}}$ was synthesized from single-step carbonization of MOF-5 precursor at $900{ }^{\circ} \mathrm{C}\left(2 \mathrm{~h}, \mathrm{~N}_{2}\right.$ flow). The amorphous porous carbon showed rich porosity with hierarchical pore size distribution (average $D_{\text {pore }}=\sim 7 \mathrm{~nm}$ ). Under $3 \mathrm{E}$ system operating in $0.5 \mathrm{M} \mathrm{Na}_{2} \mathrm{SO}_{4}$ electrolyte, the as-made porous carbon electrode yielded maximum specific capacitance of $148.8 \mathrm{~F} \mathrm{~g}^{-1}$ at $5 \mathrm{~A} \mathrm{~g}^{-1}$ and high rate capacity (88.6\% retention) at $50 \mathrm{~A} \mathrm{~g}^{-1}$. With the extension of operating voltage up to $1.8 \mathrm{~V}$, the carbon-based electrode was also applied to the symmetric all-solid-phase supercapacitor acting in $\mathrm{Na}_{2} \mathrm{SO}_{4} / \mathrm{PVA}$ 
(PVA = polyvinyl alcohol) gel electrolyte. At $1 \mathrm{~A} \mathrm{~g}^{-1}$, the SSC delivered a high energy density of $17.37 \mathrm{~W} \mathrm{~h} \mathrm{~kg}^{-1}$ with a power density of $449.9 \mathrm{~W} \mathrm{~kg}^{-1}$. This was a rare example of MOF-derived carbon employed as electrode material for solid-state supercapacitor (Figure 1).

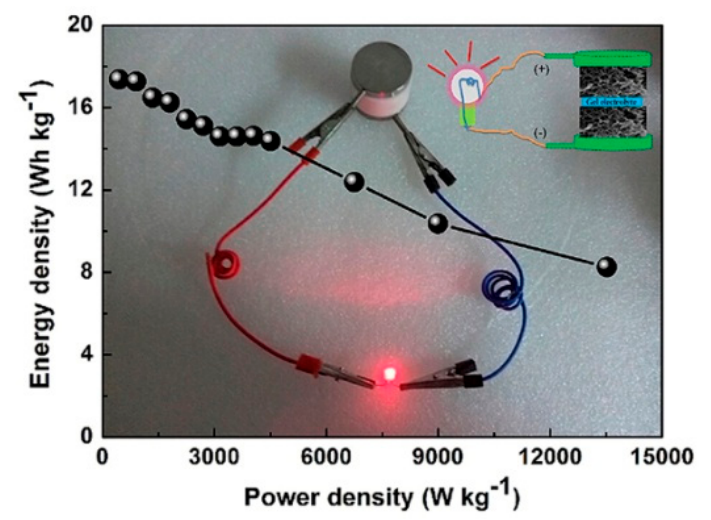

Figure 1. A Ragone plot and schematic descriptions of the all-solid-phase SSC assembled from MOF-5 derived porous carbon electrode with $\mathrm{Na}_{2} \mathrm{SO}_{4}$-PVA gel electrolyte [35].

The MOF-5-derived carbon (CMOF-5) electrode with potential environmental and industrial applicabilities was reported [36]. First, the economical and structurally effective (free from void/cracking) PVDF/CMOF-5 nanocomposite coating on the current collector was easily achieved via evaporation of acetone suspension containing poly (vinylidene fluoride) (PVDF) and CMOF-5. The CMOF- 5 was synthesized from simple carbonization of MOF- 5 at $1000{ }^{\circ} \mathrm{C}(1 \mathrm{~h}$, Ar flow $)$ and subsequent $\mathrm{HCl}$ treatment. After successive ultra-sonification, dropping, and evaporation, there was an adequate contact of CMOF-5 with the PVDF binder in the nanocomposite. The solvent evaporated PVDF/CMOF-5 composite held thinner thickness and more stable architecture in comparison with PVDF/CMOF-5 composite prepared by high-pressure pressing. The PVDF/CMOF-5 composite prepared by evaporation also exhibited better porosity than PVDF/CMOF- 5 composite made from compressing. Therefore, when applied as a working electrode for SSC in $1 \mathrm{M} \mathrm{H}_{2} \mathrm{SO}_{4}$ electrolyte, the evaporation induced CMOF-5 electrode showed high specific capacitance of $138 \mathrm{~F} \mathrm{~g}^{-1}$ at $3 \mathrm{~A} \mathrm{~g}^{-1}$ and a good rate capacity. Interestingly, the CMOF- 5 could be prepared from the recycled raw materials. Using distilled waste DMF solvent and hydrothermally depolymerized polyethylene terephthalate (PET)-based terephthalic acid, or 1,4-benzenedicarboxylic acid, the obtained r1-CMOF-5 possessed good electrochemical performance. Finally, the CMOF- 5 was a reusable working electrode fabricated from spent electrodes. Acetone washing of the previously used electrode and following $\mathrm{HCl}$ washing, the CMOF-5 (r2-CMOF-5) was effectively recovered.

\subsubsection{Other Zn-MOF-Derived Carbons}

There are two reports about carbon electrodes derived from nonporous Zn-MOF [37,38]. A hollow porous carbon (HPC) with laminated morphology was prepared from a nonporous metal-organic coordinate polymer (MOCP) self-sacrificing template and phenol resin polymer as a secondary carbon source [37]. After the carbonization of $\mathrm{MOCP} / \mathrm{phenol}$ resin polymer composite at $850{ }^{\circ} \mathrm{C}$ ( $3 \mathrm{~h}, \mathrm{~N}_{2}$ flow), the obtained HPC showed high $\mathrm{S}_{\mathrm{BET}}$ and laminated nanostructure containing both micropores and mesopores. The enhancement of ionic diffusion and electrochemically effective surface area could be attributable to this hierarchical porosity. Therefore, the carbon material for EDLC in 3E system in $6 \mathrm{M} \mathrm{KOH}$ electrolyte yielded a maximum capacitance of $234 \mathrm{~F} \mathrm{~g}^{-1}$ at $0.01 \mathrm{~A} \mathrm{~g}^{-1}$ with high capacitive retention. A series of porous carbon materials have been synthesized through simple direct carbonization of as-prepared nonporous Zn-MOFs at $1000{ }^{\circ} \mathrm{C}(3 \mathrm{~h}$, Ar flow) except for MOF-5 with $\mathrm{S}_{\mathrm{BET}}=2385 \mathrm{~m}^{2} \mathrm{~g}^{-1}$ [38]. The self-sacrificing templates were MOF-5 $\left[\mathrm{Zn}_{4} \mathrm{O}(\mathrm{bdc})_{3}\right], \mathrm{MOF}-2\left[\left(\mathrm{H}_{2} \mathrm{NEt}\right)_{2}\left[\mathrm{Zn}_{3}(\mathrm{bdc})_{4}\right] \cdot 3 \mathrm{DEF}\right], \mathrm{Zn}-\mathrm{btc}\left[\mathrm{Zn}_{3}(\mathrm{btc})_{2}(\mathrm{DMSO})_{4}\right], \mathrm{Zn}-\mathrm{ndc}\left[\mathrm{Zn}(\mathrm{ndc})\left(\mathrm{H}_{2} \mathrm{O}\right)\right]$, 
and Zn-paa $\left[\mathrm{Zn}_{2}(\text { paa })_{2}\right]$. In addition, the corresponding carbons were C-MOF-5, C-MOF-2, C-Zn-btc (btc $=1,3,5$-benzenetricarboxylic acid), C-Zn-ndc (ndc = 2,6-naphthalenedicarboxylic acid), C-Zn-paa (paa = 1,4-phenylenediacetic acid), and C-Zn-ada (ada = 1,3-adamantanediacetic acid). Systematic studies about the influence of linker nature upon the resultant carbons' properties were performed by variation of linkers in the MOF templates. The linkers contained flexible alicyclic or rigid aromatic backbones. The morphology of the resulting carbons was dependent on the flexibility of linkers. The rigid aromatic linker containing MOF-based carbons (C-MOF-5, C-MOF-2, C-Zn-ndc, and C-Zn-btc) showed well-defined and periodically arranged carbon sheets. However, the flexible alicyclic linker containing MOF-based carbons (C-Zn-paa and C-Zn-ada) had less-ordered and 2D carbon sheets. The linker flexibility also affected the porosity of the obtained carbons. The carbons derived from the rigid linker containing MOFs possessed improved $\mathrm{S}_{\mathrm{BET}}$ (C-MOF-5, C-MOF-2, C-Zn-btc, and C-Zn-ndc are 2184, 1378, 1326, and $920 \mathrm{~m}^{2} \mathrm{~g}^{-1}$, respectively) compared with flexible linker possessing MOF-derived ones (C-Zn-paa and C-Zn-ada were 495 and $513 \mathrm{~m}^{2} \mathrm{~g}^{-1}$, respectively). In addition, the linear correlation between $\mathrm{S}_{\mathrm{BET}}$ of carbons and the $\mathrm{Zn} / \mathrm{C}$ proportion of the MOFs could be only applied to the MOF precursors constructed from rigid linkers. Furthermore, the former carbons contained larger pores $(5-10 \mathrm{~nm})$ than the latter carbons $(2-7 \mathrm{~nm})$. Interestingly, the flexibility of the linker could control the electrochemical performance of SSC assembled from the relevant porous carbons in $2 \mathrm{E}$ symmetric cell with $1 \mathrm{M} \mathrm{H}_{2} \mathrm{SO}_{4}$ electrolyte. The specific capacitance of each carbon was mainly dependent on the surface area.

Many other reports that introduced different aromatic linkers [39-43] or aliphatic linkers [44-46] into the $\mathrm{Zn}$-MOF templates were published. The former reports are further divided into two parts based on whether bdc modified linkers were employed [39,40] or not [41-43]. A NH $\mathrm{N}_{2}$-bdc or 2-aminobenzene-1,4-dicarboxylic acid-based Zn-MOF (IRMOF-3) was used as a self-sacrificing template for the scalable synthesis of a hierarchical $\mathrm{N}$-doped porous carbon $(\mathrm{N}$-doping level $=3.3 \%$ ) [39]. With no extra nitrogen- or carbon-containing precursors and purification process, CIRMOF-3-950 was prepared from a single-step carbonization of the template at $950{ }^{\circ} \mathrm{C}(6 \mathrm{~h}$, Ar flow). Other CIRMOF-3-s ( $\mathrm{s}=$ carbonization temperature) carbons carbonized at lower temperature required further $\mathrm{HCl}$ treatment to remove residual $\mathrm{ZnO}$. Compared with them, the CIRMOF-3-950 had high hierarchical porosity and graphitization degree. A N-free-control CMOF-5-950 derived from MOF-5 exhibited similar pore features to the CIRMOF-3-950. However, there were different electrochemical properties between CIRMOF-3-950 and CMOF-5-950 electrodes for SSC operated in $1.0 \mathrm{M} \mathrm{H}_{2} \mathrm{SO}_{4}$. The difference might be originated from the $\mathrm{N}$-dopant related factors, such as improved electrolyte wettability (electrolyte-electrode interaction), reduced carbon defects, and additional pseudocapacitance. As a result, the CIRMOF-3-950 showed good specific capacitances of $239 \mathrm{~F} \mathrm{~g}^{-1}$ at $5 \mathrm{mV} \mathrm{s}^{-1}$ and $212 \mathrm{~F} \mathrm{~g}^{-1}$ at $0.5 \mathrm{~A} \mathrm{~g}^{-1}$. However, the CMOF-5-950 showed only $24 \mathrm{~F} \mathrm{~g}^{-1}$ at $0.5 \mathrm{~A} \mathrm{~g}^{-1}$. In addition, the observed specific capacitances of CIRMOF-3-950 were $166 \mathrm{~F} \mathrm{~g}^{-1}$ at $100 \mathrm{mV} \mathrm{s}{ }^{-1}$ and $162 \mathrm{~F} \mathrm{~g}^{-1}$ at $10 \mathrm{~A} \mathrm{~g}^{-1}$. These high rate capabilities were resulted from efficient electrolyte diffusion facilitated by the hierarchical pore structure.

A facile and effective method to prepare an outstanding 2D carbon electrode for supercapacitor was successfully accomplished [40]. MOF-74 with salicylic acid as a modulator facilitating rod-shaped morphology was synthesized from the anhydrous zinc acetate and 2,5-dihydroxyterephthalic acid under mild reaction condition at room temperature. Without another catalyst or carbon source, MOF-74-Rod self-sacrificing template was transformed into 1D-carbon nanorods (CNrod) by simple carbonization at $1000{ }^{\circ} \mathrm{C}(4 \mathrm{~h}, \mathrm{Ar}$ flow). Subsequently, 2D-graphene nanoribbons (GNRib) composed of two- to six-laminated structure was obtained with high yield $(>75 \%)$ and purity $(>90 \%)$ by sonochemical $\mathrm{KOH}$ treatment of the CNrod followed by pyrolytic activation at $800^{\circ} \mathrm{C}(2 \mathrm{~h}, \mathrm{Ar}$ flow) with acid washing $(1 \mathrm{~N} \mathrm{HCl})$. The GNRib exhibited high $\mathrm{S}_{\mathrm{BET}}$ and electrical conductivity $\left(4.93 \mathrm{~S} \mathrm{~cm}^{-1}\right)$. Furthermore, it held 2D laminated structure for enhanced connectivity and interlayer void for easy ionic accessibility. Thus, the GNRib was a good electrode material for SSC. The specific capacitances obtained from CV are 193 and $123 \mathrm{~F} \mathrm{~g}^{-1}$ at 10 and $400 \mathrm{mV} \mathrm{s}^{-1}$, respectively, in $1 \mathrm{M} \mathrm{H}_{2} \mathrm{SO}_{4}$ electrolyte. The electrode could 
operate in ionic liquid of 1-ethyl-3-methylimidazolium dicyanamide with the extension of applied voltage from 1.0 to $3.0 \mathrm{~V}$. It delivered high specific capacitances of $273 \mathrm{~F} \mathrm{~g}^{-1}$ at $10 \mathrm{mV} \mathrm{s}^{-1}$ and $227 \mathrm{~F} \mathrm{~g}^{-1}$ at $0.05 \mathrm{~A} \mathrm{~g}^{-1}$.

$\mathrm{Zn}$ (thip) (thip = 5-tert-butyl isophpthalate) was employed as a precursor for the preparation of 3D sponge shaped porous carbons (PCs) with interconnected hierarchical porosity as shown in Figure 2 [41]. From a single-step carbonization ( $2 \mathrm{~h}$, Ar flow) of two different particle sized $\mathrm{Zn}-\mathrm{MOFs}$ (Zn(thip)-B and $\mathrm{Zn}$ (thip)-S), the corresponding carbon samples (C-B-n, C-S-n, n = carbonization temperature in ${ }^{\circ} \mathrm{C}$ ) were obtained. C-S-900 was the best sample for good structural and electrochemical properties. The hierarchically porous C-S-900 had high $\mathrm{S}_{\mathrm{BET}}$ and $\mathrm{V}_{\text {total }}\left(2.72 \mathrm{~cm}^{3} \mathrm{~g}^{-1}\right)$. These structural characteristics could effectively improve ion diffusion/transport, electrochemically accessible surface area, and conductivity. In addition, maximum energy density of $12.5 \mathrm{~W} \mathrm{~h} \mathrm{~kg}^{-1}$ and maximum power density of $7200 \mathrm{~W} \mathrm{~kg}^{-1}$ were obtained. A flexible all-solid-phase device for SSC was investigated in PVA/KOH electrolyte, too. Its highest areal specific capacitance was found to be $159 \mathrm{mF} \mathrm{cm}{ }^{-2}$ at $0.15 \mathrm{~A} \mathrm{~cm}^{-2}$. Furthermore, high mechanical stability was shown up to bending angle of $180^{\circ}$.
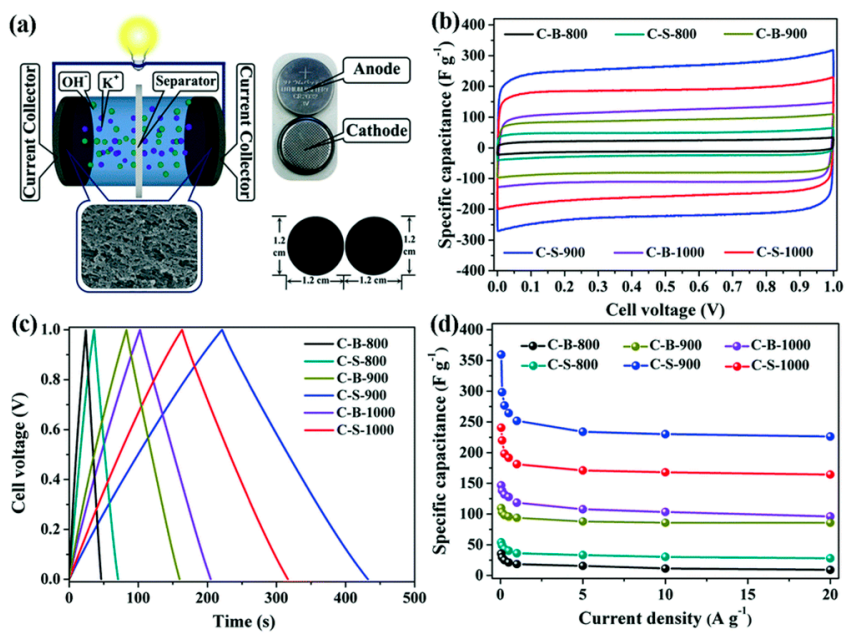

Figure 2. (a) Illustrations of the SSC in $6 \mathrm{M} \mathrm{KOH}$ electrolyte; (b) CV curves at $50 \mathrm{mV} \mathrm{s}^{-1}$ for C-B-n and C-S-n; (c) Galvanostatic charge-discharge (GCD) curves at $0.5 \mathrm{~A} \mathrm{~g}^{-1}$ for C-B-n and C-S-n; (d) dependence of specific capacitance on applied current densities [41].

There was an interesting report of carbon derived from an anionic Zn-MOF containing $4,4^{\prime}$-biphenyldicarboxylate (bpdc) bridging ligand [42]. In the report, a cation-exchanged form of the anionic Zn-MOF template has been prepared and carbonized for the sake of generating well-developed microporosity of the resultant MOF-derived carbon through in situ activation by the encapsulated $\mathrm{K}^{+}$ions. The anionic bio-MOF-1 has a formula of $\left[\mathrm{Me}_{2} \mathrm{NH}_{2}\right]_{2}\left[\mathrm{Zn}_{8}(\mathrm{ad})_{4}(\mathrm{bpdc})_{6}\right]$ (ad = adeninate). The $\mathrm{K}^{+}$ion-encapsulated bio-MOF-1 (K@bio-MOF-1) was prepared from a DMF solution of $0.1 \mathrm{M} \mathrm{KNO}_{3}$. $\left[\mathrm{Me}_{2} \mathrm{NH}_{2}\right]^{+}$ions were easily exchanged with $\mathrm{K}^{+}$ions. After carbonization of the templates ( $4 \mathrm{~h}, \mathrm{~N}_{2}$ flow) and followed by $2 \mathrm{M} \mathrm{HCl}$ treatment, mesoporous BM-T (from bio-MOF-1) and microporous KBM-T (from K@bio-MOF-1) were produced ( $\mathrm{T}=$ carbonization temperature in ${ }^{\circ} \mathrm{C}$ ). As a result of effective in situ $\mathrm{K}^{+}$-activation, $\mathrm{KBM}-700$ with a narrow pore size distribution has high values of $\mathrm{S}_{\mathrm{BET}}, \mathrm{V}_{\text {micro }}$ ratio $(73 \%)$, and nitrogen content $(10.16 \%)$. Its $3 \mathrm{E}$ cell also showed a good electrochemical performance in $6 \mathrm{M} \mathrm{KOH}$ electrolyte. It showed high specific capacitance of $230 \mathrm{~F} \mathrm{~g}^{-1}$ at $1 \mathrm{~A} \mathrm{~g}^{-1}$. These excellent properties could be ascribed to the hierarchical microporosity as well as the high $\mathrm{N}$-dopant content.

PFA/Zn-btc-MOF composite was used to synthesize microporous carbons (MPCs) [43]. The composite was prepared by incorporating FA secondary carbon source into the bare MOF template and subsequent polymerization of the encapsulated FA. After a single-step carbonization of the composite at $950{ }^{\circ} \mathrm{C}(6 \mathrm{~h}, \mathrm{Ar}$ flow $)$, the resultant MPC-950 showed high $\mathrm{S}_{\mathrm{BET}}$ with large 
$\mathrm{V}_{\text {total }}\left(2.013 \mathrm{~cm}^{3} \mathrm{~g}^{-1}\right)$. Furthermore, improved carbon yield (28\%) and a wide range of pore regions (micropore, mesopore, and macropore) were accomplished for MPC-950. Combined with good $\mathrm{S}_{\mathrm{BET}}$ and $\mathrm{V}_{\text {total }}$, these various pore regions played a key role in enhancing the specific capacitance of MPC-950-based working electrode for 3E system in $6 \mathrm{M} \mathrm{KOH}$ electrolyte. The electrode showed high specific capacitances of $471 \mathrm{~F} \mathrm{~g}^{-1}$ at $2 \mathrm{mV} \mathrm{s}^{-1}$ and $320 \mathrm{~F} \mathrm{~g}^{-1}$ at $100 \mathrm{mV} \mathrm{s}^{-1}$.

Wang et al. published two papers about carbon materials derived from $\mathrm{Zn}$-glutamate MOF [44,45]. In the first paper, a simple and green synthetic approach for carbon precursor of $\left[\mathrm{Zn}(\mathrm{L}-\mathrm{glu}) \mathrm{H}_{2} \mathrm{O} \cdot \mathrm{H}_{2} \mathrm{O}\right]_{n}$ microrods (L-glu $=\mathrm{L}$-glutamate) was reported [44]. The carbon precursor was synthesized from the aqueous solution of zinc acetate hydrate and monosodium glutamate (MSG) at room temperature. In addition, the 3D nanoporous material with hierarchical porosity was obtained from the MOF microrods via carbonization $\left(2 \mathrm{~h}, \mathrm{~N}_{2}\right)$ and acid treatment with $1 \mathrm{M} \mathrm{HCl}$. The resultant carbon with co-doping of $\mathrm{N}$ and $\mathrm{O}$ had interconnected microporous structure with thin shell cavity. Among three carbons (S700, S800, and S900) prepared from different carbonization temperatures, S800 contained well-developed microporosity $\left(S_{\text {micro }}=403 \mathrm{~m}^{2} \mathrm{~g}^{-1}, \mathrm{~V}_{\text {micro }}=0.21 \mathrm{~cm}^{3} \mathrm{~g}^{-1}\right.$ ) despite smaller $\mathrm{S}_{\mathrm{BET}}$. As a working electrode material for $3 \mathrm{E}$ cell in $6 \mathrm{M} \mathrm{KOH}$ electrolyte, the $\mathrm{S} 800$ exhibited best performance among them. The specific capacitances were $418 \mathrm{~F} \mathrm{~g}^{-1}$ at $10 \mathrm{mV} \mathrm{s}^{-1}$ and $276 \mathrm{~F} \mathrm{~g}^{-1}$ at $200 \mathrm{mV} \mathrm{s}^{-1}$. In this electrode, a high $\mathrm{N}$-doping level (7.67\%) improved electronic conductivity and surface wettability for effective ionic transport. Moreover, 3D interconnected hierarchical porosity enhanced the charge accommodation. In the second paper, another simple and green synthetic approach for the electrostatically assembled graphene oxide (GO)-MOF composite-based carbon precursor was reported [45]. The etching of MOF facets by GO sheets was discovered for the first time. The GO-MOF composite was prepared from positive GO sheets and a negative $\mathrm{Zn}$-glutamate MOF under aqueous condition. The GO-MOF composite derived porous carbons were synthesized from carbonization $\left(2 \mathrm{~h}, \mathrm{~N}_{2}\right)$ and subsequent acid washing $(1 \mathrm{M} \mathrm{HCl})$. The heteroatom-doped and 3D-interconnected porous carbons showed "egg-shell" architecture with crumpled graphene thin sheets. Among the final three carbon products (S800, S900, and S1000) from different carbonization temperatures, $S 900$ exhibited an improved microporosity $\left(S_{\text {micro }}=567 \mathrm{~m}^{2} \mathrm{~g}^{-1}, \mathrm{~V}_{\text {micro }}=0.24 \mathrm{~cm}^{3} \mathrm{~g}^{-1}\right)$. Therefore, S900 carbon working electrode showed good capacitive performance in 3E system using $6 \mathrm{M}$ $\mathrm{KOH}$ electrolyte. At $20 \mathrm{mV} \mathrm{s}^{-1}$, its gravimetric and volumetric specific capacitances were $318 \mathrm{~F} \mathrm{~g}^{-1}$ and $299 \mathrm{~F} \mathrm{~cm}^{-3}$, respectively. Both hierarchical porosity (micro-/mesopore) and 3D-interconnected cellular structure may have synergistic effects on enhanced accommodation of charges. Furthermore, 2D graphene architectures improved conductivity and speed of electronic double-layer formation.

A simple and economical fabrication of mesoporous carbon nanofibers was achieved from the self-sacrificing template of zinc glycolate [46]. The self-sacrificing template was prepared from ethylene glycol (EG) solution of cheap zinc acetate. After heat treatment of the zinc glycolate fibers at $600{ }^{\circ} \mathrm{C}$ $(2 \mathrm{~h}, \mathrm{Ar}$ flow) and subsequent $2.0 \mathrm{M} \mathrm{HCl}$ treatment, the mesoporous carbon nanofibers (CNFs) were successfully synthesized. The $\mathrm{CNFs}$ showed $1 \mathrm{D}$-fibrous nanostructure, high $\mathrm{S}_{\mathrm{BET}}$, large $\mathrm{V}_{\text {total }}$ $\left(2.7 \mathrm{~cm}^{3} \mathrm{~g}^{-1}\right)$, well-defined micropores $(1.1 \mathrm{~nm})$ and mesopores (3.4 and 10 20 nm), 3D interconnected mesoporosity, and abundant surface oxygen functionalities ( $\sim 9 \mathrm{wt} . \%)$. As a result, the CNFs-based working electrode showed good capacitive performance in both $6 \mathrm{M} \mathrm{KOH}$ electrolyte (3E cell) and $1.0 \mathrm{M} \mathrm{Et}_{4} \mathrm{NF}_{4} / \mathrm{PC}(\mathrm{PC}=$ propylene carbonate; $2 \mathrm{E}$ cell).

Two other reports using pyridine-containing linker or dabco (dabco = 1,4-diazabicyclo [2.2.2] octane) as N-dopant sources were published $[47,48]$. Two $\mathrm{N}$-doped porous carbons (NPCs) derived from ([Zn(bpydc)DMA].DMF (bpydc $=2,2^{\prime}$-bipyridine-5, $5^{\prime}$-dicarboxylate, DMA = dimethyl acetamide, $\mathrm{DMF}=\mathrm{N}, \mathrm{N}$-dimethylformamide, the abbreviation of "bpydc" is used here instead of "bpdc" to avoid any confusion with the same term for 4,4'-biphenyldicarboxylic acid) were synthesized from direct carbonization $\left(3 \mathrm{~h}, \mathrm{~N}_{2}\right.$ flow) at two different temperatures $\left(800\right.$ and $\left.1000^{\circ} \mathrm{C}\right)$ [47]. The NPC 800 showed a higher $\mathrm{S}_{\mathrm{BET}}$ with a larger $\mathrm{V}_{\text {pore }}$ as well as a higher N-dopant content than NPC1000. On the contrary, it held better graphitization degree and a good conductivity than NPC800. As a working electrode of supercapacitor for 3E system operating in $6 \mathrm{M} \mathrm{KOH}$ electrolyte, the NPC 800 possessed superior 
electrochemical properties than the NPC1000. Synergistic contributions of EDLC (from high surface area and mesoporosity) and pseudocapacitance (from nitrogen contents) could effectively support the result.

Schmidt et al. investigated a facile and effective preparation of nano-MOF with solvent controlled morphology and its influence on volumetric capacitance of the resultant carbon electrode [48]. The dual roles of solvent in mild conditional synthesis of $\left[\mathrm{Zn}_{2}(\mathrm{bdc})_{2}(\mathrm{dabco})\right]_{\mathrm{n}}(\mathrm{ZBD})$ were template and crystallization modulator. The selective formation of either an 1D-hexagonal rod MOF (ZBDh) or a 2D-tetragonal plate MOF (ZBDt) was induced by $\mathrm{DMF}$ and $\mathrm{MeOH}$, respectively. One-step direct carbonization of the ZBDs at $900{ }^{\circ} \mathrm{C}(2 \mathrm{~h}$, Ar flow) produced nanoporous carbons of ZBDh-D10-900 (hexagonal nanorods) and ZBDt-M10-900 (tetragonal nanoplates). They had similar graphitization degree and nitrogen content $(4.2 \mathrm{wt} . \%)$ but different $\mathrm{S}_{\mathrm{BET}}\left(1490 \mathrm{~m}^{2} \mathrm{~g}^{-1}\right.$ for ZBDh-D10-900 and $1230 \mathrm{~m}^{2} \mathrm{~g}^{-1}$ for ZBDt-M10-900). EDLC-type supercapacitive performance of symmetric ZBD-derived carbon electrodes was measured in $1 \mathrm{M} \mathrm{TEABF}_{4} / \mathrm{AN}$ electrolyte. The two electrodes showed similar gravimetric capacitances. However, the volumetric capacitances of the $2 \mathrm{D}$ tetragonal plate carbon electrode were almost 2-fold larger than those of hexagonal carbon rod in the scan rate ranging from 10 to $500 \mathrm{mV} \mathrm{s}^{-1}$. The 2D morphology and comparatively high packing density could account for this result.

For pure and heteroatom-doped carbons, the electrodes with high $\mathrm{S}_{\mathrm{BET}}$ usually exhibited high capacitances. The surface area of MPC-950 with the highest gravimetric capacitance of $471 \mathrm{~F} \mathrm{~g}^{-1}$ is as large as $1455 \mathrm{~m}^{2} \mathrm{~g}^{-1}$ as shown in Table 1. Although there are additional critical factors such as suitable pore dimension and pore structure for capacitance enhancement, the surface area of the porous carbons from MOFs is primarily important.

\subsubsection{ZIF-8-Derived Carbons}

Porous carbons can be efficiently prepared from zeolitic imidazolate frameworks (ZIFs). Notably, ZIFs contain imidazole-based bridging ligands which are potential N-dopant sources. Since the carbonization of ZIF-8 was most intensively investigated, the electrochemical capacitive properties of the porous carbons derived from ZIF-8 are summarized in Table 2. ZIF-derived carbon electrodes for supercapacitor were first reported by $\mathrm{Xu}$ et al. [49]. ZIF-8, one of the most famous zeolite-type MOFs, has been chosen as both a primary carbon source and a sacrificial self-sacrificing template for $\mathrm{N}$-doped porous carbon due to its high chemical and thermal stabilities along with high porosity. As a secondary carbon source, FA was infiltrated into thermally activated ZIF-8 for the construction of FA/ZIF-8 composite despite the limited accessibility of FA to small ZIF-8 pores. After polymerization of FA, the FA/ZIF-8 composite was transformed into PFA/ZIF-8 composite. Carbonization of the PFA/ZIF-8 composite at different temperatures at 800 or $1000{ }^{\circ} \mathrm{C}(8 \mathrm{~h}$, Ar flow) was conducted to produce the $\mathrm{N}$-doped porous carbon materials (C800 or $\mathrm{C} 1000)$. $\mathrm{C} 1000$ contained higher $\mathrm{S}_{\mathrm{BET}}$ and $\mathrm{V}_{\text {pore }}$ than $\mathrm{C} 800$. Both $\mathrm{N}$-doped carbon electrodes of SSC operating in $1 \mathrm{M} \mathrm{H}_{2} \mathrm{SO}_{4}$ electrolyte exhibited high specific capacitance about $200 \mathrm{~F} \mathrm{~g}^{-1}$ at $0.250 \mathrm{~A} \mathrm{~g}^{-1}$. They also showed excellent rate performances $\left(188 \mathrm{~F} \mathrm{~g}^{-1}\right.$ for $\mathrm{C} 800$ and $161 \mathrm{~F} \mathrm{~g}^{-1}$ for $\mathrm{C} 1000$ at $5 \mathrm{mV} \mathrm{s}^{-1}, 160 \mathrm{~F} \mathrm{~g}^{-1}$ for $\mathrm{C} 800$ and $137 \mathrm{~F} \mathrm{~g}^{-1}$ for $\mathrm{C} 1000$ at $50 \mathrm{mV} \mathrm{s}^{-1}$ ).

The nanoporous carbon series of $Z-n\left(n=\right.$ carbonization temperature in $\left.{ }^{\circ} \mathrm{C}\right)$ was synthesized from direct carbonization of ZIF-8 (5 h, $\mathrm{N}_{2}$ ) and following $10 \mathrm{wt} . \%$ HF solution treatment [50]. Except for Z-600, the resultant carbons exhibited high surface areas and narrow porosity. Z-900-based working electrode of $3 \mathrm{E}$ cell with $0.5 \mathrm{M} \mathrm{H}_{2} \mathrm{SO}_{4}$ electrolyte had gravimetric capacitances of $214 \mathrm{~F} \mathrm{~g}^{-1}$ at $5 \mathrm{mV} \mathrm{s}^{-1}$ and $115 \mathrm{~F} \mathrm{~g}^{-1}$ at $100 \mathrm{mV} \mathrm{s}^{-1}$. In addition, the electrode held the highest volumetric capacitance of $200 \mathrm{~F} \mathrm{~cm}^{-3}$ at $5 \mathrm{mV} \mathrm{s}^{-1}$ among the reported values for MOF-derived carbon electrodes at that time. 
Table 2. The electrochemical capacitive performances of porous carbons derived from ZIF-8.

\begin{tabular}{|c|c|c|c|c|c|c|}
\hline Samples & $S_{\text {BET }}\left(\mathrm{m}^{2} \mathrm{~g}^{-1}\right)$ & $C_{\max }\left(\mathrm{F} \mathrm{g}^{-1}\right)$ & $E_{\max }\left(\mathrm{Wh} \mathrm{kg^{-1 } )}\right.$ & $P_{\max }\left(\mathrm{W} \mathrm{kg}^{-1}\right)$ & System & Ref \\
\hline C1000 & 3405 & 188 & - & - & $2 \mathrm{E}$ & 49 \\
\hline Z-900 & 1075 & 214 & - & - & $3 \mathrm{E}$ & 50 \\
\hline AS-ZC-800 & 2972 & 251 & - & - & $2 \mathrm{E}$ & 51 \\
\hline NMCs & 2737 & 307 & - & - & $3 \mathrm{E}$ & 52 \\
\hline C-ZIF-8 & 745 & 181 & - & - & $3 \mathrm{E}$ & 53 \\
\hline NPC & 1523 & 251 & 10.86 & 2281 & $3 \mathrm{E} / 2 \mathrm{E}$ & 54 \\
\hline Carbon-ZS & 934 & 285.8 & - & - & $3 \mathrm{E}$ & 55 \\
\hline $\mathrm{NPC}$ & 1873 & 21.0 & $\sim 6.6^{\mathrm{a}}$ & - & $2 \mathrm{E}$ & 56 \\
\hline $\begin{array}{c}\text { 3D hybrid-porous } \\
\text { carbon }\end{array}$ & 1057 & 332 & - & - & $3 \mathrm{E}$ & 57 \\
\hline S-900 & 1823 & 219 & 14.64 & - & $3 \mathrm{E} / 2 \mathrm{E}$ & 58 \\
\hline HPCNFs-N & 418 & 307.2 & 10.96 & 25,000 & $2 \mathrm{E}$ & 59 \\
\hline NPCF & 315 & 332 & - & - & $3 \mathrm{E}$ & 60 \\
\hline NHCF-66.7\%ZIF-8 & 560 & 302 & - & - & $3 \mathrm{E}$ & 61 \\
\hline 3D-BN-CNF-ZF900 & 352 & 295 & - & - & $3 \mathrm{E}$ & 62 \\
\hline N-NFC-8 & 277 & 387.3 & 7.9 & - & $3 \mathrm{E} / 2 \mathrm{E}$ & 63 \\
\hline NMCS-8 & 1937 & 232 & - & - & $3 \mathrm{E}$ & 64 \\
\hline
\end{tabular}

Xu et al. reported the 3D carbon framework with well-interconnected hierarchical porosity derived from ZIF-8 [51]. Microporous ZIF-8 NPs were prepared from ultra-sonification method, and additional micro-/macropores of the ZIF-8 were also generated by sonochemically induced interparticle spaces. The resultant S-ZIF-8 with hierarchical porosity was transformed into S-ZC-800 via direct carbonization at $800{ }^{\circ} \mathrm{C}(10 \mathrm{~h}, \mathrm{Ar}$ flow $)$ and subsequent $\mathrm{HCl}\left(5 \mathrm{vol} \%\right.$ in $\left.\mathrm{H}_{2} \mathrm{O}\right)$ treatment. Hierarchically porous AS-ZC-800 was obtained by $\mathrm{KOH}$ activation of the S-ZC-800 $\left(\mathrm{C} / \mathrm{KOH}=0.5 ; 800{ }^{\circ} \mathrm{C}, 1 \mathrm{~h}\right.$, Ar flow). The AS-ZC-800 carbon framework showed high $S_{\text {BET }}$ and large $V_{\text {total }}\left(2.56 \mathrm{~cm}^{3} \mathrm{~g}^{-1}\right)$ in addition to well-interconnected micro-, meso-, and macropores. The AS-ZC-800 electrode for SSC under $1 \mathrm{M} \mathrm{H}_{2} \mathrm{SO}_{4}$ electrolytic condition presented high specific capacitances and excellent capacitive rate performance $\left(187 \mathrm{~F} \mathrm{~g}^{-1}\right.$ at $400 \mathrm{mV} \mathrm{s}^{-1}$ and $204 \mathrm{~F} \mathrm{~g}^{-1}$ at $50 \mathrm{~A} \mathrm{~g}^{-1}$ ).

A single-template synthesis of $\mathrm{N}$-doped mesoporous carbons (NMCs) with ordered morphology were achieved by only a single-step carbonization at $1000{ }^{\circ} \mathrm{C}\left(2 \mathrm{~h}, \mathrm{~N}_{2}\right.$ flow $)$ of nano-sized ZIF-8 polyhedrons [52]. The NMCs exhibited ultra-high $\mathrm{S}_{\mathrm{BET}}$ of $2737 \mathrm{~m}^{2} \mathrm{~g}^{-1}$ as well as dominant mesoporosity (average $\mathrm{D}_{\text {pore }}=4.27 \mathrm{~nm}$, the ratio of mesopore volume/total pore volume $=74.09 \%$ ) with moderate $\mathrm{N}$-doping level (4.84 at\%). Under 3E supercapacitor cell at $1 \mathrm{M} \mathrm{H}_{2} \mathrm{SO}_{4}$ electrolyte, it showed $307 \mathrm{~F} \mathrm{~g}^{-1}$ at $1 \mathrm{~A} \mathrm{~g}^{-1}$ and $182.5 \mathrm{~F} \mathrm{~g}^{-1}$ at $50 \mathrm{Ag}^{-1}$. It also had great capacitive rate capability of $74.6 \%$ retention when the scan rate increased from $10 \mathrm{mV} \mathrm{s}^{-1}\left(212.1 \mathrm{~F} \mathrm{~g}^{-1}\right)$ to $1000 \mathrm{mV} \mathrm{s}^{-1}\left(158.3 \mathrm{~F} \mathrm{~g}^{-1}\right)$. The efficient formation of electrical double-layer (EDL) from mesoporosity-driven facile ionic transport, nitrogen functional group induced enhancement of electrode wettability, effective redox reaction may synergistically operate for the superior performances.

An easy and cost-effective synthetic strategy was developed for ZIF-8-based carbon series with bimodal micro-/mesoporosity [53]. With or without incorporation of extra porogenes of silica colloids (fumed silica or Ludox) into a sacrificial template of ZIF-8, carbonization $\left(800{ }^{\circ} \mathrm{C}, 5 \mathrm{~h}\right.$, Ar flow) of the as-prepared ZIF-8 or silica/ZIF- 8 and subsequent $10 \mathrm{wt} . \% \mathrm{HF}$ treatment generated a series of hierarchical porous carbons (C-ZIF-8, LC-ZIF-8, and FC-ZIF-8). In addition to microporous ZIF-8 cavities and mesopores from self-aggregation of carbon NPs, the colloidal silica/ZIF-8 derived carbon samples had additional mesopores ( $3 \mathrm{~nm}$ for LC-ZIF-8, and $17 \mathrm{~nm}$ for FC-ZIF-8) resulted from self-assembly or elimination of additional silica porogenes. The resultant mesoporosity of the carbon series greatly influenced electrochemical performance of the working electrode for 3E system operating in $6 \mathrm{M} \mathrm{KOH}$ electrolyte. At a scan rate of $5 \mathrm{mV} \mathrm{s}^{-1}$, the specific capacitances of C-ZIF-8, LC-ZIF-8, and FC-ZIF-8 were 181,175 , and $164 \mathrm{~F} \mathrm{~g}^{-1}$, respectively. Interestingly, these values matched well with the decreasing order of micropore volumes $\left(0.23,0.16\right.$, and $0.15 \mathrm{~cm}^{3} \mathrm{~g}^{-1}$ of C-ZIF-8, LC-ZIF-8, and FC-ZIF-8) possibly because of the critical role of micropore for charge storage. In addition, mesopore volumes of the 
carbons greatly influenced equivalent series resistance (ESR) and capacitive retention performance due to their different ionic transfer abilities. Therefore, the ESR values for C-ZIF-8, LC-ZIF-8, and FC-ZIF-8 were $0.21,0.25$, and $0.42 \Omega \mathrm{cm}^{2}$, respectively.

Another easy and economical synthetic approach was applied to nanoporous carbon (NPC) via direct carbonization of particle size-controlled ZIF-8 self-sacrificing template at $800{ }^{\circ} \mathrm{C}\left(5 \mathrm{~h}, \mathrm{~N}_{2}\right.$ flow $)$ and subsequent 10\% HF treatment [54]. The obtained NPC had high $\mathrm{S}_{\mathrm{BET}}$ with microporosity (mean $\mathrm{D}_{\text {pore }}=\sim 1 \mathrm{~nm}$ ). With the help of polyvinylpyrrolidone (PVP) modulator, a large-size ZIF-8 self-sacrificing template was prepared and could be transformed into a large-size NPC. Under 3E configuration in $1 \mathrm{M} \mathrm{H}_{2} \mathrm{SO}_{4}$ electrolyte, the large-size NPC showed superior capacitance $\left(251 \mathrm{~F} \mathrm{~g} \mathrm{~g}^{-1}\right)$ at $5 \mathrm{mV} \mathrm{s}^{-1}$ than the small-size NPC $\left(125 \mathrm{~F} \mathrm{~g}^{-1}\right)$ because particle aggregation limiting the electrolyte transport was not observed. In addition, the SSC from the large-size NPC within the same electrolyte showed high cell capacitance at $0.5 \mathrm{~A} \mathrm{~g}^{-1}\left(98 \mathrm{~F} \mathrm{~g}^{-1}\right)$. It also delivered a high energy density of $10.86 \mathrm{~W} \mathrm{~h} \mathrm{~kg}^{-1}$ with a power density of $225 \mathrm{~W} \mathrm{~kg}^{-1}$ at $0.5 \mathrm{~A} \mathrm{~g}^{-1}$. In addition, at $5 \mathrm{~A} \mathrm{~g}^{-1}$, the specific energy was slightly decreased $\left(6.97 \mathrm{~W} \mathrm{~h} \mathrm{~kg}^{-1}\right)$ but the specific power was largely increased (2281 $\left.\mathrm{W} \mathrm{kg}^{-1}\right)$.

A simple single-step co-carbonization of ZIF-8 with secondary carbon precursors (such as melamine, urea, xylitol, and sucrose $)$ at $950{ }^{\circ} \mathrm{C}(5 \mathrm{~h}$, Ar flow $)$ was performed to synthesize a series of $\mathrm{N}$-doped porous carbon electrodes operating in basic electrolyte [55]. The ZIF-8/secondary carbon source co-derived carbons (Carbon-ZM, Carbon-ZU, Carbon-ZX, and Carbon-ZS) with hierarchical porosity exhibited higher $S_{B E T}$ and $V_{\text {total }}$ as well as specific capacitances than bare ZIF-8 derived carbon (Carbon-Z). During the carbonization, pre-melting and polymerization of the additional carbon precursor incorporated into the ZIF-8 self-sacrificing template could facilitate the graphitization and construct a protective layer for the passivation of structural collapse and nitrogen loss from the ZIF-8. As a result, the Carbon-ZS showed good electrical conductivity with moderate N-dopant level (4.5\%). Therefore, it was the best working electrode for supercapacitor with 3E in $6 \mathrm{M} \mathrm{KOH}$ electrolyte among the five samples.

Yamauchi et al. introduced organic electrolyte into ZIF-8-derived carbon-based supercapacitor [56]. Simple direct carbonization of ZIF-8 at $900{ }^{\circ} \mathrm{C}\left(5 \mathrm{~h}, \mathrm{~N}_{2}\right.$ flow) and subsequent HF (10 wt.\%) treatment were conducted to prepare N-doped nanoporous carbon (NPC). The N-doped NPC had high $\mathrm{S}_{\mathrm{BET}}$ with micro-/mesoporosity. At $10 \mathrm{mV} \mathrm{s}^{-1}$, the NPC-based SSC in $2 \mathrm{M} \mathrm{NEt}_{4} \mathrm{BF}_{4} / \mathrm{PC}$ electrolyte exhibited stack cell capacitance of $9.24 \mathrm{~F} \mathrm{~cm}^{-3}$ and gravimetric cell capacitance of $21.0 \mathrm{~F} \mathrm{~g}^{-1}$. The supercapacitor showed low ESR values, which resulted from low ionic resistance within the pores. At $0.001 \mathrm{~Hz}$, it also held high specific cell capacitances $\left(9.10 \mathrm{~F} \mathrm{~cm}^{-3}\right.$ and $\left.20.6 \mathrm{~F} \mathrm{~g}^{-1}\right)$. Its stack cell capacitance obtained at $5 \mathrm{~mA}$ was $4.23 \mathrm{~F} \mathrm{~cm}^{-3}$ (gravimetric cell capacitance $=10.6 \mathrm{~F} \mathrm{~g}^{-1}$ ). Its peak value of volumetric energy was found to be $\sim 6.6 \mathrm{~mW} \mathrm{~h} \mathrm{~cm}^{-3}$ with $\sim 0.64 \mathrm{~W} \mathrm{~cm}^{-3}$ of volumetric power.

A single-template synthesis of 3D hybrid-porous carbon with hierarchical porosity has been successfully accomplished by the carbonization of ZIF-8 microcrystal at $950{ }^{\circ} \mathrm{C}\left(3 \mathrm{~h}, \mathrm{~N}_{2}\right.$ flow) [57]. The obtained bimodal porous carbon (micro- and mesopores) showed high $\mathrm{S}_{\mathrm{BET}}$ and large $\mathrm{V}_{\text {total }}$ of $0.693 \mathrm{~cm}^{3} \mathrm{~g}^{-1}$. Porosity of the carbon was micropore-dominant $\left(S_{\text {micro }}=747 \mathrm{~m}^{2} \mathrm{~g}^{-1}\right.$, $\left.\mathrm{V}_{\text {micro }}=0.380 \mathrm{~cm}^{3} \mathrm{~g}^{-1}\right)$. Using electrode of SSC in $1 \mathrm{M} \mathrm{KOH}$ electrolyte, it showed high specific capacitance of $332 \mathrm{~F} \mathrm{~g}^{-1}$ with volumetric capacitance of $\sim 400 \mathrm{~F} \mathrm{~cm}^{-3}$ at $500 \mathrm{~mA} \mathrm{~g}^{-1}$. It yielded high capacitive rate capability at $40 \mathrm{~A} \mathrm{~g}^{-1}$ as well. It held superior surface properties for good ionic accessibility and low resistance for ionic diffusion.

Yamauchi et al. conducted direct carbonization of ZIF-8 crystals ( $5 \mathrm{~h}, \mathrm{~N}_{2}$ flow) and following HF (10 wt.\%) treatment to prepare nanoporous carbon materials [58]. The resultant carbons stood for S-n ( $n=$ carbonization temperature in ${ }^{\circ} \mathrm{C}$ ). S-900 sample had highest values of $S_{\text {BET }}$ and $V_{\text {total. }}$. In addition, its hierarchical micro-/mesoporous bimodal porosity and suitable ratio of micropore/mesopore were critical factors for electrochemical performance in $1 \mathrm{M} \mathrm{H}_{2} \mathrm{SO}_{4}$ electrolyte. Under 3E system, the S-900 yielded $219 \mathrm{~F} \mathrm{~g}^{-1}$ at $5 \mathrm{mV} \mathrm{s}^{-1}$ and $\sim 109 \mathrm{~F} \mathrm{~g}^{-1}$ at $500 \mathrm{mV} \mathrm{s}^{-1}$. In addition, S-900-based SSC showed 
a maximum specific capacitance value of $53.8 \mathrm{~F} \mathrm{~g}^{-1}$ (or $23.6 \mathrm{~F} \mathrm{~cm}^{-3}$ or $11.80 \mu \mathrm{F} \mathrm{cm}{ }^{-2}$ ) with high capacitance retention of $73.9 \%$ at $2 \mathrm{~A} \mathrm{~g}^{-1}$.

Production of hollow particle-based N-doped carbon nanofibers (HPCNFs) with hierarchical porosity was effectively achieved by two-step pyrolysis $\left(550^{\circ} \mathrm{C}, 1 \mathrm{~h}\right.$ and $\left.900^{\circ} \mathrm{C}, 2 \mathrm{~h}\right)$ of the electrospun $1 \mathrm{D}$ ZIF-8/PAN (PAN = polyacrylonitrile) composite precursor under $\mathrm{N}_{2}$ atmosphere and subsequent $3.0 \mathrm{M}$ $\mathrm{H}_{2} \mathrm{SO}_{4}$ treatment [59]. The 1D structure and high nitrogen content of the ZIF-8 NP/PAN composite were well preserved in the HPCNFs-N. Compared to N-doped carbon (C-N; $\mathrm{S}_{\mathrm{BET}}=223 \mathrm{~m}^{2} \mathrm{~g}^{-1}$ ) derived from bare ZIF-8 particles, the HPCNFs-N exhibited improved $S_{\text {BET }}$ value of $418 \mathrm{~m}^{2} \mathrm{~g}^{-1}$. Under 2.0 $\mathrm{M} \mathrm{H}_{2} \mathrm{SO}_{4}$ electrolyte, SSC assembled from the HPCNFs-N electrode showed $307.2 \mathrm{~F} \mathrm{~g}^{-1}$ at 1.0 $\mathrm{A} \mathrm{g}^{-1}$ and $193.4 \mathrm{~F} \mathrm{~g}^{-1}$ at $50.0 \mathrm{~A} \mathrm{~g}^{-1}$. The SSC also had good recycling stability of $98.2 \%$ retention of initial capacitance at $5.0 \mathrm{~A} \mathrm{~g}^{-1}$ after 10,000 cycles. Enhancements of electrochemical active sites and electrochemical kinetics as well as structural stability were due to the hierarchical porosity from many interconnected hollow carbon NPs. Furthermore, good ionic and electronic transport were resulted from the 1D fibrous structure.

Other N-doped hierarchical nanoporous carbon fibers (NPCFs) with 1D hollow structure was synthesized from two-step thermolysis $\left(240{ }^{\circ} \mathrm{C}, 1 \mathrm{~h}\right.$ and $\left.800{ }^{\circ} \mathrm{C}, 3 \mathrm{~h}\right)$ of electrospun ZIF-8/PAN nanofibers under $\mathrm{N}_{2}$ [60]. The optimized sample of NPCFs- 0.6 had $S_{B E T}$ of $315 \mathrm{~m}^{2} \mathrm{~g}^{-1}$ and $\mathrm{V}_{\text {total }}$ of $0.33 \mathrm{~cm}^{3} \mathrm{~g}^{-1}$. The NPCFs- 0.6 showed a high specific capacitance of $332 \mathrm{~F} \mathrm{~g}^{-1}$ at $1 \mathrm{~A} \mathrm{~g}^{-1}$ under $3 \mathrm{E}$ system with $1 \mathrm{M} \mathrm{H}_{2} \mathrm{SO}_{4}$ electrolyte. The N-doped hollow structure of the NPCFs- 0.6 with hierarchical micro-/mesoporosity generated high conductivity of $7.74 \mathrm{~S} \mathrm{~cm}^{-1}$ for fast electronic and ionic transport.

The electrospinning method was also employed for the synthesis of $\mathrm{N}$-enriched hierarchically porous carbon nanofibers (NHCFs) for binder-free and flexible electrode [61]. The ZIF-8/PAN composite precursor was transformed into the NHCFs by thermal stabilization at $250{ }^{\circ} \mathrm{C}(120 \mathrm{~min}$, air), carbonization ( $2 \mathrm{~h}$, Ar flow), and $\mathrm{HCl}$ treatment. After fine control of ZIF-8 contents ( $66.7 \mathrm{wt} . \% \mathrm{ZIF}-8$ contained PAN) and carbonization temperature $\left(800{ }^{\circ} \mathrm{C}\right)$, the optimized NHCF- $66.7 \%$ ZIF- 8 sample with hierarchical and interconnected porosity was obtained. It held high values of $\mathrm{S}_{\mathrm{BET}}\left(559.63 \mathrm{~m}^{2} \mathrm{~g}^{-1}\right)$, $\mathrm{V}_{\text {total }}\left(0.789 \mathrm{~cm}^{3} \mathrm{~g}^{-1}\right)$, and $\mathrm{N}$-dopant content $(15.59 \mathrm{wt} . \%)$. In addition to these favorable textural properties, both pseudocapacitance from $\mathrm{N}-/ \mathrm{O}$-functionalities and good electrical conductivity from high graphitization degree made the NHCF-66.7\% ZIF-8 had the best capacitive performance for 3E cell in $6 \mathrm{M} \mathrm{KOH}$ electrolyte.

Kim et al. reported a binder-free working electrode made of $\mathrm{B} / \mathrm{N}$-co-doped $3 \mathrm{D}$ porous carbon nanofiber network derived from the electrospun PAN/ZIF-8 raw material [62]. After electrospinning embedment of ZIF-8 NPs into PAN nanofiber, $\mathrm{NABH}_{4}$ treatment of the PAN/ZIF-8 nanofiber was performed to preserve 3D structure. B/N-co-doping of the $\mathrm{NaBH}_{4}$ treated PAN/ZIF- 8 was achieved by wet chemical treatment with ammonium borate $\left(\mathrm{NH}_{4} \mathrm{HB}_{4} \mathrm{O}_{7} \cdot 3 \mathrm{H}_{2} \mathrm{O}\right)$. The product 3D-BN-CNF-ZF-900 was obtained from the following successive steps of freeze-drying (for maintaining cross-linking), stabilization at $250{ }^{\circ} \mathrm{C}\left(2 \mathrm{~h}\right.$, air), carbonization at $900{ }^{\circ} \mathrm{C}\left(2 \mathrm{~h}, \mathrm{~N}_{2}\right.$ flow $)$, and acid washing $\left(2 \mathrm{M} \mathrm{H}_{2} \mathrm{SO}_{4}\right)$. The 3D-BN-CNF-ZF-900 had 3D-layered structure, cross-linked network, B/N-co-doping ( $\mathrm{B}=1.3 \mathrm{at} \%$, $\mathrm{N}=11.24$ at $\%), \mathrm{S}_{\mathrm{BET}}$ of $352 \mathrm{~m}^{2} \mathrm{~g}^{-1}$, high $\mathrm{V}_{\text {pore }}$ of $1.789 \mathrm{~cm}^{3} \mathrm{~g}^{-1}$, mesoporosity, and hydrophilic character (contact angle $=0^{\circ}$ ). Therefore, as a binder-free working electrode of supercapacitor with $3 \mathrm{E}$ cell in $2 \mathrm{M}$ $\mathrm{KOH}$ electrolyte, it held high specific capacitance of $295 \mathrm{~F} \mathrm{~g}^{-1}$ at $0.5 \mathrm{~A} \mathrm{~g}^{-1}$ with good rate performance ( $50 \%$ retention) of $147 \mathrm{~F} \mathrm{~g}^{-1}$ at $5 \mathrm{~A} \mathrm{~g}^{-1}$. In addition, its normalized areal capacitance at $0.5 \mathrm{~A} \mathrm{~g}^{-1}$ was $83.9 \mu \mathrm{F} \mathrm{cm}^{-2}$.

The electrospinning method was applied to the synthesis of polymer nanofibers [63]. The electrospun polymer nanofiber was decorated with a monolayer sheath of ZIF-8 particles with uniform size and morphology by polarity-assisted approach. The strong interaction between polar-carbon nanosheets $(\mathrm{CN})$ group on PAN side chains and $\mathrm{Zn}^{2+}$ ions initiated nucleation and coordinative growth of ZIF-8. The obtained PAN@ZIF-8 hybrid nanofibers were transformed into $\mathrm{N}$-doped nanofibrous carbon by dual-step pyrolysis $\left(550{ }^{\circ} \mathrm{C}, 2 \mathrm{~h}\right.$ and $900{ }^{\circ} \mathrm{C}, 3 \mathrm{~h}$ under $\mathrm{N}_{2}$ flow). From the fine-tuned molar ratio of 8 organic ligand to 1 metal ion, the optimized N-NFC-8 with a 
hollow frame had $\mathrm{S}_{\mathrm{BET}}$ of $277.2 \mathrm{~m}^{2} \mathrm{~g}^{-1}$ and high doping of heteroatoms $(\mathrm{N}=7.68 \mathrm{at} \%, \mathrm{O}=12.83 \mathrm{at} \%)$. When the N-NFC-8 was used as a working electrode for supercapacitor with $3 \mathrm{E}$ cell in $1 \mathrm{M} \mathrm{H}_{2} \mathrm{SO}_{4}$ electrolyte, its specific capacitance at $1 \mathrm{~A} \mathrm{~g}^{-1}$ was as high as $387.3 \mathrm{~F} \mathrm{~g}^{-1}$. A symmetric N-NFC-8-based supercapacitor operating in the same electrolyte exhibited maximum cell capacitance of $85.0 \mathrm{~F} \mathrm{~g}^{-1}$ at $1 \mathrm{~A} \mathrm{~g}^{-1}$ and the rate retention of $60 \%$ at $10 \mathrm{~A} \mathrm{~g}^{-1}$. Solid-state SSC fabricated from the N-NFC-8 electrode and PVA- $\mathrm{H}_{2} \mathrm{SO}_{4}$ gel showed the highest cell capacitance of $42.2 \mathrm{~F} \mathrm{~g}^{-1}$ at $5 \mathrm{~A} \mathrm{~g}^{-1}$. The device held good flexibility at different bending angles and good recycling performance of $\sim 90 \%$ retention after 10,000 cycles at $1 \mathrm{~A} \mathrm{~g}^{-1}$. Highly conductive core containing 1D nanofiber facilitated electronic transport. Additionally, the incorporated heteroatoms ( $\mathrm{N}$ and $\mathrm{O}$ ) rendered extra electrochemical active sites. Moreover, a monolayer sheath of hollow carbon frames decreased the interfacial resistance and increased ionic transport with favorable electrode kinetics.

Inorganic molten salts such as $\mathrm{LiCl}$ and $\mathrm{KCl}$ were employed for the synthesis of ZIF-8 derived carbon with 2D sheet structure and mesopores (Figure 3) [64]. From the carbonization of ZIF-8/molten salt mixture at $800{ }^{\circ} \mathrm{C}\left(5 \mathrm{~h}, \mathrm{~N}_{2}\right.$ flow) followed by $0.5 \mathrm{M} \mathrm{HCl}$ treatment, $\mathrm{N}$-doped mesoporous carbon nanosheets (NMCS) with 2D structure and hierarchical porosity were successfully prepared due to the activation of molten salts. The series of $2 \mathrm{D}$ carbon nanosheets were denoted as NMCS-X ( $\mathrm{X}=$ carbonization time in $\mathrm{h}$ ). Compared to bare ZIF-8 derived N-doped porous carbon polyhedron (NPCP-5) with dominant microporosity $\left(S_{\text {meso }}=37 \mathrm{~m}^{2} \mathrm{~g}^{-1}, \mathrm{~V}_{\text {meso }}=0.398 \mathrm{~cm}^{3} \mathrm{~g}^{-1}\right)$, the three NMCS-X have well-developed mesoporosity with high $S_{\text {meso }}\left(200-407 \mathrm{~m}^{2} \mathrm{~g}^{-1}\right)$ and large $V_{\text {meso }}$ $\left(0.425-0.886 \mathrm{~cm}^{3} \mathrm{~g}^{-1}\right)$. As a result, they hold higher $S_{\mathrm{BET}}$ and larger $V_{\text {total }}$ than the NPCP-5. The improvements of ionic accessible active sites from mesoporosity, wettability from N-doped polar surface, and electrode packing, and ionic conductivity from the 2D nanosheet structure with large aspect ratio synergistically supported the superior electrochemical performance of NMCS-X-based supercapacitor (6 $\mathrm{M} \mathrm{KOH}, 3 \mathrm{E}$ cell).
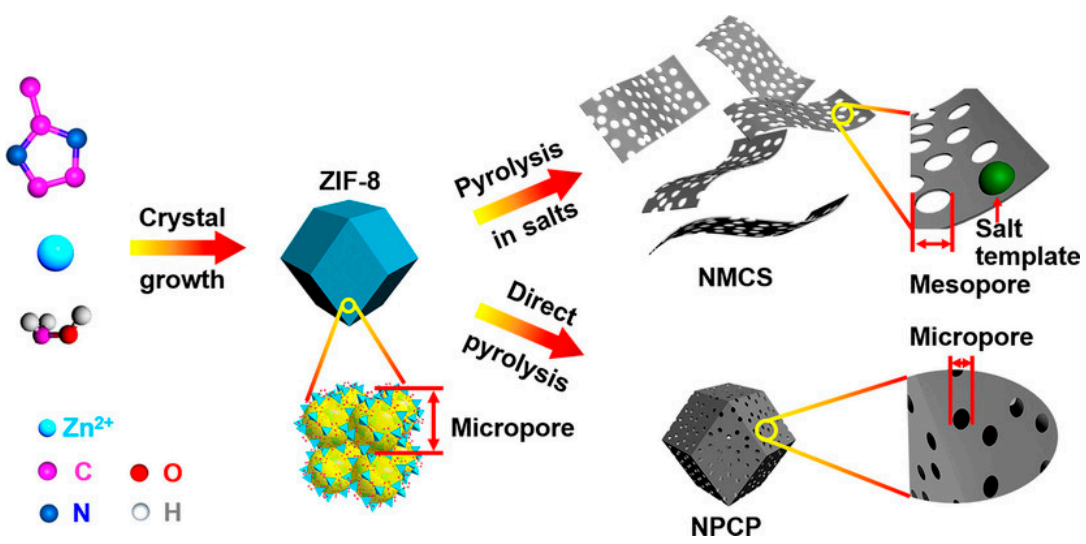

Figure 3. Synthetic procedure of NMCS and NPCPs (N-doped porous carbon polyhedrons) with or without the mediation of molten salts [64].

It is clearly revealed that porous carbons directly derived from ZIF-8 are supercapacitor electrodes with good performance (Table 2). The unique crystal structure and pore geometry of ZIF-8 provided ideal carbon matrices for supercapacitors upon pyrolysis.

\subsubsection{Other ZIF-Derived Carbons}

The electrochemical performances of porous carbon electrodes derived from other ZIFs are collected in Table 3. Generally, their capacitances are a little bit lower than those of ZIF-8-derived carbon electrodes depicted in Table 2. Thus, ZIF-8 may be a superior precursor for porous carbons compared to other ZIFs. 
Table 3. The electrochemical capacitive performances of porous carbons derived from other ZIF-based Zn-MOFs.

\begin{tabular}{|c|c|c|c|c|c|c|}
\hline Samples & $S_{\text {BET }}\left(\mathrm{m}^{2} \mathrm{~g}^{-1}\right)$ & $C_{\max }\left(\mathrm{F} \mathrm{g}^{-1}\right)$ & $E_{\max }\left(\mathrm{Wh} \mathrm{kg^{-1 } )}\right.$ & $P_{\max }\left(\mathrm{W} \mathrm{kg}^{-1}\right)$ & System & Ref. \\
\hline CZIF68 & 472 & 54 & - & - & $3 \mathrm{E}$ & 65 \\
\hline CZIF69 & 586 & 37 & - & - & $3 \mathrm{E}$ & 65 \\
\hline CZIF68a & 1861 & 112 & - & - & $3 E$ & 65 \\
\hline CZIF69a & 2264 & 168 & - & - & $3 \mathrm{E}$ & 65 \\
\hline Carbon-L-750 & 455 & 127.6 & - & - & $3 \mathrm{E}$ & 66 \\
\hline Carbon-L-850 & 686 & 200.72 & - & - & $3 \mathrm{E}$ & 66 \\
\hline Carbon-L-950 & 783 & 228.1 & - & - & $3 \mathrm{E}$ & 66 \\
\hline Carbon-L-1000 & 799 & 135.4 & - & - & $3 \mathrm{E}$ & 66 \\
\hline Carbon-G-950 & 640 & 238 & - & - & $3 \mathrm{E}$ & 66 \\
\hline Carbon-F-950 & 566 & 100.9 & - & - & $3 \mathrm{E}$ & 66 \\
\hline Carbon-E-950 & 515 & 152 & - & - & $3 \mathrm{E}$ & 66 \\
\hline Carbon-Z-950 & 406 & 202 & - & - & $3 E$ & 66 \\
\hline Z950 & 76 & 210 & 41.3 & 3600 & $2 \mathrm{E}$ & 67 \\
\hline N-PCMPs & 895 & 180 & - & - & $3 \mathrm{E}$ & 68 \\
\hline N-PCMPs-A & 2188 & 307 & - & - & $3 \mathrm{E}$ & 68 \\
\hline UT-CNSs & 1535 & 347 & - & - & $3 \mathrm{E}$ & 69 \\
\hline NNPC-700 & 736 & 158 & - & - & $3 \mathrm{E}$ & 70 \\
\hline NNPC-800 & 942 & 272 & 5.36 & $\sim 1000$ & $3 \mathrm{E} / 2 \mathrm{E}$ & 70 \\
\hline NNPC-900 & 1018 & 225 & - & - & $3 \mathrm{E}$ & 70 \\
\hline
\end{tabular}

The correlation between local structure of carbon products and composition of carbon sources was systematically investigated by employment of three ZIFs (ZIF-8, ZIF-68, and ZIF-69) [65]. Direct carbonization of the ZIFs at $1000{ }^{\circ} \mathrm{C}(5 \mathrm{~h}$, Ar) yielded carbonization products (CZIF8, CZIF68, and CZIF69). After $\mathrm{KOH}$ activation of the resultant $\mathrm{N}$-doped carbons at $750{ }^{\circ} \mathrm{C}(1 \mathrm{~h}$, Ar flow, mass ratio of $\mathrm{C} / \mathrm{KOH}=0.2$ ), the activated carbon materials (CZIF8a, CZIF68a, and CZIF69a) were obtained. Macropores were only displayed in benzimidazolate-containing ZIF-based carbons (CZIF68, CZIF69, CZIF68a, and CZIF69a). The chloride functional group in ZIF-69's benzimidazole ligand was able to greatly influence the structure and property of carbonized porous products. As a result, CZIF69a showed high $\mathrm{S}_{\mathrm{BET}}$, large $\mathrm{V}_{\text {total }}\left(1.184 \mathrm{~cm}^{3} \mathrm{~g}^{-1}\right)$, and hierarchical micro-/mesoporosity. Therefore, as a working electrode of $3 \mathrm{E}$ cell supercapacitor in $0.5 \mathrm{M} \mathrm{H}_{2} \mathrm{SO}_{4}$ electrolyte, it yielded $168 \mathrm{~F} \mathrm{~g}^{-1}$ at $5 \mathrm{mV} \mathrm{s}^{-1}$ and $135 \mathrm{~F} \mathrm{~g}^{-1}$ at $200 \mathrm{mV} \mathrm{s}^{-1}$.

A simple co-carbonization ( $5 \mathrm{~h}$, Ar flow) of ZIF-7 with additional green carbon precursors (glucose, ethylene glycol, glycerol, and FA) was employed to prepare a series of conducting agent-free carbon electrodes [66]. The resultant carbons were Carbon-L-T ( $\mathrm{T}=$ carbonization temperature in ${ }^{\circ} \mathrm{C}, \mathrm{L}=$ glucose), Carbon-E-950 (ethylene glycol), Carbon-G-950 (glycerol), Carbon-F-950 (FA), and Carbon-Z-950 (carbon source free ZIF-7), respectively. The optimized Carbon-L-950 sample contained high $\mathrm{S}_{\mathrm{BET}}$ and large $\mathrm{V}_{\text {total }}$. It also had hierarchical micro-/mesoporosity with conductive graphene-like structure as well as good surface properties (hydrophilicity and wettability). When applied to conducting agent-free working electrode of $3 \mathrm{E}$ cell in $6 \mathrm{M} \mathrm{KOH}$ electrolyte, its maximum specific capacitance at $0.1 \mathrm{~A} \mathrm{~g}^{-1}$ was $228 \mathrm{~F} \mathrm{~g}^{-1}$.

Flexible and free-standing carbon electrodes (Z800, Z900, and Z1000) with no current collector and separating substrate were synthesized from the thermal stabilization for cross-linking at $280^{\circ} \mathrm{C}(30 \mathrm{~min}$, air flow) and subsequent carbonization of electrospun ZIF-7/PAN composite (60 min, Ar flow) [67]. The ZIF-7/CNF (CNF = carbon nanofiber) was simply prepared in a large scale with an optimal PAN concentration of $7 \mathrm{wt} . \%$. In addition, as an electrode for SSC operating in $6 \mathrm{M} \mathrm{KOH}$ electrolyte, Z950 (the sample carbonized at $950{ }^{\circ} \mathrm{C}$ ) showed the best performance among the three samples.

Zhang et al. prepared ZIF-11-derived carbon materials. After single-step carbonization of benzimidazole containing ZIF-11 polyhedrons at $1000{ }^{\circ} \mathrm{C}\left(2 \mathrm{~h}, \mathrm{~N}_{2}\right.$ flow), the $\mathrm{N}$-doped porous carbon micropolyhedrons (N-PCMPs) were successfully synthesized [68]. The activated forms of N-PCMPs (N-PCMPs-A) were also generated from $\mathrm{KOH}$ activation of the $\mathrm{N}-\mathrm{PCMPs}$ (mass ratio of $\mathrm{C}$ and $\mathrm{KOH}=1: 5$; 
$\left.750{ }^{\circ} \mathrm{C}, 1 \mathrm{~h}, \mathrm{~N}_{2}\right)$. The N-PCMPs-A with improved mesoporosity had higher $\mathrm{S}_{\mathrm{BET}}\left(2188 \mathrm{~m}^{2} \mathrm{~g}^{-1}\right)$ and $\mathrm{V}_{\text {total }}\left(1.24 \mathrm{~cm}^{3} \mathrm{~g}^{-1}\right)$ than the N-PCMPs $\left(895 \mathrm{~m}^{2} \mathrm{~g}^{-1}, 0.58 \mathrm{~cm}^{3} \mathrm{~g}^{-1}\right)$. In addition, compared to the $\mathrm{N}-\mathrm{PCMPs}$, O- and N-containing functional groups of the N-PCMPs-A were more exposed to the carbon surface. Therefore, as a working electrode of $3 \mathrm{E}$ cell with $1.0 \mathrm{M} \mathrm{H}_{2} \mathrm{SO}_{4}$ electrolyte, the N-PCMPs-A was superior to the N-PCMPs. At a scan rate of $1 \mathrm{mV} \mathrm{s}^{-1}$, their specific capacitances were $295 \mathrm{~F} \mathrm{~g}^{-1}$ for N-PCMPs-A and $180 \mathrm{~F} \mathrm{~g}^{-1}$ for N-PCMPs. When the scan rate increased to $50 \mathrm{mV} \mathrm{s}^{-1}$, the N-PCMPs-A exhibited better capacitance retention $\left(194 \mathrm{~F} \mathrm{~g}^{-1}\right)$ than the N-PCMPs $\left(106 \mathrm{~F} \mathrm{~g}^{-1}\right)$.

The highest specific capacitance of $283 \mathrm{~F} \mathrm{~g}^{-1}$ at $10 \mathrm{~A} \mathrm{~g}^{-1}$ among the already reported MOF-derived carbon nanosheet electrodes was achieved by the ultrathin carbon nanosheets (UT-CNSs) in 2018 [69]. He et al. reported the effective and economical bottom-up synthetic strategy for 2D ultrathin $\mathrm{Zn}(\mathrm{bim})(\mathrm{OAc})(\mathrm{UT}-\mathrm{Zn}(\mathrm{bim})(\mathrm{OAc})$, bim = benzimidazole) and N-doped porous UT-CNSs derived from $\mathrm{Zn}(\mathrm{bim})(\mathrm{OAc})$. From the hydrophilic gluconate-aided synthetic approach, the UT-Zn(bim)(OAc) self-sacrificing template with a small thickness $(\sim 5 \mathrm{~nm})$ was prepared in high yield $(\sim 65 \%)$. The corresponding slightly less thickened $(\sim 2.5 \mathrm{~nm})$ UT-CNSs were produced in high yield $(45.7 \%)$ by the direct carbonization of the template $\left(800^{\circ} \mathrm{C}, 3 \mathrm{~h}, \mathrm{Ar} / \mathrm{H}_{2} 10 \mathrm{vol} \%\right)$ and subsequent $1 \mathrm{M} \mathrm{HCl}$ treatment. The UT-CNSs had many promising properties for the improved electrochemical performance such as high graphitization degree, few layered ultrathin nanosheets morphology, high $\mathrm{S}_{\mathrm{BET}}, \mathrm{N}$-doping, and hierarchical porosity. Consequently, key favorable factors for supercapacitive properties of UT-CNSs-based working electrode were displayed such as high electric conductivity of $4.5 \mathrm{~S} \mathrm{~cm}^{-1}$, small contact resistance, facilitated charge transfer and ionic diffusion, and highly effective specific surface area for ion storable capacity.

N-decorated nanoporous carbons (NNPCs) were derived from ZTIF-1 containing 5-methyltetrazole and 2-ethylimidazole ligands [70]. From carbonization for $2 \mathrm{~h}$ and $\mathrm{HCl}$ etching, the TZIF-1 polyhedral crystals could be converted into NNPCs (NNPC-700, NNPC-800, and NNPC-900). The NNPC-800 had high values of $\mathrm{S}_{\mathrm{BET}}$ as well as $\mathrm{N}$-dopant content (14.23 wt.\%), and contained micro-/mesoporous hierarchical porosity. This carbon working electrode of $3 \mathrm{E}$ cell in $6 \mathrm{M} \mathrm{KOH}$ electrolyte showed $272 \mathrm{~F} \mathrm{~g}^{-1}$ at $0.1 \mathrm{~A} \mathrm{~g}^{-1}$. Its maximum specific capacitance in the same electrolytic $2 \mathrm{E}$ system at $0.1 \mathrm{~A} \mathrm{~g}^{-1}$ was $154 \mathrm{~F} \mathrm{~g}^{-1}$. At $2 \mathrm{~A} \mathrm{~g}^{-1}$, it showed $57 \%$ capacitive retention.

\subsection{Other MOF-Derived Carbons}

Table 4 summarizes the electrochemical performances of porous carbons derived from other types of MOFs. Depending on MOF precursors, the surface areas and capacitances show a wide range of values. It is notable that capacitances are strongly dependent on the surface area. Thus, the use of MOF precursors which can give high-surface porous carbons is primarily important for better supercapacitors. 
Table 4. The electrochemical capacitive performances of carbons derived from other types of MOFs.

\begin{tabular}{|c|c|c|c|c|c|c|}
\hline Samples & $S_{\mathrm{BET}}\left(\mathrm{m}^{2} \mathrm{~g}^{-1}\right)$ & $C_{\max }\left(\mathrm{F} \mathrm{g}^{-1}\right)$ & $E_{\max }\left(\mathrm{Wh} \mathrm{kg}^{-1}\right)$ & $P_{\max }\left(\mathrm{W} \mathrm{kg}^{-1}\right)$ & System & Ref. \\
\hline MIL-C & 1328 & 145 & - & - & $2 \mathrm{E}$ & 71 \\
\hline MIL-C-0.5 & 1699 & 143 & - & - & $2 \mathrm{E}$ & 71 \\
\hline MIL-C-1 & 2116 & 180 & - & - & $2 \mathrm{E}$ & 71 \\
\hline MIL-C-2 & 1397 & 185 & - & - & $2 \mathrm{E}$ & 71 \\
\hline $\mathrm{CNs}$ & 415 & 119 & 4.3 & 2068 & $3 \mathrm{E} / 2 \mathrm{E}$ & 72 \\
\hline PC-bib & 224 & 107 & - & - & $3 \mathrm{E}$ & 73 \\
\hline PC-bbib & 56 & 63 & - & - & $3 \mathrm{E}$ & 73 \\
\hline PC-bibp & 165 & 93 & - & - & $3 \mathrm{E}$ & 73 \\
\hline PC-bbibp & 18 & 48 & - & - & $3 \mathrm{E}$ & 73 \\
\hline APC-bib & 1290 & 164 & - & - & $3 E$ & 73 \\
\hline APC-bbib & 997 & 121 & - & - & $3 \mathrm{E}$ & 73 \\
\hline APC-bibp & 1269 & 127 & - & - & $3 \mathrm{E}$ & 73 \\
\hline APC-bbibp & 622 & 115 & - & - & $3 \mathrm{E}$ & 73 \\
\hline PC-me & 23 & 32 & - & - & $3 \mathrm{E}$ & 74 \\
\hline PC-eth & 51 & 54 & - & - & $3 \mathrm{E}$ & 74 \\
\hline PC-ipr & 10 & 7 & - & - & $3 \mathrm{E}$ & 74 \\
\hline PC-dmf & 122 & 92 & - & - & $3 \mathrm{E}$ & 74 \\
\hline PC-nmp & 96 & 76 & - & - & $3 E$ & 74 \\
\hline APC-me & 1143 & 106 & - & - & $3 E$ & 74 \\
\hline APC-eth & 1312 & 103 & - & - & $3 E$ & 74 \\
\hline APC-ipr & 1074 & 85 & - & - & $3 E$ & 74 \\
\hline APC-dmf & 1408 & 156 & - & - & $3 \mathrm{E}$ & 74 \\
\hline APC-nmp & 1337 & 105 & - & - & $3 E$ & 74 \\
\hline NPC-800 & 943 & 238 & 19.6 & 22,900 & $3 \mathrm{E} / 2 \mathrm{E}$ & 75 \\
\hline NPC-600 & 286 & 114 & - & - & $3 \mathrm{E}$ & 76 \\
\hline NPC-750 & 440 & 110 & - & - & $3 E$ & 76 \\
\hline NPC-900 & 553 & 149 & - & - & $3 \mathrm{E}$ & 76 \\
\hline $\mathrm{APC}$ & 2491 & 260.5 & 18.38 & 6881 & $3 \mathrm{E} / 2 \mathrm{E}$ & 77 \\
\hline C-S700 & 817 & 182 & - & - & $3 \mathrm{E}$ & 78 \\
\hline C-S900 & 704 & 156 & - & - & $3 E$ & 78 \\
\hline C-C1700 & 311 & 117 & - & - & $3 \mathrm{E}$ & 78 \\
\hline C-C1900 & 199 & 70 & - & - & $3 \mathrm{E}$ & 78 \\
\hline HCPs & 1147 & 214 & - & - & $2 \mathrm{E}$ & 79 \\
\hline NPS-800 & 1192 & 1636 & 89.73 & - & $2 \mathrm{E}$ & 80 \\
\hline CP-II & 768 & 121 & - & - & $3 E$ & 81 \\
\hline CP-III & 732 & 127 & - & - & $3 \mathrm{E}$ & 81 \\
\hline PGC-900 & 1148 & 217 & - & - & $3 E$ & 82 \\
\hline NPGC-1-900 & 1116 & 254 & - & - & $3 \mathrm{E}$ & 82 \\
\hline NPGC-2-900 & 1027 & 293 & 47.5 & $\sim 30,000$ & $3 \mathrm{E} / 2 \mathrm{E}$ & 82 \\
\hline NPGC-3-900 & 993 & 284 & - & - & $3 \mathrm{E}$ & 82 \\
\hline NPGC-2-1000 & 579 & 184 & - & - & $3 \mathrm{E}$ & 82 \\
\hline NPGC-2-800 & 649 & 167 & - & - & $3 \mathrm{E}$ & 82 \\
\hline AC-2-900 & 1002 & 205 & - & - & $3 \mathrm{E}$ & 82 \\
\hline GC-2-900 & 196 & 49 & - & - & $3 \mathrm{E}$ & 82 \\
\hline N-C-450 & - & 42 & - & - & $3 \mathrm{E}$ & 83 \\
\hline N-C-550 & - & 229.9 & - & - & $3 E$ & 83 \\
\hline N-C-650 & - & 223.7 & - & - & $3 \mathrm{E}$ & 83 \\
\hline NC0.9 & 603 & 296 & - & - & $3 E$ & 84 \\
\hline NC1.1 & 773 & 426 & - & - & $3 \mathrm{E}$ & 84 \\
\hline NC1.35 & 786 & 425 & - & - & $3 \mathrm{E}$ & 84 \\
\hline NC2.0 & 534 & 210 & - & - & $3 \mathrm{E}$ & 84 \\
\hline $\mathrm{NC} 2.7$ & 393 & 186 & - & - & $3 \mathrm{E}$ & 84 \\
\hline UCN-10-550 & 367 & 125 & - & - & $3 \mathrm{E}$ & 85 \\
\hline UCN-20-550 & 1084 & 210 & - & - & $3 \mathrm{E}$ & 85 \\
\hline UCN-30-550 & 1034 & 175 & - & - & $3 \mathrm{E}$ & 85 \\
\hline UCN-40-550 & 837 & 140 & - & - & $3 E$ & 85 \\
\hline
\end{tabular}


Table 4. Cont.

\begin{tabular}{|c|c|c|c|c|c|c|}
\hline Samples & $S_{\text {BET }}\left(\mathrm{m}^{2} \mathrm{~g}^{-1}\right)$ & $C_{\max }\left(\mathrm{F} \mathrm{g}^{-1}\right)$ & $E_{\max }\left(\mathrm{Wh} \mathrm{kg^{-1 } )}\right.$ & $P_{\max }\left(\mathrm{W} \mathrm{kg}^{-1}\right)$ & System & Ref. \\
\hline UCN-20-650 & 931 & 165 & - & - & $3 \mathrm{E}$ & 85 \\
\hline UCN-20-750 & 843 & 256 & - & - & $3 \mathrm{E}$ & 85 \\
\hline UCN-20-850 & 426 & 128 & - & - & $3 \mathrm{E}$ & 85 \\
\hline WMC & 2587 & 344 & - & - & $3 \mathrm{E}$ & 86 \\
\hline HPCs-0.1 & 2137 & 215 & - & - & $3 \mathrm{E}$ & 87 \\
\hline HPCs-0.4 & 2857 & 241 & - & - & $3 \mathrm{E}$ & 87 \\
\hline $\mathrm{MC}-\mathrm{Cu}$ & 50 & 142.3 & - & - & $3 E$ & 88 \\
\hline MC-Al & 1103 & 232.8 & - & - & $3 \mathrm{E}$ & 88 \\
\hline PC-Cd & 1430 & 126 & - & - & $3 E$ & 89 \\
\hline GC-Ni & 151 & 43 & - & - & $3 \mathrm{E}$ & 89 \\
\hline GC-Co & 118 & 42 & - & - & $3 E$ & 89 \\
\hline GC-Mn & 232 & 60 & - & - & $3 \mathrm{E}$ & 89 \\
\hline $\mathrm{C}-\mathrm{Cu}$ & 86 & 26 & - & - & $3 \mathrm{E}$ & 89 \\
\hline CC@NC & - & 321.9 & - & - & $3 E$ & 95 \\
\hline TM-NPCs & 998 & 330 & - & - & $3 \mathrm{E}$ & 97 \\
\hline C2-700 & - & 186 & - & - & $3 \mathrm{E}$ & 138 \\
\hline$C-300$ & 145 & 207 & - & - & $3 E$ & 180 \\
\hline NPC & 1757 & 272 & - & - & $3 E$ & 182 \\
\hline
\end{tabular}

\subsubsection{Al-MOF-Derived Carbons}

An unprecedented double-template method using Al-MIL-101- $\mathrm{NH}_{2}$ and the encapsulated $\mathrm{Cu}^{2+}$ ions was introduced as a simple and effective synthetic method of MOF-derived carbons [71]. For the fabrication of XCu@Al-MIL-101- $\mathrm{NH}_{2}$ ( $X=$ the weight percent of metal ions in the MOFs), the encapsulation of $\mathrm{Cu}^{2+}$ ions was employed to the $\mathrm{NH}_{2}$-bdc containing Al-MOF self-sacrificing template via double-solvents method. MOF-derived carbons (MIL-C, MIL-C-X (X = 0.5, 1, and 2)) were prepared from carbonization of the MOF or Cu@MOF composite at $800{ }^{\circ} \mathrm{C}(5 \mathrm{~h}$, Ar flow), followed by acid treatment. The encapsulated $\mathrm{Cu}^{2+}$ ions were greatly influenced by pore generation and the control of porosity. As a result, the increment of encapsulated amount of the $\mathrm{Cu}^{2+}$ ions improved hierarchical porosity and $\mathrm{V}_{\text {total }}$ of the resultant carbons. The development degree of the hierarchical porosity could be seen according to the following sequence: carbon with dominant microporosity (MIL-C), carbons with micro-/mesoporosity (MIL-C-0.5, MIL-C-1), and carbons with hierarchical micro-/meso-/macroporosity (MIL-C-2). Under 2E system with $1 \mathrm{M} \mathrm{H}_{2} \mathrm{SO}_{4}$ electrolyte, the maximum specific capacitances at $10 \mathrm{mV} \mathrm{s}^{-1}$ were $145,143,180$, and $185 \mathrm{~F} \mathrm{~g}^{-1}$ for the carbon series of MIL-C, MIL-C-0.5, MIL-C-1, and MIL-C-2, respectively.

Liu et al. introduced a simple and effective self-sacrificing template synthetic strategy for constructing porous carbon nanosheets (CNs) from Al-based MOF (DUT-5) [72]. The 4,4'-biphenyldicarboxylate (bpdc) containing DUT-5 self-sacrificing template was converted into the pure mesoporous carbon nanosheets by carbonization at $700{ }^{\circ} \mathrm{C}\left(3 \mathrm{~h}, \mathrm{~N}_{2}\right.$ flow $)$ and subsequent $\mathrm{HCl}$ washing. The obtained $\mathrm{CNs}$ exhibited moderately high values of $\mathrm{S}_{\mathrm{BET}}$ and $\mathrm{V}_{\text {pore }}\left(0.99 \mathrm{~cm}^{3} \mathrm{~g}^{-1}\right)$. In the $2 \mathrm{E}$ system, the maximum value of specific energy was $4.3 \mathrm{~W} \mathrm{~h} \mathrm{~kg}^{-1}$ at $0.25 \mathrm{~A} \mathrm{~g}^{-1}$. At $3 \mathrm{~A} \mathrm{~g}^{-1}$, the specific energy was minimized to $2.7 \mathrm{~W} \mathrm{~h} \mathrm{~kg}^{-1}$ and specific power was maximized to $2068 \mathrm{~W} \mathrm{~kg}^{-1}$. High specific power was due to the 2D sheet-shaped structure and well-developed mesoporosity.

\subsubsection{Cd-MOF-Derived Carbons}

$\mathrm{Li}$ et al. revealed two reports about Cd-MOFs-based carbon electrodes [73,74]. The Li's group first introduced Cd-MOFs as carbon precursors [73]. The four Cd-MOFs were prepared by employment of $\mathrm{H}_{2}$ bdc linker combined with four structure-interconnected bis(imidazole) linkers (bib = 1,4-bis(imidazol-1-yl)benzene, bbib = 1,4-bis(benzimidazol-1-yl)benzene, bibp $=4,4^{\prime}$-bis(imidazol-1-yl)biphenyl, and bbibp $=4,4^{\prime}$-bis(benzimidazol-1-yl)biphenyl. The Cd-MOF-derived porous carbons (PCs) were synthesized from the carbonization of Cd-MOFs 
$\left(1000{ }^{\circ} \mathrm{C}, 12 \mathrm{~h}, \mathrm{~N}_{2}\right)$ and following acid treatment $(5 \mathrm{vol} \% \mathrm{HCl}) . \mathrm{PC} @ \mathrm{KOH}$ composites $(\mathrm{PC} / \mathrm{KOH}=1 / 4)$ were transformed into activated porous carbon (APC) via pyrolysis at $800{ }^{\circ} \mathrm{C}\left(1 \mathrm{~h}, \mathrm{~N}_{2}\right.$ flow) and subsequent washing (5 vol\% $\mathrm{HCl}$ and water). The APC-bib possessed the largest $\mathrm{S}_{\mathrm{BET}}$ and $\mathrm{V}_{\text {total }}\left(1.37 \mathrm{~cm}^{3} \mathrm{~g}^{-1}\right)$ among the eight samples. Electrochemical performance was investigated in 3E system with $6 \mathrm{M} \mathrm{KOH}$ electrolyte. The order of specific capacitances of PCs was PC-bib > PC-bibp > PC-bbib > PC-bbibp at low scan rates and low current loads. It was the same order of $\mathrm{S}_{\mathrm{BET}}$ controlled by $\mathrm{Cd} / \mathrm{C}$ ratio of the MOF templates. Moreover, the APCs showed enhanced specific capacitances compared with the PCs due to the increase of conductivity, ionic diffusion, and charge transfer.

They also investigated the role of different solvents for Cd-MOF carbon precursors in the preparation of MOF-derived PCs [74]. Five different solvents (methanol, ethanol, isopropanol, DMF, NMP = N-methyl-2-pyrrolidone) were used to synthesize a series of new Cd-MOFs under the same mixed ligand system (bib and $\mathrm{H}_{2}$ ipa = isophthalic acid). After carbonization at $1000{ }^{\circ} \mathrm{C}\left(12 \mathrm{~h}, \mathrm{~N}_{2}\right.$ flow) and following $2 \mathrm{M} \mathrm{HCl}$ washing, the five Cd-MOFs were transformed into the PCs. The resultant PCs possessed relatively low $\mathrm{S}_{\mathrm{BET}}$. The composites of $\mathrm{PC} @ \mathrm{KOH}(\mathrm{PC} / \mathrm{KOH}=0.25)$ were also transformed into activated APCs through carbonization at $800{ }^{\circ} \mathrm{C}\left(1 \mathrm{~h}, \mathrm{~N}_{2}\right.$ flow $)$ and followed by washing process $(2 \mathrm{M}$ $\mathrm{HCl}$ and water). The values of $\mathrm{S}_{\mathrm{BET}}$ of the APCs (APC-me, APC-eth, APC-ipr, APC-dmf, and APC-nmp) were $1143,1312,1074,1408$, and $1337 \mathrm{~m}^{2} \mathrm{~g}^{-1}$, respectively. These textural improvements inducing both microporosity and mesoporosity by $\mathrm{KOH}$ activation supported the electrochemical performance differences found in 3E cells with the electrolyte of $6 \mathrm{M} \mathrm{KOH}$. The APCs exhibited improved specific capacitances compared to the PCs because of the enhanced properties of conductance, ionic diffusion, and charge transfer.

\subsubsection{Co-MOF-Derived Carbons}

Yamauchi et al. reported the ZIF-67 derived nanoporous carbon (NPC) with high degree of graphitization [75]. The direct carbonization of the ZIF-67 at $800{ }^{\circ} \mathrm{C}\left(5 \mathrm{~h}, \mathrm{~N}_{2}\right.$ flow) produced Co/NPC composite, and this composite was transformed into the pure nanoporous carbon (NPC-800) via $10 \% \mathrm{HF}$ etching. The NPC-800 had high $\mathrm{S}_{\mathrm{BET}}$ with a large $\mathrm{V}_{\text {pore }}\left(0.84 \mathrm{~cm}^{3} \mathrm{~g}^{-1}\right)$. It also exhibited micro-/mesoporous porosity and ultra-high graphitization degree $\left(I_{\mathrm{G}} / I_{\mathrm{D}}=2.07\right)$. In the $3 \mathrm{E}$ system with $0.5 \mathrm{M} \mathrm{H}_{2} \mathrm{SO}_{4}$ electrolyte, it delivered $238 \mathrm{~F} \mathrm{~g}^{-1}$ at $20 \mathrm{mV} \mathrm{s}^{-1}$ and $171 \mathrm{~F} \mathrm{~g}^{-1}$ at $200 \mathrm{mV} \mathrm{s}^{-1}$ (Figure 4). Moreover, with an operation cell voltage of $1.4 \mathrm{~V}$, the specific capacitance of $2 \mathrm{E}$ cell at $2 \mathrm{~A} \mathrm{~g}^{-1}$ was $62 \mathrm{~F} \mathrm{~g}^{-1}$. High rate performance was observed in both $3 \mathrm{E}$ and $2 \mathrm{E}$ cells because of the hierarchical porosity and high graphitization degree of NPC-800.

\subsubsection{Cu-MOF-Derived Carbons}

A Cu-MOF containing 1,4-bis(imidazol-1-yl) benzene (bib) was employed as a self-sacrificing template to prepare hierarchical flower-like N-doped porous carbon materials (NPCs) by Li et al. [76]. The self-sacrificing template possessed a formula of $\left\{\left[\mathrm{Cu}(\mathrm{bib})_{2}\left(\mathrm{H}_{2} \mathrm{O}\right)_{2}\right]\left(\mathrm{ClO}_{4}\right)_{2}\left(\mathrm{H}_{2} \mathrm{O}\right)\right\}$, and its $1 \mathrm{D}$ pores contained potentially explosive perchlorate ions. This unique pore structure could enhance the porosity of $\mathrm{Cu} @ \mathrm{C}$ composites during the carbonization of the template $\left(12 \mathrm{~h}, \mathrm{~N}_{2}\right.$ flow). In addition, $\mathrm{HCl}$ etching of the composites might induce the additional pore generation. Among the NPCs, NPC-900 (carbonization at $900^{\circ} \mathrm{C}$ ) showed superior porosity and graphitization to other NPC samples. Therefore, better electrochemical performance was displayed for the NPC-900 with 3E system employing $6 \mathrm{M}$ $\mathrm{KOH}$ electrolyte. 

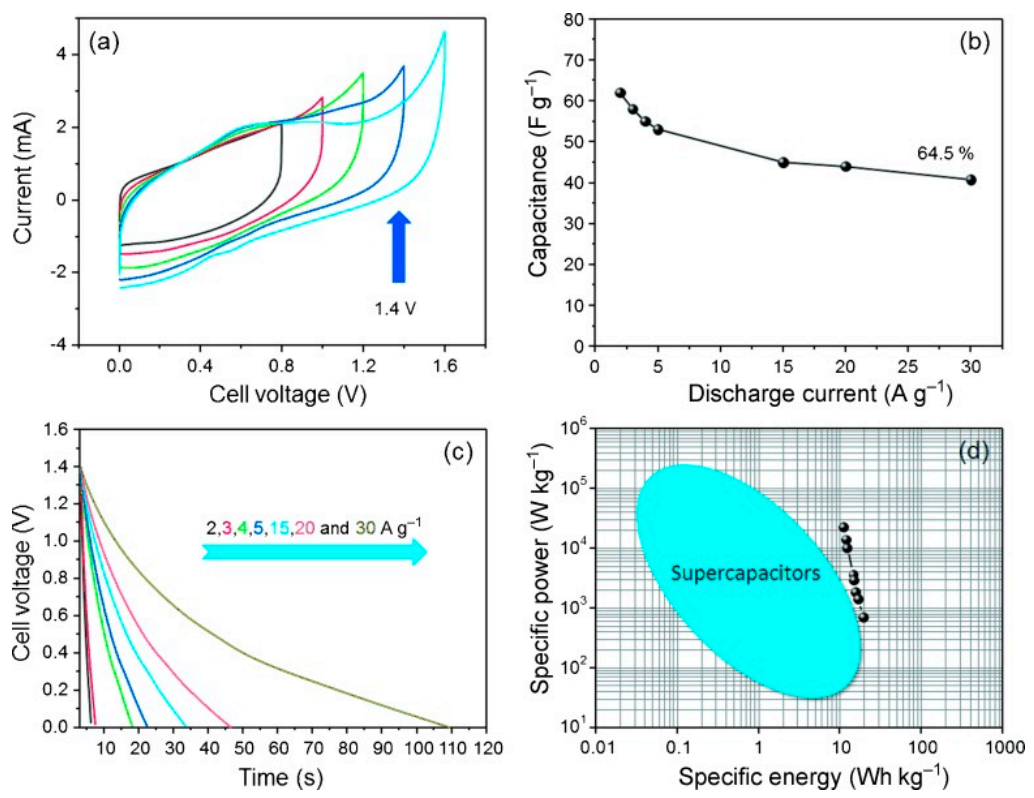

Figure 4. The electrochemical performance of SSC based on NPC-800 using $0.5 \mathrm{M} \mathrm{H}_{2} \mathrm{SO}_{4}$ electrolyte. (a) Cyclic voltammograms at $20 \mathrm{mV} \mathrm{s}^{-1}$ combined with diverse cell voltages (from 0.8 to $1.6 \mathrm{~V}$ ).

(b) Specific capacitances obtained by charge-discharge data with a cell voltage of $1.4 \mathrm{~V}$. (c) Galvanostatic discharge curves at different current loads (from 2 to $30 \mathrm{Ag}^{-1}$ ) with $1.4 \mathrm{~V}$ cell voltage. (d) Ragone plot [75].

New bib-based $\mathrm{Cu}-\mathrm{MOF}$ for the synthesis of novel porous carbon nanosheets were prepared by the same group under different solvent system, $\mathrm{MeOH}$ and chloroform, and $\mathrm{Cu}$ source, $\mathrm{Cu}\left(\mathrm{NO}_{3}\right)_{2} \cdot 3 \mathrm{H}_{2} \mathrm{O}$ [77]. A formula of the $\mathrm{Cu}-\mathrm{MOF}$ was $\left\{\left[\mathrm{Cu}(\mathrm{bib})_{2}\left(\mathrm{NO}_{3}\right)\left(\mathrm{H}_{2} \mathrm{O}\right)\right]\left(\mathrm{NO}_{3}\right)\left(\mathrm{H}_{2} \mathrm{O}\right)_{0.5}\right\}$. Direct carbonization of the $\mathrm{Cu}-\mathrm{MOF}$ at $800{ }^{\circ} \mathrm{C}\left(3 \mathrm{~h}, \mathrm{~N}_{2}\right)$ induced the formation of $\mathrm{Cu} @ \mathrm{C}$ composite with the preservation of hierarchically layered morphology, and helped $\mathrm{Cu}$-catalyzed graphitization. After the etching process of $\mathrm{Cu} @ \mathrm{C}$ with $\mathrm{HCl}$, the activation of acid-etched $\mathrm{Cu} @ \mathrm{C}$ with $\mathrm{KOH}\left(800{ }^{\circ} \mathrm{C}, 1 \mathrm{~h}, \mathrm{~N}_{2}\right.$ flow, $\mathrm{Cu} @ \mathrm{C} / \mathrm{KOH}$ $=1 / 4$ ) generated APC with hierarchical porosity. The exfoliation of the layered morphology into nanosheet also occurred. Thus, the APC nanosheet showed a high $S_{\text {BET }}$ with a large $V_{\text {pore }}\left(1.50 \mathrm{~cm}^{3} \mathrm{~g}^{-1}\right)$. In $6 \mathrm{M} \mathrm{KOH}$ electrolyte with 3E cell, the specific capacitances of the APC were $231 \mathrm{~F} \mathrm{~g}^{-1}$ at $5 \mathrm{mV} \mathrm{s}^{-1}$ and $260.5 \mathrm{~F} \mathrm{~g}^{-1}$ at $0.5 \mathrm{~A} \mathrm{~g}^{-1}$. The APC nanosheet electrode also exhibited good electrochemical properties in symmetric $2 \mathrm{E}$.

\subsubsection{Fe-MOF-Derived Carbons}

Nonporous iron-based coordination polymer (CP) nanodisks were synthesized and used as carbon precursor for the fabrication of hexagonal-nanodisk shaped mesoporous graphitic carbons [78]. The different iron-based $\mathrm{CPs}\left(\mathrm{CP}-\mathrm{FeSO}_{4}\right.$ and $\left.\mathrm{CP}-\mathrm{FeCl}_{2}\right)$ were constructed from constructed by hydrothermal reaction of the NTCDA (1,4,5,8-naphthalenetetracarboxylic dianhydride) with Fe sources $\left(\mathrm{FeSO}_{4}\right.$ or $\left.\mathrm{FeCl}_{2}\right)$ under economical and green condition. Catalytic carbonization $\left(4 \mathrm{~h}, \mathrm{~N}_{2}\right.$ flow) of the CPs controlled by carbonization temperature and Fe source could determine the hierarchical porosity and graphitization degree of the carbonized sample. In addition, $\mathrm{HCl}(2 \mathrm{M})$ washing of the carbonized sample generated additional mesopore. More porous but less graphitized carbons were produced by lower carbonization temperature $\left(900^{\circ} \mathrm{C}\right)$ and $\mathrm{CP}$ - $\mathrm{FeSO}_{4}$-based conditions. These conditions could also influence the capacitive property of the carbon samples in $6 \mathrm{M} \mathrm{KOH}$ electrolyte with 3E system. At $2 \mathrm{mV} \mathrm{s}^{-1}$, the gravimetric specific capacitance values of C-S700, C-S-900, C-Cl700 and C-C1900 were $182,156,117$ and $70 \mathrm{~F} \mathrm{~g}^{-1}$, respectively.

Zhuang et al. reported porous carbon derived from MIL-101(Fe) [79]. Mild and green synthetic condition (room temperature, organic solvent-free) of the MOF self-sacrificing template with a cheap metal source $\left(\mathrm{FeSO}_{4}\right)$ in a large scale could meet the needs of industrial and environmental chemistry. 
Carbonization of MIL-101(Fe) at $800^{\circ} \mathrm{C}(0.5 \mathrm{~h}$, Ar flow $)$ followed by $2 \mathrm{M} \mathrm{HCl}$ treatment generated hollow carbon polyhedra (HCPs). The resultant porous HPCs $\left(\mathrm{V}_{\text {pore }}=1.68 \mathrm{~cm}^{3} \mathrm{~g}^{-1}\right)$ showed highly graphitized and ultrathin carbon layer with micro-/mesoporous hierarchical porosity. Therefore, the HPCs were good electrode materials under symmetric $2 \mathrm{E}$ system in $6 \mathrm{M} \mathrm{KOH}$ electrolyte. The capacitances were high levels for 2E cells, $214 \mathrm{~F} \mathrm{~g}^{-1}$ at $0.05 \mathrm{~A} \mathrm{~g}^{-1}$ and $145 \mathrm{~F} \mathrm{~g}^{-1}$ at $5 \mathrm{~A} \mathrm{~g}^{-1}$.

\subsubsection{K-MOF-Derived Carbons}

The first example of MOF-derived carbon-based SSCs in a redox electrolyte $\left(\mathrm{KI}\right.$ in $\left.\mathrm{H}_{2} \mathrm{SO}_{4}\right)$ was reported by Fischer and coworkers [80]. As a self-sacrificing template and a precursor for 2D porous carbon nanosheets (NPCs), the K-MOF was prepared from KI and BTC. The formula of the K-MOF was $\left\{\mathrm{K}_{3}\left\{\mathrm{C}_{6} \mathrm{H}_{3}\left(\mathrm{CO}_{2}\right)\left(\mathrm{CO}_{2} \mathrm{H}_{0.5}\right)\left(\mathrm{CO}_{2} \mathrm{H}\right)\right\}_{2}\right\}\left(\mathrm{H}_{2} \mathrm{O}\right)_{2}$. After two-step pyrolysis under $\mathrm{N}_{2}$ $\left(450{ }^{\circ} \mathrm{C}\right.$ for $6 \mathrm{~h}$ and $800{ }^{\circ} \mathrm{C}$ for $8 \mathrm{~h}$ ) followed by $\mathrm{HCl}(5 \mathrm{wt} . \%)$ treatment, the activated MOF nanorods was successfully transformed into 2D graphitic nanoporous carbon sheets (NPS-800). The obtained NPS-800 with high specific surface area had hierarchical porosity as well as large $V_{\text {total }}\left(1.06 \mathrm{~cm}^{3} \mathrm{~g}^{-1}\right)$. Electrochemical properties of SSC based on the NPS-800 electrode were investigated in $1 \mathrm{M} \mathrm{H}_{2} \mathrm{SO}_{4}$ electrolyte with/without addition of redox-active KI. The supercapacitor exhibited outstanding value of BET-surface-normalized capacitance $\left(21.4 \mu \mathrm{F} \mathrm{cm}{ }^{-2}\right)$ at $5 \mathrm{mV} \mathrm{s}^{-1}$. In addition, the cell showed large values of gravimetric and volumetric energy densities, $24.8 \mathrm{~W} \mathrm{~h} \mathrm{~kg}^{-1}$ and $14.93 \mathrm{~mW} \mathrm{~h} \mathrm{~cm}{ }^{-3}$, at $533 \mathrm{~W} \mathrm{~kg}^{-1}\left(320 \mathrm{~mW} \mathrm{~cm}{ }^{-3}\right)$ power density. Furthermore, great improvements of electrochemical properties of the symmetric cell could be seen after addition of $0.2 \mathrm{M} \mathrm{KI}$ to $1 \mathrm{M} \mathrm{H}_{2} \mathrm{SO}_{4}$ electrolyte. From CV data, significantly increased gravimetric and areal capacitances were observed, $1636 \mathrm{~F} \mathrm{~g}^{-1}$ and $137.3 \mu \mathrm{F} \mathrm{cm}^{-2}$. It also delivered remarkably enhanced values of volumetric specific capacitance $\left(151 \mathrm{~F} \mathrm{~cm}^{-3}\right)$ and energy/power density $\left(89.7 \mathrm{~W} \mathrm{~h} \mathrm{~kg}^{-1}, 53.8 \mathrm{~W} \mathrm{~h} \mathrm{~cm}^{-3}\right)$ based on GCD cycles. Thus, both battery grade energy density and capacitor grade power density were achieved by this NPC-based cell.

\subsubsection{Mg-MOF-Derived Carbons}

From using the inexpensive ligands (bdc or btc) and $\mathrm{Mg}$ salts, four Mg-MOFs were solvothermally synthesized with/without polyethylene terephthalate (PET) inducer for tuning the quantity of $\mathrm{MgCl}_{2}$ impurity [81]. The $\mathrm{Mg}-\mathrm{MOF} / \mathrm{MgCl}_{2}$ hybrid products had different morphologies, and they were used as carbon precursors. They were transformed into the carbons via carbonization at $800{ }^{\circ} \mathrm{C}\left(5 \mathrm{~h}, \mathrm{~N}_{2}\right.$ flow) and $\mathrm{HCl}$ washing. Addition of the inducer decreased the $\mathrm{MgCl}_{2}$ impurity of the hybrid products. Therefore, the resultant carbon samples (CP-II and CP-III) contained higher values of $\mathrm{S}_{\mathrm{BET}}$ and specific capacitance than those of carbons derived from PET-free precursors (C-II and C-III). Electrochemical properties of the carbon samples were studied in $6 \mathrm{M} \mathrm{KOH}$ electrolyte with 3E cell. The CP-II carbon derived from btc-based Mg-MOF exhibited the highest specific capacitance of $127 \mathrm{~F} \mathrm{~g}^{-1}$ at $1 \mathrm{~A} \mathrm{~g}^{-1}$. On the other hand, the CP-III carbon (with laminated structure) derived from bdc-based Mg-MOF showed a better capacitive rate capability $(80 \%)$ with slightly smaller specific capacitance of $121 \mathrm{~F} \mathrm{~g}^{-1}$ at $1 \mathrm{Ag}^{-1}$.

\subsubsection{Ni-MOF-Derived Carbons}

Fu et al. reported N-doped porous graphitic carbon (NPGC) from a combined synthetic route of coordination-pyrolysis [82]. Precursor of the NPGC was prepared from coordinative assembly of porogen (tetraethyl orthosilicate or TEOS), graphitic catalyst source (nickel nitrate), carbon precursor (glucose), and nitrogen source (melamine) by a low-temperature reaction $\left(80^{\circ} \mathrm{C}\right.$, $4 \mathrm{~h})$. After carbonization at $900{ }^{\circ} \mathrm{C}(1 \mathrm{~h}), \mathrm{SiO}_{2}-\mathrm{Ni}-\mathrm{N}$-doped graphitic carbon was prepared. The SNGC-2-900 (from $2 \mathrm{~g}$ of melamine) was transformed into NPGC-2-900 via $10 \mathrm{wt} . \%$ HF solution treatment. The nanosheet-like NPGC-2-900 showed a large $\mathrm{S}_{\mathrm{BET}}\left(1027 \mathrm{~m}^{2} \mathrm{~g}^{-1}\right)$, interconnected porosity (micro-/mesopore, $\mathrm{D}_{\text {pore }}=5 \mathrm{~nm}$ ), a high $\mathrm{N}$-dopant content $(7.72 \mathrm{wt} . \%)$, and a high graphitic degree $\left(I_{\mathrm{G}} / I_{\mathrm{D}}=2.33\right)$. These properties were adequate for electrochemical energy storage in both $6 \mathrm{M} \mathrm{KOH}$ and $1 \mathrm{M} \mathrm{Et}_{4} \mathrm{NBF}_{4} / \mathrm{PC}$ electrolytes. When the NPGC-2-900 was applied to $3 \mathrm{E}$ cell with $6 \mathrm{M} \mathrm{KOH}$, it showed 
$293 \mathrm{~F} \mathrm{~g}^{-1}$ at $1 \mathrm{~A} \mathrm{~g}^{-1}$ and $184 \mathrm{~F} \mathrm{~g}^{-1}$ at $30 \mathrm{~A} \mathrm{~g}^{-1}$. For $2 \mathrm{E}$ cell system, its total-cell specific capacitances at $1 \mathrm{~A} \mathrm{~g}^{-1}$ were $73 \mathrm{~F} \mathrm{~g}^{-1}$ in $6 \mathrm{M} \mathrm{KOH}$ and $47 \mathrm{~F} \mathrm{~g}^{-1}$ in $1 \mathrm{M} \mathrm{Et}_{4} \mathrm{NBF}_{4} / \mathrm{PC}$.

\subsubsection{Sr-MOF-Derived Carbons}

There was a rare example of $\mathrm{N}$-doped carbon materials derived from Sr-MOF. 7,7,8,8-tetracyanoquinodimethane (TCNQ) was chosen as a N-rich linker to synthesize $\mathrm{N}$-doping Sr-MOF self-sacrificing template and its corresponding $\mathrm{N}$-doped porous carbons [83]. Temperature-controlled carbonization under $\mathrm{N}_{2}$ atmosphere of the Sr-MOF self-sacrificing template and subsequent $\mathrm{Sr}$ species removal by c- $\mathrm{HCl}$ etching could generate the $\mathrm{N}$-doped carbon series (N-C-450, N-C-550, and N-C-650). Interestingly, the carbonization temperature-driven adjustment of heteroatom $(\mathrm{N}$ and $\mathrm{O}$ ) contents strongly influenced capacitive properties of the carbon series. As a result, N-C-650, carbonized at $650{ }^{\circ} \mathrm{C}$, was the best working electrode material for $3 \mathrm{E}$ system under $6 \mathrm{M} \mathrm{KOH}$ electrolytic conditions (Figure 5).
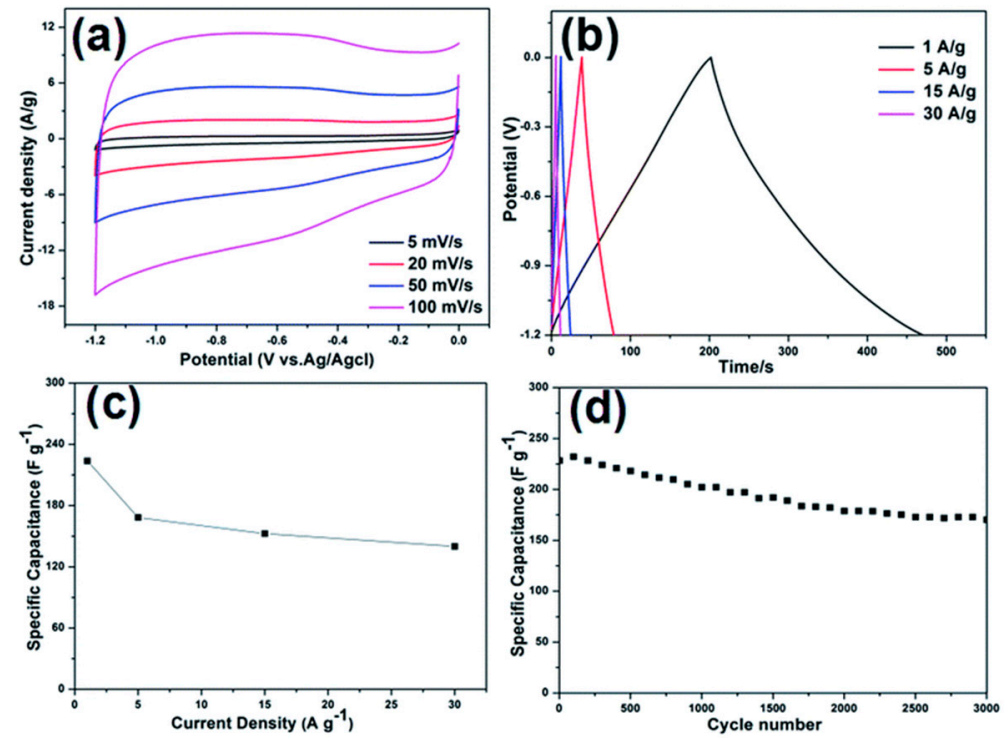

Figure 5. The electrochemical property of N-C-650-based supercapacitor for 3E system in $6 \mathrm{M} \mathrm{KOH}$ electrolyte. (a) CV curves at various scan rates. (b) GCD curves at various current densities. (c) Specific capacitances calculated from the GCD curves. (d) Cyclic stability at $1 \mathrm{~A} \mathrm{~g}^{-1}$ for 3000 cycles [83].

\subsubsection{Zr-MOF-Derived Carbons}

Nanoporous carbons (NCs) with controlled particle size and morphology were efficiently prepared from MOF-525 nanocrystals [84]. The porphyrin-based $\mathrm{Zr}-\mathrm{MOF}$ s were synthesized from $\mathrm{ZrCl}_{2}$ and porphyrin ligand (5,10,15,20-tetrakis(4-carboxyphenyl) porphyrin) under different quantitative addition of benzoic acid modulator. The size of the cubic MOF was proportional to the amount of the modulator, and it also determined the size of resultant NCs. Direct carbonization at $800{ }^{\circ} \mathrm{C}\left(1 \mathrm{~h}, \mathrm{~N}_{2}\right.$ flow $)$ and subsequent HF (10 wt.\%) treatment of the Zr-MOF series (MOF0.9, MOF1.1, MOF1.35, MOF2.0, and MOF2.7) produced a series of corresponding star-shaped NCs (NC0.9, NC1.1, NC1.35, NC2.0, and NC2.7). The porous NC1.35 electrode for capacitor was operable in $1 \mathrm{M} \mathrm{H}_{2} \mathrm{SO}_{4}$ electrolyte with $3 \mathrm{E}$ configuration. It exhibited high specific capacitance of $425 \mathrm{~F} \mathrm{~g}^{-1}$ at $2 \mathrm{~A} \mathrm{~g}^{-1}$. This excellent performance was mainly due to the combination of the large $S_{\mathrm{BET}}$ and hierarchical pore structure. Enhanced surface wettability and pseudocapacitance generated from N-/O-functionalities could also contribute to the specific capacitance.

Gan et al. pioneered a facile and effective synthetic approach for MOF-derived ultra-microporous carbon NPs (UCNs) [85]. MOFs of UiO-67 nanocrystals played the key dual roles as a sacrificial template and a carbon precursor for the UCNs preparation. The Zr-based MOF was synthesized 
form $\mathrm{ZrCl}_{2}$ and $\mathrm{H}_{2}$ bpdc with benzoic acid modulator. The $\mathrm{UiO}_{67}-\mathrm{x}$ derived $\mathrm{UCN}-\mathrm{x}-\mathrm{y}$ ( $\mathrm{x}=$ modulator equivalent based on the $\mathrm{ZrCl}_{2}, \mathrm{y}=$ carbonization temperature) was constructed from carbonization ( $3 \mathrm{~h}$, $\mathrm{N}_{2}$ flow) of the Zr-MOF crystals and HF treatment. Both the amount of modulator and temperature of carbonization could determine morphological and porous properties of the UCNs. As the optimal condition, UCN-20-750 achieved balance between specific surface area and conductivity. Nanoscale UCN-20-750 particles had high $\mathrm{S}_{\mathrm{BET}}$ together with narrow distribution of micropore $(0.53 \mathrm{~nm})$. As an electrode material for supercapacitor working in $3 \mathrm{E}$ cell under $6 \mathrm{M} \mathrm{KOH}$ electrolytic condition, it showed a high value of specific capacitance.

\subsection{Other Kinds}

There exist two reports about ZnBi-MOF-derived carbon which were published by Yuan et al. The carbons were synthesized via single-step carbonization at $1000{ }^{\circ} \mathrm{C}\left(8 \mathrm{~h}, \mathrm{~N}_{2}\right.$ flow) [86,87]. In the first example, worm-like mesoporous carbon (WMC) was derived from glycerol/MOCP (MOCP = metal-organic coordination polymer) composites [86]. The self-sacrificing template of bdc-based ZnBi-MOCP was combined with a secondary carbon source of glycerol to construct the composites. An environmentally friendly and simple direct carbonization of the composites generated the NMC, and the obtained mesoporous carbon exhibited high $\mathrm{S}_{\mathrm{BET}}$ and a large $\mathrm{V}_{\text {pore }}$ $\left(3.14 \mathrm{~cm}^{3} \mathrm{~g}^{-1}\right)$. High maximum specific capacitance of $344 \mathrm{~F} \mathrm{~g}^{-1}$ at $50 \mathrm{~mA} \mathrm{~g}^{-1}$ in $6 \mathrm{M} \mathrm{KOH}$ as well as high rate capability behavior of $109 \mathrm{~F} \mathrm{~g}^{-1}$ at $2 \mathrm{~A} \mathrm{~g}^{-1}$ was supported by low ohmic property resulting from micro-/mesoporous hierarchical porosity. Yuan et al. investigated the synergistic effect of the amount of $\mathrm{Bi}\left(\mathrm{NO}_{3}\right)_{3} \cdot 5 \mathrm{H}_{2} \mathrm{O}$ and the volume of glycerol on porosity of the resultant series of hierarchical porous carbon (HPC) [87]. HPCs- 0.4 sample had the highest $S_{\text {BET }}$ and $V_{\text {pore }}$ of $3.9 \mathrm{~cm}^{3} \mathrm{~g}^{-1}$ among the series. The specific capacitance of HPCs- 0.4 reached up to $241 \mathrm{~F} \mathrm{~g}^{-1}$ at $0.1 \mathrm{~A} \mathrm{~g}^{-1}$. This performance could also be ascribed to hierarchical porosity especially micro- and mesopore regions.

MOF-derived carbons (MCs) were obtained from the direct carbonization at $800{ }^{\circ} \mathrm{C}(5 \mathrm{~h}, \mathrm{Ar}$ flow) of three MOFs (HKUST-1, MOF-5 and Al-porous carbon polyhedrons (PCP)) and further HF treatment [88]. All the carbon samples had mesoporosity. In addition, the $\mathrm{S}_{\mathrm{BET}}$ of the corresponding MC-Cu, MC-Zn and MC-Al samples were 50, 420, and $1103 \mathrm{~m}^{2} \mathrm{~g}^{-1}$. Among them, the Al-PCP derived carbon (MC-Al) possessed the highest degree of graphitization and the most suitable hierarchical pore structure. Therefore, the high $\mathrm{S}_{\mathrm{BET}}$ and hierarchical porosity of the MC-Al might have synergistic effect on the best electrochemical properties under $3 \mathrm{E}$ cell in $30 \% \mathrm{KOH}$ electrolyte. At $100 \mathrm{~mA} \mathrm{~g}^{-1}$, the maximum specific capacitances of the MC-Cu, MC- $\mathrm{Zn}$, and MC-Al carbons were 142.3, 121.3, and $232.8 \mathrm{~F} \mathrm{~g}^{-1}$, respectively.

$\mathrm{Li}$ et al. investigated the role of metal ion in MOF self-sacrificing templates during the synthesis of MOF-derived carbon using six isomorphous MOFs in 2018 [89]. The 3D window-beam structured MOFs had a formula with $\left\{\left[\mathrm{M}_{3}(\mathrm{btc})_{2}(\text { bibp })_{2}\left(\mathrm{H}_{2} \mathrm{O}\right)_{2}\right] \cdot 3 \mathrm{H}_{2} \mathrm{O}\right\}\left(\mathrm{M}=\mathrm{Zn}^{\mathrm{II}}, \mathrm{Cd}^{\mathrm{II}}, \mathrm{Ni}^{\mathrm{II}}, \mathrm{Mn}^{\mathrm{II}}, \mathrm{Co}^{\mathrm{II}}\right.$, and $\left.\mathrm{Cu}^{\mathrm{II}}\right)$. In the cases of $\mathrm{Zn}$ - and Cd-MOFs, a single-step carbonization at $1000^{\circ} \mathrm{C}\left(3 \mathrm{~h}, \mathrm{~N}_{2}\right.$ flow $)$ was required to synthesize carbon products known as PC-Zn and PC-Cd, respectively. However, in other cases, additional $\mathrm{HCl}$ etching was performed to prepare pure carbonaceous products (GC-Ni, GC-Mn, GC-Co, and C-Cu). From the carbon precursors with same morphology, the resultant carbons with different types were produced and they were categorized into three types: porous carbons (PCs), graphitized carbons (GCs), and C-Cu. The PCs exhibited pore generation effect by $\mathrm{Zn}$ or $\mathrm{Cd}$ vapor during the carbonization process, so the values of $\mathrm{S}_{\mathrm{BET}}$ were relatively high, $1558 \mathrm{~m}^{2} \mathrm{~g}^{-1}$ for PC-Zn and $1430 \mathrm{~m}^{2} \mathrm{~g}^{-1}$ for PC-Zn. In the case of $\mathrm{Ni}, \mathrm{Co}$, and Mn-MOFs, the GCs with relatively small $\mathrm{S}_{\mathrm{BET}}$ were formed by metal species induced catalytic graphitization of carbon matrix. In addition, C-Cu with no graphitization showed the lowest $\mathrm{S}_{\mathrm{BET}}$ with no decent microporosity. The specific capacitances from $3 \mathrm{E}$ cell in $6 \mathrm{M} \mathrm{KOH}$ electrolyte decreased in the order of PCs $>\mathrm{GCs}>\mathrm{C}-\mathrm{Cu}$. Therefore, the SBET was thought to be a key factor determining the electrochemical properties by controlling electrochemically accessible surface area and ionic diffusion. 


\subsection{Asymmetic Supercapacitor (ASC)}

Table 5 depicts the electrochemical performances of asymmetric supercapacitors (ASCs) made of pure and heteroatom-doped carbons derived from MOFs and other electrode materials.

Table 5. Electrochemical performances of the ASCs based on pure and heteroatom-doped carbons.

\begin{tabular}{|c|c|c|c|c|c|}
\hline Samples & $S_{\mathrm{BET}}\left(\mathrm{m}^{2} \mathrm{~g}^{-1}\right)$ & $C_{\max }\left(\mathrm{F} \mathrm{g}^{-1}\right)$ & $E_{\max }\left(\mathrm{Wh} \mathrm{kg} \mathrm{kg}^{-1}\right)$ & $P_{\max }\left(\mathrm{W} \mathrm{kg}^{-1}\right)$ & Ref. \\
\hline MOF-DC//Li ${ }_{4} \mathrm{Ti}_{5} \mathrm{O}_{12}$ & $2714 / /-$ & - & $\sim 65$ & $\sim 10,000$ & 90 \\
\hline $\mathrm{WO}_{3} / \mathrm{C} / / \mathrm{MOF}-\mathrm{NC}$ & $127 / / 1474$ & 184.3 & 159.97 & 1736 & 91 \\
\hline CNT@NiO//PCPs & $-/ / 1980$ & 72 & 25.4 & 16,000 & 92 \\
\hline $\mathrm{Mn}_{2} \mathrm{O}_{3} @ \mathrm{NF} / / \mathrm{MC}$ & $76 / / 365$ & 317.5 & 112.82 & $\sim 2000$ & 93 \\
\hline Zn-Co-O@CC//NPC@CC & $90 / /-$ & 210 & 117.92 & 13,520 & 94 \\
\hline Ni-Co-O@CFP//NPC@CFP & $119 / / 332$ & 201 & 69 & - & 95 \\
\hline $\mathrm{CC} @ \mathrm{Co}_{3} \mathrm{O}_{4} / / \mathrm{CC} @ \mathrm{NC}$ & $-1 /-$ & $\sim 116.8$ & 41.5 & 49,200 & 96 \\
\hline $\mathrm{CC} @ \mathrm{NiCo}_{2} \mathrm{O}_{4} / / \mathrm{CC} @ \mathrm{NC}$ & $12 / /-$ & $\sim 89.7$ & 31.9 & 22,900 & 97 \\
\hline TM-nanorods//TM-NPCs & $477 / / 998$ & 161 & 47.1 & 17,104 & 98 \\
\hline
\end{tabular}

MOF-derived carbon (MOF-DC) was first employed as cathode electrode material for Li-ion hybrid electrochemical capacitors (Li-HECs) [90]. The MOF-DC was facilely synthesized from a single-step carbonization of MOF- 5 at $1000^{\circ} \mathrm{C}(8 \mathrm{~h}$, Ar flow). The MOF-DC with 3D cuboid structure showed ultra-high $\mathrm{S}_{\mathrm{BET}}$, hierarchical assembly of crumpled sheet, and hierarchical porosity (micro- and mesopores). After control of mass ratio (anode: cathode $=1: 2$ ), the $\mathrm{Li}-\mathrm{HEC}$ of $\mathrm{MOF}-\mathrm{DC} / \mathrm{Li}_{4} \mathrm{Ti}_{5} \mathrm{O}_{12}$ was operated in $1 \mathrm{M} \mathrm{LIPF}_{6}$ in EC-DMC (ethylene carbonate-dimethyl carbonate) electrolyte. The Li-HEC could deliver a high energy density about $65 \mathrm{~W} \mathrm{~h} \mathrm{~kg}^{-1}$ with good power performance. This value was superior to symmetric cell assembled from the MOF-DC electrode $\left(\sim 20 \mathrm{~W} \mathrm{~h} \mathrm{~kg}^{-1}\right)$. Another Li-HEC was reported by Huo et al. from ZIF-8-derived carbon cathode material [91]. After carbonization of the ZIF-8 at $800{ }^{\circ} \mathrm{C}$ followed by $\mathrm{HCl}$ treatment, MOF-derived N-doped carbon hollow polyhedrons (MOF-NC) were synthesized. The MOF-NC had high $\mathrm{S}_{\mathrm{BET}}\left(\mathrm{S}_{\text {micro }}=496.3 \mathrm{~m}^{2} \mathrm{~g}^{-1}, \mathrm{~S}_{\text {meso }}=974.6 \mathrm{~m}^{2} \mathrm{~g}^{-1}\right)$. As a working electrode of the $3 \mathrm{E}$ cell in $1 \mathrm{M} \mathrm{LiPF}_{6}$ in $\mathrm{EC} / \mathrm{DMC}$, it showed a capacitance of $269.9 \mathrm{~F} \mathrm{~g}^{-1}$ at $0.2 \mathrm{~A}$ $\mathrm{g}^{-1}$. In addition, at $6 \mathrm{~A} \mathrm{~g}^{-1}$, it yielded good rate performance (63\% retention). $\mathrm{WO}_{3} / \mathrm{C} / / \mathrm{MOF}-\mathrm{NC} \mathrm{Li}-\mathrm{HEC}$ was also operable in the same electrolyte with a controlled mass ratio of $\mathrm{WO}_{3} / \mathrm{C}: \mathrm{MOF}-\mathrm{NC}=1: 7.6$. At $0.5 \mathrm{~A} \mathrm{~g}^{-1}$, the Li-HEC exhibited the highest values of discharging cell capacitance $\left(184.3 \mathrm{~F} \mathrm{~g}^{-1}\right)$ and energy density $\left(159.97 \mathrm{~W} \mathrm{~h} \mathrm{~kg}^{-1}\right)$ with a power density of $172.6 \mathrm{~W} \mathrm{~kg}^{-1}$.

ZIF-8-derived PCPs were first used as a negative electrode for ASCs operating in an aqueous electrolyte [92]. The PCPs were synthesized form two-step pyrolysis of the ZIF-8 polyhedrons $\left(150^{\circ} \mathrm{C}\right.$ for $2 \mathrm{~h}$ and $1000{ }^{\circ} \mathrm{C}$ for $8 \mathrm{~h}$ in $\left.\mathrm{N}_{2}\right)$. The well-shaped PCPs with plentiful micropores $(\sim 1.8 \mathrm{~nm})$ and mesopores $(\sim 3.6 \mathrm{~nm})$ showed high $S_{\text {BET }}$ of $1980 \mathrm{~m}^{2} \mathrm{~g}^{-1}$ as well as large $V_{\text {total }}$ of $1.13 \mathrm{~cm}^{3} \mathrm{~g}^{-1}$. Under $1 \mathrm{M}$ $\mathrm{KOH}$ electrolyte with 3E cell, carbon electrode based on the PCPs with hierarchical porosity yielded capacitances of $245 \mathrm{~F} \mathrm{~g}^{-1}$ at $1 \mathrm{~A} \mathrm{~g}^{-1}$ and $162 \mathrm{~F} \mathrm{~g}^{-1}$ at $20 \mathrm{~A} \mathrm{~g}^{-1}$. After the optimization of mass ratio (CNT@NiO: PCPs = 0.5), the ASC of CNT@NiO//PCPs behaved well in the same electrolyte. In the ASC, the CNT@NiO was a battery-like faradaic positive electrode for energy source, while the PCP was a capacitive negative electrode for power source. At a current density of $0.5 \mathrm{~A} \mathrm{~g}^{-1}$, the ASC had maximum values (capacitance $=72 \mathrm{~F} \mathrm{~g}^{-1}$, energy density $=25.4 \mathrm{~W} \mathrm{~h} \mathrm{~kg}^{-1}$ ) with a specific power of $400 \mathrm{~W} \mathrm{~kg}^{-1}$. A new solid-phase hybrid supercapacitor (HSC) of $\mathrm{Mn}_{2} \mathrm{O}_{3} @ \mathrm{NF} / / \mathrm{MC}$ was reported [93]. The MC with mesoporous structure was prepared by direct carbonization at $800{ }^{\circ} \mathrm{C}\left(4 \mathrm{~h}, \mathrm{~N}_{2}\right.$ flow $)$ of ZIF-8 polyhedra and subsequent $2 \mathrm{M} \mathrm{HCl}$ washing. Its $\mathrm{S}_{\mathrm{BET}}$ was $365 \mathrm{~m}^{2} \mathrm{~g}^{-1}$. With the proper mass ratio of $\mathrm{MC}$ to $\mathrm{Mn}_{2} \mathrm{O}_{3}$ (1.033), the HSC was assembled from binder-free positive electrode $\left(\mathrm{Mn}_{2} \mathrm{O}_{3} @ \mathrm{NF}\right)$ and MC negative electrode in $\mathrm{PVA} / \mathrm{LiCl}$ electrolyte. At a current density of $0.4 \mathrm{~A} \mathrm{~g}^{-1}$, the solid-phase HSC yielded the highest values of capacitance (317.5 F g-1) and energy density $\left(112.82 \mathrm{~W} \mathrm{~h} \mathrm{~kg}^{-1}\right)$ with a power density of $320 \mathrm{~W} \mathrm{~kg}^{-1}$.

The flexible ASC of Zn-Co-O@CC//NPC@CC was reported [94]. The NPC was synthesized via carbonization of 2-methylimidazole-based $\mathrm{Zn}-\mathrm{Co}-\mathrm{MOF}$ and followed by $\mathrm{HCl}$ treatment. 
The all-solid-phase ASC was assembled from binder-free electrodes using flexible carbon cloth (CC) substrate and PVA/LiCl electrolyte. At a current density of $1.5 \mathrm{~A} \mathrm{~g}^{-1}$, it yielded maximum capacitance of $210 \mathrm{~F} \mathrm{~g}^{-1}$ and energy density of $117.92 \mathrm{~W} \mathrm{~h} \mathrm{~kg}^{-1}$ with delivering power density of $1490.4 \mathrm{~W} \mathrm{~kg}^{-1}$. In addition, at $20 \mathrm{~A} \mathrm{~g}^{-1}$, it showed the highest power density of $13.52 \mathrm{~kW} \mathrm{~kg}^{-1}$ with high rate performance (capacitance $=138.75 \mathrm{~F} \mathrm{~g}^{-1}$, energy density $=76.69 \mathrm{~W} \mathrm{~h} \mathrm{~kg}^{-1}$ ). Moreover, it had great structural stabilities $\left(84.52 \%\right.$ preservation after 1000 bending cycles with $180^{\circ}$ bending angle, $89.41 \%$ preservation after 6000 cycles with different bending states).

The 2-methylimidazole-based Zn-Co-MOF was used for the fabrication of NPC@CFP (CFP = carbon fiber paper) electrode for a flexible ASC of Ni-Co-O@CFP//NPC@CFP [95]. The bimetallic MOF was directly grown on CFP support. Then, the NPC@CFP was synthesized by carbonization at $800{ }^{\circ} \mathrm{C}\left(2 \mathrm{~h}, \mathrm{~N}_{2}\right.$ flow $)$ of the NPC@CFP. The NPC@CFP anode exhibited a high specific capacitance $\left(265 \mathrm{~F} \mathrm{~g}^{-1}\right.$ at $\left.1 \mathrm{~A} \mathrm{~g}^{-1}\right)$ in $1 \mathrm{M} \mathrm{KOH}$. The ASC showed a high specific capacitance (201 $\mathrm{F} \mathrm{g}^{-1}$ at $0.55 \mathrm{~A} \mathrm{~g}^{-1}$ ) with excellent rate performance $\left(69 \mathrm{~W} \mathrm{~h} \mathrm{~kg}^{-1}\right.$ at $840 \mathrm{~W} \mathrm{~kg}^{-1}$ and $58 \mathrm{~W} \mathrm{~h} \mathrm{~kg}^{-1}$ at $2985 \mathrm{~W} \mathrm{~kg}^{-1}$ ) in $\mathrm{KOH} / \mathrm{PVA}$ hydrogel electrolyte.

A 2D ZIF-67 was first used to single-templated synthesis of electrode materials (both anode and cathode) for flexible solid-phase ASC [96]. At first, the direct growth of Co-based ZIF-67 on conducting $\mathrm{CC}$ was performed to form flexible precursor of $\mathrm{CC} @ \mathrm{Co}-\mathrm{MOF}$. A cathode of $\mathrm{CC} @ \mathrm{Co}_{3} \mathrm{O}_{4}$ nanosheet was prepared by two-step pyrolysis $\left(50{ }^{\circ} \mathrm{C}, 1 \mathrm{~h}, \mathrm{~N}_{2}\right.$ flow and $350{ }^{\circ} \mathrm{C}, 2 \mathrm{~h}$, air flow) of the precursor. However, the precursor was transformed into an anode of CC@N-doped carbon nanosheet (CC@NC) via carbonization at $800{ }^{\circ} \mathrm{C}\left(5 \mathrm{~h}, \mathrm{~N}_{2}\right)$ and subsequent $1 \mathrm{M} \mathrm{FeCl}_{3}$ treatment. In the $3 \mathrm{E}$ cell with $2 \mathrm{M}$ $\mathrm{KOH}$ electrolyte, the CC@NC yielded high capacitance of $321.9 \mathrm{~F} \mathrm{~g}^{-1}$ at $6.25 \mathrm{~A} \mathrm{~g}^{-1}$. The ASC of $\mathrm{CC} @ \mathrm{Co}_{3} \mathrm{O}_{4} / / \mathrm{CC} @ \mathrm{NC}$ was fabricated in PVA/KOH electrolyte. This device also exhibited a maximum capacitance of $\sim 116.8 \mathrm{~F} \mathrm{~g}^{-1}$ at $7.7 \mathrm{~A} \mathrm{~g}^{-1}$.

Another self-templating synthetic approach from ZIF-67 was applied to flexible supercapacitor of $\mathrm{CC} @ \mathrm{NiCo}_{2} \mathrm{O}_{4} / / \mathrm{CC} @ \mathrm{NC}$ [97]. The raw precursor of CC@Co-MOF was converted into CC@Ni-Co $\mathrm{LDH}\left(\mathrm{LDH}=\right.$ layered double-hydroxide) by $\mathrm{Ni}\left(\mathrm{NO}_{3}\right)_{2}$-driven ion-exchange and etching. The cathode, $\mathrm{CC} @ \mathrm{NiCo}_{2} \mathrm{O}_{4}$, was synthesized via a one-step pyrolysis of the CC@Ni-Co $\mathrm{LDH}$ at $350{ }^{\circ} \mathrm{C}$ ( $2 \mathrm{~h}$, air flow). In addition, the anode, $\mathrm{CC} @ \mathrm{NC}$, was prepared from carbonization at $800^{\circ} \mathrm{C}(2 \mathrm{~h}, \mathrm{Ar})$ and following $3 \mathrm{M}$ $\mathrm{HCl}$ treatment. The CC@NiCo $\mathrm{O}_{4} / / \mathrm{CC} @ N C$ cell was operated in PVA/KOH electrolyte. At $5 \mathrm{~mA} \mathrm{~cm}{ }^{-2}$, it yielded maximum values of capacitance $\left(\sim 89.7 \mathrm{~F} \mathrm{~g}^{-1}\right)$ and energy density $\left(31.9 \mathrm{~W} \mathrm{~h} \mathrm{~kg}^{-1}\right)$ with a power density of $2.9 \mathrm{~kW} \mathrm{~kg}^{-1}$. In addition, at $40 \mathrm{~mA} \mathrm{~cm}{ }^{-2}$, it exhibited maximum power density of $22.9 \mathrm{~kW} \mathrm{~kg}^{-1}$ with ultra-high rate performance of capacitance $\left(\sim 76 \mathrm{~F} \mathrm{~g} \mathrm{~g}^{-1}\right)$ and energy density $\left(27.3 \mathrm{~W} \mathrm{~h} \mathrm{~kg} \mathrm{k}^{-1}\right)$. Other types of ASC were constructed from another self-sacrificing template of Ni-DMOF-TM ([Ni(tmbdc)(dabco $\left.)_{0.5}\right]$, tmbdc $=2,3,5,6$-tetramethyl-1,4-benzenedicarboxylic acid) [98] . A new battery-like positive electrode was CFP@TM-nanorods, synthesized from two-step thermal growth $\left(85^{\circ} \mathrm{C}\right.$ for $24 \mathrm{~h}$ and $120^{\circ} \mathrm{C}$ for $\left.24 \mathrm{~h}\right)$ of the binder-free TM-nanorods on conducting carbon fiber paper (CFP) with the assistance of triethylamine. This positive electrode was transformed into negative electrode of CFP@TM-NPCs (NPCs = N-doped hierarchical porous carbon nanorods) via carbonization at $1000^{\circ} \mathrm{C}(3 \mathrm{~h}$, Ar flow $)$ followed by $\mathrm{HCl}$ treatment. The TM-NPCs contained large $\mathrm{S}_{\mathrm{BET}}$ of $998 \mathrm{~m}^{2} \mathrm{~g}^{-1}$ as well as hierarchical porosity. Under 3E mode with $2 \mathrm{M} \mathrm{KOH}$ electrolyte, the TM-NPC had capacitances of $330 \mathrm{~F} \mathrm{~g}^{-1}$ at $1 \mathrm{~A} \mathrm{~g}^{-1}$ and $290 \mathrm{~F} \mathrm{~g}^{-1}$ at $20 \mathrm{~A} \mathrm{~g}^{-1}$. With the optimization of mass ratio of TM-nanorods to TM-NPCs (1:3.6), the ASC of TM-nanorods//TM-NPCs was operated in the same electrolyte. At $1 \mathrm{~A} \mathrm{~g}^{-1}$, high capacitance $\left(161 \mathrm{~F} \mathrm{~g}^{-1}\right)$ and energy density $\left(47.1 \mathrm{~W} \mathrm{~h} \mathrm{~kg}^{-1}\right)$ could be found with a power density of $1018 \mathrm{~W} \mathrm{~kg}^{-1}$.

\section{Metallic NP-Containing Carbons}

The metallic NPs as well as heteroatom dopants in carbon matrices can enhance the capacitive properties by good electrical conductivity, pseudocapacitance, and favorable wetting of electrode surfaces. The electrochemical performances of metallic NP-containing carbons are summarized in Table 6. 
Table 6. The electrochemical capacitive performances of metallic NP-containing carbons derived from MOFs.

\begin{tabular}{|c|c|c|c|c|c|c|}
\hline Samples & $S_{\text {BET }}\left(\mathrm{m}^{2} \mathrm{~g}^{-1}\right)$ & $C_{\max }\left(\mathrm{F} \mathrm{g}^{-1}\right)$ & $E_{\max }\left(\mathrm{Wh} \mathrm{kg} \mathrm{kg}^{-1}\right)$ & $P_{\max }\left(\mathrm{W} \mathrm{kg}^{-1}\right)$ & System & Ref. \\
\hline C800MOF & 140 & 886 & 25 & 11,250 & $3 \mathrm{E}$ & 99 \\
\hline $\mathrm{CNT}$ & 400 & $272^{\mathrm{a}}$ & $0.0544^{b}$ & $5.988^{c}$ & $2 \mathrm{E}$ & 100 \\
\hline HP-Ni@C-N & 111 & 912 & - & - & $3 \mathrm{E}$ & 101 \\
\hline CNRod700 & 373 & 67 & - & - & $3 \mathrm{E}$ & 102 \\
\hline CNRod800 & 367 & 127 & 4.4 & - & $3 \mathrm{E}$ & 102 \\
\hline CNRod900 & 375 & 98 & - & - & $3 \mathrm{E}$ & 102 \\
\hline $\mathrm{Ni} / \mathrm{P} / \mathrm{N} / \mathrm{C}-500$ & 22 & 2887.87 & - & - & $3 \mathrm{E}$ & 103 \\
\hline $\mathrm{Ni} / \mathrm{P} / \mathrm{N} / \mathrm{C}-600$ & 27 & 1699.3 & - & - & $3 \mathrm{E}$ & 103 \\
\hline $\mathrm{Ni} / \mathrm{P} / \mathrm{N} / \mathrm{C}-700$ & 35 & 1901.9 & - & - & $3 \mathrm{E}$ & 103 \\
\hline $\mathrm{Ni} / \mathrm{P} / \mathrm{N} / \mathrm{C}-800$ & 247 & 402 & - & - & $3 \mathrm{E}$ & 103 \\
\hline Metallic cobalt/carbon & 236 & 144.5 & - & - & $3 \mathrm{E}$ & 104 \\
\hline Ni foam/cobalt/carbon & - & 512.0 & - & - & $3 \mathrm{E}$ & 105 \\
\hline LIMDG & 440 & $1.36^{\mathrm{a}}$ & $0.14^{\mathrm{b}}$ & $580^{c}$ & $2 \mathrm{E}$ & 106 \\
\hline $\mathrm{Co}\left(\mathrm{CO}_{2}\right)_{2} \mathrm{Pz} 700 \mathrm{AL}$ & 320 & 330 & 9.1 & 7000 & $3 \mathrm{E} / 2 \mathrm{E}$ & 107 \\
\hline $\mathrm{Co}\left(\mathrm{CO}_{2}\right)_{2} \mathrm{Pz} 900 \mathrm{AL}$ & 394 & 430 & - & - & $3 \mathrm{E}$ & 107 \\
\hline CNS-800 & 770 & 156 & - & - & $2 \mathrm{E}$ & 108 \\
\hline NC-800 & 84 & 1069 & - & - & $3 \mathrm{E}$ & 109 \\
\hline Ni-Co@carbon & 238 & 236 & - & - & $3 \mathrm{E}$ & 110 \\
\hline Co@carbon & - & 50 & - & - & $3 \mathrm{E}$ & 110 \\
\hline Nanoporous carbon & 350 & 272 & 7.1 & - & $3 \mathrm{E} / 2 \mathrm{E}$ & 111 \\
\hline Ni/N-doped PC-500 & 112 & 2002.6 & - & - & $3 \mathrm{E}$ & 112 \\
\hline GC & 496 & 119 & - & - & $3 \mathrm{E}$ & 141 \\
\hline $\mathrm{Au} @ \mathrm{NC} 800$ & 954 & 171.7 & - & - & $3 \mathrm{E}$ & 170 \\
\hline Co@Carbon & 110 & 109 & 1.83 & 3500 & $3 \mathrm{E} / 2 \mathrm{E}$ & 182 \\
\hline $\mathrm{Co} / \mathrm{C}$ & 216 & 146 & - & - & $3 \mathrm{E}$ & 200 \\
\hline
\end{tabular}

\subsection{Ni-MOF-Derived Carbons}

\subsubsection{Ni-bdc MOF-Derived Carbons}

Ni-bdc MOF was introduced as a carbon precursor for supercapacitor [99]. After calcination of the Ni-bdc at $400{ }^{\circ} \mathrm{C}$ in air, Ni particles embedded porous carbons were prepared. After further carbonization at $800{ }^{\circ} \mathrm{C}$ under $\mathrm{N}_{2}$ atmosphere, the resultant $\mathrm{C} 800 \mathrm{MOF}$ showed optimized porosities. Electronic conductivity (from graphitic structure), ionic transport (from large mesopores and macropores), and pseudocapacitance (from redox reactions by uniformly dispersed Ni particles: $\mathrm{Ni}(\mathrm{OH})_{2}+\mathrm{OH}^{-} \leftrightarrow \mathrm{NiOOH}+\mathrm{H}_{2} \mathrm{O}+\mathrm{e}^{-}, \mathrm{NiO}+\mathrm{OH}^{-} \leftrightarrow \mathrm{NiOOH}+\mathrm{e}^{-}$) synergistically supported good capacitive properties of the C800MOF-based working electrode in $3 \mathrm{E}$ cell under $1 \mathrm{M} \mathrm{KOH}$ electrolyte (Figure 6). It showed $886 \mathrm{~F} \mathrm{~g}^{-1}$ at $1 \mathrm{~A} \mathrm{~g}^{-1}$ and $746 \mathrm{~F} \mathrm{~g}^{-1}$ at $30 \mathrm{~A} \mathrm{~g}^{-1}$. High rate capability could be seen in energy density (from 25 to $18 \mathrm{~W} \mathrm{~h} \mathrm{~kg}^{-1}$ ) when the power density increases from $225 \mathrm{~W} \mathrm{~kg}^{-1}$ to $11,250 \mathrm{~W} \mathrm{~kg}^{-1}$.

Ni-bdc was also unprecedentedly used as a self-sacrificing template for in situ growth of CNT [100]. Without additional materials such as secondary carbon source, catalyst, and reducing agent, the single sacrificial template was directly carbonized at $800{ }^{\circ} \mathrm{C}\left(8 \mathrm{~h}, \mathrm{~N}_{2}\right.$ flow $)$ and then treated with $\mathrm{HNO}_{3}$. The resultant CNT was first employed as an electrode material for all-solid-phase SSC using PVA/KOH gel electrolyte. High areal specific capacitance with good capacitive rate capability could be obtained $\left(272 \mathrm{mF} \mathrm{cm}^{-2}\right.$ at $0.5 \mathrm{~mA} \mathrm{~cm}{ }^{-2}$ and $168 \mathrm{mF} \mathrm{cm}^{-2}$ at $\left.10 \mathrm{~mA} \mathrm{~cm}^{-2}\right)$. Its highest energy density and power density were $0.0544 \mathrm{~mW} \mathrm{~h} \mathrm{~cm}^{-2}$ and $5.988 \mathrm{~mW} \mathrm{~cm}^{-2}$, respectively. These good properties might result from high $S_{\mathrm{BET}}$, uniform porosity, and high electronic conductivity from graphitized carbon matrix and a few residual Ni species. 

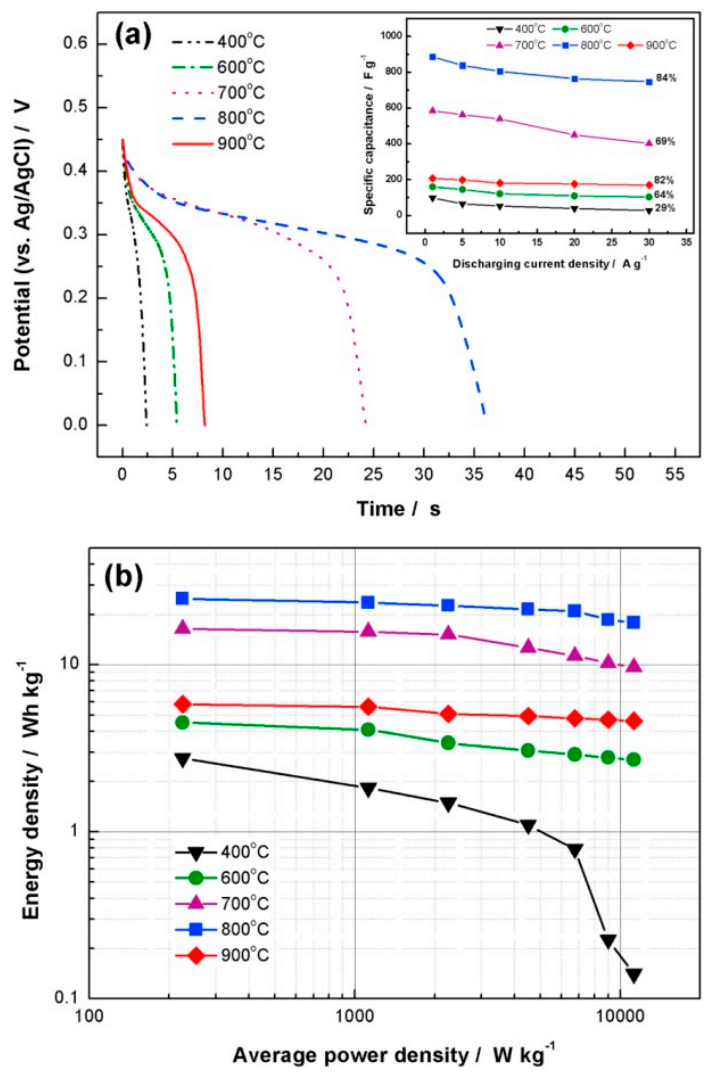

Figure 6. Electrochemical behaviors of working electrodes based on carbonized Ni-BDC for 3E setup using $1 \mathrm{M} \mathrm{KOH}$ electrolyte. (a) Discharge curves at $10 \mathrm{~A} \mathrm{~g}^{-1}$ and influence of discharge current load on the specific capacitance (inset). (b) Ragone plots [99].

\subsubsection{Ni-btc MOF-Derived Carbons}

Yoon et al. reported Ni-btc-derived hierarchical porous Nickel@Carbon nanospheres (HP-Ni@C-N) [101]. During the shape-preserved simple carbonization at $400{ }^{\circ} \mathrm{C}\left(2 \mathrm{~h}, \mathrm{~N}_{2}\right.$ flow), individual core-shell structure was constructed with graphitized carbon layers which encapsulated nickel NPs. The resultant HP-Ni@C-N exhibited good mesoporosity $\left(\right.$ main $\left.\mathrm{V}_{\text {pore }}=13.27 \mathrm{~nm}\right)$. Compared to the Ni-btc MOF, the HP-Ni@C-N showed better capacitive performance in $3 \mathrm{M} \mathrm{KOH}$ electrolyte in 3E cell system (Ni-MOF: $493 \mathrm{~F} \mathrm{~g}^{-1}$ at $10 \mathrm{mV} \mathrm{s}^{-1}$ and $221 \mathrm{~F} \mathrm{~g}^{-1}$ at $100 \mathrm{mV} \mathrm{s}^{-1}$, HP-Ni@C-N: $912 \mathrm{~F} \mathrm{~g}^{-1}$ at $10 \mathrm{mV} \mathrm{s}^{-1}$ and $397 \mathrm{~F} \mathrm{~g}^{-1}$ at $100 \mathrm{mV} \mathrm{s}^{-1}$ ). Porous structure with high $\mathrm{S}_{\mathrm{BET}}$ as well as electronic conductivity improved by core-shell structure might have synergistic effects on these superior properties.

\subsubsection{Other Ni-MOF-Derived Carbons}

The carbonization of nanorod-shaped hhtp-based Ni-CAT MOF (hhtp $=2,3,6,7,10,11$ hexahydroxytriphenylene, $\mathrm{CAT}=$ catecholate) and subsequent $2 \mathrm{M} \mathrm{HCl}$ etching were conducted to prepare nanoporous carbon nanorod (CNRods) showing micro-/mesoporosity [102]. The carbonization was performed at 700,800 , and $900{ }^{\circ} \mathrm{C}\left(2 \mathrm{~h}, \mathrm{~N}_{2}\right.$ flow $)$. The particle morphology was preserved during carbonization. After suitable control of O-dopant contents and Ni-catalyzed graphitization degree during the carbonization, CNRod 800 (carbonized at $800{ }^{\circ} \mathrm{C}, \mathrm{S}_{\mathrm{BET}}=367 \mathrm{~m}^{2} \mathrm{~g}^{-1}$ ) showed improved electrochemical performance in $3 \mathrm{E}$ cell in $6 \mathrm{M} \mathrm{KOH}$ due to good ionic and electronic conductivities as well as wettability. At $0.5 \mathrm{~A} \mathrm{~g}^{-1}$, it had a gravimetric specific capacitance of $127 \mathrm{~F} \mathrm{~g}^{-1}$ and normalized areal specific capacitance of $34.6 \mu \mathrm{F} \mathrm{cm} \mathrm{cm}^{-2}$.

A unique Ni-MOF with multi-component dopant sources, such as $\mathrm{P}, \mathrm{N}$, and $\mathrm{O}$, was synthesized and used as a self-sacrificing template for the preparation of uncommon carbon 
materials $\left(\mathrm{Ni} / \mathrm{P} / \mathrm{N} / \mathrm{C}-\mathrm{T}, \mathrm{T}=\right.$ carbonization temperature in $\left.{ }^{\circ} \mathrm{C}\right) . \quad$ The resulting $\mathrm{Ni} / \mathrm{P} / \mathrm{N} / \mathrm{C}-\mathrm{T}$ carbons showed uniformly incorporated aforementioned multi-component dopants and $\mathrm{Ni}$ element $\left(\mathrm{Ni}, \mathrm{P}, \mathrm{N}\right.$, and O) [103]. The Ni-MOF with a formula of $\left[\mathrm{Ni}_{3}\left(\mathrm{H}_{2} \mathrm{O}\right)(\mathrm{bpy})_{3}(\mathrm{~L} 1)\right]$ was prepared from the mixed ligand system of bpy and hexakis(4-formylphenoxy)cyclotriphosphazene $\left(\mathrm{H}_{6} \mathrm{~L} 1\right)$. Then, it was transformed into the $\mathrm{Ni} / \mathrm{P} / \mathrm{N} / \mathrm{C}-\mathrm{T}$ carbons through single-step carbonization at varying temperatures. During the carbonization, many properties influencing electrochemical performance, such as hierarchical porosity, dopant distribution, wettability, and conductivity, were regulated. The $\mathrm{Ni} / \mathrm{P} / \mathrm{N} / \mathrm{C}-500$ was found to be the best electrode material for capacitor in $6 \mathrm{M} \mathrm{KOH}$ with $3 \mathrm{E}$ cell configuration.

\subsection{Co-MOF-Derived Carbons}

\subsubsection{ZIF-67-Derived Carbons}

Wei et al. introduced a single-step carbonization of ZIF-67 at $1000{ }^{\circ} \mathrm{C}\left(5 \mathrm{~h}, \mathrm{~N}_{2}\right.$ flow) to produce metallic Co-containing carbon electrode without additional purification steps [104]. The resultant carbon $\left(\mathrm{S}_{\mathrm{BET}}=236 \mathrm{~m}^{2} \mathrm{~g}^{-1}\right)$ had well-interconnected structure. The metallic Co particles (34.05 wt.\%) were crucial centers for electronic transport and pseudocapacitive faradaic reaction in $1 \mathrm{M} \mathrm{KOH}$ electrolyte $\left(\mathrm{Co}(\mathrm{OH})_{2}+2 \mathrm{e}^{-} \leftrightarrow \mathrm{Co}+2 \mathrm{OH}^{-}\right)$. As a result, the obtained carbon electrode under $3 \mathrm{E}$ cell showed capacitances of $144.5 \mathrm{~F} \mathrm{~g}^{-1}$ at $0.5 \mathrm{~A} \mathrm{~g}^{-1}$. They also reported binder-free and Co-containing carbon electrodes on Ni foam conducting substate [105]. The uniformly and closely packed ZIF-67 membrane precursor on the $\mathrm{Ni}$ foam was prepared for the synthesis of $\mathrm{Co} / \mathrm{carbon}$ on the conducting substrate. The resultant Ni foam/ZIF-67 was directly carbonized for $5 \mathrm{~h}$ to produce the Co/carbon-based electrodes. The optimized carbon obtained at $800{ }^{\circ} \mathrm{C}$ with a ladder-like morphological surface formed thin membrane (thickness $\approx 1.5 \mu \mathrm{m}$ ). In addition, Co NPs on the carbon surfaces showed well-defined size (diameter $\approx 2.6 \mathrm{~nm}$ ) and homogeneous distribution with no evident agglomeration. Thus, the facilely synthesized working electrode of 3E configuration with $1 \mathrm{M} \mathrm{KOH}$ electrolyte exhibited mainly pseudocapacitive behavior and good conductivity. It delivered a remarkably high capacitance of $512.0 \mathrm{~F} \mathrm{~g}^{-1}$ at $1 \mathrm{~A} \mathrm{~g}^{-1}$ and $274.3 \mathrm{~F} \mathrm{~g}^{-1}$ at $20 \mathrm{~A} \mathrm{~g}^{-1}$.

Ogale et al. employed laser carbonization method under ambient conditions to synthesize carbon electrode for a flexible interdigitated micro-supercapacitor (Figure 7) [106]. The new term of LIMDG represents laser-induced MOF-derived graphene. The LIMDG had interconnected network along with curled edges containing few layered graphenes. The hierarchically micro-/mesoporous LIMDG exhibited the $S_{\text {BET }}$ of $440 \mathrm{~m}^{2} \mathrm{~g}^{-1}$. This carbon-based symmetric device was operable with PVA/ $\mathrm{H}_{2} \mathrm{SO}_{4}$ gel electrolyte. The device displayed great cycling stability $(\sim 100 \%$ capacitive retention up to 200,000 cycles) and mechanical durability (98\% capacitive retention at bending angle of $150^{\circ}$ ). Therefore, the LIMDG electrode can be potentially applied to flexible electronic devices.

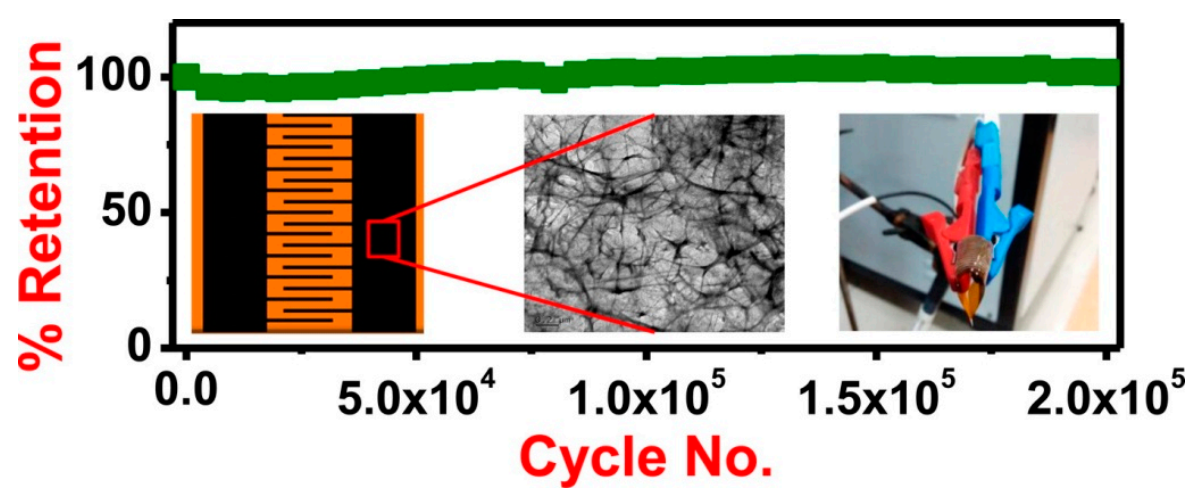

Figure 7. Graphical summary of structural and electrochemical properties for LIMDG electrode [106]. 


\subsubsection{Other Kinds}

$\mathrm{Co}$ and $\mathrm{N}$ co-doped mesoporous carbons were synthesized from the carbonization of $\mathrm{N}$-heterocyclic ligands containing four Co-coordination compounds [107]. Different carbonization temperatures $\left(700{ }^{\circ} \mathrm{C}\right.$ or $900{ }^{\circ} \mathrm{C}, 2 \mathrm{~h}, \mathrm{~N}_{2}$ flow) and subsequent $0.5 \mathrm{M} \mathrm{H}_{2} \mathrm{SO}_{4}$ etching process were applied. Increasing the carbonization temperature generated reduced $\mathrm{S}_{\mathrm{BET}}$ in the carbons in the absence of acid treatment. Meanwhile, after the acid etching, they increased to $307-462 \mathrm{~m}^{2} \mathrm{~g}^{-1}$. This result could be explained by the increase of the $S_{\text {meso }}$, from 78-152 to 202-290 $\mathrm{m}^{2} \mathrm{~g}^{-1}$, during the metallic species dissolution caused by the acid etching. Electrochemical measurements of the $3 \mathrm{E}$ system were conducted in $6 \mathrm{M}$ $\mathrm{KOH}$ and $0.5 \mathrm{M} \mathrm{H}_{2} \mathrm{SO}_{4}$ electrolytes. Acid-treated carbon sample derived from $\mathrm{Co}\left(\mathrm{CO}_{2}\right) \mathrm{pz}$ at $700{ }^{\circ} \mathrm{C}$ had a specific capacitance of $330 \mathrm{~F} \mathrm{~g}^{-1}$ at $1 \mathrm{~A} \mathrm{~g}^{-1}$. The acid-treated carbon sample derived from $\mathrm{Co}$ $\left(\mathrm{CO}_{2}\right)$ pz at $900{ }^{\circ} \mathrm{C}$ showed improved capacitance of $430 \mathrm{~F} \mathrm{~g}^{-1}$ at $0.5 \mathrm{~A} \mathrm{~g}^{-1}$ in a mixed electrolyte of $1 \mathrm{M} \mathrm{K}_{4} \mathrm{Fe}(\mathrm{CN})_{6}$ and $3 \mathrm{M} \mathrm{KOH}$. From the parameters of $S_{\text {meso }}$ and the Co content (\%Co), the following relationship equation about specific capacitance was proposed, $\mathrm{C}($ simulated $)=\mathrm{s}\left(\mathrm{S}_{\text {meso }}\right)+\mathrm{c}(\% \mathrm{Co})$. It can be inferred that the overall specific capacitance is the sum of pseudocapacitance contribution $(\% \mathrm{Co})$ and EDLC contribution $\left(\mathrm{S}_{\text {meso }}\right)$. In $2 \mathrm{E}$ system with the $\mathrm{Co}\left(\mathrm{CO}_{2}\right) \mathrm{pz}$ at $700{ }^{\circ} \mathrm{C}$ with acid etching in $6 \mathrm{M} \mathrm{KOH}$ electrolyte, the specific capacitance reached to $33.5 \mathrm{~F} \mathrm{~g}^{-1}$ and the specific energy was $9.1 \mathrm{~W} \mathrm{~h} \mathrm{~kg}^{-1}$ at $0.1 \mathrm{~A} \mathrm{~g}^{-1}$. At $10 \mathrm{~A} \mathrm{~g}^{-1}$, its maximum specific power was $7 \mathrm{~kW} \mathrm{~kg}^{-1}$.

\subsection{Fe-MOF-Derived Carbons}

A commercially available Fe-btc MOF (Basolite F300) was employed as a carbon precursor for the hierarchically porous CNSs with hollow nanostructure [108]. Carbonization of the precursor in Ar and following $\mathrm{EtOH} / \mathrm{HCl}(1: 5 v / v)$ treatment of the carbonized sample produced the CNSs. The hierarchical porosity of the CNSs was composed of micropores in their graphitic layered shell and mesopores in their inner voids. Among the three CNSs (CNS-700, CNS-800, CNS-900), the CNS-800 had optimized property from good balance between graphitization degree and accessible surface area. CNS-800-based SSC operating in $1 \mathrm{M} \mathrm{H}_{2} \mathrm{SO}_{4}$ electrolyte yielded capacitances of $91 \mathrm{~F} \mathrm{~g}^{-1}$ at $200 \mathrm{mV} \mathrm{s}^{-1}$ and $72 \mathrm{~F} \mathrm{~g}^{-1}$ at $500 \mathrm{mV} \mathrm{s}^{-1}$. When the electrolyte was replaced with 1-ethyl-3-methylimidazolium tetrafluoroborate $\left(\mathrm{EMIBF}_{4}\right)$, it delivered capacitances of $156 \mathrm{~F} \mathrm{~g}^{-1}$ at $2 \mathrm{mV} \mathrm{s}^{-1}$ and $88 \mathrm{~F} \mathrm{~g}^{-1}$ at $100 \mathrm{mV} \mathrm{s}^{-1}$.

\subsection{Other Kinds}

$\mathrm{Ni}-\mathrm{Co}-\mathrm{MOF}-74$ was used as a raw precursor for the preparation of carbon-based supercapacitor electrode materials [109]. The spherical precursor was solvothermally synthesized from bimetallic salts with 2,5-dihydroxyterephthalic acid under PVP modulator. After a simple single-step carbonization at $800{ }^{\circ} \mathrm{C}\left(2 \mathrm{~h}, \mathrm{~N}_{2}\right.$ flow $), \mathrm{NC}-800$ was obtained. Because bimetallic system-driven redox reaction was more effective than monometallic Co-MOF-74 derived C-800, improved specific capacitances were observed in the NC-800 with $6 \mathrm{M} \mathrm{KOH}$ electrolytic 3E cell. The NC-800 exhibited fairly high capacitances of $1069 \mathrm{~F} \mathrm{~g}^{-1}$ at $0.5 \mathrm{~A} \mathrm{~g}^{-1}$ and $566 \mathrm{~F} \mathrm{~g}^{-1}$ at $5 \mathrm{~A} \mathrm{~g}^{-1}$. These good results of the NPC-800 could be explained by electric conductivity from bimetallic system and graphitic carbon, electrolytic diffusion from mesoporosity, and large electrochemically active surface area. The similar single-step carbonization $\left(600{ }^{\circ} \mathrm{C}, 3 \mathrm{~h}, \mathrm{~N}_{2}\right.$ flow) was applied to the pseudo-bimetallic MOF (nickelocene filled ZIF-67) [110]. The nickelocene@ZIF-67-derived carbon contained dispersed small Ni-Co core particles. In addition, it showed the $S_{\mathrm{BET}}$ of $237.6 \mathrm{~m}^{2} \mathrm{~g}^{-1}$ with well-defined mesoporosity ( $D_{\text {pore }}=4.2 \mathrm{~nm}$ ). As a working electrode material of supercapacitor operating in $6 \mathrm{M} \mathrm{KOH}$ electrolytic $3 \mathrm{E}$ mode, the resultant carbon showed a capacitance of $236 \mathrm{~F} \mathrm{~g}^{-1}$ at $1 \mathrm{~A} \mathrm{~g} \mathrm{~g}^{-1}$. Synergistic heterostructure of $\mathrm{Co}\left(\mathrm{Co}+2 \mathrm{OH}^{-} \leftrightarrow\right.$ $\left.\mathrm{Co}(\mathrm{OH})_{2}+2 \mathrm{e}^{-}\right)$and $\mathrm{Ni}\left(\mathrm{Ni}+2 \mathrm{OH}^{-} \leftrightarrow \mathrm{Ni}(\mathrm{OH})_{2}+2 \mathrm{e}^{-}\right)$with highly mesoporous architecture could result in good electrochemical performance. 


\subsection{Asymmetic Supercapacitor (ASC)}

The Co-MOF, ZIF-67, was used for the efficient fabrication of ASCs [111]. The positive electrode of uniform 3D nanoporous $\mathrm{Co}_{3} \mathrm{O}_{4}$ was synthesized from two-step thermolysis $\left(500{ }^{\circ} \mathrm{C}, 30 \mathrm{~min}, \mathrm{~N}_{2}\right.$ and $350{ }^{\circ} \mathrm{C}, 2 \mathrm{~h}$, air). The negative electrode of 3D Co-doped NPC $\left(\mathrm{S}_{\mathrm{BET}}=350 \mathrm{~m}^{2} \mathrm{~g}^{-1}\right)$ was prepared by carbonization at $800{ }^{\circ} \mathrm{C}\left(5 \mathrm{~h}, \mathrm{~N}_{2}\right.$ flow $)$ followed by $\mathrm{HF}$ treatment. As a working electrode of $3 \mathrm{E}$ cell in $6 \mathrm{M} \mathrm{KOH}$ electrolyte, the capacitances of NPC were moderately good levels of $272 \mathrm{~F} \mathrm{~g}^{-1}$ at $5 \mathrm{mV} \mathrm{s}^{-1}$ and $163 \mathrm{~F} \mathrm{~g}^{-1}$ at $200 \mathrm{mV} \mathrm{s}^{-1}$. In the same electrolyte, the ASC of $\mathrm{Co}_{3} \mathrm{O}_{4} / / \mathrm{NPC}$ yielded capacitances of $101 \mathrm{~F} \mathrm{~g}^{-1}$ at $2 \mathrm{~A} \mathrm{~g}^{-1}$ and $43 \mathrm{~F} \mathrm{~g}^{-1}$ at $10 \mathrm{~A} \mathrm{~g}^{-1}$. Interestingly, the $\mathrm{Co}_{3} \mathrm{O}_{4} / / \mathrm{NPC}$ cell showed a much higher value of maximum specific energy of $36 \mathrm{~W} \mathrm{~h} \mathrm{~kg}^{-1}$ at $2 \mathrm{~A} \mathrm{~g}^{-1}$ compared to the NPC//NPC $\left(7.1 \mathrm{~W} \mathrm{~h} \mathrm{~kg}^{-1}\right)$ and $\mathrm{Co}_{3} \mathrm{O}_{4} / / \mathrm{Co}_{3} \mathrm{O}_{4}\left(7.9 \mathrm{~W} \mathrm{~h} \mathrm{~kg}^{-1}\right)$ cells.

The Ni-MOF, $\left[\mathrm{Ni}(\mathrm{bdc})(\mathrm{ted})_{0.5} \cdot 2 \mathrm{H}_{2} \mathrm{O}\right]$ (ted $=$ triethyldiamine), was employed as a precursor for the cathode carbon material (Ni/N-doped PC-500) of ASC [112]. After a single-step carbonization at $500{ }^{\circ} \mathrm{C}$ of the precursor $\left(2 \mathrm{~h}, \mathrm{~N}_{2}\right.$ flow), the Ni/N-doped PC-500 $\left(\mathrm{S}_{\mathrm{BET}}=112 \mathrm{~m}^{2} \mathrm{~g}^{-1}\right.$, $D_{\text {pore }}=2.7 \mathrm{~nm}$ ) with graphitic carbon walls was successfully synthesized. In the basic electrolyte of $6 \mathrm{M} \mathrm{KOH}, \mathrm{Ni}$ NPs on its surface could be effectively transformed into $\mathrm{NiO}$ or $\mathrm{Ni}(\mathrm{OH})_{2}$, and these two $\mathrm{Ni}$ species showed pseudocapacitive faradaic reactions $\left(\mathrm{NiO}+\mathrm{OH}^{-} \leftrightarrow \mathrm{NiOOH}+\mathrm{e}^{-}, \mathrm{Ni}(\mathrm{OH})_{2}+\mathrm{OH}^{-} \leftrightarrow \mathrm{NiOOH}+\mathrm{H}_{2} \mathrm{O}+\mathrm{e}^{-}\right)$. Therefore, it showed very large capacitances of $2002.6 \mathrm{~F} \mathrm{~g}^{-1}$ at $1 \mathrm{~A} \mathrm{~g}^{-1}$ and $534.8 \mathrm{~F} \mathrm{~g}^{-1}$ at $20 \mathrm{~A} \mathrm{~g}^{-1}$ in $3 \mathrm{E}$ cell. Combined with AC negative electrode, the Ni/N-doped PC-500 cathode was use for the assembly of ASC (mass ratio of $\mathrm{Ni} / \mathrm{N}$-doped PC-500 to AC $\approx 0.3: 1$ ). The ASC delivered a capacitance of $115.7 \mathrm{~F} \mathrm{~g}^{-1}$ and an energy density of $41.14 \mathrm{~W} \mathrm{~h} \mathrm{~kg}^{-1}$ at $1 \mathrm{~A} \mathrm{~g}^{-1}$ with a power density of $800 \mathrm{~W} \mathrm{~kg}^{-1}$.

\section{Carbon-Based Composites}

\subsection{Carbon/Carbon Composites}

\subsubsection{Zn-MOF-Derived Composites}

MOF-5-Derived Composites

The $\mathrm{rGO} / \mathrm{CMOF}-5$ ( $\mathrm{rGO}=$ reduced graphene oxide) composite was easily synthesized from the carbonization of GO/MOF-5 composite at $1000{ }^{\circ} \mathrm{C}(3 \mathrm{~h}$, Ar flow) [113]. The mesoporous ( 3.6 nm) rGO/CMOF-5 showed high $\mathrm{S}_{\mathrm{BET}}$. In the composite, uniformly intercalated rGO layers effectively operated as small current collectors for electronic transfer and conduction. In addition, the nanoporous CMOF- 5 efficiently inhibited the self-restacking of the composite via incorporation of rGO. Therefore, $\mathrm{rGO} / \mathrm{CMOF}-5$-based working electrode exhibited a good performance in $6 \mathrm{M} \mathrm{KOH}$ electrolyte. In the 3 E cell, it showed high capacitances of $265 \mathrm{~F} \mathrm{~g}^{-1}$ at $40 \mathrm{mV} \mathrm{s}^{-1}$ and $312 \mathrm{~F} \mathrm{~g}^{-1}$ at $0.5 \mathrm{~A} \mathrm{~g}^{-1}$. MOF-5/GO composite (GMOF)-derived C-GMOF was prepared by two-step pyrolysis $\left(270{ }^{\circ} \mathrm{C}, 30 \mathrm{~min}\right.$ in air and $800{ }^{\circ} \mathrm{C}, 2 \mathrm{~h}, \mathrm{~N}_{2}$ flow) and following $2 \mathrm{M} \mathrm{HCl}$ treatment [114]. The obtained C-GMOF had "brick-and-mortar" lamellar structure with high $S_{\text {BET }}$ as well as a large $V_{\text {total }}\left(1.43 \mathrm{~cm}^{3} \mathrm{~g}^{-1}\right)$. The basic role of brick (2D graphene sheets) was a conductive and structural substrate, and that of mortar (carbon film with interconnected mesoporosity) was a kind of divider of bricks for charge storage sites and ion transfer channels. In the $3 \mathrm{E}$ mode with $6 \mathrm{M} \mathrm{KOH}$ electrolyte, it yielded $345 \mathrm{~F} \mathrm{~g}^{-1}$ at $2 \mathrm{mV} \mathrm{s}^{-1}$ and $201 \mathrm{~F} \mathrm{~g}^{-1}\left(402 \mathrm{mF} \mathrm{cm}{ }^{-2}\right)$ even at the fast scan rate of $2 \mathrm{~V} \mathrm{~s}^{-1}$. In the $2 \mathrm{E}$ mode with $1 \mathrm{M} \mathrm{Na}_{2} \mathrm{SO}_{4}$ electrolyte, C-GMOF//C-GMOF cell delivered a maximum energy density of $30.3 \mathrm{~W} \mathrm{~h} \mathrm{~kg}^{-1}$ at a power density of $137 \mathrm{~W} \mathrm{~kg}^{-1}$.

\section{ZIF-8-Derived Composites}

Composites containing reduced graphene oxide (rGO). ZIF-8-derived carbon/graphene composite was first reported for supercapacitor electrode application [115]. ZIF-8/3D-graphene (G-ZIF8) composite was synthesized via a counter diffusion synthetic strategy. After carbonization of the G-ZIF-8 at 
$800{ }^{\circ} \mathrm{C}$ ( $4 \mathrm{~h}, \mathrm{Ar}$ flow), $\mathrm{HCl}$ washing was conducted to afford a product named C-GZ. As a result of effective union of porous ZIF-8 to the 3D-graphene (hydrothermally reduced GO), the C-GZ had enhanced $S_{\text {BET }}\left(280.4 \mathrm{~m}^{2} \mathrm{~g}^{-1}\right)$ compared to the bare 3D-graphene $\left(186 \mathrm{~m}^{2} \mathrm{~g}^{-1}\right)$. In addition, in comparison with microporous C-ZIF-8, the C-GZ exhibited micro-/meso-/macroporous hierarchical porosity. This multilength scale porosity was a very favorable factor for good capacitive performance. Therefore, binder-free and conducting agent-free working electrode from the C-GZ for SSC yielded good results in $1 \mathrm{M} \mathrm{H}_{2} \mathrm{SO}_{4}$ electrolyte. The C-GZ electrode showed a high capacitance at $0.1 \mathrm{~A} \mathrm{~g}^{-1}$ as well as high rate capability up to $50 \mathrm{~A} \mathrm{~g}^{-1}$ (86\% retention). In addition, at $5 \mathrm{~A} \mathrm{~g}^{-1}$, it showed good cycling stability after 5000 cycle ( $84 \%$ capacitance retention, $90.3 \%$ coulombic efficiency). Moreover, C-GZ-2 derived from G-ZIF-2 (two-cycled growth of the ZIF-8 on the graphene) showed improved results because of the increase of both $\mathrm{S}_{\mathrm{BET}}\left(352.8 \mathrm{~m}^{2} \mathrm{~g}^{-1}\right)$ and $\mathrm{D}_{\text {pore }}$ (from 1.6 to $4 \mathrm{~nm}$ ). Its capacitance obtained at $1 \mathrm{~A} \mathrm{~g}^{-1}$ was $238 \mathrm{~F} \mathrm{~g}^{-1}$ and capacitance improvements could be seen up to $50 \mathrm{~A} \mathrm{~g}^{-1}$. The electrochemical capacitive properties of carbon/carbon composites are summarized in Table 7 .

Table 7. The electrochemical capacitive properties of Zn-MOF-derived carbon/carbon composites.

\begin{tabular}{|c|c|c|c|c|c|c|}
\hline Samples & $S_{\mathrm{BET}}\left(\mathrm{m}^{2} \mathrm{~g}^{-1}\right)$ & $C_{\max }\left(\mathrm{F} \mathrm{g}^{-1}\right)$ & $E_{\max }\left(\mathrm{Wh} \mathrm{kg} \mathrm{kg}^{-1}\right)$ & $P_{\max }\left(\mathrm{W} \mathrm{kg}^{-1}\right)$ & System & Ref \\
\hline rGO/CMOF-5 & 2040 & 312 & 17.2 & 5200 & $3 \mathrm{E} / 2 \mathrm{E}$ & 113 \\
\hline C-GMOF & 979 & 345 & 30.3 & 11,900 & $3 \mathrm{E} / 2 \mathrm{E}$ & 114 \\
\hline C-GZ-2 & 353 & 238 & - & - & $2 \mathrm{E}$ & 115 \\
\hline $\mathrm{NPC} / \mathrm{G}$ & 703 & 235 & - & - & $3 \mathrm{E}$ & 116 \\
\hline GNPC & - & 144 & - & - & $3 \mathrm{E}$ & 117 \\
\hline HPNCs/rGO-800 & 710 & 298 & 18.0 & 12,000 & $3 \mathrm{E} / 2 \mathrm{E}$ & 118 \\
\hline ZIF-8/GO (1|700) & 1201 & 181 & - & - & $3 \mathrm{E}$ & 119 \\
\hline ZIF-8/GO (1|800) & 1304 & 246 & - & - & $3 \mathrm{E}$ & 119 \\
\hline ZIF-8/GO (1|900) & 1303 & 81 & - & - & $3 \mathrm{E}$ & 119 \\
\hline NCGs-600 & 204 & 143 & - & - & $3 \mathrm{E}$ & 120 \\
\hline NCGs-700 & 773 & 174 & - & - & $3 \mathrm{E}$ & 120 \\
\hline NCGs-800 & 816 & 225 & 12.7 & 15,126 & $3 \mathrm{E} / 2 \mathrm{E}$ & 120 \\
\hline ZC@G-40 & 1091 & 77 & - & - & $2 \mathrm{E}$ & 121 \\
\hline HC-40-4 & 2837 & 206 & 87.5 & 43,750 & $2 \mathrm{E}$ & 121 \\
\hline $\mathrm{NC} / \mathrm{rGO}-1$ & 400 & 188 & - & - & $2 \mathrm{E}$ & 122 \\
\hline $\mathrm{NC} / \mathrm{rGO}-2$ & 489 & 280 & 19.45 & $\sim 10,000$ & $2 \mathrm{E}$ & 122 \\
\hline $\mathrm{NC} / \mathrm{rGO}-3$ & 290 & 184 & - & - & $2 \mathrm{E}$ & 122 \\
\hline C(ZIF8)@GQDs & 668 & 159.6 & - & - & $3 \mathrm{E}$ & 123 \\
\hline hCNT/PCP & 898 & $\sim 130$ & - & - & $2 \mathrm{E}$ & 124 \\
\hline C-ZIF-8@MWCNT & 569 & 326 & - & - & $3 \mathrm{E}$ & 125 \\
\hline CNTs/NCP & 898 & 308 & 12.0 & $\sim 7000$ & $3 \mathrm{E} / 2 \mathrm{E}$ & 126 \\
\hline MWCNT/NPC-S & 643 & 198.6 & - & - & $3 \mathrm{E}$ & 127 \\
\hline MWCNT/NPC-M & 885 & 229 & - & - & $3 \mathrm{E}$ & 127 \\
\hline MWCNT/NPC-L & 928 & 302.2 & 12.65 & 2257.2 & $3 \mathrm{E} / 2 \mathrm{E}$ & 127 \\
\hline CNCF-5/1 & 468 & 243 & - & - & $3 \mathrm{E}$ & 128 \\
\hline CNCF-10/1 & 645 & 340 & 26.6 & 5000 & $3 \mathrm{E} / 2 \mathrm{E}$ & 128 \\
\hline CNCF-15/1 & 600 & 270 & - & - & $3 \mathrm{E}$ & 128 \\
\hline CNT@CZIF-1 & 264 & 168 & - & - & $3 \mathrm{E}$ & 129 \\
\hline CNT@CZIF-2 & 287 & 324 & - & - & $3 \mathrm{E}$ & 129 \\
\hline CTAs@NCBs-700(T) & - & 244 & - & - & $3 \mathrm{E}$ & 130 \\
\hline ZM-C-800 & 558 & 376.2 & 16.4 & 4985 & $3 \mathrm{E} / 2 \mathrm{E}$ & 131 \\
\hline $\mathrm{g}-\mathrm{CN} / \mathrm{NCPPs} 0.1$ & 454 & 495 & 11.89 & - & $3 \mathrm{E} / 2 \mathrm{E}$ & 132 \\
\hline GCNP-800 & 920 & 426 & 59.40 & 4560 & $3 \mathrm{E} / 2 \mathrm{E}$ & 133 \\
\hline PC1000@C & 1116 & 225 & - & - & $3 \mathrm{E}$ & 134 \\
\hline NHCSF-1 & 585 & 198.5 & - & - & $3 \mathrm{E}$ & 135 \\
\hline NHCSF-2 & 679 & 208.2 & - & - & $3 \mathrm{E}$ & 135 \\
\hline NHCSF-3 & 816 & 253.6 & 13.33 & $\sim 8000$ & $3 \mathrm{E} / 2 \mathrm{E}$ & 135 \\
\hline NHCSF-4 & 667 & 219.5 & - & - & $3 \mathrm{E}$ & 135 \\
\hline N-GQD@cZIF-8/CNT & 520 & 541 & 18.75 & 2175 & $3 \mathrm{E} / 2 \mathrm{E}$ & 136 \\
\hline PMC & - & 180.4 & - & - & $3 \mathrm{E}$ & 177 \\
\hline AQ-NPCs & 268 & 373 & - & - & $3 \mathrm{E}$ & 180 \\
\hline TN-NPCs & 356 & 392 & - & - & $3 \mathrm{E}$ & 180 \\
\hline $\begin{array}{c}\mathrm{N} \text {-doped } \\
\text { carbon/CNTs }\end{array}$ & 600 & 250 & - & - & $3 \mathrm{E}$ & 201 \\
\hline
\end{tabular}


The N-doped nanoporous carbon/graphene (NPC/G) network hybrids derived from ZIF-8/graphene (ZIF-8/G) composite were prepared for supercapacitor electrode materials [116]. A homogeneous encapsulation of the ZIF-8 to GO nanosheets started from the electrostatic interaction-driven adsorption of $\mathrm{Zn}^{2+}$ ions onto O-functionalized GO surfaces. After the homogeneous nucleation of ZIF-8, the ZIF-8 formed passive layers to inhibit aggregation of rGO during carbonization process at $800{ }^{\circ} \mathrm{C}$ ( $5 \mathrm{~h}, \mathrm{~N}_{2}$ flow). In this way, the carbonized product resulted from freeze-dried composite was transformed into the NPC/G. The acid-treated NPC/G $\left(S_{\text {BET }}=703 \mathrm{~m}^{2} \mathrm{~g}^{-1}\right)$ contained hierarchical micro-/meso-/macroporosity. Thus, large contact area between electrode and electrolyte along with improved ionic diffusion could be seen in the NPC/G. Moreover, high content of N-dopant (11.17 wt.\%) induced simultaneous enhancements of electronic conductivity and pseudocapacitance. Therefore, these factors could account for good electrochemical performance of the NPC/G in a 3E system with $1 \mathrm{M} \mathrm{KOH}$ electrolyte. It showed high capacitances with acceptable rate capabilities $\left(136 \mathrm{~F} \mathrm{~g}^{-1}\right.$ at $100 \mathrm{mV} \mathrm{s}^{-1}$ and $119 \mathrm{~F} \mathrm{~g}^{-1}$ at $5 \mathrm{~A} \mathrm{~g}^{-1}$ ).

The carbonization of in situ synthesized GO@ZIF-8 carbon precursor and subsequent $\mathrm{HCl}$ $(5 \mathrm{wt} . \%)$ treatment were conducted to prepare graphene-based N-doped porous carbons (GNPC) [117]. The obtained GNPC, which had a long-range 2D ordering of graphitic carbon structure, contained layered morphology, high $\mathrm{N}$-dopant content $(10.61 \%)$, and well-defined porosity. In the $3 \mathrm{E}$ configuration coupled with $6 \mathrm{M} \mathrm{KOH}$ electrolyte, the GNPC-based electrode showed a capacitance of $144 \mathrm{~F} \mathrm{~g}^{-1}$ at $0.1 \mathrm{~A} \mathrm{~g}^{-1}$. This result was attributed to synergistic effects of graphene structure and $\mathrm{N}$-dopant. The PVP-aided ultra-sonification method was introduced as an exfoliation method of GO. The uniform growth of ZIF-8 on the exfoliated GO surface was achieved for the preparation of ZIF-8/GO precursor [118]. In the precursor, the layered GO structure prevented the aggregation of ZIF-8 crystals. The ZIF-8/GO was converted into HPNCs/rGO-800 by a single-step carbonization at $800{ }^{\circ} \mathrm{C}$ under $\mathrm{N}_{2}$ flow. Although it had lower $\mathrm{S}_{\mathrm{BET}}$ than HPNCs derived from bare ZIF-8 $\left(820 \mathrm{~m}^{2} \mathrm{~g}^{-1}\right)$, its higher graphitization degree $\left(I_{\mathrm{G}} / I_{\mathrm{D}}=1.2\right.$ vs. 10.1), larger $N$-dopant content $(13.53$ at $\%$ vs. $10.18 \mathrm{at} \%)$, and mesoporosity led to better capacitive results than those of HPNCs.

A novel mesopore-templating approach of "Nanopore Lithography" (Figure 8) was introduced for the fabrication of carbon composite with hierarchical porosity [119]. In this approach, GO nanosheets were used as both mesopore template and lithography mask. The uniform-sized ZIF-8 obtained by using $25 \mathrm{mg} \mathrm{mL}^{-1}$ of Hmim concentration was effectively wrapped by the GO nanosheets with the help of PVP-induced interaction. After carbonization of ZIF-8/GO at $700{ }^{\circ} \mathrm{C}\left(30 \mathrm{~min}, \mathrm{~N}_{2}\right.$ flow), the carbonized ZIF-8/GO along with generation of incipient porosity was obtained. This incipient porosity in the carbonized ZIF-8/GO was employed as selective activation site for the mesopore formation during $\mathrm{KOH}$ activation process (weight ratio of $\mathrm{KOH} / \mathrm{C}=1 ; 800{ }^{\circ} \mathrm{C}, 1 \mathrm{~h}, \mathrm{~N}_{2}$ flow). The resultant carbon composite activated at $800^{\circ} \mathrm{C}, \mathrm{ZIF}-8 / \mathrm{GO}(1 \mid 800)$, had 2D-layered network morphology with well-defined mesoporosity ( $\sim 4-4 \mathrm{~nm}$ diameters). Moreover, it also showed high $\mathrm{S}_{\mathrm{BET}}$ and $\mathrm{V}_{\text {total }}\left(1.219 \mathrm{cc} \mathrm{g}^{-1}\right)$. Therefore, it gave a high capacitance of $246 \mathrm{~F} \mathrm{~g}^{-1}$ at $2 \mathrm{mV} \mathrm{s}^{-1}$ for the $3 \mathrm{E}$ cell with $1 \mathrm{M} \mathrm{H}_{2} \mathrm{SO}_{4}$ electrolyte.

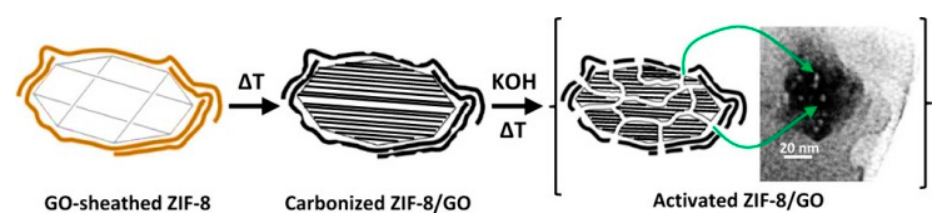

Figure 8. Mesopore generation process to the activated ZIF-8/GO composite via "Nanopore Lithography" approach [119].

The composites of N-doped carbon decorated graphene sheets (NCGs) were synthesized from in situ crystal growth of ZIF-8 on GO sheets and the subsequent carbonization of ZIF-8/GO and $3 \mathrm{M} \mathrm{HCl}$ treatment [120]. With no aggregations of the graphene sheets or the ZIF-8 derived carbon, the unique sandwich-like structure of the NCGs induced highly accessible surface area for ionic diffusion and electron transport. The optimized sample of NCGs-800 $\left(800{ }^{\circ} \mathrm{C}, \mathrm{N}_{2}\right.$ flow) contained 
high $\mathrm{S}_{\mathrm{BET}}\left(816.4 \mathrm{~m}^{2} \mathrm{~g}^{-1}\right)$ and with an appropriate N-doping $(18.6 \%)$. As a result, NCGs-800 electrode in a $3 \mathrm{E}$ cell in $6 \mathrm{M} \mathrm{KOH}$ electrolyte had capacitances of $225 \mathrm{~F} \mathrm{~g}^{-1}$ at $0.5 \mathrm{~A} \mathrm{~g}^{-1}$ and $181 \mathrm{~F} \mathrm{~g}^{-1}$ at $20 \mathrm{~A} \mathrm{~g}^{-1}$. NCGs-800//NCGs-800 cell operating in $1 \mathrm{M} \mathrm{Na}_{2} \mathrm{SO}_{4}$ electrolyte also showed good cycling stability. This symmetric cell had maximum values of capacitance $\left(28.5 \mathrm{~F} \mathrm{~g}^{-1}\right)$ and energy density $\left(12.7 \mathrm{~W} \mathrm{~h} \mathrm{~kg}^{-1}\right)$ at $0.5 \mathrm{~A} \mathrm{~g}^{-1}$ with a power density of $447 \mathrm{~W} \mathrm{~kg}^{-1}$. An easy and green synthetic process of hierarchically carbon composite (HC) derived from ZIF-8@GO hybrid was first applied to flexible solid-phase supercapacitor [121]. The precursor of ZIF-8@GO was constructed via in situ growth of nanoscale ZIF-8 on the surface of GO layer in aqueous environment. ZC@G-x ( $x=$ the weight of GO) was obtained by carbonization of the precursor at $800{ }^{\circ} \mathrm{C}(5 \mathrm{~h}, \mathrm{Ar})$ followed by $2 \mathrm{M} \mathrm{HCl}$ washing, then ZC@G-x was transformed into HC-x-y (y = mass ratio of KOH/ZC@G-x) through KOH activation at $700{ }^{\circ} \mathrm{C}(2 \mathrm{~h}, \mathrm{Ar}$ flow) and subsequent $2 \mathrm{M} \mathrm{HCl}$ treatment. The HC-x-y had hierarchical structure with strong binding between ZIF-8 derived micro-/mesoporous carbons and highly conductive graphene networks. Moreover, HC-40-4 showed ultra-high $S_{B E T}$ with large $V_{\text {pore }}\left(2.12 \mathrm{~cm}^{3} \mathrm{~g}^{-1}\right)$ and well-defined mesoporosity $\left(D_{\text {pore }}=3.03 \mathrm{~nm}\right.$ ) compared to the control sample of microporous ZC@G-40. It also presented appropriate heteroatom doping $(\mathrm{O}=9.68 \mathrm{at} \%, \mathrm{~N}=2.41 \mathrm{at} \%)$, which enhanced electrical conductivity $\left(6678 \mathrm{~S} \mathrm{~m}^{-1}\right)$, pseudocapacitance, and surface wettability. By using the ionic liquid electrolyte of [EMIM][BF 4 , symmetric HC-40-4//HC-40-4 cell exhibited capacitances of $206 \mathrm{~F} \mathrm{~g}^{-1}$ at $0.5 \mathrm{~A} \mathrm{~g}^{-1}$ and $122 \mathrm{~F} \mathrm{~g}^{-1}$ at $50 \mathrm{~A} \mathrm{~g}^{-1}$. It also delivered high energy density $\left(87.5 \mathrm{~W} \mathrm{~h} \mathrm{~kg}^{-1}\right.$ at $\left.438 \mathrm{~W} \mathrm{~kg}^{-1}\right)$ and high power density $\left(43750 \mathrm{~W} \mathrm{~kg}^{-1}\right.$ at $\left.52 \mathrm{~W} \mathrm{~h} \mathrm{~kg}^{-1}\right)$. When the polymer gel electrolyte of [EMIM] $\left[\mathrm{BF}_{4}\right] /$ PVDF-HFP was used for the symmetric cell, the flexible solid-phase supercapacitor showed capacitances of $201 \mathrm{~F} \mathrm{~g}^{-1}$ at $0.5 \mathrm{~A} \mathrm{~g}^{-1}$ and $117 \mathrm{~F} \mathrm{~g}^{-1}$ at $50 \mathrm{~A} \mathrm{~g}^{-1}$, ultra-high energy density ( $86 \mathrm{~W} \mathrm{~h} \mathrm{~kg}^{-1}$ at $438 \mathrm{~W} \mathrm{~kg}^{-1}$ ) and power density (17500 $\mathrm{W} \mathrm{kg}^{-1}$ at $61 \mathrm{~W} \mathrm{~h} \mathrm{~kg}^{-1}$ ).

Binder-free electrode of NC/rGO nanopaper was synthesized from NC/GO and applied to flexible SSC. The N-doped porous carbon polyhedrons (NC) were prepared by carbonization at $900{ }^{\circ} \mathrm{C}(2 \mathrm{~h}, \mathrm{Ar}$ flow $)$ and $2 \mathrm{M} \mathrm{HNO}_{3}$ treatment [122]. After that, the NC/GO nanopaper was produced by sonification in DMF and subsequent vacuum filtration on a nylon filter. By thermal reducing process at $500{ }^{\circ} \mathrm{C}$ under $\mathrm{Ar}$, the $\mathrm{NC} / \mathrm{GO}$ was transformed into the $\mathrm{NC} / \mathrm{rGO}$ with a special inter-layered structure and strong interfacial interactions. The best sample of NC/rGO-2 (from $10 \mathrm{mg}$ $\mathrm{NC}$ ) had high $\mathrm{S}_{\mathrm{BET}}$, large $\mathrm{V}_{\text {total }}\left(0.73 \mathrm{~m}^{2} \mathrm{~g}^{-1}\right)$, and hierarchical porosity (micro-/mesopores) and proper heteroatom contents $(\mathrm{N}=2.35$ at $\%, \mathrm{O}=14.73$ at $\%$ ). Therefore, the binder-free electrode showed good electrochemical activities in a 2E cell with $6 \mathrm{M} \mathrm{KOH}$ electrolyte. A new precursor of ZIF-8@GQDs (GQDs = graphene quantum dots) was first introduced to the synthesis of C(ZIF-8)@GQDs by Yuan et al. [123]. The precursor was facilely prepared from in situ self-assembly between $\mathrm{Zn}^{2+}$ ions and imidazole-modified GQDs. After carbonization of the precursor at $1000^{\circ} \mathrm{C}\left(3 \mathrm{~h}, \mathrm{~N}_{2}\right.$ flow $)$ and acid treatment $(1 \mathrm{M} \mathrm{HCl})$, the $\mathrm{C}(\mathrm{ZIF}-8) @ \mathrm{GQDs}\left(\mathrm{V}_{\text {pore }}=0.807 \mathrm{~cm}^{3} \mathrm{~g}^{-1}\right)$ was produced, which had narrow distribution of mesopore $(\sim 2.3 \mathrm{~nm})$ and higher $\mathrm{C}$ - and $\mathrm{N}$-dopant contents $(\mathrm{C}=84.58 \%, \mathrm{~N}=5.67 \%)$ than bare C(ZIF-8). As a result, the 3E cell with $6 \mathrm{M} \mathrm{KOH}$ electrolyte, C(ZIF-8)@GQDs-based working electrode showed high capacitance $\left(159.6 \mathrm{~F} \mathrm{~g}^{-1}\right.$ at $\left.0.25 \mathrm{~A} \mathrm{~g}^{-1}\right)$, and good rate capacity $\left(115 \mathrm{~F} \mathrm{~g}^{-1}\right.$ at $\left.10 \mathrm{~A} \mathrm{~g}^{-1}\right)$.

Composites containing CNT. CNTs/ZIF-8 precursor was first employed for the preparation of hierarchical porous $\mathrm{CNT}$ /porous carbon polyhedrons (hCNT/PCP) composite [124]. The precursor was prepared from electrostatic bonding between $\mathrm{Zn}^{2+}$ ions and - $\mathrm{COOH}$ functionalized CNT followed by in situ homogeneous loading of ZIF-8 crystals. After carbonization of the CNTs/ZIF-8, the resultant hCNT/PCP showed large $S_{\mathrm{BET}}, \mathrm{V}_{\text {pore }}\left(1.13 \mathrm{~cm}^{3} \mathrm{~g}^{-1}\right)$, proper $\mathrm{N}$ content $(9.43 \mathrm{wt} . \%)$, and enhanced electrical conductivity due to high graphitization degree of carbon $\left(I_{\mathrm{G}} / I_{\mathrm{D}}=1.10\right)$ compared to bare PCP $\left(I_{\mathrm{G}} / I_{\mathrm{D}}=0.97\right)$. Moreover, the hCNT/PCP formed a conductive network composed of CNT-embedded-PCP with hierarchical porosity. As a result, the hCNT/PCP-based SSC operating in $1 \mathrm{M}$ $\mathrm{NaCl}$ electrolyte showed a capacitance of $104.2 \mathrm{~F} \mathrm{~g}^{-1}$ at $5 \mathrm{mV} \mathrm{s}^{-1}$. A new hybrid of C-ZIF-8@MWCNT was synthesized from ZIF-8@MWCNT with necklace-like structure [125]. MWCNTs was modified their surface by PVP. Then, the oriented growth of ZIF-8 on the modified surface of MWCNTs occurred. 
The necklace-like ZIF-8@MWCNT was carbonized at $800{ }^{\circ} \mathrm{C}\left(3 \mathrm{~h}, \mathrm{~N}_{2}\right.$ flow) and treated with $3 \mathrm{M} \mathrm{HCl}$ to produce the C-ZIF-8@MWCNT. The C-ZIF-8@MWCNT $\left(\mathrm{V}_{\text {pore }}=0.9867 \mathrm{~cm}^{3} \mathrm{~g}^{-1}\right)$ showed synergistic effects of high conductivity (from MWCNT and partially graphitized C-ZIF-8) and hierarchical porosity (micropores from ZIF-8 and mesopores from MWCNT). Therefore, it exhibited high capacitances and good rate performance $\left(225.5 \mathrm{~F} \mathrm{~g}^{-1}\right.$ at $100 \mathrm{mV} \mathrm{s}^{-1}$ and $298 \mathrm{~F} \mathrm{~g}^{-1}$ at $\left.10 \mathrm{~A} \mathrm{~g}^{-1}\right)$. Pan et al. reported $\mathrm{CNTs} / \mathrm{NCP}(\mathrm{NCP}=\mathrm{N}$-doped carbon polyhedrons). CNTs/ZIF-8 precursor was synthesized via electrostatic adsorption of $\mathrm{Zn}^{2+}$ ions onto acid-treated CNTs and following coordinative in situ crystal growth of ZIF-8 [126]. The CNTs/NCP with intertwined architecture was prepared by carbonization of the precursor at $1000{ }^{\circ} \mathrm{C}\left(4 \mathrm{~h}, \mathrm{~N}_{2}\right.$ flow $)$. The obtained CNTs $/ \mathrm{NCP}\left(\mathrm{V}_{\text {pore }}=1.31 \mathrm{~cm}^{3} \mathrm{~g}^{-1}\right)$ with high $\mathrm{N}$-dopant content (9.43 wt.\%) showed hierarchical porosity: microporosity from ZIF-8, mesoporosity from small pore connection and CNT, and macroporosity from interparticle voids. Due to the 3D conducting network as well as hierarchical porosity, it showed good electrochemical results at $1 \mathrm{M}$ $\mathrm{H}_{2} \mathrm{SO}_{4}$ electrolyte. In a $3 \mathrm{E}$ cell, it had a capacitance of $308 \mathrm{~F} \mathrm{~g}^{-1}$ at $5 \mathrm{mV} \mathrm{s}^{-1}$. Moreover, in a $2 \mathrm{E}$ cell, the symmetric cell assembled from the CNTs/NCP yielded high cell capacitance $\left(135.0 \mathrm{~F} \mathrm{~g}^{-1}\right.$ at $\left.5 \mathrm{mV} \mathrm{s}^{-1}\right)$.

The size-controlled ZIF-8 crystals were introduced as MWCNT/ZIF-8 precursor for the preparation of MWCNT/N-doped porous carbons (MWCNT/NPCs) composite [127]. Different sized ZIF-8 crystals were grown on the surface of acid-functionalized MWCNTs. The resultant MWCNT/ZIF-8-S/M/L ( $\mathrm{S}=$ small; $\mathrm{M}=$ middle; $\mathrm{L}=$ large) precursors were directly carbonized at $800{ }^{\circ} \mathrm{C}(5 \mathrm{~h}, \mathrm{Ar}$ flow $)$ and then washed with acid $(35 \% \mathrm{HCl})$ to obtain MWCNT/NPC-S/M/L products containing NCPs (high surface area, N-doping) and MWCNTs (improved conductivity, hierarchical porosity). Among the three products, the MWCNT/NPC-L derived from large-size ZIF-8 had the highest value of $S_{B E T}$ and $\mathrm{V}_{\text {total }}\left(0.64 \mathrm{~cm}^{3} \mathrm{~g}^{-1}\right)$ because of the effective inhibition of NPC particle aggregation. Thus, MWCNT/NPC-L-based working electrode showed superior capacitive results in $1 \mathrm{M} \mathrm{H}_{2} \mathrm{SO}_{4}$ electrolyte. For the 3E cell, it yielded high capacitances $\left(293.4 \mathrm{~F} \mathrm{~g}^{-1}\right.$ at $200 \mathrm{mV} \mathrm{s}^{-1}, 302.2 \mathrm{~F} \mathrm{~g}^{-1}$ at $2 \mathrm{~A} \mathrm{~g}^{-1}$ ) with excellent rate capabilities $\left(219.5 \mathrm{~F} \mathrm{~g}^{-1}\right.$ at $200 \mathrm{mV} \mathrm{s}^{-1}, 247.8 \mathrm{~F} \mathrm{~g}^{-1}$ at $\left.10 \mathrm{Ag}^{-1}\right)$. For the $2 \mathrm{E}$ cell, it delivered a high capacitance $\left(112.4 \mathrm{~F} \mathrm{~g}^{-1}\right)$ and an energy density $\left(12.65 \mathrm{~W} \mathrm{~h} \mathrm{~kg}^{-1}\right)$ with a power density of $225.1 \mathrm{~W} \mathrm{~kg}^{-1}$ at $0.5 \mathrm{~A} \mathrm{~g}^{-1}$.

Peng et al. reported new binder-free electrodes derived from ZIF-8/CNT composite thin film [128]. First, oxidized CNTs with negative charge and zinc hydroxide nanostrands (ZHN) with positive charge were mixed to form a homogeneous suspension. After that, a free-standing thin film of ZHN/CNT was prepared via vacuum filtration of the suspension on polycarbonate (PC) substrate. The ZHN/CNT was reacted with 2-methylimidazole in EtOH/ $\mathrm{H}_{2} \mathrm{O}$ solution to obtain ZIF-8/CNT. The ZIF-8/CNT-N ( $\mathrm{N}$ = weight ratios of ZIF-8/CNT: 5/1, 10/1, and 15/1) was converted into CNT-threaded N-doped porous carbon film (CNCF-N) through carbonization at $900^{\circ} \mathrm{C}\left(3 \mathrm{~h}, \mathrm{~N}_{2}\right.$ flow) and diluted $\mathrm{HCl}$ treatment. The lightweight and free-standing $\mathrm{CNCF}_{\text {s }}$ had good mechanical flexibility, high $\mathrm{S}_{\mathrm{BET}}$, hierarchical porosity with micropores and mesopores, proper heteroatom doping, and suitable electrical conductivity. Among the three samples, the CNCF-10/1 showed maximum $\mathrm{S}_{\mathrm{BET}}$. Therefore, the CNCF-10/1 electrode operating under $6 \mathrm{M} \mathrm{KOH}$ electrolytic condition with $3 \mathrm{E}$ configuration exhibited a high capacitance of $340 \mathrm{~F} \mathrm{~g}^{-1}$ at $2 \mathrm{~A} \mathrm{~g}^{-1}$ with moderate rate capability of $43 \%$ at $400 \mathrm{~A} \mathrm{~g}^{-1}$. In addition, with $2 \mathrm{E}$ configuration, it delivered high maximum capacitance of $191.2 \mathrm{~F} \mathrm{~g}^{-1}$ and an energy density of $26.6 \mathrm{~W} \mathrm{~h} \mathrm{~kg}^{-1}$ at $1 \mathrm{~A} \mathrm{~g}^{-1}$.

Wang et al. synthesized noble CNT/N-doped porous carbon composites (CNT@CZIFs) from carbonization of CNT/ZIF-8 composite at $800^{\circ} \mathrm{C}(3 \mathrm{~h}$, Ar flow) followed by acid $(2 \mathrm{M} \mathrm{HCl})$ washing [129]. Through the effective introduction of $-\mathrm{OH}$ functionalities by polydopamine (PDA) coating on 2D CNT, the resultant CNT@PDA had many nucleation sites on the surface. Next, heterogeneous growth of ZIF-8 on the CNT@PDA afforded CNT@ZIF-N (ZIF-8 growth time: 3 min for CNT@ZIF-1, 30 min for CNT@ZIF-2). The CNT@PDA electrostatically attracted $\mathrm{Zn}^{2+}$ ions to give CNT@ZIF-N. Both CNT and ZIF-8-derived carbons in CNT@CZIF-N could synergistically affect electrical energy storage. For example, highly conducting networks of the CNT promoted ionic diffusion and reduced interfacial 
resistance for electron transfer. In addition, the N-doped ZIF-8-derived carbons with high surface area provided fast ionic transport route as well as rich active sites for electrochemical accessibility. Moreover, the CNT@CZIF-2 showed high surface area along with large pyridinic N-dopant content (29.56\%) and mesoporosity compared to the CNT@CZIF-1. Therefore, the CNT@CZIF-2-based working electrode showed superior performance under $6 \mathrm{M} \mathrm{KOH}$ electrolytic $3 \mathrm{E}$ cell.

A CC substrate was used for assembling electrode material of flexible SSC using CNT containing carbon composite derived from ZIF-8 [130]. After in situ catalytic carbon layer deposition on ZnO@ZIF-8 nanorod arrays (NRAs) and subsequent reduction-evaporation steps, the ZnO@ZIF-8 NRA templates were converted into N-doped carbon bubbles on hollow carbon tube arrays (CTAs@NCBs) with 3D hierarchical porosity and high flexibility. The ZnO@ZIF-8 NRA on the CC substrate was prepared by 2-MeIM-driven ion-exchange into ZnO NRA on the substrate, where 2-MeIM is 2-methylimidazole. In addition, the deposited carbon layer on the surface of NRA template was generated from in situ thermal decomposition of ethanol vapor ( $2 \mathrm{~h}, \mathrm{~N}_{2}$ flow). Next, the resultant ZnO@C@ZIF-8 was transformed into the CTAs@NCBs via reduction-evaporation stages at $800{ }^{\circ} \mathrm{C}(4 \mathrm{~h}, 10 \mathrm{vol} \%$ $\mathrm{H}_{2}$ /air flow). The obtained CTAs@NCBs had well-interconnected hierarchical micro-/mesoporosity along with large electroactive surface area. The 3-fold increase of 2-MeIM concentration generating ZnO@ZIF-T precursor. The optimized sample, CTAs@NCBs-700, was obtained by catalytic conversion of the ZnO@ZIF-T precursor at $700{ }^{\circ} \mathrm{C}$. CTAs@NCBs-700 yielded good capacitive results. In the 3E configuration with $1 \mathrm{M} \mathrm{H}_{2} \mathrm{SO}_{4}$, it showed high capacitances $\left(244 \mathrm{~F} \mathrm{~g}^{-1}\right.$ at $0.67 \mathrm{~A} \mathrm{~g}^{-1}, 366 \mathrm{mF} \mathrm{cm}^{-2}$ at $1 \mathrm{~mA} \mathrm{~cm}^{-2}$ ) and good rate performance ( $139 \mathrm{~F} \mathrm{~g}^{-1}$ at $134 \mathrm{~A} \mathrm{~g}^{-1}, 208 \mathrm{mF} \mathrm{cm}^{-2}$ at $\left.20 \mathrm{~mA} \mathrm{~cm}^{-2}\right)$. In the $2 \mathrm{E}$ cell with $1 \mathrm{M} \mathrm{H}_{2} \mathrm{SO}_{4}$, it delivered high areal capacitances $\left(580 \mathrm{mF} \mathrm{cm}^{-2}\right.$ at $1 \mathrm{~mA} \mathrm{~cm}^{-2}, 241 \mathrm{mF} \mathrm{cm}^{-2}$ at $\left.200 \mathrm{~mA} \mathrm{~cm}^{-2}\right)$ and volumetric capacitances $\left(7.6 \mathrm{~F} \mathrm{~cm}^{-3}\right.$ at $0.013 \mathrm{~A} \mathrm{~cm}^{-3}, 3.2 \mathrm{~F} \mathrm{~cm}^{-3}$ at $\left.2.6 \mathrm{~A} \mathrm{~cm}^{-3}\right)$.

Composites containing $\mathrm{CN}$. A facile and economical synthesis of ZIF-8/melamine-derived nanocomposite (ZM-C-800) was accomplished via carbonization at $800^{\circ} \mathrm{C}\left(3 \mathrm{~h}, \mathrm{~N}_{2}\right)$ and a subsequent washing $(2 \mathrm{M} \mathrm{HCl}$ ) [131]. The ZIF-8/melamine composite (weight ratio of ZIF-8/melamine = 5) was prepared by a simple sonification. The pre-melted melamine layer was formed at an early stage of the carbonization, and this layer provided stable structural integrity to the composite. The ZM-C-800 contained a 3D broccoli-like carbon nitride architecture, high graphitization degree, ultra-high nitrogen content $(28.3 \mathrm{at} \%)$, and hierarchical porosity (micro- and mesopore). In the $3 \mathrm{E}$ cell with $6 \mathrm{M} \mathrm{KOH}$ electrolyte, it showed high specific capacitances, suitable rate performance $\left(253.6 \mathrm{~F} \mathrm{~g}^{-1}\right.$ at $\left.20 \mathrm{~A} \mathrm{~g}^{-1}\right)$, and good cycling durability. In the same electrolyte at $0.5 \mathrm{~A} \mathrm{~g}^{-1}$, the symmetric ZM-C-800//ZM-C-800 cell delivered high values of capacitance $\left(118.5 \mathrm{~F} \mathrm{~g}^{-1}\right)$ and energy density $\left(16.4 \mathrm{~W} \mathrm{~h} \mathrm{~kg}^{-1}\right)$ along with a power density of $249.1 \mathrm{~W} \mathrm{~kg}^{-1}$. In addition, at $10 \mathrm{~A} \mathrm{~g}^{-1}$, it yielded a power density $\left(4985 \mathrm{~W} \mathrm{~kg}^{-1}\right)$ with good retention $\left(80 \mathrm{~F} \mathrm{~g}^{-1}, 11.4 \mathrm{~W} \mathrm{~h} \mathrm{~kg}^{-1}\right)$. Graphitic carbon nitride/N-doped carbon polyhedral particles (g-CN/NCPPs) hybrid was synthesized via two-step carbonization and acid etching (2 M $\mathrm{HCl}$ ) [132]. The carbonization of ZIF-8 at $800{ }^{\circ} \mathrm{C}$ ( $3 \mathrm{~h}, \mathrm{~N}_{2}$ flow) produced $\mathrm{Zn}-\mathrm{NCPPs}$. Then, the mixture of $\mathrm{Zn}-\mathrm{NCPPs}$, urea, and glucose was calcined in air at $550{ }^{\circ} \mathrm{C}(3 \mathrm{~h})$. The second carbonization of the calcined sample at $800{ }^{\circ} \mathrm{C}\left(1 \mathrm{~h}, \mathrm{~N}_{2}\right)$ generated g-CN/Zn-NCPPs. The acid washing of the $\mathrm{g}-\mathrm{CN} / \mathrm{Zn}-\mathrm{NCPPs}$ gave the final g-CN/NCPPs. The optimized product of g-CN/NCPPs ${ }_{0.1}$ (obtained from $0.1 \mathrm{~g}$ of $\mathrm{Zn}-\mathrm{NCPP}$ ) had high $\mathrm{S}_{\mathrm{BET}}$, well-defined hierarchical porosity (meso- and macropores), and high level of $\mathrm{N}$-doping (20.55\%). Therefore, in the $3 \mathrm{E}$ cell with $1.0 \mathrm{M} \mathrm{H}_{2} \mathrm{SO}_{4}$ electrolyte, it yielded ultra-high capacitance and moderate rate capacity $\left(188.0 \mathrm{~F} \mathrm{~g}^{-1}\right.$ at $\left.20 \mathrm{~A} \mathrm{~g}^{-1}\right)$. In addition, in the $2 \mathrm{E}$ cell with the same electrolyte, its maximum capacitance $\left(349.7 \mathrm{~F} \mathrm{~g}^{-1}\right)$ and energy density $\left(11.89 \mathrm{~W} \mathrm{~h} \mathrm{~kg}^{-1}\right)$ were obtained at $0.5 \mathrm{~A} \mathrm{~g}^{-1}$ with a power density of $247.40 \mathrm{~W} \mathrm{~kg}^{-1}$.

Other ZIF-8-derived composites. The graphitic carbon nitride polyhedron (GCNP) electrode for flexible supercapacitor with high durability and energy density was prepared by the carbonization ( $3 \mathrm{~h}, \mathrm{~N}_{2}$ flow) of CNTs wired ZIF-8 composite (CNTs/ZIF-8) and a subsequent acid washing (2 M $\mathrm{HCl}$ [133]. The CNTs/ZIF-8 composite was fabricated by in situ ZIF-8 growth on acid-treated CNT, and then transformed into the GCNPs with a highly N-doped continuous hierarchical structure. Among the GCNPs, GCNP-800 (carbonized at $800^{\circ} \mathrm{C}$ ) showed the highest value of $\mathrm{S}_{\mathrm{BET}}$ and electrical 
conductivity (278 S m $\mathrm{m}^{-1}$ ) with O-dopant content $(7.03$ at $\%)$, hierarchical porosity $\left(\mathrm{D}_{\text {pore }}=2.5 \mathrm{~nm}\right)$, and large N-dopant content (17.82 at\%). Therefore, the GCNP-800 working electrode operating in a $3 \mathrm{E}$ cell with $1 \mathrm{M} \mathrm{H}_{2} \mathrm{SO}_{4}$ electrolyte yielded ultra-high maximum capacitance $\left(426 \mathrm{~F} \mathrm{~g}^{-1}\right.$ at $1 \mathrm{~A} \mathrm{~g}^{-1}$ ) and moderately good rate performance up to $10 \mathrm{~A} \mathrm{~g}^{-1}$. With the introduction of a new electrolyte of $70 \mathrm{wt}$ \% polyoxyethylene/nitrile butadiene (PEO/NBR) interpenetrating polymer network (IPN) with 1-ethyl-3-methylimidazole tetrafluoroborate $\left(\mathrm{EMIBF}_{4}\right)$, which had higher ionic conductivity and mechanical stability than PVA, the GCNP-800-based solid-phase SSC showed a maximum capacitance of $190 \mathrm{~F} \mathrm{~g}^{-1}$ and a large maximum energy density of $59.40 \mathrm{~W} \mathrm{~h} \mathrm{~kg}^{-1}$ at $1 \mathrm{~A} \mathrm{~g}^{-1}$. It also demonstrated high structural stability and flexibility (at twisted state, stretchable state, and bending state) and long-term cycled foldability.

Zhang et al. reported the conversion of ZIF-8@CTAB hybrid (CTAB = cetyltrimethylammonium bromide) into $\mathrm{N}$-doped porous carbon composite (PC1000@C) through carbonization at $1000{ }^{\circ} \mathrm{C}(4 \mathrm{~h}$, $\mathrm{N}_{2}$ flow) and acid treatment (4 M HCl) [134]. In the ZIF-8@CTAB, the surfactant micelle of CTAB was employed as capping reagents for controlling the growth rate of ZIF-8 crystals. This had a great effect on the structural and capacitive properties of PC1000@C. Compared to PC1000 derived from ZIF-8, the PC1000@C showed high $S_{\mathrm{BET}}$, large $\mathrm{V}_{\text {total }}\left(1.68 \mathrm{~cm}^{3} \mathrm{~g}^{-1}\right)$, and hierarchical micro-/mesoporosity. Therefore, the PC1000@C showed better rate performance (65\%) than the PC1000 (53\%) when the current load extended from 0.5 to $6 \mathrm{~A} \mathrm{~g}^{-1}$ under $3 \mathrm{E}$ mode in $6 \mathrm{M} \mathrm{KOH}$ electrolyte. However, at $0.5 \mathrm{~A} \mathrm{~g}^{-1}$, the PC1000 yielded slightly higher maximum capacitance than PC1000@C (225 F g $\left.{ }^{-1}\right)$. This small improvement was ascribed to the enhanced pseudocapacitive N-dopants level (10.2\%) and graphitization degree $(\mathrm{R}=2.28)$ of PC1000. Qiu et al. synthesized N-rich hollow carbon shell frameworks (NHCSHs) with 3D structure comprised of hollow porous shells and 2D thin porous nanoflakes derived from core/shell $P P-\mathrm{SiO}_{2} / \mathrm{ZIF}-8$ hybrid precursor [135]. The polyelectrolyte-decorated $\mathrm{SiO}_{2}\left(P P-\mathrm{SiO}_{2}\right)$ was synthesized through the treatment of $30 \mathrm{wt} \%$ poly(styrene sulfonic acid sodium salt) (PSS) to $\mathrm{PDDA}-$ decorated $\mathrm{SiO}_{2}\left(P-\mathrm{SiO}_{2}, \mathrm{PDDA}=\right.$ poly(diallyldimethylammonium chloride)). The PDDA-modified $\mathrm{SiO}_{2}$ was designated as $P P-\mathrm{SiO}_{2}-\mathrm{n}(\mathrm{n}=$ amount of added $\mathrm{SiO} 2$ in g). After electrostatic ion adsorption of $\mathrm{Zn}^{2+}$ ions on the negatively charged surface of $P P-\mathrm{SiO}_{2}-3$, coordination bond-driven reaction of 2-MeIM ligand occurred and the $P P-\mathrm{SiO}_{2}-3 / \mathrm{ZIF}-8$ formed where nano-sized ZIF-8 crystals were deposited on the $P P-S_{2} \mathrm{O}_{2}-3$ surface. The optimized sample of NHCSF-3 was prepared through the carbonization of $P P-\mathrm{SiO}_{2}-3 / \mathrm{ZIF}-8$ and subsequent acid etching $(1 \mathrm{M} \mathrm{HCl}$ and $5 \% \mathrm{HF}$ ). No additional activation process was conducted. The NHCSF-3 with hierarchical porosity held high $\mathrm{S}_{\mathrm{BET}}$, large $\mathrm{V}_{\text {total }}\left(1.85 \mathrm{~cm}^{3} \mathrm{~g}^{-1}\right)$, and large heteroatom contents $(\mathrm{N}=20.29$ at $\%, \mathrm{O}=8.27$ at $\%)$. In the 3E setup with $6 \mathrm{M} \mathrm{KOH}$ electrolyte, its specific capacitances decreased from 253.6 to $200.4 \mathrm{~F} \mathrm{~g}^{-1}$ (79.0\% retention) when current densities increased from 1 to $50 \mathrm{~A} \mathrm{~g}^{-1}$. In the same electrolyte with 2E setup, it showed a high specific capacitance $\left(\sim 180 \mathrm{~F} \mathrm{~g}^{-1}\right.$ at $\left.1 \mathrm{~A} \mathrm{~g}^{-1}\right)$ and a good rate performance (76\% retention, $135.4 \mathrm{~F} \mathrm{~g}^{-1}$ at $30 \mathrm{~A} \mathrm{~g}^{-1}$ ) (Figure 9).

A new and complex carbon composite of N-GQD@cZIF-8/CNT with 3D hierarchical structure was synthesized in the same year through carbonization $\left(800^{\circ} \mathrm{C}, 8 \mathrm{~h}, \mathrm{~N}_{2}\right.$ flow) and acid washing $(2 \mathrm{M}$ $\mathrm{HCl})$ steps and a subsequent electrochemical deposition $(2 \mathrm{~V}, 3 \mathrm{~h})$ of $\mathrm{N}$-doped graphene quantum dots (N-GQDs) [136]. ZIF-8 crystals were uniformly grown on -COOH-functionalized CNTs with PVP modulator, and then CNT-crosslinked ZIF-8 (ZIF-8/CNT) formed. After the carbonization-washing steps, the obtained precursor of c-ZIF-8/CNT with hierarchical networks contained a highly active surface area from c-ZIF-8 as well as good conductivity and mechanical properties from CNTs. Therefore, the c-ZIF-8/CNT could act as an effective template for attracting the N-GQDs. The colloidal N-GQD was prepared from 1,3,6-trinitropyrene and hydrazine hydrate via hydrothermal method at $200{ }^{\circ} \mathrm{C}$ $(12 \mathrm{~h})$ followed by filtration. In addition, the N-GQD provided efficient pseudocapacitance and surface wettability to the N-GQD@CZIF-8/CNT $\left(\mathrm{S}_{\mathrm{BET}}=520 \mathrm{~m}^{2} \mathrm{~g}^{-1}, \mathrm{~N}=16.3 \mathrm{at} \%\right)$. As the result of synergistic effects of pseudocapacitance from N-GQD, accessible surface area from c-ZIF-8, and good electrical conductivity from CNT, the N-GQD@CZIF-8/CNT-based SSC showed an excellent performance in both $1 \mathrm{M} \mathrm{H}_{2} \mathrm{SO}_{4}$ and $\mathrm{H}_{2} \mathrm{SO}_{4} / \mathrm{PVA}$ electrolytes. In the aqueous electrolyte, it yielded a great areal capacitance 
(622 $\mathrm{mF} \mathrm{cm}^{-2}$ at $1 \mathrm{~mA} \mathrm{~cm}{ }^{-2}$ ), appropriate rate performance (61.5\% retention from 0.5 to $20 \mathrm{~A} \mathrm{~g}^{-1}$ ), a ultra-high energy density (18.75 $\mathrm{W} \mathrm{h} \mathrm{kg}-1$ at $\left.108.7 \mathrm{~W} \mathrm{~kg}^{-1}\right)$ and a high power density $\left(2175 \mathrm{~W} \mathrm{~kg}^{-1}\right.$ at $12.62 \mathrm{~W} \mathrm{~h} \mathrm{~kg}^{-1}$ ). The flexible SSC based on the N-GQD@CZIF-8/CNT with the gel electrolyte delivered ultra-high capacitances $\left(400 \mathrm{~F} \mathrm{~g}^{-1}, 564 \mathrm{mF} \mathrm{cm}^{-2}\right)$ and high energy densities $\left(14 \mathrm{~W} \mathrm{~h} \mathrm{~kg}^{-1}\right.$, $\left.78.3 \mu \mathrm{W} \mathrm{h} \mathrm{cm}{ }^{-2}\right)$ with a power density of $89.5 \mathrm{~W} \mathrm{~kg}^{-1}\left(0.5 \mathrm{~mW} \mathrm{~cm}^{-2}\right)$ at $0.3 \mathrm{~A} \mathrm{~g}^{-1}$. More importantly, the flexible solid-phase device demonstrated outstanding mechanical stabilities.
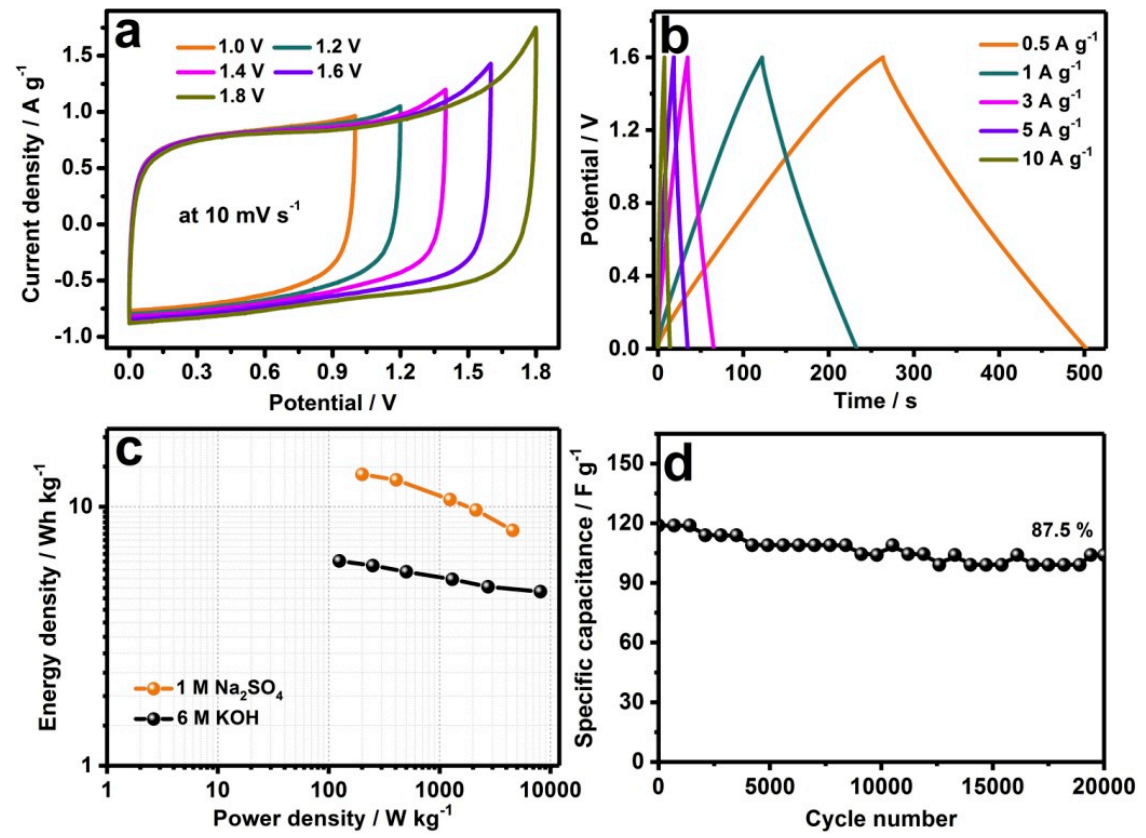

Figure 9. Electrocapacitive features for SSC of NHCSF-3//NHCSF-3 operating in $1 \mathrm{M} \mathrm{Na}_{2} \mathrm{SO}_{4}$ electrolyte. (a) CVs at $10 \mathrm{mV} \mathrm{s}^{-1}$ under different conditions of potential window; (b) GCD curves at different current loads; (c) Ragone plots; (d) cyclic performance at $4 \mathrm{~A} \mathrm{~g}^{-1}$ up to 20,000 cycles [135].

\subsubsection{Co-MOF-Derived Composite}

Table 8 shows the capacitive data for MOF-derived carbon/carbon composite-based electrode materials. The Co-MOF, $\mathrm{Cu}-\mathrm{MOF}$, and $\mathrm{Zr}-\mathrm{MOF}$ are good precursors for these composites.

The Co-MOF-derived carbon/N-doped graphene aerogel composite (C/NG-A) was prepared via carbonization of $\mathrm{Co}-\mathrm{MOF} / \mathrm{NG}-\mathrm{A}$ at $750{ }^{\circ} \mathrm{C}(2 \mathrm{~h}, \mathrm{Ar}$ flow $)$ and $\mathrm{HCl}$ treatment [137]. As a first step, the dispersed GO was hydrothermally reacted with ammonia to produce $\mathrm{N}$-doped graphene hydrogel. Next, the Co-MOF (ZIF-67) polyhedrons were loaded into the hydrogel, and supercritical $\mathrm{CO}_{2}$ drying and subsequent thermal activation of the hydrogel were conducted to form the Co-MOF/NG-A precursor for carbonization. The C/NG-A contained high $S_{\mathrm{BET}}$, uniform mesoporosity $\left(D_{\text {pore }}=5 \mathrm{~nm}\right)$, and interconnected graphene networks. In the $3 \mathrm{E}$ cell using $1 \mathrm{M} \mathrm{H}_{2} \mathrm{SO}_{4}$, the $\mathrm{C} / \mathrm{NG}$-A-based working electrode yielded a high capacitance with great rate performance $\left(305 \mathrm{~F} \mathrm{~g}^{-1}\right.$ at $\left.50 \mathrm{~A} \mathrm{~g}^{-1}\right)$. Using $\mathrm{PVA} / \mathrm{H}_{2} \mathrm{SO}_{4}$ electrolyte, solid-phase SSC showed outstanding recycling stabilities. 
Table 8. The electrochemical capacitive properties of other MOF-derived carbon/carbon composites.

\begin{tabular}{|c|c|c|c|c|c|c|}
\hline Samples & $S_{\text {BET }}\left(\mathrm{m}^{2} \mathrm{~g}^{-1}\right)$ & $C_{\max }\left(\mathrm{F} \mathrm{g}^{-1}\right)$ & $E_{\max }\left(\mathrm{Wh} \mathrm{kg}^{-1}\right)$ & $P_{\max }\left(\mathrm{W} \mathrm{kg}^{-1}\right)$ & System & Ref. \\
\hline $\mathrm{C} / \mathrm{NG}-\mathrm{A}$ & 814 & 421 & 33.89 & 25,000 & $3 \mathrm{E} / 2 \mathrm{E}$ & 137 \\
\hline HPCF1 & 330 & 177.4 & - & - & $3 \mathrm{E}$ & 138 \\
\hline HPCF2 & 449 & 249.4 & - & - & $3 \mathrm{E}$ & 138 \\
\hline HPCF3 & 525 & 356.1 & - & - & $3 \mathrm{E}$ & 138 \\
\hline HPCF4 & 620 & 381.2 & $\sim 10$ & $\sim 5000$ & $3 \mathrm{E} / 2 \mathrm{E}$ & 138 \\
\hline HPCF5 & 569 & 323.7 & - & - & $3 \mathrm{E}$ & 138 \\
\hline$C-600$ & 1094 & 252 & - & - & $3 \mathrm{E}$ & 139 \\
\hline C-700 & 1563 & 302 & - & - & $3 \mathrm{E}$ & 139 \\
\hline C-800 & 1446 & 265 & - & - & $3 \mathrm{E}$ & 139 \\
\hline C-900 & 1354 & 223 & - & - & $3 \mathrm{E}$ & 139 \\
\hline GA@CZIF-67-E & 207 & 53 & - & - & $2 \mathrm{E}$ & 140 \\
\hline NC@GC(0.05) & 1276 & 270 & - & - & $3 \mathrm{E}$ & 141 \\
\hline NC@GC(0.15) & - & 255 & - & - & $3 \mathrm{E}$ & 141 \\
\hline NC@GC(0.35) & 813 & 149 & - & - & $3 \mathrm{E}$ & 141 \\
\hline NC@GC(0.5) & - & 136 & - & - & $3 \mathrm{E}$ & 141 \\
\hline $\mathrm{Co} / \mathrm{Zn} \mathrm{NPC}$ & 415 & 286 & - & - & $3 \mathrm{E}$ & 142 \\
\hline HZ-NPC & 298 & 171 & - & - & $3 E$ & 174 \\
\hline CNT@NC & - & 278.8 & - & - & $3 \mathrm{E}$ & 179 \\
\hline
\end{tabular}

\subsubsection{Cu-MOF-Derived Composite}

HKUST-1/CNT was introduced as a precursor for the fabrication of hierarchical porous carbon films (HPCFs) [138]. The precursor was prepared from the assembly between positively charged copper hydroxide nanostrands (CHNs) and negatively charged CNT. The separation of solids by filtration produced $\mathrm{CHNs} / \mathrm{CNT}$ thin film. The immersion of $\mathrm{CHNs} / \mathrm{CNT}$ thin film in ethanol-water solution of $\mathrm{H}_{3}$ btc afforded HKUST-1/CNT thin film. The HKUST-1/CNT thin film was converted into HPCFs with meso-/macroporosity via carbonization ( $3 \mathrm{~h}, \mathrm{~N}_{2}$ flow) and acid etching $\left(0.7 \mathrm{M} \mathrm{HNO}_{3}\right)$. With the fine tuning of the carbonization temperature, i.e., $800^{\circ} \mathrm{C}$, and weight ratio (HKUST-1/CNT $=40 / 1)$, the optimized HPCF4 had the largest $S_{\text {BET }}$ and $V_{\text {total }}\left(0.63 \mathrm{~cm}^{3} \mathrm{~g}^{-1}\right)$ among the HPCFs. In addition, the HPCF4 with hierarchical pore structure also exhibited a good electrical conductivity of $1320 \mathrm{~S} \mathrm{~m}^{-1}$. As a result, both HKUST-1-derived carbon polyhedron and CNT had synergetic effects on the electrochemical performance of flexible and binder-free electrode based on the HPCF4 for supercapacitor in $6 \mathrm{M} \mathrm{KOH}$ electrolyte. In the 3E mode, it showed high capacitances and good rate performance (253.9 $\mathrm{F} \mathrm{g}^{-1}$ at $200 \mathrm{mV} \mathrm{s}^{-1}, 120.9 \mathrm{~F} \mathrm{~g}^{-1}$ at $100 \mathrm{~A} \mathrm{~g}^{-1}$ ). In the $2 \mathrm{E}$ mode, the HPCF4//HPCF4 showed an outstanding rate performance $\left(157.9 \mathrm{~F} \mathrm{~g}^{-1}\right.$ at $1 \mathrm{~A} \mathrm{~g}^{-1}$ and $128.9 \mathrm{~F} \mathrm{~g}^{-1}$ at $\left.10 \mathrm{~A} \mathrm{~g}^{-1}\right)$ and a high energy density $\left(9.1 \mathrm{~W} \mathrm{~h} \mathrm{~kg}^{-1}\right.$ at $\left.3500 \mathrm{~W} \mathrm{~kg}^{-1}\right)$.

\subsubsection{Zr-MOF-Derived Composite}

The carbonized UiO-66- $\mathrm{NO}_{2} /$ reduced carboxyl graphene (CUiO-66- $\mathrm{NO}_{2} / \mathrm{rCXYG}$ ) was prepared from the carbonization of a UiO-66- $\mathrm{NO}_{2} /$ carboxyl graphene composite $\left(5 \mathrm{~h}, \mathrm{~N}_{2}\right.$ flow) followed by $\mathrm{HF}$ treatment [139]. The conductive graphene layer was effectively incorporated into bare $C_{2}-700$ to give a high-surface precursor leading to the optimized sample C-700 carbonized at $700{ }^{\circ} \mathrm{C}$. The graphene layer successfully inhibited the aggregation of precursor particles. As a result, the C-700 had high $\mathrm{S}_{\mathrm{BET}}$, large $\mathrm{V}_{\text {tot }}\left(0.79 \mathrm{~cm}^{3} \mathrm{~g}^{-1}\right)$, well-defined microporosity (most probable diameter $=1.061 \mathrm{~nm} ; \mathrm{V}_{\text {micro }} / \mathrm{V}_{\text {total }}$ $=72 \%)$, suitable mesoporosity $(2.0-8.0 \mathrm{~nm})$, and good surface wettability. Therefore, in the 3E cell with $6 \mathrm{M} \mathrm{KOH}$ electrolyte, it showed a high capacitance of $302 \mathrm{~F} \mathrm{~g}^{-1}$ at $0.15 \mathrm{~A} \mathrm{~g}^{-1}$.

\subsubsection{Other Kinds}

An effective synthesis of light-weighted porous carbon composite electrodes for all-solid-phase SSCs operating in PVA/KOH gel electrolyte started from heterogeneous crystal nucleation of ZIFs (ZIF-8 or ZIF-67) on 3D macroporous graphene aerogels (GAs) support [140]. The carbonized samples 
(GA@CZIF-8 or GA@CZIF-67) were produced after crystal growth and a subsequent carbonization at $800{ }^{\circ} \mathrm{C}$ ( $3 \mathrm{~h}$, Ar flow). Then, the carbonized samples were transformed into final products (GA@CZIF-8-E or GA@CZIF-67-E) via acid etching (2 M HCl). The obtained GA@CZIFs-E contained 3D hierarchical porosity (interconnected mesopore from carbonized zeolitic imidazolate frameworks (CZIFs) and uniform macropore from the GA) with even distribution of nitrogen element compared to bare CZIFs-E. The GA@CZIF-67-E showed co-catalyzed graphitization compared to the GA@CZIF-8-E. Thus, it showed better capacitances than the GA@CZIF-8-E.

Yamauchi et al. reported N-doped carbon/highly graphitic carbon (NC@GC) composites by introduction of a new core/shell template of ZIF-8@ZIF-67 (Figure 10) [141]. The template was synthesized from the growth of ZIF-67 on ZIF-8 seed, and then it was converted into the NC@GC through carbonization at $800{ }^{\circ} \mathrm{C}\left(3 \mathrm{~h}\right.$, Ar flow) and acid treatment $(10 \mathrm{wt} . \% \mathrm{HF}) . \mathrm{Co}^{2+} / \mathrm{Zn}^{2+}$ molar ratio (x) of ZIF-8@ZIF-67(x) templates could control the core size as well as shell thickness, and eventually structural and electrochemical (3E in $1 \mathrm{M} \mathrm{H}_{2} \mathrm{SO}_{4}$ ) properties of the corresponding $\mathrm{NC@GC(x)} \mathrm{samples.}$ To summarize, the optimized NC@GC $(0.05)$ had high $\mathrm{S}_{\mathrm{BET}}$, large $\mathrm{V}_{\text {pore }}\left(1.78 \mathrm{~cm}^{3} \mathrm{~g}^{-1}\right)$, reasonable $\mathrm{N}$-doping (10.6 wt.\%), adequate shell thickness of the GC, and well-developed and hierarchically interconnected micro-/mesoporosity. Therefore, it showed satisfactory maximum capacitance and moderate rate performance.

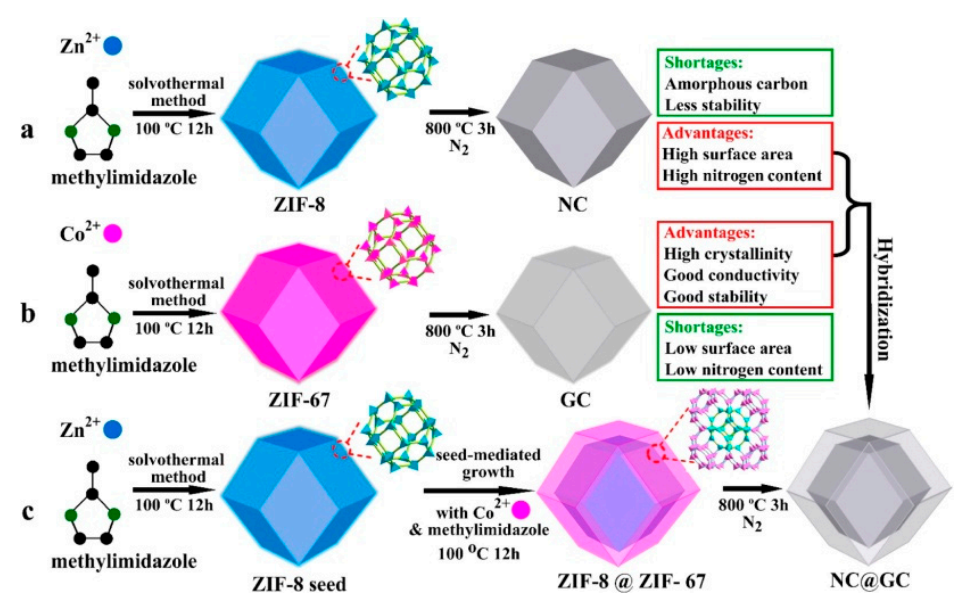

Figure 10. Preparation steps for (a) ZIF-8 crystals and NC, (b) ZIF-67 crystals and GC, and (c) core/shell ZIF-8@ZIF-67 crystals and NC@GC [141].

The same group reported bimetallic-ZIF-derived nanoporous carbon (NPC) with CNT on the surface [142]. The bimetallic-template, Co/Zn-ZIF, was synthesized in a large scale without PVP modulator $(\mathrm{Co} / \mathrm{Zn}$ molar ratio $=2 / 1)$. The hybrid template was transformed into $\mathrm{Co} / \mathrm{Zn} \mathrm{NPC}$ via carbonization $\left(800^{\circ} \mathrm{C}, 5 \mathrm{~h}, \mathrm{~N}_{2}\right.$ flow) and acid washing ( $\left.10 \mathrm{wt} . \% \mathrm{HF}\right)$. With the introduction of synergistic advantages of both ZIF-8 and ZIF-67, the resultant Co/Zn NPC contained microporosity, mesoporosity, graphitic CNTs, and N-dopant (3.5 at\%). As a result, in the $3 \mathrm{E}$ cell with $0.5 \mathrm{M} \mathrm{H}_{2} \mathrm{SO}_{4}$, it yielded capacitances of $286 \mathrm{~F} \mathrm{~g}^{-1}$ at $2.5 \mathrm{~A} \mathrm{~g}^{-1}$ and $103.7 \mathrm{~F} \mathrm{~g}^{-1}$ at $10 \mathrm{~A} \mathrm{~g}^{-1}$. Good cycling stabilities of the SSC up to 10,000 cycles could be displayed in both $0.5 \mathrm{M} \mathrm{H}_{2} \mathrm{SO}_{4}$ and $1.0 \mathrm{M} \mathrm{TBAPF}_{6} / \mathrm{AN}$ electrolytes.

\subsection{Carbon/Metal Oxide Composite}

The carbon/metal oxide composites are also good supercapacitors due to the favorable role of metal oxides for better performance. Table 9 shows the electrochemical capacitive properties of the known carbon/metal oxide composite-based electrode materials. 
Table 9. The electrochemical capacitive properties of carbon/metal oxide composites.

\begin{tabular}{|c|c|c|c|c|c|c|}
\hline Samples & $S_{\text {BET }}\left(\mathrm{m}^{2} \mathrm{~g}^{-1}\right)$ & $C_{\max }\left(\mathrm{F} \mathrm{g}^{-1}\right)$ & $E_{\max }\left(\mathrm{Wh} \mathrm{kg} \mathrm{kg}^{-1}\right)$ & $P_{\max }\left(\mathrm{W} \mathrm{kg}{ }^{-1}\right)$ & System & Ref. \\
\hline $\mathrm{CeO}_{2} @ \mathrm{C}(\mathrm{RT})$ & 384 & 895 & - & - & $3 \mathrm{E}$ & 143 \\
\hline $\mathrm{CeO}_{2} @ \mathrm{C}(\mathrm{ST})$ & 53 & 1102 & - & - & $3 \mathrm{E}$ & 143 \\
\hline $\mathrm{Co}_{3} \mathrm{O}_{4} / \mathrm{C} \mathrm{NAs}$ & - & 776.5 & 8.54 & - & $3 \mathrm{E} / 2 \mathrm{E}$ & 144 \\
\hline $\mathrm{Co}_{3} \mathrm{O}_{4} / \mathrm{NC}-90-15$ & 74 & $1.22^{\mathrm{a}}$ & - & - & $3 \mathrm{E}$ & 145 \\
\hline NC600 & 310 & 57 & - & - & $3 \mathrm{E}$ & 146 \\
\hline NC600AT & 764 & 98 & - & - & $3 \mathrm{E}$ & 146 \\
\hline NC900 & 115 & 88 & - & - & $3 \mathrm{E}$ & 146 \\
\hline NC900AT & 272 & 67 & - & - & $3 \mathrm{E}$ & 146 \\
\hline $\mathrm{Cu}-\mathrm{Cu}_{2} \mathrm{O}-\mathrm{CuO} / \mathrm{C} 700$ & - & 782 & - & - & $3 \mathrm{E}$ & 147 \\
\hline $\mathrm{Cu}-\mathrm{Cu}_{2} \mathrm{O}-\mathrm{CuO} / \mathrm{C} 800$ & - & 773 & - & - & $3 \mathrm{E}$ & 147 \\
\hline $\mathrm{Fe}_{3} \mathrm{O}_{4} /$ carbon & 38 & 162 & - & - & $3 \mathrm{E}$ & 148 \\
\hline MOFC-300 & - & 232 & - & - & $3 \mathrm{E}$ & 149 \\
\hline MOFC-400 & - & 520 & - & - & $3 \mathrm{E}$ & 149 \\
\hline MOFC-500 & - & 109 & - & - & $3 \mathrm{E}$ & 149 \\
\hline MOFC-600 & 72 & 972 & - & - & $3 \mathrm{E}$ & 149 \\
\hline MOFC-700 & - & 381 & - & - & $3 \mathrm{E}$ & 149 \\
\hline $\mathrm{NC} / \mathrm{Mn}_{3} \mathrm{O}_{4}-1$ & - & 136 & - & - & $3 \mathrm{E}$ & 150 \\
\hline $\mathrm{MoO}_{2} @ \mathrm{Cu} @ \mathrm{C}$ & 183 & $28.56^{\mathrm{b}}$ & 2.58 & 790.38 & $3 \mathrm{E} / 2 \mathrm{E}$ & 151 \\
\hline $\mathrm{RuO}_{2} / \mathrm{PCs}-1$ & - & 444.4 & - & - & $3 \mathrm{E}$ & 152 \\
\hline $\mathrm{RuO}_{2} / \mathrm{PCs}-2$ & - & 481.4 & - & - & $3 \mathrm{E}$ & 152 \\
\hline $\mathrm{RuO}_{2} /$ PCs-3 & 198 & 539.6 & 23.38 & 12,000 & $3 \mathrm{E} / 2 \mathrm{E}$ & 152 \\
\hline $\mathrm{RuO}_{2} / \mathrm{PCs}-4$ & - & 493.3 & - & - & $3 \mathrm{E}$ & 152 \\
\hline $\mathrm{ZnO} / \mathrm{C}$ & 140 & 394 & - & - & $3 \mathrm{E}$ & 153 \\
\hline$\left(\mathrm{Co}_{0.94} \mathrm{Fe}_{0.06}\right)_{3} \mathrm{O}_{4} @ \mathrm{CON}$ & - & 161 & - & - & $3 \mathrm{E}$ & 154 \\
\hline $\mathrm{ZMCN}$ & 143 & 589 & - & - & $3 \mathrm{E}$ & 155 \\
\hline BMM-9-800 & - & 159.4 & - & - & $3 \mathrm{E}$ & 156 \\
\hline BMM-9-900 & - & 263.2 & - & - & $3 \mathrm{E}$ & 156 \\
\hline BMM-9-1000 & - & 159.5 & - & - & $3 \mathrm{E}$ & 156 \\
\hline M/MO@C-700 & 242 & 894 & - & - & $3 \mathrm{E}$ & 157 \\
\hline $\begin{array}{c}\mathrm{ZnO@C@NiCo} \mathrm{O}_{4} \\
\text { NRSA }\end{array}$ & - & 2650 & - & - & $3 \mathrm{E}$ & 158 \\
\hline $\mathrm{Co}_{3} \mathrm{O}_{4} / \mathrm{C}$ & 273 & 793 & - & - & $3 \mathrm{E}$ & 172 \\
\hline $\mathrm{CuO}_{\mathrm{x}} @ \mathrm{mC700}$ & - & 93.3 & - & - & $3 \mathrm{E}$ & 178 \\
\hline C/CoO-200 & 5 & 1052 & - & - & $3 \mathrm{E}$ & 181 \\
\hline $\mathrm{Co}_{3} \mathrm{O}_{4} @$ Carbon & 24 & 261 & 0.97 & 6000 & $3 \mathrm{E} / 2 \mathrm{E}$ & 182 \\
\hline MOXC-700 & 181 & 600 & - & - & $3 \mathrm{E}$ & 183 \\
\hline S- $\alpha-\mathrm{Fe}_{2} \mathrm{O}_{3} @ \mathrm{C}$ & 117 & 1538 & - & - & $3 \mathrm{E}$ & 184 \\
\hline $\mathrm{MnO}_{\mathrm{x}}-\mathrm{CSs}-600$ & 182 & 220 & - & - & $3 \mathrm{E}$ & 186 \\
\hline $\mathrm{MnO}_{\mathrm{x}}-\mathrm{CS} s-800$ & 61 & 130 & - & - & $3 \mathrm{E}$ & 186 \\
\hline MNCMn-60 & 906 & 163 & - & - & $3 \mathrm{E}$ & 187 \\
\hline $\mathrm{Mn}_{2} \mathrm{O}_{3} / \mathrm{C}$ & 22 & 776 & - & - & $3 \mathrm{E}$ & 188 \\
\hline $\mathrm{NiCO}_{2} \mathrm{O}_{4}-\mathrm{NC}$ & 126 & 310 & - & - & $3 \mathrm{E}$ & 191 \\
\hline $\mathrm{Cr}_{2} \mathrm{O}_{3} / \mathrm{C}$ & 60 & 426 & - & - & $3 \mathrm{E}$ & 192 \\
\hline $\mathrm{Fe}_{\mathrm{x}} \mathrm{O}_{\mathrm{y}} / \mathrm{C}$ & 68 & 114 & - & - & $3 \mathrm{E}$ & 192 \\
\hline ZnO QDs/carbon & - & 85.4 & - & - & $3 \mathrm{E}$ & 201 \\
\hline
\end{tabular}

\subsubsection{Composite Containing $\mathrm{CeO}_{2}$}

$\mathrm{CeO}_{2}$ has natural abundance, green features, and dynamic redox couple. Thus, $\mathrm{CeO}_{2}$-containing carbon composites can show good capacitive behaviors. In this regard, new rod-shaped $\mathrm{CeO}_{2} @ \mathrm{C}$ nanocomposites were prepared from the Ce-btc MOFs synthesized under different synthetic conditions $(\mathrm{ST}=$ solvothermal, $\mathrm{RT}=$ room temperature) [143]. The MOF templates, i.e., Ce-btc (ST) or Ce-btc (RT), were transformed into the $\mathrm{CeO}_{2} @ \mathrm{C}$ via a two-step pyrolysis $\left(600{ }^{\circ} \mathrm{C}, 3 \mathrm{~h}\right.$, Ar flow and $350{ }^{\circ} \mathrm{C}, 2 \mathrm{~h}$ in air). In the $\mathrm{CeO}_{2} @ \mathrm{C}, \mathrm{CeO}_{2}$ was rod-shaped matrix and pseudocapacitive redox center. Moreover, partially graphitic carbons (C) provided electronic conductivity, surface wettability, and porosity. In addition, compared to $\mathrm{CeO}_{2} @ \mathrm{C}(\mathrm{ST})\left(\mathrm{S}_{\mathrm{BET}}=53 \mathrm{~m}^{2} \mathrm{~g}^{-1}, \mathrm{C}=9.5 \mathrm{wt} . \%\right), \mathrm{CeO}_{2} @ \mathrm{C}(\mathrm{RT})$ held good crystallinity, high $\mathrm{S}_{\mathrm{BET}}\left(384 \mathrm{~m}^{2} \mathrm{~g}^{-1}\right)$ and carbon contents (13.4 wt.\%), and developed hierarchical mesoporosity $(3.4 \mathrm{~nm}$ for most probable pore size, $6.2 \mathrm{~nm}$ for average pore size, and $6.5 \mathrm{~nm}$ for interparticle pore size). As a result, the $\mathrm{CeO}_{2} @ \mathrm{C}(\mathrm{RT})$ electrode demonstrated better performance in 
$2 \mathrm{M} \mathrm{KOH}+0.1 \mathrm{M} \mathrm{K}_{4} \mathrm{Fe}(\mathrm{CN})_{6}$ electrolyte through two main electrochemical reactions in a 3E mode: non-faradaic surface adsorption-desorption, $\left(\mathrm{CeO}_{2}\right)_{\text {surface }}+\mathrm{K}^{+}+\mathrm{e}^{-} \leftrightarrow\left(\mathrm{CeO}_{2} \cdot \cdot \mathrm{K}^{+}\right)_{\text {surface; }}$ faradaic intercalation-deintercalation, $\mathrm{Ce}^{\mathrm{IV}} \mathrm{O}_{2}+\mathrm{K}^{+}+\mathrm{e}^{-} \leftrightarrow \mathrm{Ce} \mathrm{CII}^{\mathrm{III}} \mathrm{O} \cdot \mathrm{OK}$. Additional faradaic reaction of $\mathrm{CeO}_{2}$ also occurred because of $\mathrm{K}_{4} \mathrm{Fe}(\mathrm{CN})_{6}$ electrolyte: $\mathrm{K}_{4} \mathrm{Fe}(\mathrm{CN})_{6} \leftrightarrow \mathrm{K}_{3} \mathrm{Fe}(\mathrm{CN})_{6}+\mathrm{e}^{-}$. The $\mathrm{CeO}_{2} @ \mathrm{C}(\mathrm{RT})$ electrode showed an ultra-high capacitance of $1102 \mathrm{~F} \mathrm{~g}^{-1}$ at $2 \mathrm{~A} \mathrm{~g}^{-1}$ and moderate rate capacity $\left(418 \mathrm{~F} \mathrm{~g}^{-1}\right.$ at $\left.20 \mathrm{~A} \mathrm{~g}^{-1}\right)$,

\subsubsection{Composite Containing $\mathrm{Co}_{3} \mathrm{O}_{4}$}

$\mathrm{Co}_{3} \mathrm{O}_{4}$ has many advantages because it is cheap, eco-friendly, and highly active in catalysis. Nevertheless, its pseudocapacitive kinetics was limited by low electric conductivity and slow ionic diffusion rate. To overcome these restrictions, $\mathrm{Co}_{3} \mathrm{O}_{4}$-embedded porous carbon composite $\left(\mathrm{Co}_{3} \mathrm{O}_{4} / \mathrm{C}\right)$ was generated from $\mathrm{Co}-\mathrm{MOF}$ precursor on a flexible and conductive $\mathrm{Ni}$ foam substrate [144]. The precursor, Co-MOF nanowire arrays (NAs), was synthesized by solvothermal reaction of $\mathrm{Co}\left(\mathrm{NO}_{3}\right)_{2} \cdot 6 \mathrm{H}_{2} \mathrm{O}$ and 2,5-dihydroxybenzenedicarboxylic acid (2,5-dhbdc) on the substrate at $120{ }^{\circ} \mathrm{C}$. After two-step thermolysis of the Co-MOF NAs $\left(400^{\circ} \mathrm{C}, 1 \mathrm{~h}\right.$, Ar flow and $250^{\circ} \mathrm{C}, 2 \mathrm{~h}$ in air), the porous $\mathrm{Co}_{3} \mathrm{O}_{4} / \mathrm{C}$ NAs with synergistic architecture and hierarchical porosity were obtained. Under $3 \mathrm{E}$ mode in $3 \mathrm{M} \mathrm{KOH}$ electrolyte, the $\mathrm{Co}_{3} \mathrm{O}_{4} / \mathrm{C}$ hybrid showed a ultra-high capacitance of $1.32 \mathrm{~F} \mathrm{~cm}^{-2}\left(776.5 \mathrm{~F} \mathrm{~g}^{-1}\right)$ at $1 \mathrm{~mA} \mathrm{~cm}{ }^{-2}$ and outstanding rate performance up to $20 \mathrm{~mA} \mathrm{~cm}{ }^{-2}$. Moreover, under 2E mode in $\mathrm{PVA} / \mathrm{KOH}$ electrolyte, the $\mathrm{Co}_{3} \mathrm{O}_{4} / \mathrm{C}$ NAs-based flexible SSC showed maximum values of capacitances $\left(203 \mathrm{mF} \mathrm{cm}^{-2}, 61.5 \mathrm{~F} \mathrm{~g}^{-1}\right)$ and energy densities $\left(0.14 \mathrm{~mW} \mathrm{~h} \mathrm{~cm}^{-3}, 8.54 \mathrm{~W} \mathrm{~h} \mathrm{~kg}^{-1}\right)$ at $1 \mathrm{~mA} \mathrm{~cm}^{-2}$, suitable rate performance (58.9\% retention) at $10 \mathrm{~mA} \mathrm{~cm}^{-2}$, and good long-term stabilities of mechanical bending $\left(90.1 \%\right.$ retention after 1000 bending cycles at $\left.90^{\circ}\right)$. These excellent results could be explained by the improved electrical conductivity and porosity from the Ni foam and MOF-derived carbon, as well as binder-free direct contact between the $\mathrm{CO}_{3} \mathrm{O}_{4} / \mathrm{C}$ NAs and $\mathrm{Ni}$ foam.

Another 3D composite of $\mathrm{Co}_{3} \mathrm{O}_{4} /$ nanoporous carbon $\left(\mathrm{Co}_{3} \mathrm{O}_{4} / \mathrm{NC}\right)$ was fabricated from the new core/shell type of precursor, $\mathrm{Co}\left(\mathrm{CO}_{3}\right)_{0.5}(\mathrm{OH}) \cdot 0.11 \mathrm{H}_{2} \mathrm{O} @ \mathrm{ZIF}-67$ [145]. The $\mathrm{Co}\left(\mathrm{CO}_{3}\right)_{0.5}(\mathrm{OH}) \cdot 0.11 \mathrm{H}_{2} \mathrm{O}$ was hydrothermally synthesized from the mixture of $\mathrm{Co}\left(\mathrm{NO}_{3}\right)_{2} \cdot 6 \mathrm{H}_{2} \mathrm{O}$, urea, and $\mathrm{NH}_{4} \mathrm{~F}$ at $120{ }^{\circ} \mathrm{C}$, then it acted as a nucleation site for chemical vapor deposition (CVD)-mediated growth of ZIF-67 film to prevent self-aggregation. For the crystallinity and uniformity of the film, 2-MeIM vapor was introduced into the nucleation site via the CVD method. The precursor was generated by a subsequent heating $\left(\mathrm{x}^{\circ} \mathrm{C}, \mathrm{y} \mathrm{h}\right)$ in a sealed high-pressure reactor. The resultant $\left(\mathrm{CO}_{3}\right)_{0.5}(\mathrm{OH}) \cdot 0.11 \mathrm{H}_{2} \mathrm{O} @ \mathrm{ZIF}-67-\mathrm{x}-\mathrm{y}$ was converted into $\mathrm{Co}_{3} \mathrm{O}_{4} / \mathrm{NC}-\mathrm{x}-\mathrm{y}$ through two-step heat treatment $\left(400^{\circ} \mathrm{C}, 1 \mathrm{~h}, \mathrm{~N}_{2}\right.$ flow and $250{ }^{\circ} \mathrm{C}$, $2 \mathrm{~h}$ in air). In the $\mathrm{Co}_{3} \mathrm{O}_{4} / \mathrm{NC}-\mathrm{x}-\mathrm{y}, \mathrm{Co}_{3} \mathrm{O}_{4}$ nanowire (NW) core was adequate for faradaic reaction site with excellent theoretical capacitance $\left(3560 \mathrm{~F} \mathrm{~g}^{-1}\right)$ while graphitic NC shell contained porous and conductive structure. The $\mathrm{Co}_{3} \mathrm{O}_{4} / \mathrm{NC}-90-15$ showed high $\mathrm{S}_{\mathrm{BET}}\left(74.0 \mathrm{~m}^{2} \mathrm{~g}^{-1}\right)$ and good preservation of 3D NW morphology in combination with effective contact for electric conduction compared to the $\mathrm{Co}_{3} \mathrm{O}_{4} / \mathrm{NC}-90-24$. In a $3 \mathrm{E}$ cell with $6 \mathrm{M} \mathrm{KOH}$, it yielded high areal capacitance of $1.22 \mathrm{~F} \mathrm{~cm}^{-2}$ at $0.5 \mathrm{~mA} \mathrm{~cm}^{-2}$.

The ZIF-67 as a sole template was also introduced to the cost-effective synthesis of Co-containing nanoporous carbon (NC) polyhedrons with hollow $\mathrm{Co}_{3} \mathrm{O}_{4}$ shells [146]. The ZIF-67 was prepared under rapid and scalable synthetic conditions (molar ratio of $\mathrm{Co}\left(\mathrm{NO}_{3}\right)_{2}: 2$-MeIM:triethylamine $=1: 10: 5$ ). After the carbonization of ZIF-67 at $600{ }^{\circ} \mathrm{C}$ or $900{ }^{\circ} \mathrm{C}\left(6 \mathrm{~h}, \mathrm{~N}_{2}\right.$ flow), as-prepared carbons named NC600 and NC900 were produced. $\mathrm{HCl}$ treatment of the as-prepared samples was conducted to generate acid-treated samples named NC600-AT and NC900-AT. The samples synthesized at lower temperature had higher $\mathrm{S}_{\mathrm{BET}}\left(309.7 \mathrm{~m}^{2} \mathrm{~g}^{-1}\right.$ for NC600, $763 \mathrm{~m}^{2} \mathrm{~g}^{-1}$ for NC600-AT), whereas samples synthesized at higher temperature showed larger $D_{\text {pore }}(5.7 \mathrm{~nm}$ for NC900, $5.9 \mathrm{~nm}$ for NC900-AT). Under $0.1 \mathrm{M} \mathrm{KOH}$ electrolyte in a 3E cell, maximum specific capacitances at $20 \mathrm{mV} \mathrm{s}^{-1}$ were 57 (NC 600), 98 (NC600-AT), 88 (NC900), and 67 (NC900-AT) $\mathrm{F} \mathrm{g}^{-1}$. Under this condition, the capacitance was mainly influenced by microporosity. However, at higher rate condition, meso-/macroporosity mostly affected on the capacitance. 


\subsubsection{Composite Containing Copper Oxides}

A simple synthetic approach was applied to the preparation of $\mathrm{Cu}-\mathrm{Cu}_{2} \mathrm{O}-\mathrm{CuO} / \mathrm{C}$ composites. After a single-step carbonization of HKUST- 1 as a single self-sacrificing template at $700{ }^{\circ} \mathrm{C}$ or $800{ }^{\circ} \mathrm{C}(4 \mathrm{~h}, \mathrm{Ar}$ flow), $\mathrm{Cu}-\mathrm{Cu}_{2} \mathrm{O}-\mathrm{CuO} / \mathrm{C} 700(\mathrm{Cu} 1)$ and $\mathrm{Cu}-\mathrm{Cu}_{2} \mathrm{O}-\mathrm{CuO} / \mathrm{C} 800(\mathrm{Cu} 2)$ were produced [147]. The obtained composites containing suitable micropores and mesopores were composed of highly interconnected graphitic carbon fibers with O-dopant and redox-active $\mathrm{Cu}$ species. The electrochemical performance of the obtained electrodes were investigated by using a $3 \mathrm{E}$ cell in $6 \mathrm{M} \mathrm{KOH}$ electrolyte. In $\mathrm{CV}$, both electrodes yielded remarkable maximum gravimetric capacitances at $2 \mathrm{mV} \mathrm{s}^{-1}\left(782 \mathrm{~F} \mathrm{~g}^{-1}\right.$ for $\mathrm{Cu} 1$, $773 \mathrm{~F} \mathrm{~g}^{-1}$ for $\mathrm{Cu} 2$ ) and moderate rate retentions at $75 \mathrm{mV} \mathrm{s}^{-1}$ ( $41 \%$ for $\mathrm{Cu} 1,43 \%$ for $\mathrm{Cu} 2$ ). In addition, in the GCD, they had improved rate retentions from $2 \mathrm{~mA} \mathrm{~cm}{ }^{-2}$ to $25 \mathrm{~mA} \mathrm{~cm}^{-2}(65 \%$ for $\mathrm{Cu} 1,67 \%$ for $\mathrm{Cu} 2)$. Moreover, high values of areal capacitances were displayed in both $2 \mathrm{mV} \mathrm{s}^{-1}\left(351 \mu \mathrm{F} \mathrm{cm}{ }^{-2}\right.$ for $\mathrm{Cu} 1,346 \mu \mathrm{F} \mathrm{cm}^{-2}$ for $\left.\mathrm{Cu} 2\right)$ and $2 \mathrm{~mA} \mathrm{~cm}^{-2}\left(363 \mu \mathrm{F} \mathrm{cm}^{-2}\right.$ for $\mathrm{Cu} 1,332 \mu \mathrm{F} \mathrm{cm}^{-2}$ for Cu2).

\subsubsection{Composite Containing $\mathrm{Fe}_{3} \mathrm{O}_{4}$}

The MOF-derived carbon supercapacitor electrode containing $\mathrm{Fe}_{3} \mathrm{O}_{4}$ was synthesized, and its temperature-dependent capacitances were studied [148]. The Fe-MIL-88B- $\mathrm{NH}_{2}$ self-sacrificing template synthesized from the reaction mixture of $\mathrm{F}-127, \mathrm{FeCl}_{3}$, acetic acid, and $\mathrm{NH}_{2}$-bdc was easily and economically transformed into $\mathrm{Fe}_{3} \mathrm{O}_{4} /$ carbon composite with agglomerated rod shape from a just single-step carbonization at $500^{\circ} \mathrm{C}\left(1 \mathrm{~h}, \mathrm{~N}_{2}\right.$ flow $)$. The $\mathrm{Fe}_{3} \mathrm{O}_{4} /$ carbon with mesoporosity $\left(\mathrm{D}_{\text {pore }}=3.0 \mathrm{~nm}\right)$ had both conducting carbon thin layers and pseudocapacitive $\mathrm{Fe}_{3} \mathrm{O}_{4}$. The GCD curves measured at $20^{\circ} \mathrm{C}$ showed capacitances of $139 \mathrm{~F} \mathrm{~g}^{-1}$ at $0.5 \mathrm{~A} \mathrm{~g}^{-1}$ and $74 \mathrm{~F} \mathrm{~g}^{-1}$ at $5 \mathrm{~A} \mathrm{~g}^{-1}$ in $1 \mathrm{M} \mathrm{KOH}$ electrolyte. When the operating temperature increased from 0 to $60^{\circ} \mathrm{C}$, its specific capacitance at $1 \mathrm{~A} \mathrm{~g}^{-1}$ showed a dramatic increase from 86 to $162 \mathrm{~F} \mathrm{~g}^{-1}$, whereas its internal resistance estimated from the EIS spectra decreased from 0.8 to $0.5 \Omega$. It exhibited good cycling stability at varying temperature regions (83.3\% retention after 4000 cycles) as shown in Figure 11.
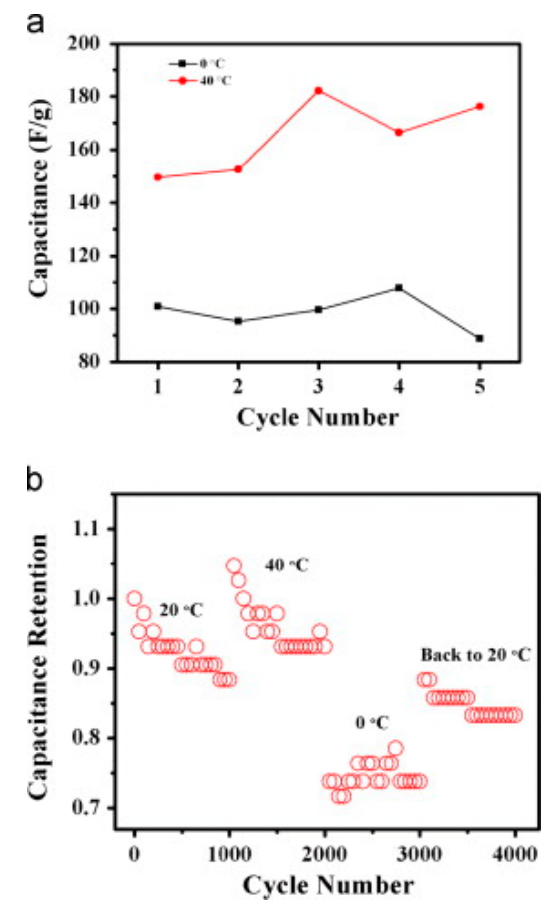

Figure 11. Temperature-dependent performances for composite electrode of $\mathrm{Fe}_{3} \mathrm{O}_{4} /$ carbon using $1 \mathrm{M}$ $\mathrm{KOH}$ electrolyte. (a) Specific capacitance variations at $1 \mathrm{~A} \mathrm{~g}^{-1}$ under repeated cycles of heating and cooling. (b) Cyclic stability at $2 \mathrm{~A} \mathrm{~g}^{-1}$ under various temperatures [148]. 
Another $\mathrm{Fe}_{3} \mathrm{O}_{4} /$ carbon composite was synthesized from Fe-bdc MOF [149]. After one-step carbonization ( $1 \mathrm{~h}$, Ar flow) of the Fe-bdc MOF prepared by using F-127, $\mathrm{FeCl}_{3} \cdot 6 \mathrm{H}_{2} \mathrm{O}$, acetic acid, and bdc, MOFC-T $\left(\mathrm{T}=300,400,500,600\right.$ and $\left.700{ }^{\circ} \mathrm{C}\right)$ carbons were produced. Among them, the optimized sample of MOFC- 600 had mesoporosity $\left(D_{\text {pore }}=3.6 \mathrm{~nm}\right)$, and its thin carbon shell with hierarchical porosity effectively covered the $\mathrm{Fe}_{3} \mathrm{O}_{4}$ cores. Therefore, it showed an ultra-high capacitance of $972 \mathrm{~F} \mathrm{~g}^{-1}$ at $1 \mathrm{~A} \mathrm{~g}^{-1}$ in $6 \mathrm{M} \mathrm{KOH}$.

\subsubsection{Composite Containing $\mathrm{Mn}_{3} \mathrm{O}_{4}$}

Although $\mathrm{Mn}_{3} \mathrm{O}_{4}$ was a cheap and green electrode material with high capacitive property, its electrochemical capacitor performance was restricted by the low electrical conductivity $\left(10^{-5}-10^{-6} \mathrm{~S} \mathrm{~cm}^{-1}\right)$ and slow rates of electrolytic penetration/diffusion processes [150]. Therefore, $\mathrm{N}$-rich Mn-coordination polymer particles (CPPs)-derived carbon/ $\mathrm{Mn}_{3} \mathrm{O}_{4}$ composites were prepared to overcome these restrictions. The CPP-1 was HATC-based Mn-CPP (HATC = 3-amino-1,2,4-triazole-5-carboxylic acid), while the CPP-2 was $\mathrm{H}_{2}$ pdc-based Mn-CPP $\left(\mathrm{H}_{2}\right.$ pdc = pyridine-2,6-dicarboxylic acid). After single-step carbonization at $450^{\circ} \mathrm{C}\left(30 \mathrm{~min}, \mathrm{~N}_{2}\right.$ flow), the N-doped porous carbon/ $/ \mathrm{Mn}_{3} \mathrm{O}_{4}\left(\mathrm{NC} / \mathrm{Mn}_{3} \mathrm{O}_{4}\right)$ composites were generated. The $\mathrm{NC} / \mathrm{Mn}_{3} \mathrm{O}_{4}-1$ prepared from the CPP-1, and the NC/Mn ${ }_{3} \mathrm{O}_{4}-2$ from the CPP-2. Compared to the NC/Mn $3 \mathrm{O}_{4}-2$, the NC/Mn $3 \mathrm{O}_{4}-1$ showed better capacitive behaviors in $1.0 \mathrm{M} \mathrm{Na}_{2} \mathrm{SO}_{4}$ electrolytic $3 \mathrm{E}$ cell mainly due to its ultra-high nitrogen contents (29.87 wt.\%). Moreover, its conductive NC part could improve pseudocapacitance of $\mathrm{Mn}_{3} \mathrm{O}_{4}$, facilitate intercalation/deintercalation of the electrolyte, and enhance electrochemical stability at long-term cycling process.

\subsubsection{Composite Containing $\mathrm{MoO}_{2}$}

$\mathrm{MoO}_{2}$ has been known for its properties of multiple oxidation state-driven charge transfer but low capacitance. As an alternative to bare $\mathrm{MoO}_{2}, \mathrm{MoO}_{2} @ \mathrm{Cu} @ \mathrm{C}$ composite was prepared from one-step co-carbonization of POM@MOF ( $\mathrm{POM}=$ polyoxometalates) composite precursor at $600{ }^{\circ} \mathrm{C}$ (2 h, $\mathrm{N}_{2}$ flow) [151]. The precursor, $\left[\mathrm{Cu}_{2}(\mathrm{btc})_{4 / 3}\left(\mathrm{H}_{2} \mathrm{O}\right)_{2}\right]_{6}[\mathrm{POM}] \cdot\left(\mathrm{C}_{4} \mathrm{H}_{12} \mathrm{~N}\right)_{2} \cdot \mathrm{xH}_{2} \mathrm{O}$, was hydrothermally synthesized from copper nitrate, phosphomolybdic acid, $\mathrm{H}_{3}$ btc, and $\left(\mathrm{CH}_{3}\right)_{4} \mathrm{NOH}$. The negatively charged Mo-based POM was well-dispersed guests of the $\mathrm{Cu}$-btc-MOF in the precursor. Therefore, the resultant $\mathrm{MoO}_{2} @ \mathrm{Cu} @ \mathrm{C}\left(\mathrm{D}_{\text {pore }}=6.0 \mathrm{~nm}\right)$ had numerous micropores and mesopores. Furthermore, it contained excellent dispersity of pseudocapacitive $\mathrm{MoO}_{2}$, conductive $\mathrm{Cu}$, and interconnected amorphous carbon sheets. Using $2 \mathrm{M} \mathrm{KOH}$ electrolyte in a 3E cell, the $\mathrm{MoO}_{2} @ \mathrm{Cu} @ \mathrm{C}$ yielded high charge capacities (28.27 mA h g $\mathrm{m}^{-1}$ at $5 \mathrm{mV} \mathrm{s}^{-1}, 28.56 \mathrm{~mA} \mathrm{~h} \mathrm{~g}^{-1}$ at $\left.0.5 \mathrm{~A} \mathrm{~g}^{-1}\right)$. Moreover, it delivered maximum values of capacity $\left(7.49 \mathrm{~mA} \mathrm{~h} \mathrm{~g}^{-1}\right)$ and energy density $\left(2.58 \mathrm{~W} \mathrm{~h} \mathrm{~kg}^{-1}\right)$ with a minimum power density of $86.8 \mathrm{~W} \mathrm{~kg}^{-1}$ at $0.25 \mathrm{~A} \mathrm{~g}^{-1}$, and a maximum power density $\left(790.38 \mathrm{~W} \mathrm{~kg}^{-1}\right)$ with minimum values of capacity $\left(3.33 \mathrm{~mA} \mathrm{~h} \mathrm{~g}^{-1}\right)$ and energy density $\left(0.71 \mathrm{~W} \mathrm{~h} \mathrm{~kg}^{-1}\right)$ at $2 \mathrm{~A} \mathrm{~g}^{-1}$.

\subsubsection{Composite Containing $\mathrm{RuO}_{2}$}

A pseudocapacitive $\mathrm{RuO}_{2}$ has several favorable factors for good electrochemical properties such as large capacitance, good electronic conductivity, and reversible charge/discharge behavior. However, it is rather expensive due to low natural abundance. Therefore, a method to take advantage of these favorable factors of $\mathrm{RuO}_{2}$ is necessary. In this sense, $\mathrm{RuO}_{2} / \mathrm{ZIF}-8$-derived porous carbons (PCs) composites were synthesized via carbonization-acid washing process followed by a two-step thermal treatment [152]. After carbonization $\left(500{ }^{\circ} \mathrm{C}, 30 \mathrm{~min}\right.$ and $800{ }^{\circ} \mathrm{C}, 2 \mathrm{~h}$ in $\left.\mathrm{N}_{2}\right)$ and subsequent $1 \mathrm{M}$ $\mathrm{HCl}$ etching, ZIF-8 precursor could be converted into the PCs with high $\mathrm{S}_{\mathrm{BET}}$ and polyhedral particle shape. Next, the PCs could be transformed into the $\mathrm{RuO}_{2} / \mathrm{PCs}$ composites under reflux conditions $\left(120{ }^{\circ} \mathrm{C}, 6 \mathrm{~h}\right)$ and subsequent thermolysis at $150{ }^{\circ} \mathrm{C}$ in air $(6 \mathrm{~h})$. Among the resultant $\mathrm{RuO}_{2} / \mathrm{PCs}-\mathrm{n}$, $\mathrm{RuO}_{2} / \mathrm{PCs}-3\left(\mathrm{RuO}_{2}\right.$ to PCs mass ratio $=0.707$ generated from addition of $10 \mathrm{~mL} \mathrm{RuCl}$ solution) yielded excellent capacitive features in $1 \mathrm{M} \mathrm{H}_{2} \mathrm{SO}_{4}$ electrolyte. In a $3 \mathrm{E}$ cell, it exhibited a capacitance of $539.6 \mathrm{~F} \mathrm{~g}^{-1}$ at $1 \mathrm{~A} \mathrm{~g} \mathrm{~g}^{-1}$ with outstanding rate performance $\left(81.5 \%\right.$ at $\left.200 \mathrm{~A} \mathrm{~g}^{-1}\right)$. In brief, the polyhedral 
shape-driven prevention of the self-stacking of PCs, graphitic N-dopant induced improvement of electrical conductivity, and heteroatom functionalities $(\mathrm{N}=7.33 \%$ and $\mathrm{O}=10.55 \%)$ led to synergistic effects on the excellent capacitive results showing the enhancement of both electrochemically accessible surface area of the $\mathrm{RuO}_{2} / \mathrm{PCs}-3\left(\mathrm{~S}_{\mathrm{BET}}=198 \mathrm{~m}^{2} \mathrm{~g}^{-1}\right.$ and the coexistence of micro-/meso-/macropores) and pseudocapacitance $\left(\mathrm{RuO}_{\mathrm{x}}(\mathrm{OH})_{\mathrm{y}}+\delta \mathrm{H}^{+}+\delta \mathrm{e}^{-} \leftrightarrow \mathrm{RuO}_{\mathrm{x}-\delta}(\mathrm{OH})_{\mathrm{y}+\delta}(0 \leq \delta \leq 2)\right)$.

\subsubsection{Composite Containing $\mathrm{ZnO}$}

Hollow $\mathrm{ZnO} / \mathrm{C}$ composite was prepared from hollow $\mathrm{Zn}$-containing carbonaceous (HZC) material [153]. At first, ZIF-8/glucose composite was transformed into the HZC through hydrothermal reaction $\left(180^{\circ} \mathrm{C}, \mathrm{y} \mathrm{h}\right)$. During the hydrothermal conversion, the ZIF-8/glucose was decomposed into hydrolysis products to generate acids and ZIF- 8 was decomposed by these acids. The degraded ZIF- 8 was reacted with the glucose-derived polymers to form the HZC. Outward diffusion of the products from the degraded ZIF-8 and inward diffusion of molecules generated by the glucose produced the hollow structure of HZC. After optimization of reaction condition for the hydrothermal transformation (glucose solution concentration $=2.5 \mathrm{M}$, reaction time $=2 \mathrm{~h}$ ), the obtained HZC-2.5M-2h was converted into the $\mathrm{ZnO} / \mathrm{C}$ via one-step carbonization $\left(500{ }^{\circ} \mathrm{C}, 2 \mathrm{~h}, \mathrm{~N}_{2}\right.$ flow). The resultant $\mathrm{ZnO} / \mathrm{C}$ showed high values of capacitance, $394 \mathrm{~F} \mathrm{~g}^{-1}$ at $1 \mathrm{~A} \mathrm{~g}^{-1}$ and $225 \mathrm{~F} \mathrm{~g}^{-1}$ at $60 \mathrm{~A} \mathrm{~g}^{-1}$, in a neutral $1 \mathrm{M} \mathrm{Na}_{2} \mathrm{SO}_{4}$ electrolyte.

\subsubsection{Other Complex Composites}

To achieve improved morphology control of $\mathrm{Co}_{3} \mathrm{O}_{4}$-based supercapacitor electrode, $\mathrm{Fe}\left(\mathrm{NO}_{3}\right)_{3}$-loaded $\mathrm{Co}_{2}(\mathrm{bdc})_{2}$ (dabco) MOF, $\left[\mathrm{Fe}\left(\mathrm{NO}_{3}\right)_{3} @ \mathrm{Co}_{2}(\mathrm{bdc})_{2}\right.$ (dabco)], was employed as a precursor for the synthesis of $\left(\mathrm{Co}_{0.94} \mathrm{Fe}_{0.06}\right)_{3} \mathrm{O}_{4}$ NPs-incorporated hollow carbon nanowire $\left[\left(\mathrm{Co}_{0.94} \mathrm{Fe}_{0.06}\right)_{3} \mathrm{O}_{4} @ \mathrm{CON}\right]$ [154]. The layer-pillar style precursor was solvothermally synthesized. After carbonization of the precursor, the $\left(\mathrm{Co}_{0.94} \mathrm{Fe}_{0.06}\right)_{3} \mathrm{O}_{4} @ \mathrm{CON}$ with porous NW architecture was produced. As a working electrode of a $3 \mathrm{E}$ mode in $1 \mathrm{M} \mathrm{KOH}$ electrolyte, the product composite showed a high capacitance $\left(162 \mathrm{~F} \mathrm{~g}^{-1}\right.$ at $\left.1 \mathrm{~A} \mathrm{~g}^{-1}\right)$ and poor rate capacity $\left(11.2 \mathrm{~F} \mathrm{~g}^{-1}\right.$ at $\left.8 \mathrm{~A} \mathrm{~g}^{-1}\right)$.

Despite several advantages of using $\mathrm{ZnMn}_{2} \mathrm{O}_{4}$ electrode material such as high capacitance and abundant redox-active sites, there are still some limitations of dispersion, surface area, and conductivity. To overcome these adverse issues, heterometallic $\mathrm{Zn}-/ \mathrm{Mn}-\mathrm{MOF}$-derived $\mathrm{ZnMn}_{2} \mathrm{O}_{4} /$ carbon nanorods $(\mathrm{ZMCN})$ was synthesized by carbonization of the MOF self-sacrificing template at $500{ }^{\circ} \mathrm{C}\left(1 \mathrm{~h}, \mathrm{~N}_{2}\right.$ flow $)$ followed by calcination in air at $300{ }^{\circ} \mathrm{C}(1 \mathrm{~h})$ [155]. The heterometallic $1 \mathrm{D}$ self-sacrificing template was prepared in the mixed solvent $\left(\mathrm{EtOH} / \mathrm{H}_{2} \mathrm{O}\right)$ at room temperature using $\mathrm{Zn}^{2+}, \mathrm{Mn}^{2+}$, and $\mathrm{H}_{3}$ btc. After the two-step pyrolysis, the resultant $\mathrm{ZMCN}$ contained 1D pore structure $\left(\mathrm{S}_{\mathrm{BET}}=143.4 \mathrm{~m}^{2} \mathrm{~g}^{-1}\right)$ and uniform dispersion of $\mathrm{ZnMn}_{2} \mathrm{O}_{4}$ in the structural support of conductive interconnected porous carbon. In a $3 \mathrm{E}$ cell with $1 \mathrm{M} \mathrm{Na}_{2} \mathrm{SO}_{4}$ electrolyte, the $\mathrm{ZMCN}$ had very high capacitances of $589 \mathrm{~F} \mathrm{~g}^{-1}$ at $1 \mathrm{~A} \mathrm{~g}^{-1}$ and $278 \mathrm{~F} \mathrm{~g}^{-1}$ at $20 \mathrm{~A} \mathrm{~g}^{-1}$.

From the microporous Zn-MOF (BMM-9, $\left[\mathrm{Zn}_{2}(\text { tpo })_{4 / 3}\left(\right.\right.$ dabco)] DMA. $\mathrm{H}_{2} \mathrm{O}$ where $\mathrm{H}_{3}$ tpo is tris(4-carboxyphenyl)phosphine oxide) containing 3D $1.7 \mathrm{~nm}$ cage with high stability, 3D micro-/mesoporous carbon composite of BMM-9-900 was generated by a single-step carbonization at $900{ }^{\circ} \mathrm{C}$ (5 h, Ar flow) [156]. In the BMM-9-900, there were coexisting $\mathrm{Zn}, \mathrm{N}, \mathrm{P}$, and $\mathrm{Zn}_{2} \mathrm{P}_{2} \mathrm{O}_{7}$. The $\mathrm{Zn}$-MOF precursor was prepared via thermal reaction of the mixture containing zinc nitrate, dabco, $\mathrm{HBF}_{4}$, and $\mathrm{H}_{3}$ tpo. The BMM-9-900 had hierarchical micro-/mesoporosity, conducting carbon support, various doping elements $(\mathrm{Zn}, \mathrm{P}, \mathrm{N})$, and pseudocapacitive active site $\left(\mathrm{Zn}_{2} \mathrm{P}_{2} \mathrm{O}_{7}\right)$. In a $3 \mathrm{E}$ cell with $3 \mathrm{M} \mathrm{KOH}$ electrolyte the following redox reaction could take place: $\left(\mathrm{Zn}_{2} \mathrm{P}_{2} \mathrm{O}_{7}\right)$ surface $+\mathrm{K}^{+}+\mathrm{e}^{-} \leftrightarrow$ $\left(\mathrm{Zn}_{2} \mathrm{P}_{2} \mathrm{O}_{7}^{-} \cdot \mathrm{K}^{+}\right)_{\text {surface. }}$. The cell showed capacitances of $263.2 \mathrm{~F} \mathrm{~g}^{-1}$ at $5 \mathrm{~A} \mathrm{~g}^{-1}$ and $132.0 \mathrm{~F} \mathrm{~g}^{-1}$ at $10 \mathrm{~A} \mathrm{~g}^{-1}$.

\subsubsection{Other Mixed Composites}

The CoMn-MOF-74 was first used as a precursor of mixed $\mathrm{CoO}$ and $\mathrm{MnO}$ incorporated carbon framework (M/MO@C) [157]. After one-step carbonization of the precursor at $700{ }^{\circ} \mathrm{C}\left(2 \mathrm{~h}, \mathrm{~N}_{2}\right.$ flow), the obtained M/MO@C-700 showed 1D-nanorod structure, uniform dispersity of NPs (Co, $\mathrm{CoO}, \mathrm{MnO})$, 
high graphitization $\left(I_{\mathrm{D}} / I_{\mathrm{G}}=0.927\right)$, developed bimodal mesoporosity $(4 \mathrm{~nm}$ and $6 \mathrm{~nm})$, and favorable wettability from $-\mathrm{OH}$ functionalities. In a $3 \mathrm{E}$ with $6 \mathrm{M} \mathrm{KOH}$ electrolyte, it showed the following diverse redox couples: $\mathrm{CoO}+\mathrm{OH}^{-} \leftrightarrow \mathrm{CoOOH}+\mathrm{e}^{-}, \mathrm{Mn}_{3} \mathrm{O}_{4} \cdot 2 \mathrm{H}_{2} \mathrm{O}+\mathrm{OH}^{-} \leftrightarrow \mathrm{MnOOH}+\mathrm{Mn}(\mathrm{OH})_{3}+\mathrm{e}^{-}$, $4 \mathrm{MnOOH}+2 \mathrm{Mn}(\mathrm{OH})_{3}+\mathrm{OH}^{-} \leftrightarrow\left(6 \mathrm{MnO}_{2}\right) \cdot 5 \mathrm{H}_{2} \mathrm{O}+3 \mathrm{H}^{+}+6 \mathrm{e}^{-}$. The specific capacitances were $894 \mathrm{~F} \mathrm{~g}^{-1}$ at $0.5 \mathrm{~A} \mathrm{~g}^{-1}$ and $272 \mathrm{~F} \mathrm{~g}^{-1}$ at $4 \mathrm{~A} \mathrm{~g}^{-1}$.

Meanwhile, $\mathrm{NiCo}_{2} \mathrm{O}_{4}$ also had many favorable properties such as low toxicity, cheap cost, plentiful resources, and great theoretical capacitance of $1370 \mathrm{~F} \mathrm{~g}^{-1}$. Nevertheless, the use of $\mathrm{NiCo}_{2} \mathrm{O}_{4}$ electrode for electrochemical energy storage was encountered with many practical restrictions including low electrical conductivity and poor rate of electrolyte diffusion. In addition, $\mathrm{ZnO}$ could be used as a profitable mechanical conducting support while it showed inferior chemical stability under acidic

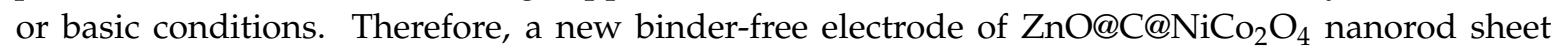
arrays (NRSAs) on flexible CC support was prepared by thermal decomposition, coordination-driven growth, carbonization, and electrodeposition [158]. As a first step, ZnO nanorod arrays (NRs) were thermally synthesized on the CC substrate using zinc nitrate hexahydrate, hexamethylenetetramine (HMTA), and ammonia. Next, ZnO@ZIF-8 NRs with uniform core/shell structure was obtained from ion-exchange-driven ZIF-8 crystal growth on the ZnO NRs. After that, the ZnO@ZIF-8 NRs were transformed into ZnO@C NRs through a single-step carbonization at $650{ }^{\circ} \mathrm{C}\left(2 \mathrm{~h}, \mathrm{~N}_{2}\right.$ flow). Finally, cathodic co-electrodeposition of $\mathrm{Co}\left(\mathrm{NO}_{3}\right)_{2}$ and $\mathrm{Ni}\left(\mathrm{NO}_{3}\right)_{2}(20$ cycles) on the $\mathrm{ZnO} @ \mathrm{C}$ NRs generated the $\mathrm{ZnO} @ \mathrm{C} @ \mathrm{NiCo}_{2} \mathrm{O}_{4}$. The resultant NRSAs with hierarchical structure was composed of ZnO NR core for the improvements of conductivity and electron transfer, protecting carbon layer for preservation of electrolytic erosion of the $\mathrm{ZnO} \mathrm{NR}$, and ultrathin $\mathrm{NiCo}_{2} \mathrm{O}_{4}$ nanosheet shell as a center of faradaic redox reactions: $\mathrm{NiCo}_{2} \mathrm{O}_{4}+\mathrm{OH}^{-}+\mathrm{H}_{2} \mathrm{O} \leftrightarrow \mathrm{NiOOH}+2 \mathrm{CoOOH}+\mathrm{e}^{-}, \mathrm{CoOOH}+\mathrm{OH}^{-} \leftrightarrow \mathrm{CoO}_{2}+\mathrm{H}_{2} \mathrm{O}+\mathrm{e}^{-}$. As a result, the $\mathrm{ZnO} @ \mathrm{C} @ \mathrm{NiCo}_{2} \mathrm{O}_{4}$ possessed a large surface area for electrochemical accessibility in $2 \mathrm{M} \mathrm{KOH}$ electrolytic 3E cell. It yielded ultra-high specific capacitance of $2650 \mathrm{~F} \mathrm{~g}^{-1}$ at $5 \mathrm{~A} \mathrm{~g}^{-1}$.

\subsection{Carbon/Metal Sulfide Composites}

Not only the carbon/metal oxide composites but also carbon/metal sulfide and other different types of composites can behave as good electrode materials for supercapacitors as given in Table 10.

\subsubsection{Composites Containing Cobalt Sulfides}

A 2D porphyrin-based paddlewheel framework-3 (PPF-3) nanosheets (thickness $=42.7 \pm 8.4 \mathrm{~nm}$ ) was used as a starting precursor for ultrathin (thickness $=24.5 \pm 6.4 \mathrm{~nm}$ ) $2 \mathrm{D} \operatorname{CoS}_{1.097} / \mathrm{N}$-doped carbon (CoSNC) nanocomposite [159]. With the assistance of PVP surfactant, the PPF-3 nanosheets composed of the dinuclear $\mathrm{CO}_{2}(\mathrm{COO})_{4}$ paddlewheel secondary building unit (SBU), tetratopic 5,10,15,20-tetrakis(4-carboxylphenyl)porphyrin (tcpp) bridging ligand, and bpy pillar ligand were synthesized in mixed solvent system (volume ratio of $\mathrm{DMF} / \mathrm{EtOH}=3: 1$ ). After that, the precursor was carbonized at $900{ }^{\circ} \mathrm{C}(3 \mathrm{~h})$ and further treated with $\mathrm{Ar} / \mathrm{O}_{2}$ plasma (15 min), and then transformed into the 2D CoSNC via concurrent sulfidation-carbonization process in the presence of $S$ powder at $650{ }^{\circ} \mathrm{C}$ (5 h, Ar flow). Despite low contents (21.0 wt.\%) of $\mathrm{CoS}_{1.097} \mathrm{NPs}$, their strong adsorption on the $\mathrm{N}$-doped (4.57 wt.\%) carbon coupled with ultrathin 2D structure of the CoSNC could account for good capacitive output of CoSNC-based working electrode in $2.0 \mathrm{M} \mathrm{KOH}$. The working electrode yielded high capacitance and moderate rate performance (56.8\% retention at $\left.30 \mathrm{~A} \mathrm{~g}^{-1}\right)$. 
Table 10. The electrochemical capacitive properties of other types of composites.

\begin{tabular}{|c|c|c|c|c|c|c|}
\hline Samples & $S_{\text {BET }}\left(\mathrm{m}^{2} \mathrm{~g}^{-1}\right)$ & $C_{\max }\left(\mathrm{F} \mathrm{g}^{-1}\right)$ & $E_{\max }\left(W h \mathrm{~kg}^{-1}\right)$ & $P_{\max }\left(\mathrm{W} \mathrm{kg} \mathbf{k g}^{-1}\right)$ & System & Ref. \\
\hline CoSNC & - & 360.1 & - & - & $3 \mathrm{E}$ & 159 \\
\hline (o)-CoS $\mathrm{C}_{2} @ \mathrm{CNT}$ & 28 & 155 & - & - & $3 \mathrm{E}$ & 160 \\
\hline (m)-CoS $\mathrm{CoCNT}_{2}$ & 8 & 422 & - & - & $3 \mathrm{E}$ & 160 \\
\hline (p)-CoS $\mathrm{CoCNT}_{2}$ & 18 & 839 & - & - & $3 \mathrm{E}$ & 160 \\
\hline $\mathrm{Co}_{9} \mathrm{~S}_{8} @ \mathrm{SNCC}$ & 212 & 429 & - & - & $3 \mathrm{E}$ & 161 \\
\hline $\mathrm{Co}_{9} \mathrm{~S}_{8} @ \mathrm{SNCB}$ & 88 & 320 & - & - & $3 \mathrm{E}$ & 161 \\
\hline $\mathrm{Cu}_{1.96} \mathrm{~S} / \mathrm{C}-650$ & 140 & 200 & - & - & $3 \mathrm{E}$ & 162 \\
\hline $\mathrm{Cu}_{7} \mathrm{~S}_{4} / \mathrm{C}$ & - & 321.9 & - & - & $3 \mathrm{E}$ & 163 \\
\hline PCM-900 & 448 & 99.0 & 13.7 & - & $3 \mathrm{E}$ & 164 \\
\hline $\mathrm{MoS}_{2} @ \mathrm{MPC}$ & - & 189 & - & - & $3 \mathrm{E}$ & 165 \\
\hline $\mathrm{Cu}_{2} \mathrm{~S} @ \mathrm{C}$ & 62 & 42 & - & - & $3 \mathrm{E}$ & 166 \\
\hline $\mathrm{Co}_{9} \mathrm{~S}_{8} @ \mathrm{C}$ & 202 & 227 & - & - & $3 \mathrm{E}$ & 166 \\
\hline $\mathrm{NiS}_{2} @ \mathrm{C}$ & 349 & 833 & - & - & $3 \mathrm{E}$ & 166 \\
\hline ZMP-0.04 & - & 500 & - & - & $3 \mathrm{E}$ & 167 \\
\hline S3 & - & 1100 & 21 & - & $3 \mathrm{E} / 2 \mathrm{E}$ & 168 \\
\hline $3 \mathrm{CPC}$ & - & 755 & - & - & $3 \mathrm{E}$ & 169 \\
\hline NC800-PEDOT & 1186 & 217.7 & - & - & $3 \mathrm{E}$ & 170 \\
\hline ZIF-8-C@NiAl LDH & 383 & 1403 & - & - & $3 \mathrm{E}$ & 171 \\
\hline $\mathrm{Co}_{3} \mathrm{O}_{4} / \mathrm{C} @ \mathrm{MoS}_{2}-10$ & - & 902 & - & - & $3 \mathrm{E}$ & 172 \\
\hline $\mathrm{Co}_{3} \mathrm{O}_{4} / \mathrm{C} @ \mathrm{MoS}_{2}-20$ & 257 & 1096 & - & - & $3 \mathrm{E}$ & 172 \\
\hline $\mathrm{Co}_{3} \mathrm{O}_{4} / \mathrm{C} @ \mathrm{MoS}_{2}-30$ & - & 713 & - & - & $3 \mathrm{E}$ & 172 \\
\hline $\mathrm{Ni}(\mathrm{OH})_{2}-\mathrm{MnO}_{2} / \mathrm{C}$ & - & 862.0 & 22.1 & 8500.0 & $3 \mathrm{E}$ & 173 \\
\hline HZ-NPFC/250-2 & 223 & 323 & - & - & $3 \mathrm{E}$ & 174 \\
\hline HZ-NPFC/250-5 & 202 & 545 & - & - & $3 \mathrm{E}$ & 174 \\
\hline HKUST-1@TS-800 & - & $1812^{\mathrm{a}}$ & - & - & $3 \mathrm{E}$ & 175 \\
\hline MCG-1 & - & 212 & - & - & $3 \mathrm{E}$ & 176 \\
\hline MCG-2 & 326 & 456 & - & - & $3 \mathrm{E}$ & 176 \\
\hline MCG-3 & - & 301 & - & - & $3 \mathrm{E}$ & 176 \\
\hline РМСР & - & 468.6 & - & - & $3 \mathrm{E}$ & 177 \\
\hline $\mathrm{CuO}_{\mathrm{x}} @ \mathrm{mC300@PANI}$ & - & 381.6 & - & - & $3 \mathrm{E}$ & 178 \\
\hline $\mathrm{CuO}_{\mathrm{x}} @ \mathrm{mC500@PANI}$ & - & 413.2 & - & - & $3 \mathrm{E}$ & 178 \\
\hline $\mathrm{CuO}_{\mathrm{x}} @ \mathrm{mC700@PANI}$ & - & 509.5 & - & - & $3 \mathrm{E}$ & 178 \\
\hline $\mathrm{CuO}_{\mathrm{x}} @ \mathrm{mC} 900 @ \mathrm{PANI}$ & - & 319.8 & - & - & $3 \mathrm{E}$ & 178 \\
\hline CuOx@mC700@PANI@rGO & - & 569.4 & - & - & $3 \mathrm{E}$ & 178 \\
\hline CoNi@SNC & 224 & 1970 & - & - & $3 \mathrm{E}$ & 193 \\
\hline $\mathrm{Co}_{9} \mathrm{~S}_{8} / \mathrm{NS}-\mathrm{C}-1.5 \mathrm{~h}$ & 66 & 734.09 & 25.49 & 2840.9 & $3 \mathrm{E}$ & 194 \\
\hline $\mathrm{Co}_{9} \mathrm{~S}_{8} @ \mathrm{C}-500$ & 63 & 1887 & - & - & $3 \mathrm{E}$ & 195 \\
\hline $\mathrm{Co}_{9} \mathrm{~S}_{8} @ \mathrm{C}-600$ & 37 & 1672 & - & - & $3 \mathrm{E}$ & 195 \\
\hline Ni-Co-S@G & 43 & 1463 & - & - & $3 \mathrm{E}$ & 196 \\
\hline CC/CNWAs@Ni@CoNi ${ }_{2} \mathrm{~S}_{4}$ & - & 3163 & - & - & $3 \mathrm{E}$ & 198 \\
\hline $\mathrm{MnS} / \mathrm{MoS}_{2} / \mathrm{C}$ & 8 & 1162 & - & - & $3 \mathrm{E}$ & 199 \\
\hline $\mathrm{MnS} / \mathrm{MoS}_{2} / \mathrm{MoO}_{3} / \mathrm{C}$ & - & 495 & - & - & $3 \mathrm{E}$ & 199 \\
\hline $\mathrm{Ni}(\mathrm{OH})_{2} @ \mathrm{Co} / \mathrm{C}$ & - & 952 & - & - & $3 \mathrm{E}$ & 200 \\
\hline $\mathrm{ZnO}$ QDs/carbon/CNTs & 435 & 185 & - & - & $3 \mathrm{E}$ & 201 \\
\hline $\mathrm{C} / \mathrm{LDH} / \mathrm{S}$ & 116 & 1653 & - & - & $3 \mathrm{E}$ & 203 \\
\hline
\end{tabular}

Co-MOF-derived $\mathrm{CoS}_{2} @ \mathrm{CNTs}$ were synthesized to overcome the weakness of cobalt sulfide which could have potentially high specific capacitances. The cobalt sulfide electrode material often suffers from poor electric conductivity and low surface area [160]. The bib-based Co-MOFs (bib = 1,4-bis(imidazol-1-yl) benzene) were solvothermally prepared with different conformational bdc linkers $(\mathrm{L}=o$-bdc for $1, m$-bdc for 2 , and $p$-bdc for 3$)$. The different conformations of these linkers could greatly influence the lattice dimensions of the Co-MOFs and their corresponding carbon composites' pore dimensions. Carbonization of the Co-MOFs $\left(900^{\circ} \mathrm{C}, 3 \mathrm{~h}, \mathrm{~N}_{2}\right.$ flow) generated Co@CNTs ((o)-Co@CNT, $(m)$-Co@CNT, $(p)-\mathrm{Co} @ C N T)$, and the Co@CNTs were further converted into $\mathrm{CoS}_{2} @ \mathrm{CNTs}$ $\left((o)-\mathrm{CoS}_{2} @ \mathrm{CNT},(m)-\mathrm{CoS}_{2} @ \mathrm{CNT},(p)-\mathrm{CoS}_{2} @ \mathrm{CNT}\right)$ via gas-sulfurization process with S powder at $400{ }^{\circ} \mathrm{C}$ ( $3 \mathrm{~h}, \mathrm{~N}_{2}$ flow). Among the Co-MOFs, Co-MOF 3 had the greatest Co-L-Co separation $(6.3 \AA$ for $1<8.9 \AA$ for $2<11.2 \AA$ for 3 ) and the largest lattice dimension, so the 3-derived carbon composite $\left((p)-\mathrm{Co} @ \mathrm{CNT}\right.$ and $\left.(p)-\mathrm{CoS}_{2} @ \mathrm{CNT}\right)$ showed larger pore sizes with hierarchical meso-/macroporositiy. As a result, the $(p)-\mathrm{CoS}_{2} @ \mathrm{CNT}$ showed many favorable properties for capacitive performance, such as 
hierarchical architecture, high graphitization $\left(I_{\mathrm{D}} / I_{\mathrm{G}}=0.83\right)$, suitable pore size distribution. It showed ultra-high capacitances ( $839 \mathrm{~F} \mathrm{~g}^{-1}$ at $5 \mathrm{mV} \mathrm{s}^{-1}$ and $825 \mathrm{~F} \mathrm{~g}^{-1}$ at $0.5 \mathrm{~A} \mathrm{~g}^{-1}$ ) and good rate capacities $\left(447 \mathrm{~F} \mathrm{~g}^{-1}\right.$ at $100 \mathrm{mV} \mathrm{s}^{-1}$ and $268 \mathrm{~F} \mathrm{~g}^{-1}$ at $10 \mathrm{~A} \mathrm{~g}^{-1}$ ) in $2 \mathrm{M} \mathrm{KOH}$.

Zhang et al. revealed that the solvents with different viscosities, i.e., $\mathrm{H}_{2} \mathrm{O}$ and ethylene glycol, used for the synthesis of Co-MOFs $\left([\mathrm{Co}(\mathrm{tdc})(\mathrm{bpy})]_{\mathrm{n}}\right.$, tdc $=$ thiophene-2,5-dicarboxylate, bpy $=4,4^{\prime}$-bipyridine) played a crucial role on several key features of the Co-MOFs, such as porosity, S/N ratio, size, and morphology, and the corresponding $\mathrm{Co}_{9} \mathrm{~S}_{8} @ \mathrm{~S}-/ \mathrm{N}$-co-doped carbons (Co958@SNCs) [161]. The Co-MOFs were synthesized in a mixed ligand system. Compared to 3D [Co(tdc)(bpy) $]_{n}$-bulk with irregular morphology prepared from $\mathrm{H}_{2} \mathrm{O}, 3 \mathrm{D}$ [Co(tdc)(bpy) $]_{\mathrm{n}}$-cuboid prepared from ethylene glycol showed uniform morphology because the role of more viscous ethylene glycol was a crystal growth stabilizer to inhibit the aggregation of seed crystals. After carbonization at $800{ }^{\circ} \mathrm{C}\left(2 \mathrm{~h}, \mathrm{~N}_{2}\right.$ flow $), \mathrm{Co}_{9} \mathrm{~S}_{8} @ S N C C$ derived from the $[\mathrm{Co}(\mathrm{tdc})(\mathrm{bpy})]_{\mathrm{n}}$-cuboid containing better properties $\left(I_{\mathrm{G}} / I_{\mathrm{D}}=1.03, \mathrm{~V}_{\text {pore }}=0.828 \mathrm{~cm}^{3} \mathrm{~g}^{-1}\right)$ than $\mathrm{Co}_{9} \mathrm{~S}_{8} @ S N C B$ derived from the $[\mathrm{Co}(\mathrm{tdc})(\mathrm{bpy})]_{\mathrm{n}}$-bulk. Therefore, in a $3 \mathrm{E}$ with $6 \mathrm{M} \mathrm{KOH}$ electrolyte, it yielded the capacitance as high as $429 \mathrm{~F} \mathrm{~g}^{-1}$ at $1 \mathrm{~A} \mathrm{~g}^{-1}$. The value measured at $50 \mathrm{~A} \mathrm{~g}^{-1}$ was $336 \mathrm{~F} \mathrm{~g}^{-1}$.

\subsubsection{Composites Containing Copper Sulfides}

Copper sulfides had many favorable properties as electrode materials such as high theoretical capacitance, cheap cost, green, and easy synthesis. With the introduction of a simple and concurrent carbonization-sulfidation process, HKUST-1 octahedrons, or $\mathrm{Cu}_{3}(\mathrm{btc})_{2}$, were converted into $\mathrm{Cu}_{1.96} \mathrm{~S}-\mathrm{C}$ composites with the preserved octahedral morphology [162]. In this process, ultrasmall $\mathrm{Cu}_{1.96} \mathrm{~S} \mathrm{NPs}$ with a dimension around $10 \mathrm{~nm}$ were homogeneously incorporated into the carbon octahedrons. Through the selection of optimal reaction temperature of $650{ }^{\circ} \mathrm{C}$, the resultant $\mathrm{Cu}_{1.96} \mathrm{~S} / \mathrm{C}-650$ $\left(\mathrm{V}_{\text {total }}=0.118 \mathrm{cc} \mathrm{g}^{-1}\right)$ showed high graphitization degree $\left(I_{\mathrm{D}} / I_{\mathrm{G}}=0.98\right)$ and micro-/mesoporous structures. It showed a high capacitance of $200 \mathrm{~F} \mathrm{~g}^{-1}$ at $0.5 \mathrm{~A} \mathrm{~g}^{-1}$. Another type of copper sulfide $\left(\mathrm{Cu}_{7} \mathrm{~S}_{4}\right)$ was embedded into carbon matrix via two-step treatment of the HKUST-1 [163]. In the first step, the HKUST-1 was directly carbonized at $650{ }^{\circ} \mathrm{C}\left(2 \mathrm{~h}, \mathrm{~N}_{2}\right.$ flow). In the following step, sulfidation of the carbonized sample was performed with thioacetamide (TAA) under hydrothermal condition at $120^{\circ} \mathrm{C}(6 \mathrm{~h})$. The obtained $\mathrm{Cu}_{7} \mathrm{~S}_{4} / \mathrm{C}$ nanocomposite with cobblestone-like polyhedral morphology had interconnected structure between amorphous carbon and $\mathrm{Cu}_{7} \mathrm{~S}_{4} \mathrm{NPs}$. Therefore, in a 3E mode with $1 \mathrm{M} \mathrm{H}_{2} \mathrm{SO}_{4}$ electrolyte, the $\mathrm{Cu}_{7} \mathrm{~S}_{4} / \mathrm{C}$ composite-based working electrode showed high capacitances and moderately good rate performance $\left(80.7 \mathrm{~F} \mathrm{~g}^{-1}\right.$ at $100 \mathrm{mV} \mathrm{s}^{-1}$ and $146.1 \mathrm{~F} \mathrm{~g}^{-1}$ at $5 \mathrm{~A} \mathrm{~g}^{-1}$ ).

\subsubsection{Composite Containing Indium Sulfides}

Huh et al. reported new porous carbon materials (PCMs) with uniform incorporation of indium sulfide NPs into carbon matrix [164]. After one-step carbonization of In-MOF ([ $\left.\left.\mathrm{Et}_{2} \mathrm{NH}_{2}\right]\left[\operatorname{In}(\mathrm{tdc})_{2}\right] \cdot \mathrm{DEF}\right)$ ( $2 \mathrm{~h}, \mathrm{~N}_{2}$ flow), the resultant PCMs showed concurrent incorporation of heteroatom dopants ( $\mathrm{S}$ and $\mathrm{N}$ ) and In-derived NPs (major species $=\operatorname{In}_{6} \mathrm{~S}_{7}$; minor species $=\mathrm{In}$ and $\mathrm{In}_{2} \mathrm{~S}_{3}$ ). Among the PCMs, PCM-900 carbonized at $900{ }^{\circ} \mathrm{C}$ showed the maximum values of surface area $\left(\mathrm{S}_{\text {micro }}=405 \mathrm{~m}^{2} \mathrm{~g}^{-1}\right)$, pore volume $\left(\mathrm{V}_{\text {total }}=0.40 \mathrm{~cm}^{3} \mathrm{~g}^{-1}, \mathrm{~V}_{\text {micro }}=0.21 \mathrm{~cm}^{3} \mathrm{~g}^{-1}\right)$, and Horváth-Kawazoe $(\mathrm{HK})$ pore size $(0.61 \mathrm{~nm})$. Thus, in a $3 \mathrm{E}$ system with $1 \mathrm{M} \mathrm{Na}_{2} \mathrm{SO}_{4}$ electrolyte, the PCM-900 electrode yielded maximum values of capacitance and energy density $\left(99.0 \mathrm{~F} \mathrm{~g}^{-1}\right.$ and $13.7 \mathrm{~W} \mathrm{~h} \mathrm{~kg}^{-1}$ at $\left.0.05 \mathrm{~A} \mathrm{~g}^{-1}\right)$ and good rate capability (78.0 $\mathrm{F} \mathrm{g}^{-1}$ at $10 \mathrm{~A} \mathrm{~g}^{-1}$ ).

\subsubsection{Composite Containing $\mathrm{MoS}_{2}$}

From the successive three-step process, i.e., exfoliation, ZIF-8 growth, and carbonization, $\mathrm{MoS}_{2} @ M P C$ with a coating of microporous carbons on the 2D MoS 2 nanosheets was synthesized [165]. As a first step, bulk $\mathrm{MoS}_{2}$ layered material was mechanically exfoliated under sonication and then multi-laminated $\mathrm{MoS}_{2}$ with 2D sheet architecture was prepared. Then, $\mathrm{MoS}_{2} @ Z$ ZIF-8 composite was produced via uniform growth of ZIF- 8 crystals on the exfoliated $\mathrm{MoS}_{2}$ nanosheets at room 
temperature (co-solvent volume ratio of $\mathrm{H}_{2} \mathrm{O}: \mathrm{EtOH}=1: 4$, mass ratio of $\mathrm{MoS}_{2}: \mathrm{Zn}(\mathrm{Ac})_{2} \cdot 2 \mathrm{H}_{2} \mathrm{O}: 2-\mathrm{MeIM}=$ 0.9:10:30). At the final step, the $\mathrm{MoS}_{2} @ Z \mathrm{ZIF}-8$ was converted into the $\mathrm{MoS}_{2} @ \mathrm{MPC}$ through a single-step carbonization at $900{ }^{\circ} \mathrm{C}(2 \mathrm{~h}$, Ar flow $)$. The obtained $\mathrm{MoS}_{2} @ \mathrm{MPC}$ nanocomposite consisted of pseudocapacitive 2D MoS 2 nanosheets and ZIF-8-derived amorphous MPC. The MPC shell was good for protection and conduction. Thus, in a $3 \mathrm{E}$ cell with $1 \mathrm{M} \mathrm{H}_{2} \mathrm{SO}_{4}$ electrolyte, it yielded capacitances of $189 \mathrm{~F} \mathrm{~g}^{-1}$ at $1 \mathrm{~A} \mathrm{~g}^{-1}$.

\subsubsection{Other Kinds}

Five $\mathrm{M}_{\mathrm{x}} \mathrm{S}_{\mathrm{y}} @ \mathrm{C}$ composites were synthesized from one-pot treatment (carbonization-sulfurization) of five MOFs with the same formula $[\mathrm{M}(\mathrm{pa})(\mathrm{bib})]_{\infty}\left(\mathrm{M}=\mathrm{Co}^{\mathrm{II}}, \mathrm{Zn}^{\mathrm{II}}, \mathrm{Cd}^{\mathrm{II}}, \mathrm{Ni}^{\mathrm{II}}\right.$, and $\mathrm{Cu}^{\mathrm{II}}$; pa $=$ phthalate $)[166]$. The five MOFs were transformed into the $\mathrm{M}_{\mathrm{x}} \mathrm{S}_{\mathrm{y}} @ \mathrm{C}$ composites with good incorporation metal sulfides via one-pot thermal treatment $\left(650{ }^{\circ} \mathrm{C}, 3 \mathrm{~h}, \mathrm{~N}_{2}\right.$ flow; MOF:S = 1:2). Among the three representative samples, i.e., $\mathrm{Cu}_{2} \mathrm{~S} @ \mathrm{C}, \mathrm{Co}_{9} \mathrm{~S}_{8} @ \mathrm{C}$, and $\mathrm{NiS}_{2} @ \mathrm{C}, \mathrm{NiS}{ }_{2} @ \mathrm{C}$ had high $\mathrm{S}_{\mathrm{BET}}$, large $\mathrm{V}_{\text {total }}\left(0.20 \mathrm{~cm}^{3} \mathrm{~g}^{-1}\right)$, improved graphitization degree due to the catalysis by Ni species, and high theoretical capacitance of $\mathrm{NiS}_{2}$. Thus, the $\mathrm{NiS}_{2} @ \mathrm{C}$ showed the best performance in a 3E configuration with $2 \mathrm{M} \mathrm{KOH}$ electrolyte. It exhibited ultra-high capacitances $\left(806 \mathrm{~F} \mathrm{~g}^{-1}\right.$ at $5 \mathrm{mV} \mathrm{s}^{-1}$ and $833 \mathrm{~F} \mathrm{~g}^{-1}$ at $0.5 \mathrm{~A} \mathrm{~g}^{-1}$ ) as well as good rate capabilities $\left(422 \mathrm{~F} \mathrm{~g}^{-1}\right.$ at $\left.100 \mathrm{mV} \mathrm{s}^{-1}\right)$.

\subsection{Carbon/Polymer Composites}

\subsubsection{Composites Containing Polyaniline}

Poor electric conductivity and low cycling stability of polyaniline (PANI)-based electrode faces problems and limitations despite its many desirable properties, such as high capacitance, cost-effective synthesis, and chemical stability. Therefore, Zn-MOF-derived carbon/PANI composite was prepared to overcome these limitations [167]. As a first step, Zn-MOF precursor was hydrothermally synthesized from zinc (II) acetate dihydrate and 8-hydroxyquinoline. After one-step carbonization at $800{ }^{\circ} \mathrm{C}\left(8 \mathrm{~h}, \mathrm{~N}_{2}\right.$ flow) followed by acid washing $(4 \mathrm{M} \mathrm{HCl})$, the Zn-MOF was converted into carbonized Zn-MOF. Then, the product composites of ZMP-X ( $\mathrm{X}=$ mass of the carbonized $\mathrm{Zn}-\mathrm{MOF}$ in $\mathrm{g}$ ) were generated through the polymerization of aniline under suspension of the carbonized Zn-MOF. The optimized composite of ZMP-0.04 (MOF-PANI-0.04) contained hierarchical sandwich-like layered structure composed of the PANI for the redox transition and the carbonized Zn-MOF for conducting and protecting carbon skeleton. Therefore, the ZMP-0.04 yielded a high capacitance of $500 \mathrm{~F} \mathrm{~g}^{-1}$ in $1 \mathrm{M} \mathrm{H}_{2} \mathrm{SO}_{4}$.

To prevent self-stacking of layered carbonaceous structure, another type of composite with a 3D core/shell structure was synthesized from ZIF-8 precursor by Yamauchi et al. [168]. First, nanoporous carbon core was derived from ZIF-8 through direct carbonization at $800{ }^{\circ} \mathrm{C}\left(4 \mathrm{~h}, \mathrm{~N}_{2}\right.$ flow $)$ and $\mathrm{HF}$ washing. Next, multifaceted core/shell carbon/PANI composite of SN ( $N=$ polymerization time in h) was produced after the polymerization of aniline on a surface of nanoporous carbon polyhedrons. The 1D PANI nanorod arrays showed uniformly perpendicular growth on the polyhedral carbon core surface under optimization of polymerization time $(3 \mathrm{~h})$. The former is helpful for conductivity while the latter is good for ionic diffusion. As a result, the optimized S3 sample showed high performance under $1 \mathrm{M} \mathrm{H}_{2} \mathrm{SO}_{4}$ electrolytic condition. It exhibited an ultra-high capacitance of $1100 \mathrm{~F} \mathrm{~g}^{-1}$ at $5 \mathrm{mV} \mathrm{s}^{-1}$ and a good rate capacity of $57 \%$ retention at $200 \mathrm{mV} \mathrm{s}^{-1}$.

The ZIF-8 carbon precursor was introduced to an interconnected PANI fiber/C composite with a 3D cross-linked structure [169]. The ZIF-8 precursor was directly carbonized at $800{ }^{\circ} \mathrm{C}\left(8 \mathrm{~h}, \mathrm{~N}_{2}\right.$ flow) and then washed with $4 \mathrm{M} \mathrm{HCl}$. The carbonized ZIF-8 was transformed into N-doped porous carbon via $\mathrm{KOH}$ activation (weight ratio of the carbonized ZIF-8 to $\mathrm{KOH}=1 / 3 ; 800{ }^{\circ} \mathrm{C}, 4 \mathrm{~h}, \mathrm{~N}_{2}$ flow) and acid treatment $(1 \mathrm{M} \mathrm{HCl})$. After the polymerization of aniline on the $\mathrm{N}$-doped porous carbon, the interconnected composite of PANI fiber/N-doped porous carbon named 3CPC was obtained. In the 3 CPC with high conductivity and $\mathrm{N}$ contents $(11.5 \%)$, the $\mathrm{N}$-doped carbon provided high surface area, and the PANI fiber offered structural stability as well as pseudocapacitance. Thus, in a 3E cell with $1 \mathrm{M}$ 
$\mathrm{H}_{2} \mathrm{SO}_{4}$ electrolyte, it showed an ultra-high capacitance and excellent rate performance $\left(618 \mathrm{~F} \mathrm{~g}^{-1}\right.$ at $\left.20 \mathrm{~A} \mathrm{~g}^{-1}\right)$.

\subsubsection{Composite Containing PEDOT}

There existed two N-doped porous carbon-based composites, i.e., Au@NC800 and NC800-PEDOT, to resolve the low capacitance or conductivity of ZIF-8-derived carbon (NC800) [170]. First, for the construction of the Au@NC800, $\mathrm{AuCl}_{4}$-@ZIF-8 suspended in an aqueous solution $(\mathrm{Au} / \mathrm{Zn}=0.1: 1)$ was reduced by $\mathrm{NaBH}_{4}$, and the obtained Au@ZIF-8 was carbonized at $800{ }^{\circ} \mathrm{C}\left(\mathrm{N}_{2}\right.$ flow). For the preparation of the NC800-PEDOT, ZIF-8 was also carbonized at $800{ }^{\circ} \mathrm{C}\left(\mathrm{N}_{2}\right.$ flow $)$ to produce the NC800, and the resultant NC800 was mixed with poly (3,4-ethylenedioxythiophene) nanotubes (PEDOT NTs) via sonication. Compared with bare NC800, the Au@NC800 had high ratio of $\left(\mathrm{V}_{\text {meso }}+\mathrm{V}_{\text {macro }}\right) / \mathrm{V}_{\text {micro }}$ (19.75), and the NC800-PEDOT contained large values of $S_{\text {BET }}$ and $V_{\text {total }}\left(1.55 \mathrm{~cm}^{3} \mathrm{~g}^{-1}\right)$. In a 3E in $1 \mathrm{M} \mathrm{NaCl}$ electrolyte, the specific capacitances at $5 \mathrm{mV} \mathrm{s}^{-1}$ of NC800, NC800-PEDOT, and Au@NC800 were $155.8,217.7$, and $171.7 \mathrm{~F} \mathrm{~g}^{-1}$, respectively. In addition, at $0.1 \mathrm{~A} \mathrm{~g}^{-1}$, the specific capacitances increased in the order of NC800 < Au@NC800 < NC800-PEDOT. Furthermore, both Au@NC800 and NC800-PEDOT exhibited lower values of internal resistance (IR)-drop at $0.1 \mathrm{~A} \mathrm{~g}^{-1}$ and ESR from EIS data than NPC 800. These results suggested that the incorporation of Au NPs or PEDOT NTs into ZIF-8-derived carbon could improve the conductivity and electrochemical performance.

\subsection{Carbon/LDH Composite}

Metal-based layered-double-hydroxides (LDHs) have many useful properties. They are relatively cheap, environmentally friendly, and highly redox-active. However, their self-aggregation tendency and low electric conductivity can often prevent their use as electrode materials. Therefore, to overcome these limitations, ZIF-8-C@NiAl-LDH composite was prepared from ZIF-8 precursor [171]. The ZIF-8-C was synthesized from the carbonization of the ZIF-8 at $900{ }^{\circ} \mathrm{C}(2 \mathrm{~h}$, Ar flow $)$ and acid etching. In a successive step, the ZIF-8-C was coated with ultrathin layers of $\mathrm{AlOOH}$ primer sol, then the obtained ZIF-8-C/AlOOH was stirred with $\mathrm{Ni}\left(\mathrm{NO}_{3}\right)_{2} \cdot 6 \mathrm{H}_{2} \mathrm{O}$ and urea. The mixed precursors were hydrothermally treated to give the ZIF-8-C@NiAl-LDH composite. With the incorporation of 2D NiAl-LDH into 3D nanoporous carbon polyhedrons, the resultant core/shell composite had hierarchical porosity (micro-/meso-/macropores), compact interaction between core and shell, and synergistic structure of the redox-active shell and core to provide surface area, conductivity, and structural stability. The composite exhibited a very high capacitance of $1370 \mathrm{~F} \mathrm{~g}^{-1}$ at $1 \mathrm{~A} \mathrm{~g}^{-1}$ in $1 \mathrm{M} \mathrm{KOH}$.

\subsection{Composites from Single-Carbon Sources}

The $\mathrm{Co}_{3} \mathrm{O}_{4}$ electrode had an ultra-high theoretical capacitance of $3560 \mathrm{~F} \mathrm{~g}^{-1}$, yet it showed low cycling stability and poor conductivity. Therefore, ZIF-67-derived carbon and graphene-like 2D $\mathrm{MoS}_{2}$ were employed as shell materials to enhance the electrochemical storage ability of $\mathrm{Co}_{3} \mathrm{O}_{4}$ through the formation of $\mathrm{Co}_{3} \mathrm{O}_{4} / \mathrm{C} @ M o S_{2}$ core/shell composite [172]. Initially, the ZIF-67 was converted into $\mathrm{Co} / \mathrm{C}$ through direct carbonization at $700{ }^{\circ} \mathrm{C}\left(5 \mathrm{~h}, \mathrm{~N}_{2}\right.$ flow $)$. The $\mathrm{Co}_{3} \mathrm{O}_{4} / \mathrm{C}$ was produced after calcination of $\mathrm{Co} / \mathrm{C}$ at $270{ }^{\circ} \mathrm{C}\left(15 \mathrm{~h}\right.$, in air). Subsequently, the solvothermal treatment of $\mathrm{Co}_{3} \mathrm{O}_{4} / \mathrm{C}$ with $\left(\mathrm{NH}_{4}\right)_{2} \mathrm{MoS}_{4}$ in DMF gave $\mathrm{Co}_{3} \mathrm{O}_{4} / \mathrm{C}_{\mathrm{MoS}}-\mathrm{n}$ ( $\mathrm{n}$ is the solvothermal treatment period in $\mathrm{h}$ ). The optimized product

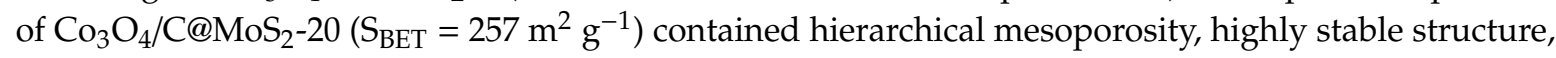
and good transfer abilities of electron and ion. As a result, it showed ultra-high capacitances of $1096 \mathrm{~F} \mathrm{~g}^{-1}$ at $5 \mathrm{mV} \mathrm{s}^{-1}$ and $1076 \mathrm{~F} \mathrm{~g}^{-1}$ at $1 \mathrm{~A} \mathrm{~g}^{-1}$ and outstanding rate performance of $840 \mathrm{~F} \mathrm{~g}^{-1}$ at $100 \mathrm{mV} \mathrm{s}^{-1}$ and $827 \mathrm{~F} \mathrm{~g}^{-1}$ at $10 \mathrm{~A} \mathrm{~g}^{-1}$ in $2 \mathrm{M} \mathrm{KOH}$.

To prevent the self-agglomeration, $2 \mathrm{D}$ nanosheets of $\mathrm{Ni}(\mathrm{OH})_{2}$ and $\mathrm{MnO}_{2}$ were incorporated into 3D carbon matrix to generate $3 \mathrm{D} \mathrm{Ni}(\mathrm{OH})_{2}-\mathrm{MnO}_{2} / \mathrm{C}$ composite with a hierarchically ordered structure [173]. The starting Ni-MOF precursor was synthesized at room temperature in an aqueous solution containing $\mathrm{NiCl}_{2} \cdot 6 \mathrm{H}_{2} \mathrm{O}, \mathrm{K}_{2} \mathrm{C}_{2} \mathrm{O}_{4}$, and ethylene diamine. The annealed Ni-MOF precursor at $300{ }^{\circ} \mathrm{C}\left(1 \mathrm{~h}, \mathrm{~N}_{2}\right.$ flow) was transformed into $\mathrm{Ni} @ \mathrm{C}$ via carbonization at $700{ }^{\circ} \mathrm{C}\left(2 \mathrm{~h}, \mathrm{~N}_{2}\right.$ flow $)$. Then, the Ni@C was 
hydrothermally oxidized with $\mathrm{KMnO}_{4}\left(150{ }^{\circ} \mathrm{C}, 24 \mathrm{~h}\right)$ to obtain the $\mathrm{Ni}(\mathrm{OH})_{2}-\mathrm{MnO}_{2} / \mathrm{C}$ composite. The resultant composite had a large accessible surface area from $2 \mathrm{D} \mathrm{Ni}(\mathrm{OH})_{2}$ and $\mathrm{MnO}_{2}$ nanosheets, highly active faradaic redox centers (major reaction: $\mathrm{Ni}(\mathrm{OH})_{2}+\mathrm{OH}^{-} \leftrightarrow \mathrm{NiOOH}+\mathrm{H}_{2} \mathrm{O}+\mathrm{e}^{-}$, minor reaction: $\mathrm{MnO}_{2}+\mathrm{K}^{+} \leftrightarrow \mathrm{MnOOK}+\mathrm{e}^{-}$), and improved electronic/ionic conductivities due to the synergistic effect between individual elements in $6 \mathrm{M} \mathrm{KOH}$ electrolyte. Therefore, this composite electrode delivered a capacitance of $862.0 \mathrm{~F} \mathrm{~g}^{-1}$, an energy density of $22.1 \mathrm{~W} \mathrm{~h} \mathrm{~kg}^{-1}$, and a power density of $430.0 \mathrm{~W} \mathrm{~kg}^{-1}$ at $2 \mathrm{~A} \mathrm{~g}^{-1}$ in $6 \mathrm{M} \mathrm{KOH}$. In addition, at $40 \mathrm{~A} \mathrm{~g}^{-1}$, it yielded the respective values of 574.0 $\mathrm{F} \mathrm{g}^{-1}$, $14.4 \mathrm{~W} \mathrm{~h} \mathrm{~kg}^{-1}$, and $8500.0 \mathrm{~W} \mathrm{~kg}^{-1}$. Moreover, using PVA/KOH gel electrolyte, solid-phase SSC with flexible and bendable stabilities showed a high volumetric capacitance of $530 \mathrm{mF} \mathrm{cm}^{-3}$ at a current density of $2.24 \mathrm{~mA} \mathrm{~cm}^{-3}$, and the highest energy density of $0.027 \mathrm{~mW} \mathrm{~h} \mathrm{~cm}^{-3}$ at a powder density of $0.672 \mathrm{~mW} \mathrm{~cm}^{-3}$ (Figure 12).
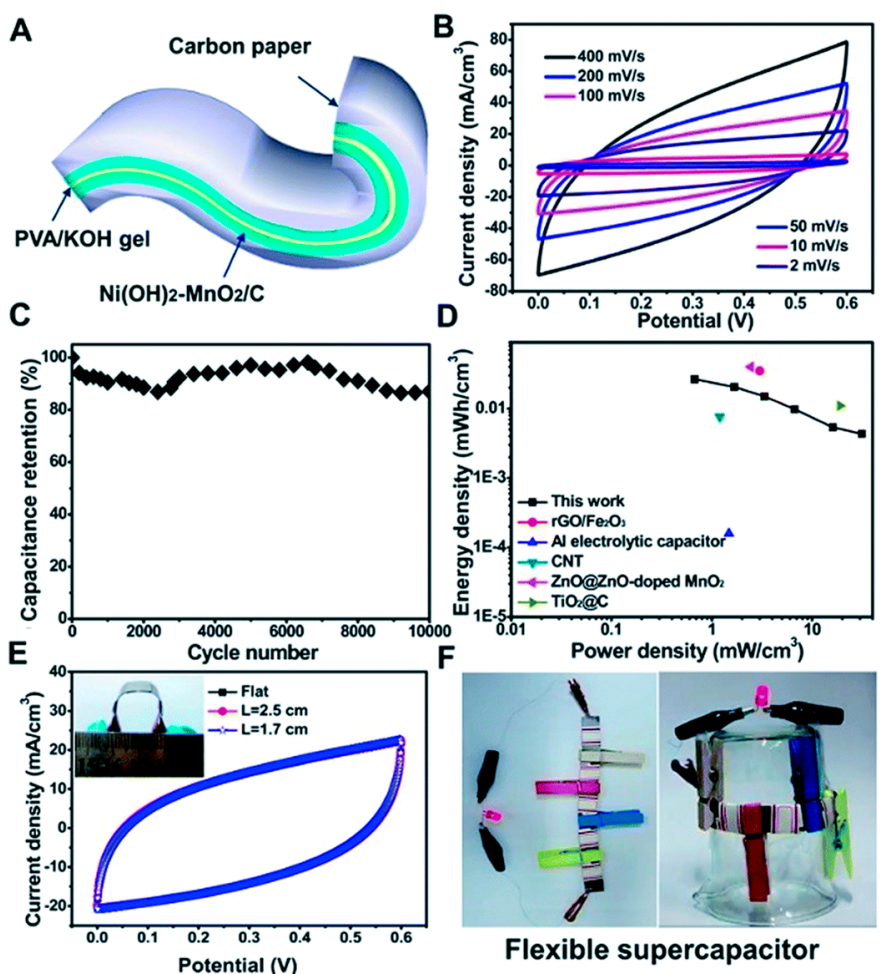

Figure 12. Electrochemical investigation of $\mathrm{Ni}(\mathrm{OH})_{2}-\mathrm{MnO}_{2} / \mathrm{C}$ composite-based flexible all-solid-phase supercapacitor cell. (A) Picture for the configuration of the assembled cell. (B) CV curves at various scan rates. (C) Cyclic performance at $11.2 \mathrm{~mA} \mathrm{~cm}^{-3}$. (D) Ragone plots. (E) $\mathrm{CV}$ curves at various bending conditions. Inset: photo for a bent cell. (F) Photos for a red LED brightened by tandem cells under the flat (left) and the bending condition (right) [173].

\subsection{Composites from Dual-Carbon Sources}

Hybrid ZIF-derived nanoporous functional composites (HZ-NPFCs) were synthesized via two-step thermal treatment of a $\mathrm{Co}^{2+}$ dominant hybrid Co/Zn-ZIF (HZ) [174]. With the introduction of a 2-fold higher amount of $\mathrm{Co}^{2+}$ ion than $\mathrm{Zn}^{2+}$ ion, the $\mathrm{HZ}$ precursor was prepared under mild conditions and subsequently transformed into hybrid ZIF-derived nanoporous carbon (HZ-NPC) through carbonization at $800{ }^{\circ} \mathrm{C}\left(5 \mathrm{~h}, \mathrm{~N}_{2}\right.$ flow $)$. The HZ-NPC had CNT and Co NPs. The HZ-NPC was further thermally oxidized in air for the generation of HZ-NPFC/X-Y $(X=$ oxidation temperature in ${ }^{\circ} \mathrm{C}, \mathrm{Y}=$ oxidation period in $\mathrm{h}$ ). After optimization of the oxidation conditions $\left(250{ }^{\circ} \mathrm{C}, 5 \mathrm{~h}\right)$, pseudocapacitive $\mathrm{Co}_{3} \mathrm{O}_{4}$, conductive elements (CNTs, CoNPs), and EDLC-active N-doped nanoporous carbon (NPC with micro-/mesoporosity) coexisted in HZ-NPFC/250-5. As a result, the HZ-NPFC/250-5 
electrode operating in the 3E mode in $6 \mathrm{M} \mathrm{KOH}$ showed capacitances of $545 \mathrm{~F} \mathrm{~g}^{-1}$ at $2 \mathrm{~A} \mathrm{~g}^{-1}$ and $180 \mathrm{~F} \mathrm{~g}^{-1}$ at $10 \mathrm{~A} \mathrm{~g}^{-1}$.

Cotton textile with high surface area was a cheap and effective natural carbon precursor. Thus, the dual-carbon source of HKUST-1 and T-shirt-derived cotton textile (TS) were employed for the synthesis of a helical and tubular hierarchical carbon composite, which contained $\mathrm{Cu}$ and $\mathrm{CuO}_{\mathrm{x}}(\mathrm{x}=1$ or 2) [175]. Initially, a carbon hybrid template of HKUST-1@TS was fabricated by 80-cycled liquid phase epitaxial (LPE) coating of the HKUST-1 on the TS. The TS was transformed into helical carbon tube, and the HKUST- 1 was converted into carbon film with incorporated $\mathrm{Cu}$ and $\mathrm{CuO}_{\mathrm{x}}$ during one-step carbonization of the hybrid template. The obtained hierarchical carbon composite (HKUST-1@TS-800) had pseudocapacitive sites, i.e., $\mathrm{Cu}$ and $\mathrm{CuO}_{\mathrm{x}}$, large electroactive surface area from the helical structure, and electrical conduction sites, i.e., $\mathrm{Cu}$ and tubular carbon structure. Therefore, in a $3 \mathrm{E}$ cell with $6 \mathrm{M}$ $\mathrm{KOH}$ electrolyte, the HKUST-1@TS-800 showed areal capacitances of $1812 \mathrm{mF} \mathrm{cm}^{-2}$ at $1 \mathrm{~mA} \mathrm{~cm}^{-2}$ and $510 \mathrm{mF} \mathrm{cm}^{-2}$ at $20 \mathrm{~mA} \mathrm{~cm}^{-2}$.

Like most other metal oxide-based electrode materials, low electric conductivity and poor ionic transfer kinetics are frequently encountered in the highly cost-effective electrode materials based on manganese oxide. Thus, using the Mn-MOF precursor, poly(styrene-co-AA) (PSA) spherical template and GO stabilizer, the 3D hollow composite of $\mathrm{Mn}_{3} \mathrm{O}_{4} @ \mathrm{~N}$-doped carbon/graphene (MCG) with ordered multilength scale porosity was prepared by two-step thermolysis [176]. The hybrid precursor of PSA@Mn-MOFs/GO-2 was prepared by ultra-sonification-agitation of the reaction mixture containing $\mathrm{MnCl}_{2}, \mathrm{PSA}, \mathrm{GO}$, and 2,3-pyridinedicarboxylic acid (2,3-pda), under controlled molar ratio $\left(\mathrm{Mn}^{2+} / 2,3-\mathrm{pda}=2\right)$. Then, the PSA@Mn-MOFs/GO-2 was carbonized at $500{ }^{\circ} \mathrm{C}(2 \mathrm{~h}$, Ar flow $)$ and subsequently stabilized in air at $150{ }^{\circ} \mathrm{C}(12 \mathrm{~h})$ to form MCG-2. The obtained MCG-2 contained high $\mathrm{N}$-dopant content (5.4 at\%), pseudocapacitive activity from the quaternary $\mathrm{N}-\mathrm{Q}$ site in carbon and $\mathrm{Mn}_{3} \mathrm{O}_{4}$, interconnected conducting system from $\mathrm{N}$-doped carbon and graphene, ordered hollow porosity of $\mathrm{N}$-doped carbon, and interlinked pores between $\mathrm{Mn}_{3} \mathrm{O}_{4} \mathrm{NPs}$ and $\mathrm{N}$-doped carbon. Therefore, the MCG-2 exhibited high capacitances.

A new hierarchical porous carbon composite (PMCP) by in situ polymerization of aniline on a carbon substrate for the preparation of integrated electrode with flexible and free-standing properties was synthesized via four-step treatment, i.e., thermal conversion, deposition, carbonization, and polymerization [177]. In the first step, electrospun polyamide acid (PAA) membrane was thermally transformed into polyimide (PI) nanofiber membrane. In the second step, ZIF-8 crystals were deposited on the electrospun PI nanofiber membrane. In the next step, the obtained PI/ZIF-8 membrane was carbonized to form PMC at $950{ }^{\circ} \mathrm{C}\left(5 \mathrm{~h}, \mathrm{~N}_{2}\right.$ flow). In the final step, vertically oriented PANI NW arrays were uniformly grown on the PMC substrate through the polymerization of aniline. Therefore, the PMCP was composed of several ideal components for better electrochemical performance: (i) ZIF-8-derived carbon for well-defined porosity, (ii) carbon nanofiber for conductive, stable, flexible, free-standing, and self-interconnection properties, and (iii) PANI NWs for conductive and pseudocapacitive features. Additionally, in the PMCP, the PANI chains had an infiltrated structure with hierarchical porous carbon-carbon nanofiber architecture and strong $\pi-\pi$ interaction with each other. As a result, $\mathrm{PMCP}$-based working electrode showed good performances in both $1 \mathrm{M} \mathrm{H}_{2} \mathrm{SO}_{4}$ aqueous electrolytic $3 \mathrm{E}$ cell and $\mathrm{PVA} / \mathrm{H}_{2} \mathrm{SO}_{4}$ gel electrolytic symmetric $2 \mathrm{E}$ cell. It delivered capacitances of $468.6 \mathrm{~F} \mathrm{~g}^{-1}$ at $0.1 \mathrm{~A} \mathrm{~g}^{-1}$ and $112 \mathrm{~F} \mathrm{~g}^{-1}$ at $5 \mathrm{~A} \mathrm{~g}^{-1}$ in the $3 \mathrm{E}$ cell. The flexible solid-phase SSC yielded a high volumetric capacitance of $1973 \mathrm{mF} \mathrm{cm}{ }^{-3}$, good bending stability, and cycling stability.

A new preparation of the complex composite of $\mathrm{CuO}_{\mathrm{x}} @ \mathrm{mC}_{700} @ \mathrm{PANI} @ \mathrm{rGO}$ started from Cu-btc MOF [178]. The MOF precursor was solvothermally synthesized and then carbonized at $700{ }^{\circ} \mathrm{C}(3 \mathrm{~h}$, $\mathrm{N}_{2}$ flow) to form $\mathrm{CuO}_{x} @ \mathrm{mC}_{700}$. The uniform octahedral $\mathrm{CuO}_{x} @ \mathrm{mC}_{700}$ particles with an ultra-high $\mathrm{Cu}$ content $(85 \%)$ was composed of the mesoporous carbon $\left(\mathrm{mC}_{700}\right)$ and $\mathrm{CuO}_{\mathrm{x}}$. Subsequently, well-arranged interfacial layers composed of PANI nanorods and rGO were formed on the surface of $\mathrm{CuO}_{\mathrm{x}} @ \mathrm{mC}_{700}$ composite after simultaneous treatments for polymerization and 3D-rGO incorporation. The former was beneficial for stability and pseudocapacitance while the latter was good for flexibility and 
conductivity. Thus, the resultant composite of $\mathrm{CuO}_{\mathrm{x}} @ \mathrm{mC}_{700} @ \mathrm{PANI} @ \mathrm{rGO}$ showed high capacitances of $569.4 \mathrm{~F} \mathrm{~g}^{-1}$ at $0.5 \mathrm{~A} \mathrm{~g}^{-1}$ and $408.2 \mathrm{~F} \mathrm{~g}^{-1}$ at $5 \mathrm{~A} \mathrm{~g}^{-1}$.

\subsection{The Asymmetic Supercapacitor (ASC)}

The electrochemical performances of carbon composite-based ASCs are depicted in Table 11. The textural information of the electrodes is given together to compare the surface area and their electrochemical capacitive properties.

Table 11. Electrochemical performances of the asymmetric supercapacitors (ASCs) based on carbon composites.

\begin{tabular}{|c|c|c|c|c|c|}
\hline Samples & $S_{\mathrm{BET}}\left(\mathrm{m}^{2} \mathrm{~g}^{-1}\right)$ & $C_{\max }\left(\mathrm{F} \mathrm{g}^{-1}\right)$ & $E_{\max }\left(\mathrm{Wh} \mathrm{kg} \mathrm{kg}^{-1}\right)$ & $P_{\max }\left(\mathrm{W} \mathrm{kg}^{-1}\right)$ & Ref. \\
\hline CNT@NiCo-LDH//CNT@NC & $-/ /-$ & 119.8 & 37.4 & - & 179 \\
\hline TN-NPCs//AQ-NPCs & $356 / / 268$ & 86 & 23.5 & $\sim 20,000$ & 180 \\
\hline $\mathrm{C} / \mathrm{CoO}-200 / / \mathrm{C}-300$ & $5 / / 145$ & 92 & 25.04 & 7000 & 181 \\
\hline Co@Carbon// $\mathrm{Co}_{3} \mathrm{O}_{4} @$ Carbon & $110 / / 24$ & 28.2 & 8.8 & 3000 & 182 \\
\hline $\mathrm{AC} / / \mathrm{Co}-\mathrm{ZIF}-450$ & $-/ /-$ & $4^{\mathrm{a}}$ & $1.32^{b}$ & $376^{c}$ & 183 \\
\hline MOXC-700//NPC & $181 / / 1757$ & 170 & 17.496 & - & 184 \\
\hline $\mathrm{S}-\alpha-\mathrm{Fe}_{2} \mathrm{O}_{3} @ \mathrm{C} / / \mathrm{Na}-\mathrm{MnO}_{2} \mathrm{NSs}$ & $117 / /-$ & $201.3^{d}$ & $135.3^{\mathrm{e}}$ & $21,998.4^{f}$ & 185 \\
\hline CF@NiCo-A-S//Fe $\mathrm{F}_{\mathrm{y}} @ \mathrm{CNS}$ & $-/ /-$ & $16.8^{\mathrm{g}}$ & 48.2 & 8300.0 & 186 \\
\hline $\mathrm{MnO}_{\mathrm{x}}-\mathrm{CSs}-600 / / \mathrm{AC}$ & $182 / /-$ & 61.1 & 27.5 & 5400 & 187 \\
\hline MNCMn60//MNC950 & $906 / / 920$ & - & 76.02 & 22,000 & 188 \\
\hline $\mathrm{AC} / / \mathrm{Mn}_{2} \mathrm{O}_{3} / \mathrm{C}$ & $-/ / 22$ & 166 & 54.9 & 22,680 & 189 \\
\hline $\mathrm{MnO}_{2} @ \mathrm{C}-\mathrm{NS} / / \mathrm{NPCS}$ & $45 / / 1292$ & $\sim 124$ & 166 & 3900 & 190 \\
\hline NQD-NC//AC & $268 / /-$ & - & 76.9 & 11,250 & 191 \\
\hline $\mathrm{NiCO}_{2} \mathrm{O}_{4}-\mathrm{NC} / / \mathrm{NC}$ & $126 / / 1823$ & 89 & 28 & 8500 & 192 \\
\hline $\mathrm{Cr}_{2} \mathrm{O}_{3} / \mathrm{C} / / \mathrm{Fe}_{\mathrm{x}} \mathrm{O}_{\mathrm{y}} / \mathrm{C}$ & $60 / / 68$ & 27.2 & 9.6 & 8000 & 193 \\
\hline CoNi@SNC//AC & $224 / /-$ & 156.7 & 55.7 & - & 194 \\
\hline $\mathrm{Cog}_{8} \mathrm{~S}_{8} / \mathrm{NS}-\mathrm{C}-1.5 \mathrm{~h} / / \mathrm{AC}$ & $66 / /-$ & 75.59 & 14.85 & 6818.18 & 195 \\
\hline $\mathrm{Co}_{9} \mathrm{~S}_{8} @ \mathrm{C}-500 / / \mathrm{AC}$ & $63 / /-$ & 166 & 58 & 17,200 & 196 \\
\hline Ni-Co-S@G//AC & $43 / /-$ & 217.8 & 51.0 & 11,700 & 197 \\
\hline $\mathrm{Ni}-\mathrm{Co}-\mathrm{S}-0.5 / \mathrm{NC} / / \mathrm{AC}$ & $10 / /-$ & 111.2 & 39.6 & 7910 & 198 \\
\hline CC/CNWAs@Ni@CoNi ${ }_{2} \mathrm{~S}_{4} / / \mathrm{AC}$ & $-\| /-$ & 151.3 & 53.8 & - & 199 \\
\hline $\mathrm{NiCo}_{2} \mathrm{~S}_{4}-\mathrm{Ni}_{9} \mathrm{~S}_{8}-\mathrm{C}$ DYMs//rGO gel & $62 / /-$ & 143.5 & 51.0 & 8004.4 & 200 \\
\hline $\mathrm{MnS} / \mathrm{MoS}_{2} / \mathrm{C} / / \mathrm{AC}$ & $8 / /-$ & 93 & 31.0 & 7722.2 & 201 \\
\hline $\mathrm{Ni}(\mathrm{OH})_{2} @ \mathrm{Co} / \mathrm{C} / / \mathrm{AC}$ & $-/ /-$ & 73.8 & 33.6 & $\sim 2000$ & 202 \\
\hline $\begin{array}{c}\mathrm{ZnO} \text { QDs/carbon/CNTs//N-doped } \\
\text { carbon/CNTs }\end{array}$ & $435 / / 600$ & 59 & 23.6 & 16,900 & 203 \\
\hline ZnO@C@CoNi-LDH//Fe $\mathrm{F}_{2} \mathrm{O}_{3} @ \mathrm{C}$ & $-1 /-$ & - & $1.078^{b}$ & $0.4^{\mathrm{h}}$ & 204 \\
\hline $\mathrm{C} / \mathrm{LDH} / \mathrm{S} / / \mathrm{CNTs}$ & $116 / /-$ & 194 & 39 & 7400 & 205 \\
\hline
\end{tabular}

\subsubsection{Carbon/Carbon Composites}

Using a flexible and conductive substrate of CNT film, a new binder-free ASC of CNT@NiCo-LDH//CNT@NC was fabricated from Co-MOF-derived working electrodes [179]. The positive electrode of Ni-Co-LDH on the CNT film (CNT@NiCo-LDH) was prepared by two steps. In the first step, Co-MOF (ZIF-67) was directly grown on the CNT substrate in aqueous medium to form CNT@Co-MOF nanosheets. In the second step, the CNT@Co-MOF was solvothermally treated in $\mathrm{Ni}\left(\mathrm{NO}_{3}\right) \cdot 6 \mathrm{H}_{2} \mathrm{O}$ ethanol solution at $120^{\circ} \mathrm{C}$ for $2 \mathrm{~h}$ to generate CNT@NiCo-LDH nanosheets. Also the negative electrode of N-doped carbon nanosheets on the CNT film (CNT@NC) was synthesized by carbonization of the CNT@Co-MOF at $500{ }^{\circ} \mathrm{C}\left(2 \mathrm{~h}, \mathrm{~N}_{2}\right.$ flow) and a subsequent treatment with $3 \mathrm{M} \mathrm{FeCl}_{3}$. The CNT@NC-based working electrode for the $3 \mathrm{E}$ cell in $6 \mathrm{M} \mathrm{KOH}$ delivered capacitances of $278.8 \mathrm{~F} \mathrm{~g}^{-1}$ at $2 \mathrm{~A} \mathrm{~g}^{-1}$ and $82 \mathrm{~F} \mathrm{~g}^{-1}$ at $10 \mathrm{~A} \mathrm{~g}^{-1}$. The CNT@NiCo-LDH//CNT@NC ASC exhibited capacitances of $119.8 \mathrm{~F} \mathrm{~g}^{-1}$ at $1 \mathrm{~A} \mathrm{~g}^{-1}$ and $53.3 \mathrm{~F} \mathrm{~g}^{-1}$ at $10 \mathrm{~A} \mathrm{~g}^{-1}$. The respective energy and power densities were $37.4 \mathrm{~W} \mathrm{~h} \mathrm{~kg}^{-1}$ and $750 \mathrm{~W} \mathrm{~kg}^{-1}$. All Ni-Co-LDH, NC, and CNTs had synergistic effects on the electrochemical performance of the ASC. The hollow and porous structure of nano-sized Ni-Co-LDH contributed to surface area. The NC provided high surface area and good conductivity. The CNTs also enhanced the conductivity and flexibility. 
Hu et al. synthesized ZIF-8-derived N-doped porous carbon materials (NPCs) and their modified composites functionalized with pseudocapacitive organic molecules [180]. The NPCs was prepared from ZIF-8 through carbonization at $800{ }^{\circ} \mathrm{C}\left(8 \mathrm{~h}, \mathrm{~N}_{2}\right.$ flow $)$ and acid etching $(1 \mathrm{M} \mathrm{HCl})$. The NPCs contained well-defined uniform shape of polyhedrons, high $\mathrm{S}_{\mathrm{BET}}$, large $\mathrm{V}_{\text {total }}\left(0.57 \mathrm{~cm}^{3} \mathrm{~g}^{-1}\right)$, micro-/mesoporosity, and good graphitization degree $\left(I_{\mathrm{D}} / I_{\mathrm{G}}=0.98\right)$. Thus, the NPCs were used as host materials to incorporate the redox-active organic molecules $(\mathrm{AQ}=$ anthraquinone; $\mathrm{NQ}=1,4$-naphthoquinone; $\mathrm{TCBQ}=$ tetrachlorobenzoquinone). The pseudocapacitive organic guests were implanted into the NPCs via noncovalent interactions through a simple evaporation of solvent. Due to the variable redox potentials of the guest molecules in $1 \mathrm{M} \mathrm{H}_{2} \mathrm{SO}_{4}$ electrolyte $(-0.09 \mathrm{~V}$ for $\mathrm{AQ}, 0.28 \mathrm{~V}$ for $\mathrm{NQ}$, and $0.53 \mathrm{~V}$ for TCBQ vs. SCE), self-matching performance of potential could be displayed in the ASC of TN-NPCs//AQ-NPCs, where TN-NPCs was a positive electrode containing both NQ and TCBQ. The negative electrode of AQ-NPCs composite ( $\mathrm{AQ}$ mass loading $=15.5 \%$; $\mathrm{D}_{\text {pore }}=2.96 \mathrm{~nm}$ ) exhibited a capacitance of $373 \mathrm{~F} \mathrm{~g}^{-1}$ at $1 \mathrm{~A} \mathrm{~g}^{-1}$ in a $3 \mathrm{E}$ cell with a potential window of $-0.4 \sim 0.2 \mathrm{~V}$. The positive electrode of TN-NPCs (NQ mass loading $=12.3 \%$; TCBQ mass loading $=1.2 \%$; $\mathrm{S}_{\mathrm{BET}}=356 \mathrm{~m}^{2} \mathrm{~g}^{-1}$; $D_{\text {pore }}=2.40 \mathrm{~nm}$ ) showed a capacitance of $392 \mathrm{~F} \mathrm{~g}^{-1}$ at $1 \mathrm{~A} \mathrm{~g}^{-1}$ with a potential window of $0.0 \sim 1.0 \mathrm{~V}$. In the ASC, satisfactory $\mathrm{H}^{+}$storage was achieved by similar porosity between the positive and negative electrodes. Moreover, the surface-controlled redox behavior was fast and reversible to facilitate the self-matching kinetics. Therefore, the ASC showed a capacitance of $86 \mathrm{~F} \mathrm{~g}^{-1}$ at $1 \mathrm{~A} \mathrm{~g}^{-1}$. The ASC delivered a superior maximum energy density of $23.5 \mathrm{~W} \mathrm{~h} \mathrm{~kg}^{-1}$ at $0.7 \mathrm{~kW} \mathrm{~kg}^{-1}$ compared to NPCs//NPCs (15.6 W h kg-1) and AC//AC (4.3 W h kg-1) SSCs.

\subsubsection{Carbon/Metal Oxide Composites}

Composites Containing Cobalt Oxides

The Co-MOF, $\left[\mathrm{Co}_{4}\right.$ (phen) $\left.{ }_{4} \mathrm{Cl}_{8}\right]$ (phen = 1,10-phenanthroline), was used as a sole precursor for the preparation of C/Co-200//C-300 ASC [181]. The Co-MOF precursor was synthesized under reflux condition at $160^{\circ} \mathrm{C}$ for $4 \mathrm{~h}$ with the help of PVP. Then, the positive electrode of $\mathrm{C} / \mathrm{CoO}-200$ was prepared by a single-step carbonization of the precursor at $200^{\circ} \mathrm{C}\left(1 \mathrm{~h}, \mathrm{~N}_{2}\right.$ flow). The resultant C/CoO-200 had mesoporous structure $\left(D_{\text {pore }}=5 \mathrm{~nm}, I_{\mathrm{D}} / I_{\mathrm{G}}=0.94\right), \mathrm{Cl} / \mathrm{O}$-dopants $(\mathrm{Cl}=1.9$ at $\%, \mathrm{O}=9.4 \mathrm{at} \%), \mathrm{CoO} \mathrm{NPs}$ $(\mathrm{Co}=1.9 \mathrm{at} \%)$ with no aggregation, and high carbon content $(86.8 \mathrm{at} \%)$. The $\mathrm{C} / \mathrm{CoO}-200$ showed a good oxygen affinity, so the favorable $\mathrm{OH}^{-}$adsorption could be displayed in the positive electrode. As a result, the C/CoO-200 electrode delivered large capacitances in $2 \mathrm{M} \mathrm{KOH}$. In addition, the negative electrode was obtained by carbonization at $300^{\circ} \mathrm{C}\left(1 \mathrm{~h}, \mathrm{~N}_{2}\right.$ flow) and subsequent acid treatment ( $3 \mathrm{M}$ $\mathrm{HCl})$. The product of $\mathrm{C} 300\left(I_{\mathrm{D}} / I_{\mathrm{G}}=0.99\right)$ also contained mesoporosity ( $\left.\mathrm{D}_{\text {pore }}=4 \mathrm{~nm}\right)$, O-dopant (13.4 at \%), high carbon content ( 86.6 at $\%)$, and a good affinity for oxygen. Therefore, the C300 showed capacitances of $207 \mathrm{~F} \mathrm{~g}^{-1}$ at $0.5 \mathrm{~A} \mathrm{~g}^{-1}$ and $81 \mathrm{~F} \mathrm{~g}^{-1}$ at $10 \mathrm{~A} \mathrm{~g}^{-1}$ under the same conditions. Finally, the ASC of C/Co-200//C-300 demonstrated capacitances of $92 \mathrm{~F} \mathrm{~g}^{-1}$ at $0.5 \mathrm{~A} \mathrm{~g}^{-1}$ and $64 \mathrm{~F} \mathrm{~g}^{-1}$ at $10 \mathrm{~A} \mathrm{~g}^{-1}$. The energy and power densities were $25.04 \mathrm{~W} \mathrm{~h} \mathrm{~kg}^{-1}$ at $350 \mathrm{~W} \mathrm{~kg}^{-1}$ and $17.4 \mathrm{~W} \mathrm{~h} \mathrm{~kg}^{-1}$ at $7000 \mathrm{~W} \mathrm{~kg}^{-1}$.

The ASC of Co@Carbon// $\mathrm{Co}_{3} \mathrm{O}_{4} @$ Carbon was assembled from the Co-bdc nanosheet-derived carbons [182]. The Co-bdc nanosheet self-sacrificing template was prepared by a layering method using $\mathrm{H}_{2}$ bdc and $\mathrm{Co}\left(\mathrm{CH}_{3} \mathrm{COO}\right)_{2} \cdot 4 \mathrm{H}_{2} \mathrm{O}$ dissolved in DMF and $\mathrm{CH}_{3} \mathrm{CN}$, respectively. Subsequently, this Co-bdc precursor with uniform morphology of parallelogram slice was transformed into the positive electrode of the ASC (Co@Carbon) via one-step carbonization at $700{ }^{\circ} \mathrm{C}\left(2 \mathrm{~h}, \mathrm{~N}_{2}\right.$ flow). In addition, the precursor was converted to the negative electrode of the $\mathrm{ASC}\left(\mathrm{Co}_{3} \mathrm{O}_{4} @ \mathrm{Carbon}\right)$ through a single-step pyrolysis at $400{ }^{\circ} \mathrm{C}\left(1 \mathrm{~h}, \mathrm{O}_{2}\right.$ flow $)$. Both electrodes had well-controlled hierarchical micro-/mesoporosity, uniform loading of Co-based NPs without aggregation, ultrathin carbon layer with laminated structure, and effective interfacial interaction between the carbon and Co-based NPs. As a result, good electrochemical performances of both electrodes were displayed in $6 \mathrm{M}$ $\mathrm{KOH}$ electrolyte. In a 3E cell, the Co@Carbon $\left(D_{\text {pore }}=9.6 \mathrm{~nm}\right)$ delivered capacitances of $109 \mathrm{~F} \mathrm{~g}^{-1}$ at $0.25 \mathrm{~A} \mathrm{~g}^{-1}$ and $52 \mathrm{~F} \mathrm{~g}^{-1}$ at $7 \mathrm{~A} \mathrm{~g}^{-1}$. Moreover, in the similar cell, the $\mathrm{Co}_{3} \mathrm{O}_{4} @$ Carbon showed 
capacitances of $261 \mathrm{~F} \mathrm{~g}^{-1}$ at $1 \mathrm{~A} \mathrm{~g}^{-1}$ and $50 \mathrm{~F} \mathrm{~g}^{-1}$ at $10 \mathrm{~A} \mathrm{~g}^{-1}$ due to efficient conducting network between the carbon and $\mathrm{Co}_{3} \mathrm{O}_{4}$ as a pseudocapacitive center. The ASC of Co@Carbon//Co $3 \mathrm{O}_{4} @$ Carbon showed capacitances of $28.2 \mathrm{~F} \mathrm{~g}^{-1}$ at $0.5 \mathrm{~A} \mathrm{~g}^{-1}$ and $8.9 \mathrm{~F} \mathrm{~g}^{-1}$ at $4 \mathrm{~A} \mathrm{~g}^{-1}$. The high voltage window of $1.5 \mathrm{~V}$ for the ASC was attributed to the ultrathin porous carbon layer.

Guo et al. reported ASCs of AC//Co-ZIF-X (X = carbonization temperature in $\left.{ }^{\circ} \mathrm{C}\right)$ [183]. The Co-ZIF nanocuboids were grown on carbon cloth via chemical bath deposition. The ZIF-67 nanocuboids were transformed into Co-ZIF-X by single-step carbonization ( $1 \mathrm{~h}$ under $\mathrm{N}_{2}$ ). In the case of Co-ZIF-450, conductive $\mathrm{Co}$ metal and redox-active cobalt oxides $\left(\mathrm{CoO}\right.$ and $\left.\mathrm{Co}_{3} \mathrm{O}_{4}\right)$ were effectively incorporated into nanoporous carbon networks. As a result, the Co-ZIF-450 electrode showed the best electrochemical properties among the Co-ZIF-X in $2 \mathrm{M} \mathrm{KOH}$. The Co-ZIF-450 exhibited good areal capacitances: $1177 \mathrm{mF} \mathrm{cm}^{-2}$ at $1 \mathrm{~mA} \mathrm{~cm}^{-2}$ and $640 \mathrm{mF} \mathrm{cm}^{-2}$ at $20 \mathrm{~mA} \mathrm{~cm}^{-2}$. The ASC of AC//Co-ZIF-450 had excellent volumetric capacitive properties: $4 \mathrm{~F} \mathrm{~cm}^{-3}$ at $1 \mathrm{~mA} \mathrm{~cm} \mathrm{~m}^{-2}, 2.15 \mathrm{~F} \mathrm{~cm}^{-3}$ at $40 \mathrm{~mA} \mathrm{~cm}^{-2}$, $1.32 \mathrm{~mW} \mathrm{~h} \mathrm{~cm}^{-3}$ at $9.4 \mathrm{~mW} \mathrm{~cm}^{-3}$, and $0.73 \mathrm{~mW} \mathrm{~h} \mathrm{~cm}^{-3}$ at $376 \mathrm{~mW} \mathrm{~cm}^{-3}$.

\section{Composites Containing Iron Oxides}

Dual precursors of btc-based MOF xerogels were used for the delicate and scalable synthesis of $\mathrm{Fe}_{3} \mathrm{O}_{4} / \mathrm{Fe} / \mathrm{C} / \mathrm{NPC}$ ASC (Figure 13) [184]. First, the polymerized MOF clusters formed nano-MOF particles (nMOFP). In addition, the MOF xerogels containing hierarchical porosity were formed by hetero-aggregated nMOFP. The MOX-Fe xerogel was prepared from MIL-100(Fe) and the MOX-Al xerogel from MIL-100(Al). MIL-100(Fe)-derived MOX-Fe was chosen as a precursor for the positive electrode due to appropriate features of Fe element, such as natural abundance, cheap cost, high conductivity, and redox-active properties. The positive electrode of MOXC-700 ( N = 3.97 at \%) was simply prepared via direct carbonization of the MOX-Fe xerogel at $700{ }^{\circ} \mathrm{C}(5 \mathrm{~h}, \mathrm{Ar}$ flow $)$. The resultant MOXC-700 was composed of thin carbon layer with hierarchical porosity ( $D_{\text {pore }}=1.2$ and $12 \mathrm{~nm}$ ) and uniformly dispersed $\mathrm{Fe}_{3} \mathrm{O}_{4} / \mathrm{Fe}$ NPs. The carbon layer played a role of maintaining structural stability and the $\mathrm{Fe}_{3} \mathrm{O}_{4} / \mathrm{Fe}$ NPs were beneficial for electrochemical performance due to their redox activities of $\mathrm{Fe} / \mathrm{Fe}^{2+}$ and $\mathrm{Fe}^{2+} / \mathrm{Fe}^{3+}$. Therefore, the MOXC-700 exhibited excellent electrochemical performance $\left(600 \mathrm{~F} \mathrm{~g}^{-1}\right.$ at $1 \mathrm{~A} \mathrm{~g}^{-1}, 500 \mathrm{~F} \mathrm{~g}^{-1}$ at $\left.8 \mathrm{~A} \mathrm{~g}^{-1}\right)$ and outstanding cycling stability. The negative electrode of $\mathrm{NPC}$ was prepared by carbonization of the MOX-Al at $1000{ }^{\circ} \mathrm{C}(5 \mathrm{~h}, \mathrm{Ar})$ and subsequent $6 \mathrm{M} \mathrm{KOH}$ solution-driven green activation. The obtained 3D NPC $\left(\mathrm{V}_{\text {pore }}=1.95 \mathrm{cc} \mathrm{g}^{-1}, \mathrm{~N}=1 \%\right)$ had hierarchically interconnected porous structure $\left(\mathrm{D}_{\text {pore }}=1.2\right.$ and $\left.5.8 \mathrm{~nm}\right)$. As a result, it showed high rate capability with capacitances of $272 \mathrm{~F} \mathrm{~g}^{-1}$ at $2 \mathrm{mV} \mathrm{s}^{-1}$ and $207 \mathrm{~F} \mathrm{~g}^{-1}$ at $250 \mathrm{mV} \mathrm{s}^{-1}$. The ASC of MOXC-700//NPC was fabricated with a controlled mass ratio of $\mathrm{m}_{+} / \mathrm{m}_{-}=0.42$, and the cell operated effectively in $6 \mathrm{M}$ $\mathrm{KOH}$ electrolyte. It delivered capacitances of $170 \mathrm{~F} \mathrm{~g}^{-1}$ at $1 \mathrm{~A} \mathrm{~g}^{-1}$ and $105 \mathrm{~F} \mathrm{~g}^{-1}$ at $6 \mathrm{~A} \mathrm{~g}^{-1}$.

A novel $\mathrm{Fe}_{2} \mathrm{O}_{3}$-based anode material for fiber shaped ASC was reported [185]. Due to low conductivity and poor ionic diffusion rate, a simple $\mathrm{Fe}_{2} \mathrm{O}_{3}$-based electrode had limitations to practical application despite its many favorable properties. $\mathrm{Fe}_{2} \mathrm{O}_{3}$ is a cheap, green, and highly abundant resource with high theoretical capacitance and broad operating voltage window. Therefore, $\mathrm{S}-\alpha-\mathrm{Fe}_{2} \mathrm{O}_{3} @ \mathrm{C}$ composite derived from MIL-88-Fe was used as an anode for ASC of S- $\alpha-\mathrm{Fe}_{2} \mathrm{O}_{3} @ \mathrm{C} / \mathrm{OCNTF} / / \mathrm{Na}-\mathrm{MnO} 2$ NSs/CNTF. The oxidized carbon nanotube fibers (OCNTFs) were prepared by electrochemical oxidation of CNTFs $\left(0.8 \mathrm{M} \mathrm{H}_{2} \mathrm{SO}_{4}, 1 \sim 2 \mathrm{~V}, 25 \mathrm{mV} \mathrm{s}^{-1}, 15\right.$ cycles $)$ and used as a substrate for anode. CNTFs contain light weight, flexibility, good conductivity, and mechanical robustness. After that, the MIL-88-Fe was grown on the substrate and then pyrolyzed in air at $350{ }^{\circ} \mathrm{C}(2 \mathrm{~h})$ to form the S- $\alpha-\mathrm{Fe}_{2} \mathrm{O}_{3} @ \mathrm{C} / \mathrm{OCNTF}$. The $\mathrm{S}-\alpha-\mathrm{Fe}_{2} \mathrm{O}_{3} @ \mathrm{C}$ showed spindle-like structure and mesoporosity $\left(\mathrm{D}_{\text {pore }}=19.2 \mathrm{~nm}\right)$. As the result of improved interfacial compatibility between $S-\alpha-\mathrm{Fe}_{2} \mathrm{O}_{3} @ \mathrm{C}$ and OCNTF, the S- $\alpha-\mathrm{Fe}_{2} \mathrm{O}_{3} @ \mathrm{C} / \mathrm{OCNTF}$ yielded a large areal capacitance of $1232.4 \mathrm{mF} \mathrm{cm}^{-2}$ at $2 \mathrm{~mA} \mathrm{~cm}^{-2}$ and $63 \%$ rate capacity at $20 \mathrm{~mA} \mathrm{~cm}^{-2}$ in $1 \mathrm{M} \mathrm{Na}_{2} \mathrm{SO}_{4}$ electrolyte. Furthermore, the ASC of $\mathrm{S}-\alpha-\mathrm{Fe}_{2} \mathrm{O}_{3} @ \mathrm{C} / \mathrm{OCNTF} / / \mathrm{Na}-\mathrm{MnO}_{2}$ showed good performance in $\mathrm{Na}_{2} \mathrm{SO}_{4}-\mathrm{CMC}$ gel electrolyte ( $\mathrm{CMC}=$ carboxymethyl cellulose sodium). It delivered areal capacitances of $201.3 \mathrm{mF} \mathrm{cm}^{-2}$ at $2 \mathrm{~mA} \mathrm{~cm}^{-2}$ and $136.4 \mathrm{mF} \mathrm{cm}^{-2}$ at $20 \mathrm{~mA} \mathrm{~cm}^{-2}$. The areal energy and power densities were $135.3 \mu \mathrm{W} \mathrm{h} \mathrm{cm}{ }^{-2}$ at $2199.9 \mu \mathrm{W} \mathrm{cm}^{-2}$, and $91.7 \mu \mathrm{W} \mathrm{h} \mathrm{cm}{ }^{-2}$ at $21998.4 \mu \mathrm{W} \mathrm{cm}^{-2}$. 


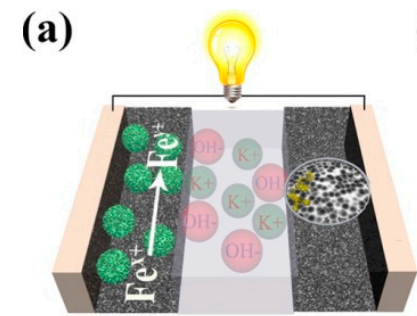

(c)

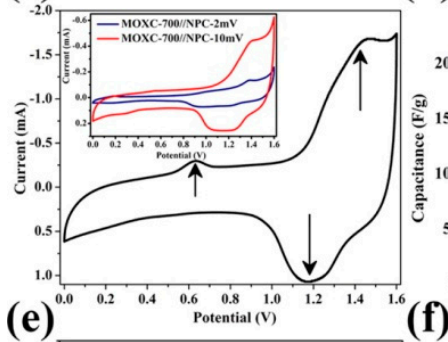

(b)

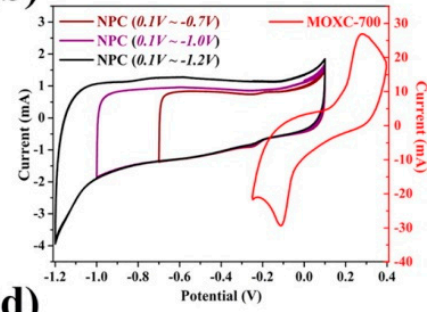

(d)

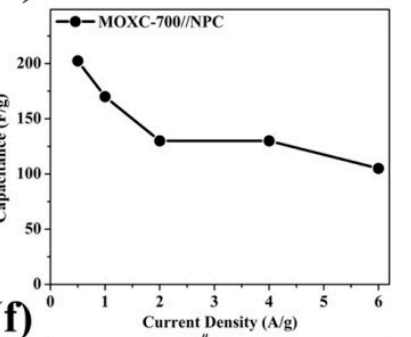

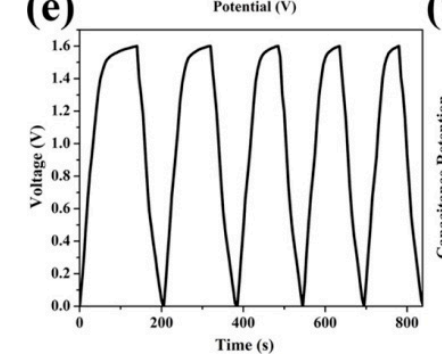

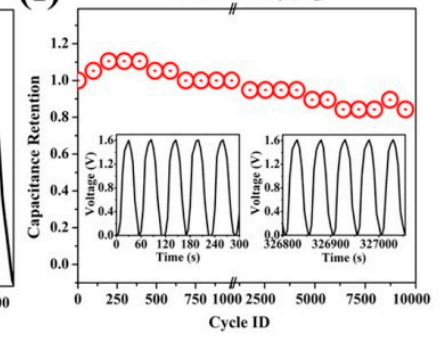

Figure 13. Schematic explanation of MOXC-700//NPC device in $6 \mathrm{M} \mathrm{KOH}$ electrolyte: (a) view of assembly, (b) comparative CV curves of positive and negative electrodes, (c) CV curves of the device, (d) capacitances of the device at different current loads, (e) charge-discharge curve of the device for the first five cycles, and (f) cycling performance for the device [184].

ZIF-8 and ZIF-67 were employed as starting precursors for the electrode materials of CF@NiCo-A-S//Fe $\mathrm{O}_{\mathrm{y}} @ \mathrm{CNS}$ ASC by Shi et al. [186]. First, 2D ZIF-8 precursor was transformed into carbon nanosheets (CNS) via direct carbonization at $930{ }^{\circ} \mathrm{C}(2 \mathrm{~h}, \mathrm{Ar}$ flow $)$. After that, the CNS were mixed with $\left(\mathrm{NH}_{4}\right)_{2} \mathrm{Fe}\left(\mathrm{SO}_{4}\right)_{2} / \mathrm{DMF}$ solution and followed by a brief calcination at $550{ }^{\circ} \mathrm{C}$ (30 min, Ar flow) to produce $\mathrm{Fe}_{\mathrm{x}} \mathrm{O}_{\mathrm{y}} @ \mathrm{CNS}$. The $\mathrm{Fe}_{\mathrm{x}} \mathrm{O}_{\mathrm{y}} @ \mathrm{CNS}$ electrode yielded an energy density of $30.3 \mathrm{~mA} \mathrm{~h} \mathrm{~g}{ }^{-1}$ at $1 \mathrm{~A} \mathrm{~g}^{-1}$ and $66 \%$ rate retention $\left(20.6 \mathrm{~mA} \mathrm{~h} \mathrm{~g}^{-1}\right)$ at $20 \mathrm{~A} \mathrm{~g}^{-1}$ in a $3 \mathrm{E}$ cell with $3 \mathrm{M} \mathrm{KOH}$ electrolyte. The fabrication of cathode material was started from ZIF-67 crystal growth on carbon fibers (CF@Co-MOF). Then, the CF@Co-MOF was ion-exchanged with $\mathrm{Ni}\left(\mathrm{NO}_{3}\right)_{2} \cdot 6 \mathrm{H}_{2} \mathrm{O}$ and thermally treated with at $120^{\circ} \mathrm{C}(2 \mathrm{~h})$ to produce $\mathrm{CF} @ \mathrm{NiCo}-\mathrm{LDH}$. After that, the $\mathrm{CF} @ \mathrm{NiCo}-\mathrm{LDH}$ nanosheets were converted into CF@NiCo-A through a reduction process at $250{ }^{\circ} \mathrm{C}\left(30 \mathrm{~min}, 10 \mathrm{vol} \% \mathrm{H}_{2} / \mathrm{Ar}\right.$ flow $)$. Finally, the cathode of $\mathrm{CF} @ \mathrm{NiCo}-\mathrm{A}-\mathrm{S}$ was prepared by the hydrothermal vulcanization of $\mathrm{CF} @ \mathrm{NiCo}-\mathrm{A}$ in the presence of TAA at $120{ }^{\circ} \mathrm{C}$ for $3 \mathrm{~h}$. In the same electrolyte, the ASC of CF@NiCo-A-S//Fe $\mathrm{O}_{\mathrm{y}} @ \mathrm{CNS}$ showed energy densities of $16.8 \mathrm{~mA} \mathrm{~h} \mathrm{~g}^{-1}$ at $1 \mathrm{~A} \mathrm{~g}^{-1}, 11.3 \mathrm{~mA} \mathrm{~h} \mathrm{~g}{ }^{-1}$ at $10 \mathrm{~A} \mathrm{~g}^{-1}, 48.2 \mathrm{~W} \mathrm{~h} \mathrm{~kg}^{-1}$ at $840.0 \mathrm{~W} \mathrm{~kg}^{-1}$, and $32.3 \mathrm{~W} \mathrm{~h} \mathrm{~kg}^{-1}$ at $8300.0 \mathrm{~W} \mathrm{~kg}^{-1}$.

\section{Composites Containing Manganese Oxides}

Manganese oxides also possess many favorable features to enhance electrochemical performance, such as high theoretical capacitance, cheap cost, and natural abundance. Nevertheless, they usually showed poor rate and cycling performance owing to unfavorable characteristics, such as low conductivity, large volume change, and partial dissolution in electrolytes. In this sense, Mn-bdc-derived composite of $\mathrm{MnO}_{\mathrm{x}}$-CSs- 600 was used as both working electrode of the 3E cell and the cathode of ASC in $1.0 \mathrm{M} \mathrm{Na}_{2} \mathrm{SO}_{4}$ electrolyte [187]. The Mn-bdc MOF precursor was synthesized from DMF solution containing $\mathrm{Mn}(\mathrm{Ac})_{2} \cdot 6 \mathrm{H}_{2} \mathrm{O}$ and $\mathrm{H}_{2}$ bdc with the help of $\mathrm{PVP}$ at room temperature. It was converted 
to the $\mathrm{MnO}_{\mathrm{x}}$-CSs-600 via one-step carbonization at $600{ }^{\circ} \mathrm{C}\left(2 \mathrm{~h}, 5 \mathrm{vol} \% \mathrm{H}_{2} / \mathrm{Ar}\right.$ flow $)$. In the obtained composite with $\mathrm{S}_{\mathrm{BET}}$ of $182.3 \mathrm{~m}^{2} \mathrm{~g}^{-1}$, numerous $\mathrm{MnO}_{\mathrm{x}}$ particles $\left(\mathrm{Mn}_{3} \mathrm{O}_{4}: \mathrm{MnO}=70.6: 29.4\right)$ were evenly distributed throughout the 2D ultrathin carbon sheet architecture without self-aggregation. As a result, the enhancements of electrical conductivity, structural stability, and defects formation could be accomplished by strong combined effects of each element in the composite. The working electrode showed capacitances of $220 \mathrm{~F} \mathrm{~g}^{-1}$ at $1 \mathrm{~A} \mathrm{~g}^{-1}$ and $106 \mathrm{~F} \mathrm{~g}^{-1}$ at $8 \mathrm{~A} \mathrm{~g}^{-1}$. $\mathrm{MnO}_{\mathrm{x}}-\mathrm{CSc}-600 / / \mathrm{AC}$ ASC delivered capacitances of $61.1 \mathrm{~F} \mathrm{~g}^{-1}$ at $0.25 \mathrm{~A} \mathrm{~g}^{-1}$ and $26.7 \mathrm{~F} \mathrm{~g}^{-1}$ at $6 \mathrm{~A} \mathrm{~g}^{-1}$.

The MOF-derived nanoporous carbon composite $\left(\mathrm{MOF}-\mathrm{NPC} / \mathrm{MnO}_{2}\right)$ was used for the fabrication of an ASC by Zhao et al. [188]. The best negative electrode of MNC950 was synthesized via carbonization of ZIF-8 at $950^{\circ} \mathrm{C}\left(5 \mathrm{~h}, \mathrm{~N}_{2}\right.$ flow $)$ and $\mathrm{HCl}$ washing. In addition, the best positive electrode of $\mathrm{MNCMn} 60$ was prepared by the reaction of $\mathrm{MNC} 950$ with $\mathrm{KMnO}_{4}$ solution for 60 min and subsequent $\mathrm{H}_{2} \mathrm{O}$ washing. Although $\mathrm{MnO}_{2}$ nanodots were confined in the pores of $\mathrm{MNC} 950$, both electrodes showed similar surface areas, $920 \mathrm{~m}^{2} \mathrm{~g}^{-1}$ for MNC950 and $906 \mathrm{~m}^{2} \mathrm{~g}^{-1}$ for MNCMn60. As a working electrode for the 3E cell in $1 \mathrm{M} \mathrm{H}_{2} \mathrm{SO}_{4}$ electrolyte, the MNCMn60 showed better maximum specific capacitance of $163 \mathrm{~F} \mathrm{~g}^{-1}$ than that of MNC950 (146 F g $\left.{ }^{-1}\right)$ due to additional pseudocapacitance provided by the $\mathrm{MnO}_{2}$. It also exhibited ultra-high rate performance up to $5 \mathrm{~A} \mathrm{~g}^{-1}\left(120 \mathrm{~F} \mathrm{~g}^{-1}\right)$. The ASC of MNCMn60//MNC950 operated in the same electrolyte with appropriate mass ratio (MNCMn60:MNC950 = 1:0.90).

$\mathrm{Mn}$-btc was introduced for the synthesis of $\mathrm{Mn}_{2} \mathrm{O}_{3} / \mathrm{C}$ composite [189]. The Mn-btc was transformed into the $\mathrm{Mn}_{2} \mathrm{O}_{3} / \mathrm{C}$ composite via a single-step carbonization at $500{ }^{\circ} \mathrm{C}(2 \mathrm{~h})$. The obtained $\mathrm{Mn}_{2} \mathrm{O}_{3} / \mathrm{C}$ $\left(\mathrm{V}_{\text {total }}=0.2442 \mathrm{~cm} \mathrm{~g}^{-1}, \mathrm{D}_{\text {pore }}=9.5 \mathrm{~nm}\right)$ contained interconnected porous network ideal for electron transfer and generation of electrochemical active sites, rectangular bar-shaped microstructure, and effective carbon coating on the $\mathrm{Mn}_{2} \mathrm{O}_{3}$ particles for prevention of dissolution and contribution of ionic adsorption. The composite yielded capacitances of $553 \mathrm{~F} \mathrm{~g}^{-1}$ at $5 \mathrm{mV} \mathrm{s}^{-1}$ and $273 \mathrm{~F} \mathrm{~g}^{-1}$ at $50 \mathrm{mV} \mathrm{s}^{-1}$, $776 \mathrm{~F} \mathrm{~g}^{-1}$ at $1 \mathrm{~A} \mathrm{~g}^{-1}$, and $125 \mathrm{~F} \mathrm{~g}^{-1}$ at $20 \mathrm{~A} \mathrm{~g}^{-1}$ in $1.0 \mathrm{M} \mathrm{Na}_{2} \mathrm{SO}_{4}$ electrolyte. The ASC of $\mathrm{AC} / / \mathrm{Mn}_{2} \mathrm{O}_{3} / \mathrm{C}$ was operable in the same electrolyte with a controlled mass ratio of $\mathrm{m}_{+} / \mathrm{m}_{-}=3.936$. It delivered capacitances of $166 \mathrm{~F} \mathrm{~g}^{-1}$ at $5 \mathrm{mV} \mathrm{s}^{-1}, 87 \mathrm{~F} \mathrm{~g}^{-1}$ at $50 \mathrm{mV} \mathrm{s}^{-1}, 122 \mathrm{~F} \mathrm{~g}^{-1}$ at $2.5 \mathrm{~A} \mathrm{~g}^{-1}$, and $28 \mathrm{~F} \mathrm{~g}^{-1}$ at $25 \mathrm{~A} \mathrm{~g}^{-1}$.

[Mn(1,4-ndc)] n was used as a precursor for anode of Li-HEC [190]. The precursor was hydrothermally synthesized from $\mathrm{MnCl}_{2} \cdot 4 \mathrm{H}_{2} \mathrm{O}$ and 1,4-ndc in the basic $\mathrm{KOH}$ solution at $180{ }^{\circ} \mathrm{C}$ (72 h). Subsequently, it was converted to $\mathrm{MnO}_{2} @ \mathrm{C}-\mathrm{NS}$ via direct carbonization at $800{ }^{\circ} \mathrm{C}\left(6 \mathrm{~h}, \mathrm{~N}_{2}\right.$ flow). The resultant $\mathrm{MnO}_{2} @ \mathrm{C}-\mathrm{NS}$ was consisted of homogeneously dispersed $\mathrm{MnO}_{2}$ nanocrystals (45 wt.\%) and ultrathin carbon nanosheets with graphene-like structure with porosity and conductivity $\left(\mathrm{S}_{\mathrm{BET}}=45 \mathrm{~m}^{2} \mathrm{~g}^{-1}, \mathrm{~S}_{\text {Langmuir }}=65 \mathrm{~m}^{2} \mathrm{~g}^{-1}\right)$. The carbon nanosheets acted as a structural substrate. Moreover, it showed large $\mathrm{V}_{\text {pore }}\left(1.09 \mathrm{~cm}^{3} \mathrm{~g}^{-1}\right)$, laminated structure, and meso-/macroporosity as well. The precursor of cathode (K-MOF) was prepared from btc, $\mathrm{KNO}_{3}$, and $\mathrm{NH}_{4} \mathrm{~F}$. Then, the cathode of $2 \mathrm{D}$ ultrathin nanoporous carbon nanosheets (NPCS) was obtained by single-step carbonization at $800{ }^{\circ} \mathrm{C}\left(8 \mathrm{~h}, \mathrm{~N}_{2}\right)$ and acid etching $(5 \mathrm{wt} . \% \mathrm{HCl})$. The cathode had 2D-layered structure, conductive network, high $\mathrm{S}_{\mathrm{BET}}$, and large $\mathrm{V}_{\text {pore }}\left(1.06 \mathrm{~cm}^{3} \mathrm{~g}^{-1}\right)$. Thus, under $1 \mathrm{M} \mathrm{LiPF}_{6}$ in EC/DMC (1:1) electrolyte, the Li-HEC of $\mathrm{MnO}_{2} @ \mathrm{C}-\mathrm{NS} / / \mathrm{NPCS}$ showed energy and power densities of $129 \mathrm{~mA} \mathrm{~h} \mathrm{~g}^{-1}\left(\sim 124 \mathrm{~F} \mathrm{~g} \mathrm{~g}^{-1}\right)$ at $0.45 \mathrm{~A} \mathrm{~g}^{-1}, 166 \mathrm{~W} \mathrm{~h} \mathrm{~kg}^{-1}$ at $550 \mathrm{~W} \mathrm{~kg}^{-1}, 49.3 \mathrm{~W} \mathrm{~h} \mathrm{~kg}^{-1}$ at $3.9 \mathrm{~kW} \mathrm{~kg}^{-1}$.

\section{Other Kinds}

$\mathrm{Nb}_{2} \mathrm{O}_{5}$ is a promising anode material for Li-HEC due to its high theoretical capacity ( 200 mA h g $\left.{ }^{-1}\right)$, long-term cycling stability, and fast rate of charge. Nonetheless, its application was restricted by poor electric conductivity $\left(3 \times 10^{-6} \mathrm{~S} \mathrm{~cm}^{-1}\right)$ and difficulty in controlling the crystal structure. Thus, Liang et al. reported a new anode material of NQD-NC, which was composed of orthorhombic phase of $\mathrm{Nb}_{2} \mathrm{O}_{5}$ quantum dots (QDs) and ZIF-8-derived N-doped porous carbon (NC) [191]. The NC was prepared by carbonization of rhombic dodecahedral ZIF-8 crystals at $900{ }^{\circ} \mathrm{C}$ ( $4 \mathrm{~h}, \mathrm{Ar}$ flow) and acid etching $(2 \mathrm{M} \mathrm{HCl})$. The NC was introduced to niobium oxalate aqueous solution, and then hydrothermally transformed at $180{ }^{\circ} \mathrm{C}$ for $12 \mathrm{~h}$. Subsequently, one-step carbonization of the 
hydrothermally synthesized product at $700{ }^{\circ} \mathrm{C}(4 \mathrm{~h}, \mathrm{Ar}$ flow $)$ generated the NQD-NC. The obtained NQD-NC $(C=10 \mathrm{wt} . \%, \mathrm{~N}=1.23 \mathrm{wt} . \%)$ had microporosity ( $\left.D_{\text {pore }}=1 \sim 2 \mathrm{~nm}\right)$, mesoporosity, high $\mathrm{S}_{\mathrm{BET}}\left(268 \mathrm{~m}^{2} \mathrm{~g}^{-1}\right)$, large $\mathrm{V}_{\text {pore }}\left(0.413 \mathrm{~cm}^{3} \mathrm{~g}^{-1}\right)$, and Li-insertion center for the following reaction: $\mathrm{Nb}_{2} \mathrm{O}_{5}+x \mathrm{Li}^{+}+x \mathrm{e}^{-} \leftrightarrow \mathrm{Li}_{x} \mathrm{Nb}_{2} \mathrm{O}_{5}$. With the controlled mass ratios (NQD-NC/AC $=2.2$ in $0.5 \sim 3.0 \mathrm{~V}, 5.5$ in $0.5 \sim 4.0 \mathrm{~V})$, Li-HEC of NQD-NC//AC was operable in EC/DMC (1:1) electrolyte containing $1.0 \mathrm{M}$ $\mathrm{LiPF}_{6}$. When the operating potential range was $0.5 \sim 3.0 \mathrm{~V}$, the Li-HEC exhibited an energy density of $51.4 \mathrm{~W} \mathrm{~h} \mathrm{~kg}^{-1}$ at $350 \mathrm{~W} \mathrm{~kg}^{-1}$, and a power density of $8750 \mathrm{~W} \mathrm{~kg}^{-1}$ at $16.3 \mathrm{~W} \mathrm{~h} \mathrm{~kg}^{-1}$. When the potential range was extended to $0.5 \sim 4.0 \mathrm{~V}$, the NQD-NC//AC showed an energy density of $76.9 \mathrm{~W} \mathrm{~h} \mathrm{~kg}^{-1}$ at $450 \mathrm{~W} \mathrm{~kg}^{-1}$ and a power density of $11,250 \mathrm{~W} \mathrm{~kg}^{-1}$ at $22.4 \mathrm{~W} \mathrm{~h} \mathrm{~kg}^{-1}$. Notably, the Li-HEC device could turn on a $3 \mathrm{~V}$ blue LED for more than $12 \mathrm{~min}$. In the NQD-NC, the $\mathrm{Nb}_{2} \mathrm{O}_{5}$ QDs facilitated the rates of $\mathrm{Li}^{+}$diffusion and electron transport.

Yamauchi et al. fabricated a new ASC of $\mathrm{NiCo}_{2} \mathrm{O}_{4}-\mathrm{NC} / \mathrm{NC}$ [192]. The nanoporous carbon (NC) with 3D polyhedral shape was synthesized via direct carbonization of ZIF-8 at $900{ }^{\circ} \mathrm{C}\left(5 \mathrm{~h}, \mathrm{~N}_{2}\right.$ flow) and followed by etching by $10 \mathrm{wt} . \%$ HF. The resultant NC was a good source for composite because of its mechanical stability, interconnected conducting pathways, and regular shape. For the preparation of the $\mathrm{NiCo}_{2} \mathrm{O}_{4}-\mathrm{NC}$, the NC was treated with c- $\mathrm{H}_{2} \mathrm{SO}_{4}$ to form hydrophilic S-NC. Then, the S-NC was transformed into sheet-like core/shell precursor of $\mathrm{NiCo}_{2} \mathrm{O}_{4}-\mathrm{NC}$ under reflux conditions with the mixture containing $\mathrm{Ni}\left(\mathrm{NO}_{3}\right)_{2} \cdot 6 \mathrm{H}_{2} \mathrm{O}, \mathrm{Co}\left(\mathrm{NO}_{3}\right)_{2} \cdot 6 \mathrm{H}_{2} \mathrm{O}$, hexamethylenetetramine (HMT), and trisodium citrate (TSC, modulator). After that, the positive electrode of $\mathrm{NiCo}_{2} \mathrm{O}_{4}-\mathrm{NC}$ was obtained by pyrolysis of the precursor at $300{ }^{\circ} \mathrm{C}\left(3 \mathrm{~h}\right.$, air flow). As a result, the $2 \mathrm{D} \mathrm{NiCo}_{2} \mathrm{O}_{4}$ nanosheets was successfully incorporated into the hierarchically structured composite. The $2 \mathrm{D} \mathrm{NiCo}_{2} \mathrm{O}_{4}$ nanosheets were cheap conductors and had a large accessible surface area for high electrochemical activity $\left(\mathrm{V}_{\text {pore }}=0.53 \mathrm{~cm}^{3} \mathrm{~g}^{-1}\right)$. Furthermore, the composite had good mesoporosity $(3 \sim 10 \mathrm{~nm})$ and favorable synergetic interaction between 3D NC core and 2D NiCo ${ }_{2} \mathrm{O}_{4}$ shell. Therefore, $\mathrm{NiCO}_{2} \mathrm{O}_{4}-\mathrm{NC}$ yielded good electrochemical properties in $1 \mathrm{M} \mathrm{KOH}$ basic electrolyte $\left(\mathrm{NiCo}_{2} \mathrm{O}_{4}+\mathrm{OH}^{-} \leftrightarrow \mathrm{NiOOH}+2 \mathrm{CoOOH}\right.$ $\left.+2 \mathrm{e}^{-}, \mathrm{CoOOH}+\mathrm{OH}^{-} \leftrightarrow \mathrm{CoO}_{2}+\mathrm{H}_{2} \mathrm{O}+\mathrm{e}^{-}\right)$. In a $2 \mathrm{E}$ cell, the ASC of $\mathrm{NiCo}_{2} \mathrm{O}_{4}-\mathrm{NC} / / \mathrm{NC}$ delivered capacitances of $89 \mathrm{~F} \mathrm{~g}^{-1}$ at $0.1 \mathrm{~A} \mathrm{~g}^{-1}$ and $26 \mathrm{~F} \mathrm{~g}^{-1}$ at $10 \mathrm{~A} \mathrm{~g}^{-1}$.

Moradi et al. reported a new ASC of $\mathrm{Cr}_{2} \mathrm{O}_{3} / \mathrm{C} / / \mathrm{Fe}_{\mathrm{x}} \mathrm{O}_{\mathrm{y}} / \mathrm{C}$ to overcome the limitations of general metal-oxide-based electrodes, such as low conductivity and inferior cycling and rate performance [193]. The MIL-101 (Fe) was hydrothermally synthesized using $\mathrm{Cr}\left(\mathrm{NO}_{3}\right)_{2} \cdot 9 \mathrm{H}_{2} \mathrm{O}, \mathrm{H}_{2} \mathrm{bdc}$, and $40 \% \mathrm{HF}$ at $220{ }^{\circ} \mathrm{C}(8 \mathrm{~h})$. Then, it was converted into the $\mathrm{Cr}_{2} \mathrm{O}_{3} / \mathrm{C}$ cathode via a single-step carbonization at $800{ }^{\circ} \mathrm{C}$ ( $5 \mathrm{~h}, \mathrm{Ar}$ flow). The resultant $\mathrm{Cr}_{2} \mathrm{O}_{3} / \mathrm{C}$ with $\mathrm{S}_{\text {BET }}$ of $59.9 \mathrm{~m}^{2} \mathrm{~g}^{-1}$ showed capacitances of $426 \mathrm{~F} \mathrm{~g}^{-1}$ at $5 \mathrm{mV} \mathrm{s}^{-1}$ in $6 \mathrm{M} \mathrm{KOH}$ electrolyte. Additionally, MIL-101(Fe) was solvothermally prepared from the mixture of $\mathrm{FeCl}_{3} \cdot 6 \mathrm{H}_{2} \mathrm{O}$ and $\mathrm{H}_{2}$ bdc $\left(110{ }^{\circ} \mathrm{C}, 20 \mathrm{~h}\right)$, and subsequently transformed into the $\mathrm{Fe}_{\mathrm{x}} \mathrm{O}_{\mathrm{y}} / \mathrm{C}$ anode through single-step carbonization at $800{ }^{\circ} \mathrm{C}(2 \mathrm{~h}$, Ar flow $)$. The obtained $\mathrm{Fe}_{\mathrm{x}} \mathrm{O}_{\mathrm{y}} / \mathrm{C}$ with $\mathrm{S}_{\mathrm{BET}}$ of $67.6 \mathrm{~m}^{2} \mathrm{~g}^{-1}$ showed a capacitance of $114 \mathrm{~F} \mathrm{~g}^{-1}$ at $2 \mathrm{~A} \mathrm{~g}^{-1}$ in the same cell conditions. In the same electrolyte, the $\mathrm{Cr}_{2} \mathrm{O}_{3} / \mathrm{C} / / \mathrm{Fe}_{\mathrm{x}} \mathrm{O}_{\mathrm{y}} / \mathrm{C}$ ASC exhibited capacitances of $27.2 \mathrm{~F} \mathrm{~g}^{-1}$ at $1 \mathrm{~A} \mathrm{~g}^{-1}$ and $14.4 \mathrm{~F} \mathrm{~g}^{-1}$ at $5 \mathrm{~A} \mathrm{~g}^{-1}$. The Ragone plots are shown in Figure 14, and the performances of $\mathrm{Cr}_{2} \mathrm{O}_{3} / \mathrm{C}^{-} / \mathrm{Fe}_{\mathrm{x}} \mathrm{O}_{\mathrm{y}} / \mathrm{C}$ ASC are better than other reported systems.

\subsubsection{Composites Containing Carbon/Metal Sulfide}

Composites Containing $\mathrm{Co}_{9} \mathrm{~S}_{8}$

$\mathrm{Co}_{9} \mathrm{~S}_{8}$-containing composite with the inclusion of $2 \mathrm{D}$ CoNi alloys NPs into S/N-co-doped carbon nanosheets (CoNi@SNC) was fabricated from the 2D Co/Ni-MOF nanosheets [194]. The $\mathrm{S}, \mathrm{N}$-containing $\mathrm{Co} / \mathrm{Ni}-\mathrm{MOF}$ were synthesized under mild basic condition at room temperature using mixed metal sources $\left(\mathrm{CoCl}_{2} \cdot 6 \mathrm{H}_{2} \mathrm{O}\right.$ and $\left.\mathrm{NiCl}_{2} \cdot 6 \mathrm{H}_{2} \mathrm{O}\right)$ and two different bridging linkers $\left(\mathrm{tdc}=\right.$ thiophene-2,5-dicarboxylate, $4.4^{\prime}$-bpy $=4,4^{\prime}$-bipyridine $)$. The as-prepared $\mathrm{Co} / \mathrm{Ni}$-MOFs with the same molar ratio of $\mathrm{Co}^{2+}$ and $\mathrm{Ni}^{2+}$ were directly carbonized to form the CoNi@SNC at $550{ }^{\circ} \mathrm{C}$ $\left(2 \mathrm{~h}, \mathrm{~N}_{2}\right.$ flow). The obtained CoNi@SNC $\left(\mathrm{V}_{\text {pore }}=0.508 \mathrm{~cm}^{3} \mathrm{~g}^{-1}\right)$ had uniform mesoporosity 
$\left(D_{\text {pore }}=3.0\right.$ and $\left.4.0 \mathrm{~nm}\right)$ and good conductivity from graphitic carbon and the CoNi alloy NPs. Interestingly, the surfaces of CoNi alloy NPs could be partially transformed into electrochemically active sites in an alkaline electrolytic environment by forming either $\mathrm{Co}_{3} \mathrm{O}_{4} / \mathrm{NiO}$ or $\mathrm{Co}(\mathrm{OH})_{2} / \mathrm{Ni}(\mathrm{OH})_{2}$. As a result, the CoNi@SNC working electrode exhibited very high capacitances of $1970 \mathrm{~F} \mathrm{~g}^{-1}$ at $10 \mathrm{~A} \mathrm{~g}^{-1}$ and $1282 \mathrm{~F} \mathrm{~g}^{-1}$ at $20 \mathrm{~A} \mathrm{~g}^{-1}$ in $6.0 \mathrm{M} \mathrm{KOH}$. Thus, this cell was very stable and highly active. Moreover, it also showed great improvement of capacitance from 972 to $1660 \mathrm{~F} \mathrm{~g}^{-1}$ after 1000 cycles at $2.0 \mathrm{~A} \mathrm{~g}^{-1}$. In the same electrolyte, the ASC of CoNi@SNC//AC showed capacitances of $156.7 \mathrm{~F} \mathrm{~g}^{-1}$ at $1 \mathrm{~A} \mathrm{~g}^{-1}$ and $109.3 \mathrm{~F} \mathrm{~g}^{-1}$ at $10 \mathrm{~A} \mathrm{~g}^{-1}$.

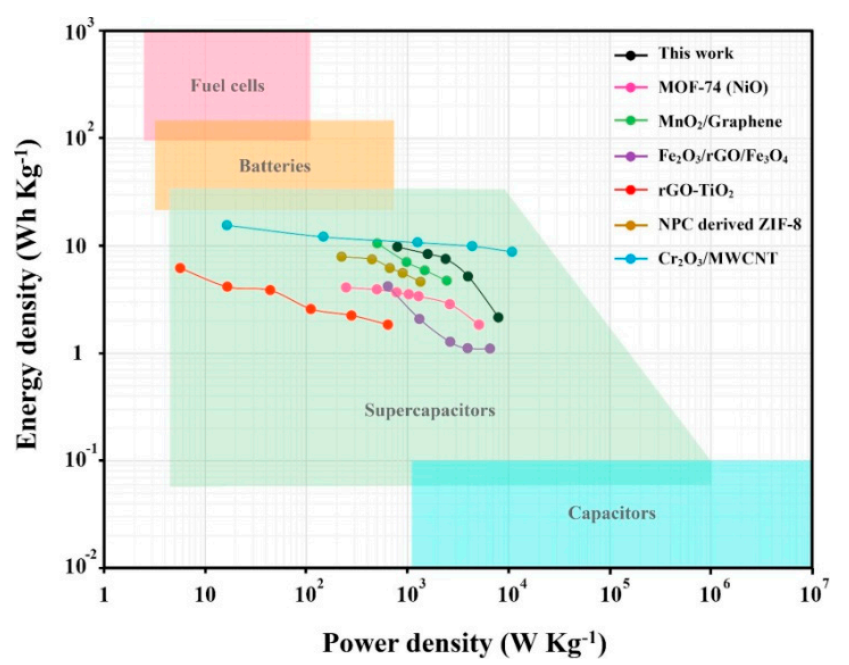

Figure 14. Ragone plots of $\mathrm{Cr}_{2} \mathrm{O}_{3} / \mathrm{C} / / \mathrm{Fe}_{x} \mathrm{O}_{y} / \mathrm{C}$ and other metal oxide/carbon composite-based ASCs [193].

DUT-58-derived composite of $\mathrm{Co}_{9} \mathrm{~S}_{8} / \mathrm{NS}-\mathrm{C}$ with $\mathrm{Co}_{9} \mathrm{~S}_{8}$ NPs and $\mathrm{S}, \mathrm{N}-$-co-doped porous graphitic carbon wall was synthesized to solve the low conductivity and stability problems of $\mathrm{Co}_{9} \mathrm{~S}_{8}$ electrode [195]. The environmentally friendly $\mathrm{Co}_{9} \mathrm{~S}_{8}$ has a high theoretical capacitance, low cost, and high natural abundance. The precursor of DUT-58 was solvothermally synthesized from the mixture containing $\mathrm{Co}\left(\mathrm{NO}_{3}\right)_{2} \cdot 6 \mathrm{H}_{2} \mathrm{O}, 4,4^{\prime}$-biphenyldicarboxylic acid (4,4'-bpdc), and 1,3-bis(imidazol-1-yl)benzene (1,3-bib). The $\mathrm{Co}_{9} \mathrm{~S}_{8} / \mathrm{NS}-\mathrm{C}$ was produced by the carbonization of TAA-encapsulated DUT- 58 at $700{ }^{\circ} \mathrm{C}\left(2 \mathrm{~h}, \mathrm{~N}_{2}\right.$ flow $)$. After that, the optimized product of $\mathrm{Co}_{9} \mathrm{~S}_{8} / \mathrm{NS}-\mathrm{C}-1.5 \mathrm{~h}$ was generated via $\mathrm{CO}_{2}$ treatment $\left(600^{\circ} \mathrm{C}, 1.5 \mathrm{~h}\right)$. The resultant $\mathrm{Co}_{9} \mathrm{~S}_{8} / \mathrm{NS}-\mathrm{C}-1.5 \mathrm{~h}\left(\mathrm{~V}_{\text {pore }}=0.136 \mathrm{~cm}^{3} \mathrm{~g}^{-1}\right)$ showed good mesoporosity $\left(\mathrm{D}_{\text {pore }}=8.2 \mathrm{~nm}\right)$ and great interfacial contact between graphitic carbon $\left(I_{\mathrm{D}} / I_{\mathrm{G}}=0.98\right)$ and pseudocapacitive $\mathrm{Co}_{9} \mathrm{~S}_{8}\left(\mathrm{Co}_{9} \mathrm{~S}_{8}+9 \mathrm{OH}^{-} \leftrightarrow \mathrm{Co}_{9} \mathrm{~S}_{8}(\mathrm{OH})_{9}+9 \mathrm{e}^{-}\right)$. Therefore, the $\mathrm{Co}_{9} \mathrm{~S}_{8} / \mathrm{NS}-\mathrm{C}-1.5 \mathrm{~h}$ electrode exhibited high capacitances of $734.09 \mathrm{~F} \mathrm{~g}^{-1}$ at $1 \mathrm{~A} \mathrm{~g}^{-1}$ and $653.64 \mathrm{~F} \mathrm{~g}^{-1}$ at $10 \mathrm{~A} \mathrm{~g}^{-1}$. The $3 \mathrm{E}$ cell was stable enough to show $99.8 \%$ capacitance retention at $10 \mathrm{~A} \mathrm{~g}^{-1}$ up to 140,000 cycles in $6 \mathrm{M} \mathrm{KOH}$. In the same electrolyte, the ASC of $\mathrm{Co}_{9} \mathrm{~S}_{8} / \mathrm{NS}-\mathrm{C}-1.5 \mathrm{~h} / / \mathrm{AC}$ delivered capacitances, energy and power densities of $75.59 \mathrm{~F} \mathrm{~g}^{-1}$ at $1 \mathrm{~A} \mathrm{~g}^{-1}, 32.41 \mathrm{Fg}^{-1}$ at $10 \mathrm{Ag}^{-1}, 14.85 \mathrm{~W} \mathrm{~h} \mathrm{~kg}^{-1}$ at $681.82 \mathrm{~W} \mathrm{~kg}^{-1}$, and $6.63 \mathrm{~W} \mathrm{~h} \mathrm{~kg}^{-1}$ at $6818.18 \mathrm{~W} \mathrm{~kg}^{-1}$.

The ASC of $\mathrm{Co}_{9} \mathrm{~S}_{8} @ \mathrm{C} / / \mathrm{AC}$ was also assembled with an actual mass loading of electrode more than $10 \mathrm{mg} \mathrm{cm}{ }^{-2}$ [196]. The $\mathrm{Co}_{9} \mathrm{~S}_{8} @ \mathrm{C}-500$ positive electrode was produced by thermolysis of Co-btc MOF with sulfur powder at $500{ }^{\circ} \mathrm{C}\left(2 \mathrm{~h}, 5 \% \mathrm{H}_{2} / \mathrm{Ar}\right.$ flow $)$ and additional heat treatment at $300{ }^{\circ} \mathrm{C}(10 \mathrm{~h})$. The $\mathrm{Co}_{9} \mathrm{~S}_{8} @ \mathrm{C}-500$ showed 3D porous honeycomb-like structure $\left(\mathrm{S}_{\mathrm{BET}}=62.95 \mathrm{~m}^{2} \mathrm{~g}^{-1}\right.$, $\mathrm{V}_{\text {pore }}=0.26 \mathrm{~cm}^{3} \mathrm{~g}^{-1}$ ) and multilength scale porosities. The pseudocapacitive $\mathrm{Co}_{9} \mathrm{~S}_{8}$ NPs buried in the conducting and structural carbon support were found in the $\mathrm{Co}_{9} \mathrm{~S}_{8} @ \mathrm{C}-500$ composite $\left(\mathrm{Co}_{9} \mathrm{~S}_{8}+11 \mathrm{OH}^{-} \leftrightarrow \mathrm{Co}_{9} \mathrm{~S}_{8}(\mathrm{OH})_{11}+11 \mathrm{e}^{-}, \mathrm{Co}_{9} \mathrm{~S}_{8}(\mathrm{OH})_{11}+9 \mathrm{OH}^{-} \leftrightarrow \mathrm{Co}_{9} \mathrm{~S}_{8} \mathrm{O}_{10}+10 \mathrm{H}_{2} \mathrm{O}+9 \mathrm{e}^{-}\right)$. As a working electrode of the $3 \mathrm{E}$ cell in $2.0 \mathrm{M} \mathrm{KOH}$ electrolyte, the composite yielded large capacitances of $1887 \mathrm{~F} \mathrm{~g}^{-1}$ at $1 \mathrm{~A} \mathrm{~g}^{-1}$ and $1182 \mathrm{~F} \mathrm{~g}^{-1}$ at $10 \mathrm{~A} \mathrm{~g}^{-1}$. The $\mathrm{Co}_{9} \mathrm{~S}_{8} @ \mathrm{C} / / \mathrm{AC}$ ASC assembled with a controlled 
mass ratio $\left(\mathrm{m}_{+} / \mathrm{m}_{-}=0.3\right)$ operating in the same electrolyte exhibited a capacitance of $166 \mathrm{~F} \mathrm{~g}^{-1}$ at $1 \mathrm{~A} \mathrm{~g}^{-1}$.

Composites Containing Nickel-Cobalt-Sulfides

Lin et al. synthesized Ni-Co-S@G from the activated nickelocene/ZIF-67 composite via single-step pyrolysis at $600{ }^{\circ} \mathrm{C}(2 \mathrm{~h}$, Ar flow, mass ratio of S/composite $=5)$ to improve rate performance and cycling stability of nickel-cobalt sulfides [197]. The obtained Ni-Co-S@G $\left(\mathrm{S}_{\mathrm{BET}}=42.5 \mathrm{~m}^{2} \mathrm{~g}^{-1}\right)$ was composed of a thin-layered graphene shell and various Ni-Co-S NPs $\left(\mathrm{NiCo}_{2} \mathrm{~S}_{4}, \mathrm{Ni}_{4} \mathrm{~S}_{3}, \mathrm{Co}_{4} \mathrm{~S}_{3}\right.$, and so on). The graphene shell was formed due to the catalysis by Co and Ni. The Ni-Co-S@G had interconnected framework architecture, uniform core/shell polyhedral structure, and mesoporosity $\left(D_{\text {pore }}=3.9\right.$ and $\left.11 \mathrm{~nm}\right)$. The pseudocapacitive behavior of the Ni-Co-S could be effectively displayed in basic electrolyte aided by interfacial binding with conductive and protective graphene layer through the following reactions: $\mathrm{CoS}+\mathrm{OH}^{-} \leftrightarrow \mathrm{CoSOH}+\mathrm{e}^{-}, \mathrm{CoSOH}+\mathrm{OH}^{-} \leftrightarrow \mathrm{CoSO}+\mathrm{H}_{2} \mathrm{O}+\mathrm{e}^{-}, \mathrm{NiS}^{-} \mathrm{OH}^{-}$ $\leftrightarrow \mathrm{NiSOH}+\mathrm{e}^{-}$. As a result, in a 3E cell with $6 \mathrm{M} \mathrm{KOH}$ electrolyte, the Ni-Co-S@G electrode showed excellent performances: $1463 \mathrm{~F} \mathrm{~g}^{-1}$ at $1 \mathrm{~A} \mathrm{~g}^{-1}, 750 \mathrm{~F} \mathrm{~g}^{-1}$ at $10 \mathrm{~A} \mathrm{~g}^{-1}$, and $12.6 \%$ capacitance loss after 1000 cycles at $17 \mathrm{~A} \mathrm{~g}^{-1}$. Moreover, the all-solid-phase ASC of Ni-Co-S@G//AC by using PVA/KOH electrolyte and flexible $\mathrm{Ni}$ film substrate also showed good performances: $217.8 \mathrm{~F} \mathrm{~g}^{-1}$ at $1 \mathrm{~A} \mathrm{~g}^{-1}$, 101.6 $\mathrm{F} \mathrm{g}^{-1}$ at $10 \mathrm{~A} \mathrm{~g}^{-1}, 51.0 \mathrm{~W} \mathrm{~h} \mathrm{~kg}^{-1}$ at $650.3 \mathrm{~W} \mathrm{~kg}^{-1}$, and $12.7 \mathrm{~W} \mathrm{~h} \mathrm{~kg}^{-1}$ at $11,700 \mathrm{~W} \mathrm{~kg}^{-1}$.

The hollow spherical composites of Ni-Co-S-n/NC (NC = N-doped carbon, $\mathrm{n}=\mathrm{Ni} /$ Co molar ratio) were also reported [198]. The Ni-Co-btc-n with spherical morphology was solvothermally synthesized in the presence of PVP. The co-carbonization of melamine and Ni-Co-BTC-n (mass ratio $=20 / 1)$ at $450{ }^{\circ} \mathrm{C}$ ( $5 \mathrm{vol} \% \mathrm{H}_{2} /$ Ar flow) was performed to produce the Ni-Co-n/NC. The Ni-Co-n/NC composite was hydrothermally sulfidated with TAA (mass ratio of TAA/composite $=4$ ) at $140^{\circ} \mathrm{C}$ for $6 \mathrm{~h}$. The optimized sample of Ni-Co-S-0.5/NC contained mesoporosity $\left(\mathrm{N}=4.96 \mathrm{wt} \%\right.$, $\left.\mathrm{S}_{\mathrm{BET}}=10.27 \mathrm{~m}^{2} \mathrm{~g}^{-1}\right)$, graphitic $\mathrm{N}$-doped carbon (55.2 wt.\%), and Ni-Co-S NPs $\left(\mathrm{Co}_{9} \mathrm{~S}_{8}\right.$ and $\left.\mathrm{NiCo}_{2} \mathrm{~S}_{4}\right)$. The reversible battery-type faradaic reactions, i.e., $\mathrm{MS} / / \mathrm{MSOH}$ and $\mathrm{MSOH} / / \mathrm{MSO}$ where $\mathrm{M}$ is $\mathrm{Ni}$ and $\mathrm{Co}$ ions, were supported by the stable and conductive NC. The Ni-Co-S-n working electrode yielded a specific capacity of $519.6 \mathrm{C} \mathrm{g}^{-1}$ at $1 \mathrm{~A} \mathrm{~g}^{-1}, 366.0 \mathrm{C} \mathrm{g}^{-1}$ at $20 \mathrm{~A} \mathrm{~g}^{-1}$, and good cycling performance after 2000 cycles in a $3 \mathrm{E}$ cell with $3 \mathrm{M} \mathrm{KOH}$. Moreover, the Li-HEC of Ni-Co-S-0.5/NC//AC acting on $1 \mathrm{M} \mathrm{LiPF}_{6}$ in EC/DMC/DEC (1:1:1) electrolyte showed a capacitance of $111.2 \mathrm{~F} \mathrm{~g}^{-1}$ at $1 \mathrm{~A} \mathrm{~g}^{-1}$ and good rate performance $(68.5 \%$ retention at $\left.10 \mathrm{~A} \mathrm{~g}^{-1}\right)$.

A new composite electrode of CC/CNWAs@Ni@CoNi $\mathrm{S}_{4}(\mathrm{CNWAs}=$ carbon nanowall arrays $)$ with hierarchical structure was fabricated [199]. The vertical growth of ZIF-67 crystals on the free-standing CC substrate was performed via solution method. Neither binder nor conducting agents were used during the synthesis. The resultant CC/ZIF-67 was directly carbonized at $800{ }^{\circ} \mathrm{C}\left(2 \mathrm{~h}, 5 \mathrm{vol} \% \mathrm{H}_{2} / \mathrm{Ar}\right.$ flow) to produce carbon nanowall arrays on CC (CC/CNWAs). Subsequently, thin Ni layer was electrodeposited on the CC/CNWAs using $\mathrm{NiSO}_{4}$ and $\mathrm{NH}_{4} \mathrm{Cl}$ for the construction of CC/CNWAs@Ni. Additional electrodeposition on the CC/CNWAs@Ni was conducted by using $\mathrm{CoCl}_{2} \cdot 6 \mathrm{H}_{2} \mathrm{O}, \mathrm{NiCl}_{2} \cdot 6 \mathrm{H}_{2} \mathrm{O}$, and thiourea to obtain the CC/CNWAs@Ni@CoNi ${ }_{2} \mathrm{~S}_{4}$ composite. In the composite, the Ni layer could act as an interfacial conducting bridge between $\mathrm{CNWAs}$ and $\mathrm{CoNi}_{2} \mathrm{~S}_{4}$. Thus, the faradaic reaction center of mesoporous $\mathrm{CoNi}_{2} \mathrm{~S}_{4}$ was effectively activated in a basic electrolyte: $\mathrm{CoNi}_{2} \mathrm{~S}_{4}+2 \mathrm{OH}^{-} \leftrightarrow$ $\mathrm{CoS}_{2 x} \mathrm{OH}+\mathrm{Ni}_{2} \mathrm{~S}_{4-2 \mathrm{x}} \mathrm{OH}+2 \mathrm{e}^{-}$. Therefore, the CC/CNWAs@Ni@CoNi $\mathrm{S}_{4}$ electrode demonstrated ultra-high capacitances of $3163 \mathrm{~F} \mathrm{~g}^{-1}$ at $1 \mathrm{~A} \mathrm{~g}^{-1}$ and $2825 \mathrm{~F} \mathrm{~g}^{-1}$ at $5 \mathrm{mV} \mathrm{s}^{-1}$, and good rate performances (1503 $\mathrm{F} \mathrm{g}^{-1}$ at $40 \mathrm{~A} \mathrm{~g}^{-1}$ and $1500 \mathrm{~F} \mathrm{~g}^{-1}$ at $50 \mathrm{mV} \mathrm{s}^{-1}$ ). Moreover, in the same electrolyte, the ASC of CC/CNWAs@Ni@CoNi ${ }_{2} \mathrm{~S}_{4} / / \mathrm{AC}$ exhibited good performances: $151.3 \mathrm{~F} \mathrm{~g}^{-1}$ at $1 \mathrm{~A} \mathrm{~g}^{-1}, 73.1 \mathrm{~F} \mathrm{~g}^{-1}$ at $30 \mathrm{~A} \mathrm{~g}^{-1}, 53.8 \mathrm{~W} \mathrm{~h} \mathrm{~kg}{ }^{-1}$ at $800 \mathrm{~W} \mathrm{~kg}^{-1}$, and $32.2 \mathrm{~W} \mathrm{~h} \mathrm{~kg}^{-1}$ at $8000 \mathrm{~W} \mathrm{~kg}^{-1}$.

Recently, Zhou et al. reported another new hierarchical composite electrode of $\mathrm{NiCo}_{2} \mathrm{~S}_{4}-\mathrm{Ni}_{9} \mathrm{~S}_{8}$-DYMs (DYMs = double-layered yolk-shell microspheres) from Co/Ni-btc-MOF [200]. The Co/Ni-MOF was transformed into the of $\mathrm{NiCo}_{2} \mathrm{~S}_{4}-\mathrm{Ni}_{9} \mathrm{~S}_{8}$-DYMs via two-step calcinations $\left(500{ }^{\circ} \mathrm{C}\right.$ for $2 \mathrm{~h}$ under $\mathrm{N}_{2}$ atmosphere and another $2 \mathrm{~h}$ under air atmosphere) followed by sulfurization $\left(400{ }^{\circ} \mathrm{C}\right.$ for 
$3 \mathrm{~h}$ under $\mathrm{N}_{2}$ atmosphere, mass ratio of $\mathrm{S} /$ calcined sample $=5$ ). Conductive carbon and heterogeneous sulfides $\left(\mathrm{NiCO}_{2} \mathrm{~S}_{4}\right.$ and $\left.\mathrm{Ni}_{9} \mathrm{~S}_{8}\right)$ with faradaic reactivity effectively constructed the composite with hierarchical and porous structure. The $\mathrm{NiCo}_{2} \mathrm{~S}_{4}-\mathrm{Ni}_{9} \mathrm{~S}_{8}$-DYMs was a battery-type electrode for ASC. The ASC of $\mathrm{NiCo}_{2} \mathrm{~S}_{4}-\mathrm{Ni}_{9} \mathrm{~S}_{8}-\mathrm{DYMs} / / \mathrm{rGO}$ gel showed high maximum capacitance $\left(143.5 \mathrm{~F} \mathrm{~g}^{-1}\right.$ at $\left.2 \mathrm{~A} \mathrm{~g}^{-1}\right)$ and suitable rate performance $\left(51.0 \mathrm{~W} \mathrm{~h} \mathrm{~kg}-1\right.$ at $1399.4 \mathrm{~W} \mathrm{~kg}^{-1}$ and $32.5 \mathrm{~W} \mathrm{~h} \mathrm{~kg}^{-1}$ at $\left.8004.4 \mathrm{~W} \mathrm{~kg}^{-1}\right)$ in $6 \mathrm{M} \mathrm{KOH}$.

\section{Another Kind}

A novel composite of $\mathrm{MnS} / \mathrm{MoS}_{2} / \mathrm{C}$ was prepared from the Mn/Mo-MOF self-sacrificing precursor, [Mn $\left(4,4^{\prime}\right.$-bpy) $\left.0.5 \cdot \mathrm{MoO}_{4}\right] \cdot 1.5 \mathrm{H}_{2} \mathrm{O}$, and sulfur powder by simultaneous thermal process of calcination and sulfurization [201]. The precursor was synthesized from $\mathrm{MnSO}_{4} \cdot 4 \mathrm{H}_{2} \mathrm{O}, \mathrm{Na}_{2} \mathrm{MoO}_{4} \cdot 2 \mathrm{H}_{2} \mathrm{O}$ and $4,4^{\prime}$-bpy under reflux at $120^{\circ} \mathrm{C}(4 \mathrm{~h})$. Then, single-step thermolysis of the precursor with the $\mathrm{S}$ (mass ratio of precursor/powder $=1: 14)$ was conducted to form the $\mathrm{MnS} / \mathrm{MoS}_{2} / \mathrm{C}$ composite at $300{ }^{\circ} \mathrm{C}(1 \mathrm{~h}$, Ar). The obtained microporous composite $\left(S_{\mathrm{BET}}=8.1 \mathrm{~m}^{2} \mathrm{~g}^{-1}, I_{\mathrm{G}} / \mathrm{I}_{\mathrm{D}}=1\right)$ was made up of $\mathrm{MnS} / \mathrm{MoS}_{2} / \mathrm{C}$ nanoflakes and $\mathrm{MoS}_{2} / \mathrm{C}$ nanorods. The carbon matrix played a role for conducting and maintaining the structure. The active centers for pseudocapacitance, such as $\mathrm{MnS}$ and $\mathrm{MoS}_{2}$, could effectively undergo the following redox reactions under basic conditions: $\mathrm{MnS}+\mathrm{OH}^{-} \leftrightarrow \mathrm{Mn}(\mathrm{OH}) \mathrm{S}+\mathrm{e}^{-}, \mathrm{Mn}(\mathrm{OH}) \mathrm{S}+\mathrm{OH}^{-}$ $\leftrightarrow \mathrm{MnOS}+\mathrm{H}_{2} \mathrm{O}+\mathrm{e}^{-},\left(\mathrm{MoS}_{2}\right)+\mathrm{K}^{+}+\mathrm{e}^{-} \leftrightarrow \mathrm{MoS}^{-S K} \mathrm{~K}^{+}$. In the 3E system with $2 \mathrm{M} \mathrm{KOH}$ electrolyte, the $\mathrm{MnS} / \mathrm{MoS}_{2} / \mathrm{C}$ electrode delivered high capacitances of $1162 \mathrm{~F} \mathrm{~g}^{-1}$ at $0.5 \mathrm{~A} \mathrm{~g}^{-1}$ and $880 \mathrm{~F} \mathrm{~g}^{-1}$ at $10 \mathrm{~A} \mathrm{~g}^{-1}$. In the same electrolyte, the ASC composed of $\mathrm{MnS} / \mathrm{MoS}_{2} / \mathrm{C}$ positive electrode and $\mathrm{AC}$ negative electrode $\left(\mathrm{m}_{+} / \mathrm{m}_{-}=1 / 2.4\right)$ also demonstrated good performances: $93 \mathrm{~F} \mathrm{~g}^{-1}$ at $0.5 \mathrm{~A} \mathrm{~g}^{-1}, 45 \mathrm{~F} \mathrm{~g}^{-1}$ at $10 \mathrm{~A} \mathrm{~g}^{-1}, 31.0 \mathrm{~W} \mathrm{~h} \mathrm{~kg}^{-1}$ at $388.3 \mathrm{~W} \mathrm{~kg}^{-1}$, and $15.0 \mathrm{~W} \mathrm{~h} \mathrm{~kg}^{-1}$ at $7722.2 \mathrm{~W} \mathrm{~kg}^{-1}$. At $1.5 \mathrm{~A} \mathrm{~g}^{-1}$, the ASC showed $81 \%$ and $61 \%$ capacitance retentions after 5000 and 10,000 GCD cycles, respectively, due to the transformation of metal sulfides into hydrated polyoxometalates or metal hydroxides (for example, $\mathrm{MoS}_{2} \rightarrow$ hydrated polymolybdates, $\left.\mathrm{MnS} \rightarrow \mathrm{Mn}(\mathrm{OH})_{\mathrm{x}}\right)$.

\subsubsection{Carbon/Metal Hydroxide Composite}

By using ZIF-67 self-sacrificing precursor, the 3D flower morphological composite of $\mathrm{Co} / \mathrm{C} @ \mathrm{Ni}(\mathrm{OH})_{2}$ was synthesized to improve the conductivity and cycling stability of $\mathrm{Ni}(\mathrm{OH})_{2}$ electrode [202]. The ZIF-67 precursor was directly carbonized at $600{ }^{\circ} \mathrm{C}\left(3 \mathrm{~h}, \mathrm{~N}_{2}\right.$ flow) to prepare $\mathrm{Co} / \mathrm{C}$ core. The obtained $\mathrm{Co} / \mathrm{C}$ contained microporosity and uniform hexagonal shape $\left(\mathrm{V}_{\text {total }}=0.640 \mathrm{~cm}^{3} \mathrm{~g}^{-1}\right)$. The $\mathrm{Co} / \mathrm{C}$ core was transformed into the core/shell type of composite, i.e., $\mathrm{Co} / \mathrm{C} @ \mathrm{Ni}(\mathrm{OH})_{2}$, via chemical deposition method using $\mathrm{K}_{2} \mathrm{~S}_{2} \mathrm{O}_{8}, \mathrm{NiSO}_{4}$, and $\mathrm{NH}_{3} \cdot 3 \mathrm{H}_{2} \mathrm{O}$ at $80{ }^{\circ} \mathrm{C}$. In the resultant composite, Co NPs tended to enhance the conductivity. The amorphous porous carbon upgraded the cycling stability, and the $2 \mathrm{D}$ ultrathin nanoflake shell, i.e., $\mathrm{Ni}(\mathrm{OH})_{2}$, provided high capacitance. As a result, in the $3 \mathrm{E}$ system with $6 \mathrm{M} \mathrm{KOH}$ electrolyte, a working electrode of the $\mathrm{Co} / \mathrm{C} @ \mathrm{Ni}(\mathrm{OH})_{2}$ showed high capacitances of $952 \mathrm{~F} \mathrm{~g}^{-1}$ at $0.5 \mathrm{~A} \mathrm{~g}^{-1}$ and $692 \mathrm{~F} \mathrm{~g}^{-1}$ at $5 \mathrm{~A} \mathrm{~g}^{-1}$, and low charge transfer resistance $\left(\mathrm{R}_{\mathrm{ct}}\right)$ of $0.28 \Omega$. $\mathrm{Co} / \mathrm{C} @ \mathrm{Ni}(\mathrm{OH})_{2} / / \mathrm{AC}$ ASC $\left(\mathrm{m}_{+} / \mathrm{m}_{-}=0.3\right)$ demonstrated moderately good performance in the same electrolyte: $73.8 \mathrm{~F} \mathrm{~g}^{-1}$ at $0.5 \mathrm{~A} \mathrm{~g}^{-1}, 61.2 \mathrm{~F} \mathrm{~g}^{-1}$ at $2 \mathrm{~A} \mathrm{~g}^{-1}$, and $33.6 \mathrm{~W} \mathrm{~h} \mathrm{~kg}^{-1}$ at $516.3 \mathrm{~W} \mathrm{~kg}^{-1}$.

\subsubsection{Other Kinds}

Lin et al. employed ZIF-8/CNTs as a sole precursor for the construction of $\mathrm{ZnO}$ QDs/carbon/CNTs//N-doped carbon/CNTs ASC as illustrated in Figure 15 [203]. First, the precursor of ZIF-8/CNT- $x$ ( $x=$ CNT contents in $\mathrm{mg}$ ) was hydrothermally synthesized from ZIF-8 and carboxyl-functionalized CNTs. Then, the positive electrode of ZnO QDs/carbon/CNTs was prepared by one-step carbonization of ZIF-8/CNT-120 at $650{ }^{\circ} \mathrm{C}\left(\mathrm{N}_{2}\right.$ flow $)$. The resultant ZnO QDs/carbon/CNTs had micro-/mesoporosity $\left(\mathrm{D}_{\text {pore }}=4.0 \mathrm{~nm}\right)$, spherical defect-free ZnO QDs, CNT, and amorphous carbon. In the $3 \mathrm{E}$ cell with $1 \mathrm{M} \mathrm{Na}_{2} \mathrm{SO}_{4}$, the positive electrode showed capacitances of $185 \mathrm{~F} \mathrm{~g}^{-1}$ at $0.5 \mathrm{~A} \mathrm{~g}^{-1}$, $152 \mathrm{~F} \mathrm{~g}^{-1}$ at $20 \mathrm{~A} \mathrm{~g}^{-1}, 175 \mathrm{~F} \mathrm{~g}^{-1}$ at $5 \mathrm{mV} \mathrm{s}^{-1}$, and $153.6 \mathrm{~F} \mathrm{~g}^{-1}$ at $100 \mathrm{mV} \mathrm{s}^{-1}$. Meanwhile, the negative electrode of N-doped carbon/CNTs was obtained from direct carbonization of the ZIF-8/CNT-120 
at $1000{ }^{\circ} \mathrm{C}\left(2 \mathrm{~h}, \mathrm{~N}_{2}\right.$ flow $)$ and $\mathrm{HCl}$ washing. The negative electrode showed micro-/mesoporosity, $\mathrm{N}$-doping $(\sim 2.7 \mathrm{at} \%)$, and hierarchical structure. Thus, it delivered capacitances of $250 \mathrm{~F} \mathrm{~g}^{-1}$ at $1 \mathrm{~A} \mathrm{~g} \mathrm{~g}^{-1}$ and $102 \mathrm{~F} \mathrm{~g}^{-1}$ at $20 \mathrm{~A} \mathrm{~g}^{-1}$. Moreover, all-solid-phase ASC of the ZnO QDs/carbon/CNTs//N-doped carbon/CNTs was assembled with a controlled mass ratio $\left(\mathrm{m}_{+} / \mathrm{m}_{-}=1.35\right)$, and it operated with PVA-NaNO ${ }_{3}$ electrolyte. The ASC exhibited capacitances of $59 \mathrm{~F} \mathrm{~g}^{-1}$ at $1 \mathrm{~A} \mathrm{~g}^{-1}$ and $27 \mathrm{~F} \mathrm{~g}^{-1}$ at $20 \mathrm{~A} \mathrm{~g}^{-1}$. These capacitive performances were attributed to the stable architecture, abundant pores for electrochemical activity, and conducting networks.

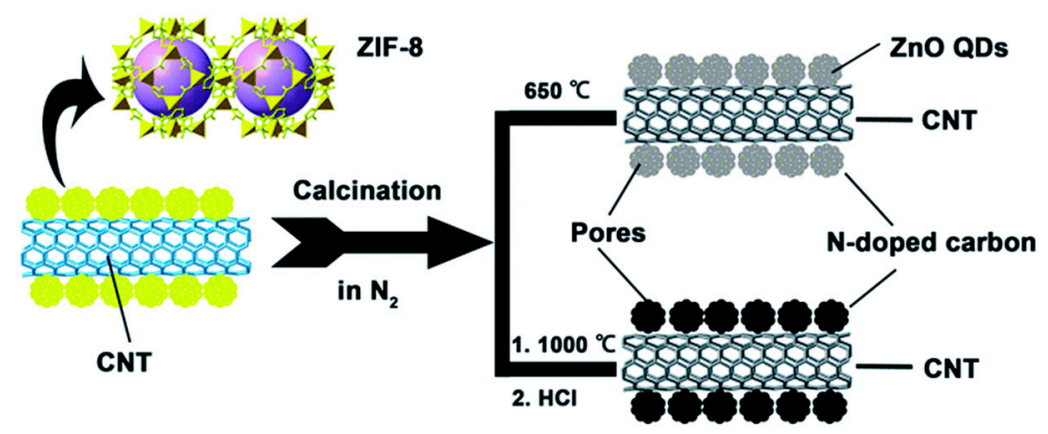

Figure 15. Fabrication process of single-templating approach for ZnO QDs/carbon/CNTs//N-doped carbon/CNTs ASC [203].

Shao et al. introduced a single-templating approach for the flexible all-solid-phase ASC of ZnO@C@CoNi-LDH//Fe $\mathrm{F}_{2} \mathrm{O}_{3} @ \mathrm{C}$ [204]. The vertical growth of $\mathrm{ZnO}$ NRAs on a Ni foam substrate surface was hydrothermally achieved. After that, the ZIF-8 template was epitaxially grown on the ZnO NRAs' surfaces. The obtained ZnO@ZIF-8 was directly carbonized to form ZnO@C at $650{ }^{\circ} \mathrm{C} \mathrm{(} 2 \mathrm{~h}, \mathrm{~N}_{2}$ flow), and the $\mathrm{ZnO} @ \mathrm{C}$ was converted into the $\mathrm{ZnO} @ \mathrm{C} @ \mathrm{CoNi}-\mathrm{LDH}$ via electrosynthesis using $\mathrm{CoCl}_{2} \cdot 6 \mathrm{H}_{2} \mathrm{O}$ and $\mathrm{Ni}\left(\mathrm{NO}_{3}\right)_{2} \cdot 6 \mathrm{H}_{2} \mathrm{O}$ at $-1.0 \mathrm{~V}$. In $1 \mathrm{M} \mathrm{KOH}$ electrolytic $3 \mathrm{E}$ cell, the positive electrode yielded an areal capacitance of $6.2578 \mathrm{~F} \mathrm{~cm}^{-2}$ at $2 \mathrm{~mA} \mathrm{~cm}^{-2}$ and $30.4 \%$ rate performance at $50 \mathrm{~mA} \mathrm{~cm}^{-2}$ with the help of two redox coupling reactions $\left(\mathrm{Co}^{2+} / \mathrm{Co}^{3+}\right.$ and $\left.\mathrm{Ni}^{2+} / \mathrm{Ni}^{3+}\right)$. Additionally, the ZnO@ZIF-8 NRAs were transformed into $\mathrm{Fe}(\mathrm{OH})_{3} @ \mathrm{ZIF}-\mathrm{Fe}$ NRAs through cation-exchange reaction followed by carbonization to produce core-shell NRAs of the $\mathrm{Fe}_{2} \mathrm{O}_{3} @ \mathrm{C}$ at $450{ }^{\circ} \mathrm{C}\left(5 \mathrm{~h}, \mathrm{~N}_{2}\right)$. Under the same cell conditions, the negative electrode showed an areal capacitance of $0.194 \mathrm{~F} \mathrm{~cm}^{-2}$ at $2 \mathrm{~mA} \mathrm{~cm}^{-2}$ with the formation of $\mathrm{Fe}(\mathrm{OH})_{2}$ and $\mathrm{FeOOH}$. Furthermore, the ASC of ZnO@C@CoNi-LDH//Fe $\mathrm{F}_{2} \mathrm{O}_{3} @ \mathrm{C}\left(\right.$ area $=1.0 \mathrm{~cm}^{2}$, thickness $=0.04 \mathrm{~cm}$ ) was fabricated and operated in PVA $/ \mathrm{KOH}$ electrolyte. The following reaction also occurred to enhance the electrochemical performances: $6 \mathrm{Ni}(\mathrm{OH})_{2}+\mathrm{Fe}_{2} \mathrm{O}_{3} \leftrightarrow 6 \mathrm{NiOOH}+2 \mathrm{Fe}+$ $3 \mathrm{H}_{2} \mathrm{O}$. It delivered volumetric energy and power densities of $1.078 \mathrm{~mW} \mathrm{~h} \mathrm{~cm}^{-3}$ at $0.02 \mathrm{~W} \mathrm{~cm}^{-3}$ and $0.4 \mathrm{~W} \mathrm{~cm}^{-3}$ at $0.254 \mathrm{~mW} \mathrm{~h} \mathrm{~cm}^{-3}$. Hierarchical core/shell structures with plentiful electrochemical active sites much favorable for conductivity and stability were found in both electrodes.

The hollow composite of $\mathrm{C} / \mathrm{LDH} / \mathrm{S}$ with inter-layered hybrid system of $\mathrm{Ni}-\mathrm{Co}-\mathrm{LDH} / \mathrm{Co}_{9} \mathrm{~S}_{8}$ was derived from ZIF-67 [205]. The ZIF-67 crystals were converted into ZIF-67-C via direct carbonization at $400{ }^{\circ} \mathrm{C}\left(2 \mathrm{~h}, \mathrm{~N}_{2}\right.$ flow). Subsequently, the ZIF-67-C was hydrothermally transformed into hollow $\mathrm{C} / \mathrm{LDH}$ by treating $\mathrm{Ni}\left(\mathrm{NO}_{3}\right)_{2} \cdot 6 \mathrm{H}_{2} \mathrm{O}$ at $120^{\circ} \mathrm{C}$ for $2 \mathrm{~h}$. Then, the hollow $\mathrm{C} / \mathrm{LDH} / \mathrm{S}$ was obtained by hydrothermal sulfurization of the $\mathrm{C} / \mathrm{LDH}$ by treating TAA at $100^{\circ} \mathrm{C}$ for $2 \mathrm{~h}$. The resultant $\mathrm{C} / \mathrm{LDH} / \mathrm{S}$ $\left(\mathrm{V}_{\text {pore }}=0.439 \mathrm{~cm}^{3} \mathrm{~g}^{-1}, \mathrm{D}_{\text {pore }}=49.4 \AA\right)$ contained polyhedral morphology, amorphous carbon, extended interlayer spacing, and $\sim 20 \mathrm{wt} . \%$ of the $\mathrm{Co}_{9} \mathrm{~S}_{8}$. As a result, the optimal interfacing system of the $\mathrm{C} / \mathrm{LDH} / \mathrm{S}$ with the combination of conductive matrix and rich redox centers could be realized in $1 \mathrm{M}$ $\mathrm{KOH}$ electrolyte. Thus, $\mathrm{C} / \mathrm{LDH} / \mathrm{S}$ working electrode in a $3 \mathrm{E}$ cell showed high capacitances of $1653 \mathrm{~F} \mathrm{~g}^{-1}$ at $4 \mathrm{~A} \mathrm{~g}^{-1}$ and $1025 \mathrm{~F} \mathrm{~g}^{-1}$ at $20 \mathrm{~A} \mathrm{~g}^{-1}$. Moreover, the $\mathrm{ASC}$ of $\mathrm{C} / \mathrm{LDH} / \mathrm{S} / / \mathrm{CNTs}\left(\mathrm{m}_{+} / \mathrm{m}\right.$. $\left.\cong 8.2\right)$ delivered capacitances of $194 \mathrm{~F} \mathrm{~g}^{-1}$ at $4 \mathrm{~A} \mathrm{~g}^{-1}$ and $151 \mathrm{~F} \mathrm{~g}^{-1}$ at $12 \mathrm{~A} \mathrm{~g}^{-1}$. 


\section{Conclusions}

Many attempts to synthesize porous carbons directly from MOFs have been intensively pursued for the past decade. It has been very clearly revealed that MOFs would be ideal self-sacrificing templates for the preparation of porous carbon electrodes in supercapacitors. This MOF-based carbonization may have several advantages compared to traditional carbonization method using organic-based precursors. For example, depending on the types of MOF templates and detailed conditions of carbonization, several different types of porous carbon-based electrode materials can be easily accessible on demand. Porous pure carbonaceous materials can be prepared through the carbonization of MOFs with/without subsequent acid etching process. Some volatile derivatives of metal ions can be removed without any difficulty during the high-temperature carbonization process. Sometimes, however mild acid etching is required to completely remove unwanted metal species. The heteroatom-doped porous carbons can be effectively synthesized by using a similar approach to use MOFs with bridging ligands containing heteroatoms, such as $\mathrm{N}, \mathrm{S}, \mathrm{P}$, and $\mathrm{B}$. The heteroatom dopants can also be derived from the solvate molecules confined in MOFs. Generally, O-dopant is also naturally occurring during the carbonization. Thus, multiply doped porous carbons can be prepared in a controlled manner. Metallic NP-containing carbons are obtainable through the pyrolysis of MOFs containing non-volatile metallic elements. Porous carbon composites with other carbon-based materials or redox-active metal species can be synthesized in a simple manner as well. As we noted, most of these MOF-derived porous carbons acted as good and stable electrodes of supercapacitors. Nonetheless, one of the most challenging issues using these porous carbon-based electrodes directly derived from MOFs is the preparation of porous carbon with sufficiently large surface area and optimal porosity. Many examples showed that the activation process was usually required to obtain such porous carbons. Therefore, further works may focus on the preparation of MOFs generating high-surface porous carbons with suitable pore dimensions without additional activation process. Additional electrochemical performance enhancement by redox-active species is also a critical factor for high performance supercapacitors. To increase the electrical conductivity of the composite electrodes is another interesting research topic. Overall, the composite-based electrodes showed enhanced energy and power densities compared to pure carbon electrodes. Notwithstanding, continuous efforts towards supercapacitors with better performance suited for practical applications may be needed. Despite several advantages of MOF-derived carbons as electrode materials for supercapacitors, one difficulty for commercializing these materials may be their high cost. Although there is no reliable production cost information about MOFs, MOFs are still more expensive than other organic-based precursors due to the constituent parts of MOFs. Therefore, future research may include the scale-up synthesis of MOF-derived carbons, development of cost-effective synthetic processes, and expansion of their practical uses.

Author Contributions: Conceptualization, S.H.; writing-review and editing, H.-C.K. and S.H., funding acquisition, S.H., please turn to the CRediT taxonomy for the term explanation. All authors have read and agreed to the published version of the manuscript.

Funding: The Basic Science Research Program of the National Research Foundation of Korea (NRF), funded by the Ministry of Education, Science and Technology, grant number 2018R1D1A1B07043017.

Acknowledgments: This work was supported by the Basic Science Research Program of the National Research Foundation of Korea (NRF), funded by the Ministry of Education, Science and Technology (2018R1D1A1B07043017). This work was also supported by the Hankuk University of Foreign Studies Research Fund of 2020.

Conflicts of Interest: The authors declare no conflict of interest.

\section{References}

1. Liu, Y.; Zhou, G.; Liu, K.; Cui, Y. Design of Complex Nanomaterials for Energy Storage: Past Success and Future Opportunity. Acc. Chem. Res. 2017, 50, 2895-2905. [CrossRef] [PubMed]

2. Zhang, Q.; Uchaker, E.; Candelaria, S.L.; Cao, G. Nanomaterials for energy conversion and storage. Chem. Soc. Rev. 2013, 42, 3127. [CrossRef] [PubMed] 
3. Dunn, B.; Kamath, H.; Tarascon, J.-M. Electrical Energy Storage for the Grid: A Battery of Choices. Science 2011, 334, 928-935. [CrossRef] [PubMed]

4. Goodenough, J.B.; Park, K.-S. The Li-Ion Rechargeable Battery: A Perspective. J. Am. Chem. Soc. 2013, 135, 1167-1176. [CrossRef] [PubMed]

5. Zhang, H.; Li, C.; Eshetu, G.G.; Laruelle, S.; Grugeon, S.; Zaghib, K.; Julien, C.; Mauger, A.; Guyomard, D.; Rojo, T.; et al. From Solid-Solution Electrodes and the Rocking-Chair Concept to Today's Batteries. Angew. Chem. Int. Ed. 2020, 59, 534-538. [CrossRef]

6. Luo, X.; Wang, J.; Dooner, M.; Clarke, J. Overview of current development in electrical energy storage technologies and the application potential in power system operation. Appl. Energy 2015, 137, 511-536. [CrossRef]

7. Zhang, C.; Nicolosi, V. Graphene and MXene-based transparent conductive electrodes and supercapacitors. Energy Storage Mater. 2019, 16, 102-125. [CrossRef]

8. Frackowiak, E.; Béguin, F. Carbon materials for the electrochemical storage of energy in capacitors. Carbon 2001, 39, 937-950. [CrossRef]

9. Inagaki, M.; Konno, H.; Tanaike, O. Carbon materials for electrochemical capacitors. J. Power Sources 2010, 195, 7880-7903. [CrossRef]

10. Zhang, L.L.; Zhao, X.S. Carbon-based materials as supercapacitor electrodes. Chem. Soc. Rev. 2009, $38,2520$. [CrossRef]

11. Díaz-Delgado, R.; Doherty, A.P. Carbons, Ionic Liquids, and Quinones for electrochemical capacitors for electrochemical capacitors. Front. Mater. 2016, 3, 18. [CrossRef]

12. Song, Y.; Liu, T.; Qian, F.; Zhu, C.; Yao, B.; Duoss, E.; Spadaccini, C.; Worsley, M.; Li, Y. Three-dimensional carbon architectures for electrochemical capacitors. J. Colloid Interface Sci. 2018, 509, 529-545. [CrossRef] [PubMed]

13. Gao, B.; Li, X.; Ding, K.; Huang, C.; Li, Q.; Chu, P.K.; Huo, K. Recent progress in nanostructured transition metal nitrides for advanced electrochemical energy storage. J. Mater. Chem. A 2019, 7, 14-37. [CrossRef]

14. Cook, T.R.; Zheng, Y.-R.; Stang, P. Metal-Organic Frameworks and Self-Assembled Supramolecular Coordination Complexes: Comparing and Contrasting the Design, Synthesis, and Functionality of Metal-Organic Materials. Chem. Rev. 2013, 44, 734-777. [CrossRef]

15. Yaghi, O.M.; O'Keeffe, M.; Ockwig, N.W.; Chae, H.K.; Eddaoudi, M.; Kim, J. Reticular synthesis and the design of new materials. Nature 2003, 423, 705-714. [CrossRef] [PubMed]

16. Rowsell, J.L.; Yaghi, O.M. Metal-organic frameworks: A new class of porous materials. Microporous Mesoporous Mater. 2004, 73, 3-14. [CrossRef]

17. Lim, S.; Suh, K.; Kim, Y.; Yoon, M.; Park, H.; Dybtsev, D.; Kim, K. Porous carbon materials with a controllable surface area synthesized from metal-organic frameworks. Chem. Commun. 2012, 48, 7447-7449. [CrossRef]

18. Wang, J.-G.; Liu, H.; Sun, H.; Hua, W.; Wang, H.; Liu, X.; Wei, B. One-pot synthesis of nitrogen-doped ordered mesoporous carbon spheres for high-rate and long-cycle life supercapacitors. Carbon 2018, 127, 85-92. [CrossRef]

19. Ma, Z.; Yang, Z.; Zhang, H.; Liu, Z. Nitrogen-doped microporous carbon materials with uniform pore diameters: Design and applications in $\mathrm{CO}_{2}$ and $\mathrm{H}_{2}$ adsorption. Microporous Mesoporous Mater. 2020, 296, 109992. [CrossRef]

20. Cui, C.; Gao, Y.; Li, J.; Yang, C.; Liu, M.; Jin, H.; Xia, Z.; Dai, L.; Lei, Y.; Wang, J.; et al. Origins of Boosted Charge Storage on Heteroatom-Doped Carbons. Angew. Chem. Int. Ed. 2020, 59, 7928-7933. [CrossRef]

21. Yuan, C.; Liu, X.; Jia, M.; Luo, Z.; Yao, J. Facile preparation of N- and O-doped hollow carbon spheres derived from poly(o-phenylenediamine) for supercapacitors. J. Mater. Chem. A 2015, 3, 3409-3415. [CrossRef]

22. Jin, H.; Feng, X.; Li, J.; Li, M.; Xia, Y.; Yuan, Y.; Yang, C.; Dai, B.; Lini, Z.; Wang, J.; et al. Heteroatom-Doped Porous Carbon Materials with Unprecedented High Volumetric Capacitive Performance. Angew. Chem. Int. Ed. 2019, 58, 2397-2401. [CrossRef] [PubMed]

23. Kim, H.-C.; Hwang, Y.-K.; Seo, S.J.; Huh, S. Gas sorption and supercapacitive properties of hierarchical porous graphitic carbons prepared from the hard-templating of mesoporous $\mathrm{ZnO} / \mathrm{Zn}(\mathrm{OH})_{2}$ composite spheres. J. Colloid Interface Sci. 2020, 564, 193-203. [CrossRef] [PubMed]

24. Yu, X.; Zhou, J.; Li, Q.; Zhao, W.-N.; Zhao, S.; Chen, H.-M.; Tao, K.; Han, L. Bi ${ }_{2} \mathrm{~S}_{3}$ nanorod-stacked hollow microtubes self-assembled from bismuth-based metal-organic frameworks as advanced negative electrodes for hybrid supercapacitors. Dalton Trans. 2019, 48, 9057-9061. [CrossRef] 
25. Du, L.; Xing, L.; Zhang, G.; Sun, S. Metal-organic framework derived carbon materials for electrocatalytic oxygen reactions: Recent progress and future perspectives. Carbon 2020, 156, 77-92. [CrossRef]

26. Lv, S.; Ma, L.; Zhou, Q.; Shen, X.; Tong, H. One-step pyrolysis toward nitrogen-doped hierarchical porous carbons for supercapacitors. J. Mater. Sci. 2020, 55, 1-12. [CrossRef]

27. Liu, B.; Shioyama, H.; Akita, T.; Xu, Q. Metal-Organic Framework as a Template for Porous Carbon Synthesis. J. Am. Chem. Soc. 2008, 130, 5390-5391. [CrossRef]

28. Liu, B.; Shioyama, H.; Jiang, H.-L.; Zhang, X.; Xu, Q. Metal-organic framework (MOF) as a template for syntheses of nanoporous carbons as electrode materials for supercapacitor. Carbon 2010, 48, 456-463. [CrossRef]

29. Hu, J.; Wang, H.; Gao, Q.; Guo, H. Porous carbons prepared by using metal-organic framework as the precursor for supercapacitors. Carbon 2010, 48, 3599-3606. [CrossRef]

30. Jin, S.-L.; Deng, H.-G.; Zhan, L.; Qiao, W.-M.; Ling, L.-C. Synthesis of 3D hierarchical porous carbon as electrode material for electric double layer capacitors. New Carbon Mater. 2012, 27, 87-92. [CrossRef]

31. Yang, S.J.; Kim, T.; Lee, K.; Kim, Y.S.; Yoon, J.; Park, C.R. Solvent evaporation mediated preparation of hierarchically porous metal organic framework-derived carbon with controllable and accessible large-scale porosity. Carbon 2014, 71, 294-302. [CrossRef]

32. Yu, M.; Zhang, L.; He, X.; Yu, H.; Han, J.; Wu, M. 3D interconnected porous carbons from MOF-5 for supercapacitors. Mater. Lett. 2016, 172, 81-84. [CrossRef]

33. Khan, I.A.; Badshah, A.; Khan, I.; Zhao, D.; Nadeem, M.A. Soft-template carbonization approach of MOF-5 to mesoporous carbon nanospheres as excellent electrode materials for supercapacitor. Microporous Mesoporous Mater. 2017, 253, 169-176. [CrossRef]

34. Wang, X.; Ma, H.; He, X.; Wang, J.; Han, J.; Wang, Y. Fabrication of interconnected mesoporous carbon sheets for use in high high-performance supercapacitors. New Carbon Mater. 2017, 32, 213-220. [CrossRef]

35. Yu, F.; Wang, T.; Wen, Z.; Wang, H. High performance all-solid-state SSC based on porous carbon made from a metal-organic framework compound. J. Power Sources 2017, 364, 9-15. [CrossRef]

36. Cendrowski, K.; Kukułka, W.; Kedzierski, T.; Zhang, S.; Mijowska, E. Poly(vinylidene fluoride) and Carbon Derivative Structures from Eco-Friendly MOF-5 for Supercapacitor Electrode Preparation with Improved Electrochemical Performance. Nanomaterials 2018, 8, 890. [CrossRef] [PubMed]

37. Deng, H.; Jin, S.; Zhan, L.; Wang, Y.; Qiao, S.; Tang, L.; Liang, X.; Qiao, W.; Ling, L. Synthesis and electrochemical performance of a laminated hollow porous carbon. Mater. Lett. 2010, 64, 1187-1189. [CrossRef]

38. Aiyappa, H.B.; Pachfule, P.; Banerjee, R.; Kurungot, S. Porous Carbons from Nonporous MOFs: Influence of Ligand Characteristics on Intrinsic Properties of End Carbon. Cryst. Growth Des. 2013, 13, 4195-4199. [CrossRef]

39. Jeon, J.-W.; Sharma, R.; Meduri, P.; Arey, B.W.; Schaef, H.T.; Lutkenhaus, J.L.; Lemmon, J.P.; Thallapally, P.K.; Nandasiri, M.I.; McGrail, B.P.; et al. In Situ One-Step Synthesis of Hierarchical Nitrogen-Doped Porous Carbon for High-Performance Supercapacitors. ACS Appl. Mater. Interfaces 2014, 6, 7214-7222. [CrossRef]

40. Pachfule, P.; Shinde, D.; Majumder, M.; Xu, Q. Fabrication of carbon nanorods and graphene nanoribbons from a metal-organic framework. Nat. Chem. 2016, 8, 718-724. [CrossRef]

41. Cao, X.-M.; Sun, Z.-J.; Zhao, S.-Y.; Wang, B.; Gao, M.-L. MOF-derived sponge-like hierarchical porous carbon for flexible all-solid-state supercapacitors. Mater. Chem. Front. 2018, 2, 1692-1699. [CrossRef]

42. Pan, Y.; Zhao, Y.; Mu, S.; Wang, Y.; Jiang, C.; Liu, Q.; Fang, Q.; Xue, M.; Qiu, S. Cation exchanged MOF-derived nitrogen-doped porous carbons for $\mathrm{CO}_{2}$ capture and supercapacitor electrode materials. J. Mater. Chem. A 2017, 5, 9544-9552. [CrossRef]

43. Khan, I.A.; Choucair, M.; Imran, M.; Badshah, A.; Nadeem, M.A. Supercapacitive behavior of microporous carbon derived from zinc based metal-organic framework and furfuryl alcohol. Int. J. Hydrog. Energy 2015, 40, 13344-13356. [CrossRef]

44. Wang, Q.; Lu, X.; Chen, Z. From condiment to metal-organic framework and its derived 3D architecture nanoporous carbon for supercapacitor electrodes. Mater. Res. Express 2017, 4, 025505. [CrossRef]

45. Wang, Q.; Wu, D.; Liu, C.-L. Electrostatic assembly of graphene oxide with Zinc-Glutamate metal-organic framework crystalline to synthesis nanoporous carbon with enhanced capacitive performance. Electrochim. Acta 2018, 270, 183-191. [CrossRef] 
46. Li, W.; Zhang, F.; Dou, Y.; Wu, Z.; Liu, H.; Qian, X.; Gu, D.; Xia, Y.; Tu, B.; Zhao, D. A Self-Template Strategy for the Synthesis of Mesoporous Carbon Nanofibers as Advanced Supercapacitor Electrodes. Adv. Energy Mater. 2011, 1, 382-386. [CrossRef]

47. Zhu, D.; Li, H.; Su, Y.; Jiang, M. Pyridine-containing metal-organic frameworks as precursor for nitrogen-doped porous carbons with high-performance capacitive behavior. J. Solid State Electrochem. 2017, 21, 2037-2045. [CrossRef]

48. Hwang, J.; Yan, R.; Oschatz, M.; Schmidt, B.V.K.J. Solvent mediated morphology control of zinc MOFs as carbon templates for application in supercapacitors. J. Mater. Chem. A 2018, 6, 23521-23530. [CrossRef]

49. Jiang, H.; Liu, B.; Lan, Y.; Kuratani, K.; Akita, T.; Longley, L.; Johnstone, D.N.; Chater, P.A.; Li, S.; Coulet, M.V.; et al. From Metal-Organic Framework to Nanoporous Carbon: Toward a Very High Surface Area and Hydrogen Uptake. J. Am. Chem. Soc. 2011, 133, 11854-11857. [CrossRef]

50. Chaikittisilp, W.; Hu, M.; Wang, H.; Huang, H.-S.; Fujita, T.; Wu, K.C.-W.; Chen, L.-C.; Yamauchi, Y.; Ariga, K. Nanoporous carbons through direct carbonization of a zeolitic imidazolate framework for supercapacitor electrodes. Chem. Commun. 2012, 48, 7259-7261. [CrossRef]

51. Amali, A.J.; Sun, J.; Xu, Q. From assembled metal-organic framework NPs to hierarchically porous carbon for electrochemical energy storage. Chem. Commun 2014, 50, 1519-1522. [CrossRef] [PubMed]

52. Xu, L.; Zhang, X.; Chen, J. Synthesis and Electrochemical Supercapacitive Properties of Nitrogen-Doped Mesoporous Carbons. Acta Phys. Chim. Sin. 2014, 30, 1274-1280.

53. Yu, G.; Zou, X.; Wang, A.; Sun, J.; Zhu, G. Generation of bimodal porosity via self-extra porogenes in nanoporous carbons for supercapacitor application. J. Mater. Chem. A 2014, 2, 15420-15427. [CrossRef]

54. Salunkhe, R.R.; Kamachi, Y.; Torad, N.L.; Hwang, S.M.; Sun, Z.; Dou, S.X.; Kim, J.H.; Yamauchi, Y. Fabrication of SSCs based on MOF-derived nanoporous carbons. J. Mater. Chem. A 2014, 2, 19848-19854. [CrossRef]

55. Zhong, S.; Zhan, C.; Cao, D. Zeolitic imidazolate framework-derived nitrogen-doped porous carbons as high performance supercapacitor electrode materials. Carbon 2015, 85, 51-59. [CrossRef]

56. Salunkhe, R.; Young, C.; Tang, J.; Takei, T.; Ide, Y.; Kobayashi, N.; Yamauchi, Y. A high-performance supercapacitor cell based on ZIF-8-derived nanoporous carbon using an organic electrolyte. Chem. Commun. 2016, 52, 4764-4767. [CrossRef]

57. Bao, W.; Mondal, A.K.; Xu, J.; Wang, C.; Su, D.; Wang, G.3D hybride porous carbon derived from carbonization of metal organic frameworks for high performance supercapacitors. J. Power Sources 2016, 325, $286-291$. [CrossRef]

58. Young, C.; Salunkhe, R.R.; Tang, J.; Hu, C.; Shahabuddin, M.; Yanmaz, E.; Hossain, M.S.A.; Kim, J.H.; Yamauchi, Y. A Zeolitic imidazolate framework (ZIF-8) derived nanoporous carbon: The effect of carbonization temperature on the supercapacitor performance in an aqueous electrolyte. Phys. Chem. Chem. Phys. 2016, 18, 29308-29315. [CrossRef]

59. Chen, L.-F.; Lu, Y.; Yu, L.; Lou, X.W. (David) Designed formation of hollow particle-based nitrogen-doped carbon nanofibers for high-performance supercapacitors. Energy Environ. Sci. 2017, 10, 1777-1783. [CrossRef]

60. Wang, C.; Liu, C.; Li, J.; Sun, X.; Shen, J.; Han, W.; Wang, L. Electrospun metal-organic framework derived hierarchical carbon nanofibers with high performance for supercapacitors. Chem. Commun. 2017, 53, 1751-1754. [CrossRef]

61. Yao, Y.; Wu, H.; Huang, L.; Li, X.; Yu, L.; Zeng, S.; Zeng, X.; Yang, J.; Zou, J.Z. Nitrogen-enriched hierarchically porous carbon nanofiber network as a binder-free electrode for high-performance supercapacitors. Electrochim. Acta 2017, 246, 606-614. [CrossRef]

62. Dahal, B.; Mukhiya, T.; Ojha, G.P.; Muthurasu, A.; Chae, S.-H.; Kim, T.; Kang, D.; Kim, H.Y. In-built fabrication of MOF assimilated B/N co-doped 3D porous carbon nanofiber network as a binder-free electrode for supercapacitors. Electrochim. Acta 2019, 301, 209-219. [CrossRef]

63. Gong, Y.; Chen, R.; Xu, H.; Yu, C.; Zhao, X.; Sun, Y.; Hui, Z.; Zhou, J.; An, J.; Du, Z.; et al. Polarity-assisted formation of hollow-frame sheathed nitrogen-doped nanofibrous carbon for supercapacitors. Nanoscale 2019, 11, 2492-2500. [CrossRef] [PubMed]

64. Hou, Y.-N.; Zhao, Z.; Yu, Z.; Zhang, S.; Li, S.; Yang, J.; Zhang, H.; Liu, C.; Wang, Z.-Y.; Qiu, J. Microporous MOFs Engaged in the Formation of Nitrogen-Doped Mesoporous Carbon Nanosheets for High-Rate Supercapacitors. Chem. A Eur. J. 2018, 24, 2681-2686. [CrossRef] [PubMed] 
65. Wang, Q.; Xia, W.; Guo, W.; An, L.; Xia, D.; Zou, R. Functional Zeolitic-Imidazolate-Framework-Templated Porous Carbon Materials for $\mathrm{CO}_{2}$ Capture and Enhanced Capacitors. Chem. Asian J. 2013, 8, 1879-1885. [CrossRef]

66. Zhang, P.; Sun, F.; Shen, Z.; Cao, D. ZIF-derived porous carbon: A promising supercapacitor electrode material. J. Mater. Chem. A 2014, 2, 12873-12880. [CrossRef]

67. Joshi, B.; Park, S.; Samuel, E.; Jo, H.S.; An, S.; Kim, M.-W.; Swihart, M.T.; Yun, J.M.; Kim, K.H.; Yoon, S.S. Zeolitic imidazolate framework-7 textile-derived nanocomposite fibers as freestanding supercapacitor electrodes. J. Electroanal. Chem. 2018, 810, 239-247. [CrossRef]

68. Hao, F.; Li, L.; Zhang, X.; Chen, J. Synthesis and electrochemical capacitive properties of nitrogen-doped porous carbon micropolyhedra by direct carbonization of zeolitic imidazolate framework-11. Mater. Res. Bull. 2015, 66, 88-95. [CrossRef]

69. Zhao, K.; Liu, S.; Ye, G.; Gan, Q.; Zhou, Z.; He, Z. High-yield bottom-up synthesis of 2D metal-organic frameworks and their derived ultrathin carbon nanosheets for energy storage. J. Mater. Chem. A 2018, 6, 2166-2175. [CrossRef]

70. Zou, J.; Liu, P.; Huang, L.; Zhang, Q.; Lan, T.; Zeng, S.; Zeng, X.; Yu, L.; Liu, S.; Wu, H.; et al. Ultrahigh-content nitrogen-decorated nanoporous carbon derived from metal organic frameworks and its application in supercapacitors. Electrochim. Acta 2018, 271, 599-607. [CrossRef]

71. Sun, J.-K.; Xu, Q. From metal-organic framework to carbon: Toward controlled hierarchical pore structures via a double-template approach. Chem. Commun. 2014, 50, 13502-13505. [CrossRef] [PubMed]

72. Liu, Y.; Xu, J.; Liu, S. Porous carbon nanosheets derived from Al-based MOFs for supercapacitors. Microporous Mesoporous Mater. 2016, 236, 94-99. [CrossRef]

73. Li, Z.-X.; Zhang, X.; Liu, Y.-C.; Zou, K.-Y.; Yue, M.-L. Controlling the BET Surface Area of Porous Carbon by Using the $\mathrm{Cd} / \mathrm{C}$ Ratio of a Cd-MOF Precursor and Enhancing the Capacitance by Activation with $\mathrm{KOH}$. Chem. A Eur. J. 2016, 22, 17734-17747. [CrossRef]

74. Yue, M.; Jiang, Y.; Zhang, L.; Yu, C.; Zou, K.; Li, Z. Solvent-Induced Cadmium(II) Metal-Organic Frameworks with Adjustable Guest-Evacuated Porosity: Application in the Controllable Assembly of MOF-Derived Porous Carbon Materials for Supercapacitors. Chem. A Eur. J. 2017, 23, 15680-15693. [CrossRef]

75. Torad, N.L.; Salunkhe, R.R.; Li, Y.; Hamoudi, H.; Imura, M.; Sakka, Y.; Hu, C.-C.; Yamauchi, Y. Electric Double-Layer Capacitors Based on Highly Graphitized Nanoporous Carbons Derived from ZIF-67. Chem. A Eur. J. 2014, 20, 7895-7900. [CrossRef] [PubMed]

76. Li, Z.-X.; Zou, K.-Y.; Zhang, X.; Han, T.; Yang, Y. Hierarchically Flower-like N-Doped Porous Carbon Materials Derived from an Explosive 3-Fold Interpenetrating Diamondoid Copper Metal-Organic Framework for a Supercapacitor. Inorg. Chem. 2016, 55, 6552-6562. [CrossRef] [PubMed]

77. Li, Z.-X.; Yang, B.-L.; Zou, K.-Y.; Kong, L.; Yue, M.-L.; Duan, H.-H. Novel porous carbon nanosheet derived from a 2D Cu-MOF: Ultrahigh porosity and excellent performances in the supercapacitor cell. Carbon 2019, 144, 540-548. [CrossRef]

78. Su, P.; Jiang, L.; Zhao, J.; Yan, J.; Li, C.; Yang, Q. Mesoporous graphitic carbon nanodisks fabricated via catalytic carbonization of coordination polymers. Chem. Commun. 2012, 48, 8769. [CrossRef]

79. Zhuang, J.-L.; Liu, X.-Y.; Mao, H.-L.; Wang, C.; Cheng, H.; Zhang, Y.; Du, X.; Zhu, S.-B.; Ren, B. Hollow carbon polyhedra derived from room temperature synthesized iron-based metal-organic frameworks for supercapacitors. J. Power Sources 2019, 429, 9-16. [CrossRef]

80. Jayaramulu, K.; Dubal, D.P.; Nagar, B.; Ranc, V.; Tomanec, O.; Petr, M.; Datta, K.K.R.; Zbořil, R.; Gómez-Romero, P.; Fischer, R.A. Ultrathin Hierarchical Porous Carbon Nanosheets for High-Performance Supercapacitors and Redox Electrolyte Energy Storage. Adv. Mater. 2018, 30, e1705789. [CrossRef]

81. Li, T.; Ma, S.; Yang, H.; Xu, Z.-L. Preparation of Carbonized MOF/ $\mathrm{MgCl}_{2}$ Hybrid Products as Dye Adsorbent and Supercapacitor: Morphology Evolution and Mg Salt Effect. Ind. Eng. Chem. Res. 2019, 58, 1601-1612. [CrossRef]

82. Sun, L.; Tian, C.; Fu, Y.; Yang, Y.; Yin, J.; Wang, L.; Fu, H. Nitrogen-Doped Porous Graphitic Carbon as an Excellent Electrode Material for Advanced Supercapacitors. Chem. A Eur. J. 2013, 20, 564-574. [CrossRef]

83. Tong, Y.; Ji, N.; Wang, P.; Zhou, H.; Akhtar, K.; Shen, X.; Zhang, J.; Yuan, A. Nitrogen-doped carbon composites derived from 7,7,8,8-tetracyanoquinodimethane-based metal-organic frameworks for supercapacitors and lithium-ion batteries. RSC Adv. 2017, 7, 25182-25190. [CrossRef] 
84. Chang, T.-H.; Young, C.; Lee, M.-H.; Salunkhe, R.R.; AlShehri, S.M.; Ahamad, T.; Islam, T.; Wu, K.C.-W.; Hossain, S.A.; Yamauchi, Y.; et al. Synthesis of MOF-525 Derived Nanoporous Carbons with Different Particle Sizes for Supercapacitor Application. Chem. Asian J. 2017, 12, 2857-2862. [CrossRef] [PubMed]

85. Liu, M.; Zhao, F.; Zhu, D.; Duan, H.; Lv, Y.; Li, L.; Gan, L. Ultramicroporous carbon NPs derived from metal-organic framework NPs for high-performance supercapacitors. Mat. Chem. Phys. 2018, 211, $234-241$. [CrossRef]

86. Yuan, D.; Chen, J.; Tan, S.; Xia, N.; Liu, Y. Worm-like mesoporous carbon synthesized from metal-organic coordination polymers for supercapacitors. Electrochem. Commun. 2009, 11, 1191-1194. [CrossRef]

87. Mo, S.; Sun, Z.; Huang, X.; Zou, W.; Chen, J.; Yuan, D. Synthesis, characterization and supercapacitive properties of hierarchical porous carbons. Synth. Met. 2012, 162, 85-88. [CrossRef]

88. Yan, X.; Li, X.; Yan, Z.; Komarneni, S. Porous carbons prepared by direct carbonization of MOFs for supercapacitors. Appl. Surf. Sci. 2014, 308, 306-310. [CrossRef]

89. Yue, M.-L.; Yu, C.-Y.; Duan, H.-H.; Yang, B.-L.; Meng, X.-X.; Li, Z.X. Six Isomorphous Window-Beam MOFs: Explore the Effects of Metal Ions on MOF-Derived Carbon for Supercapacitors. Chem. A Eur. J. 2018, 24, 16160-16169. [CrossRef]

90. Banerjee, A.; Upadhyay, K.K.; Puthusseri, D.; Aravindan, V.; Madhavi, S.; Ogale, S. MOF-derived crumpled-sheet-assembled perforated carbon cuboids as highly effective cathode active materials for ultra-high energy density Li-ion hybrid electrochemical capacitors (Li-HECs). Nanoscale 2014, 6, 4387. [CrossRef]

91. Xu, J.; Li, Y.; Wang, L.; Cai, Q.; Li, Q.; Gao, B.; Zhang, X.; Huo, K.; Chu, P.K. High-energy lithium-ion hybrid supercapacitors composed of hierarchical urchin-like $\mathrm{WO}_{3} / \mathrm{C}$ anodes and MOF-derived polyhedral hollow carbon cathodes. Nanoscale 2016, 8, 16761-16768. [CrossRef] [PubMed]

92. Yi, H.; Wang, H.; Jing, Y.; Peng, T.; Wang, X. ASSCs based on carbon nanotubes@NiO ultrathin nanosheets core-shell composites and MOF-derived porous carbon polyhedrons with super-long cycle life. J. Power Sources 2015, 285, 281-290. [CrossRef]

93. Javed, M.S.; Shah, H.U.; Shaheen, N.; Lin, R.; Qiu, M.; Xie, J.; Li, J.; Raza, R.; Maia, W.; Hu, C. High energy density hybrid supercapacitor based on 3D mesoporous cuboidal $\mathrm{Mn}_{2} \mathrm{O}_{3}$ and MOF-derived porous carbon polyhedrons. Electrochim. Acta 2018, 282,1-9. [CrossRef]

94. Javed, M.S.; Shaheen, N.; Hussain, S.; Li, J.; Shah, S.S.A.; Abbas, Y.; Ahmad, M.A.; Raza, R.; Mai, W. An ultra-high energy density flexible aSSC based on hierarchical fabric decorated with $2 \mathrm{D}$ bimetallic oxide nanosheets and MOF-derived porous carbon polyhedra. J. Mater. Chem. A 2019, 7, 946-957. [CrossRef]

95. SufyanJavedabc, M.; Aslam, M.K.; Asime, S.; Batoolf, S.; Idreesgh, M.; Hussaing, S.; Shah, S.S.A.; Saleemi, M.; Maia, W.; Hub, C. High-performance flexible hybrid-supercapacitor enabled by pairing binder-free ultrathin $\mathrm{Ni}-\mathrm{Co}-\mathrm{O}$ nanosheets and metal-organic framework derived N-doped carbon nanosheets. Electrochim. Acta 2020, 349, 136384. [CrossRef]

96. Guan, C.; Zhao, W.; Hu, Y.; Lai, Z.; Li, S.; Sun, S.; Zhang, H.; Cheetham, A.K.; Wang, J. Cobalt oxide and $\mathrm{N}$-doped carbon nanosheets derived from a single two-dimensional metal-organic framework precursor and their application in flexible aSSCs. Nanoscale Horiz. 2017, 2, 99-105. [CrossRef] [PubMed]

97. Guan, C.; Liu, X.; Ren, W.; Li, X.; Cheng, C.; Wang, J. Rational Design of Metal-Organic Framework Derived Hollow $\mathrm{NiCO}_{2} \mathrm{O}_{4}$ Arrays for Flexible Supercapacitor and Electrocatalysis. Adv. Energy Mater. 2017, 7, 1602391. [CrossRef]

98. Qu, C.; Liang, Z.; Jiao, Y.; Zhao, B.; Zhu, B.; Dang, D.; Dai, S.; Chen, Y.; Zou, R.; Liu, M. “One-for-All” Strategy in Fast Energy Storage: Production of Pillared MOF Nanorod-Templated Positive/Negative Electrodes for the Application of High-Performance Hybrid Supercapacitor. Small 2018, 14, 1800285. [CrossRef]

99. Wu, M.; Hsu, W. Nickel NPs embedded in partially graphitic porous carbon fabricated by direct carbonization of nickel-organic framework for high-performance supercapacitors. J. Power Sources 2015, 274, 1055-1062. [CrossRef]

100. Yang, J.; Guo, J.; Guo, X.; Chen, L. In-situ growth carbon nanotubes deriving from a new metal-organic framework for high-performance all-solid-state supercapacitors. Mater. Lett. 2019, 236, 739-742. [CrossRef]

101. Kumar, M.; Kim, M.S.; Jeong, D.I.; Humayoun, U.B.; Yoon, D.H. A Core-Shell Assembly of Hierarchical Porous Ni@C Nanospheres Synthesized from Metal-Organic Framework for Electrochemical Energy Application. Phys. Status Solidi A 2019, 216, 1800921. [CrossRef] 
102. Yang, Y.-W.; Liu, X.-H.; Gao, E.-P.; Feng, T.-T.; Jiang, W.-J.; Wu, J.; Jiang, H.; Sun, B. Self-template construction of nanoporous carbon nanorods from a metal-organic framework for supercapacitor electrodes. RSC Adv. 2018, 8, 20655-20660. [CrossRef]

103. Yu, F.; Xiong, X.; Zhou, L.-Y.; Li, J.; Liang, J.-Y.; Hu, S.-Q.; Lu, W.-T.; Li, B.; Zhou, H.-C. Hierarchical nickel/phosphorus/nitrogen/carbon composites templated by one metal-organic framework as highly efficient supercapacitor electrode materials. J. Mater. Chem. A 2019, 7, 2875-2883. [CrossRef]

104. Wei, F.; Jiang, J.; Yu, G.; Sui, Y. A novel cobalt-carbon composite for the electrochemical supercapacitor electrode material. Mater. Lett. 2015, 146, 20-22. [CrossRef]

105. Yang, J.; Zeng, C.; Wei, F.; Jiang, J.; Chen, K.; Lu, S. Cobalt-carbon derived from zeolitic imidazolate framework on Ni foam as high-performance supercapacitor electrode material. Mater. Des. 2015, 83, 552-556. [CrossRef]

106. Basu, A.; Roy, K.; Sharma, N.; Nandi, S.; Vaidhyanathan, R.; Rane, S.; Rode, C.V.; Ogale, S.B. CO 2 Laser Direct Written MOF-Based Metal-Decorated and Heteroatom-Doped Porous Graphene for Flexible All-Solid-State Microsupercapacitor with Extremely High Cycling Stability. ACS Appl. Mater. Interfaces 2016, 8, 31841-31848. [CrossRef]

107. Díaz-Duran, A.K.; Montiel, G.; Viva, F.A.; Roncaroli, F. Co,N-doped mesoporous carbons cobalt derived from coordination polymer as supercapacitors. Electrochim. Acta 2019, 299, 987-998. [CrossRef]

108. Klose, M.; Reinhold, R.; Pinkert, K.; Uhlemann, M.; Wolke, F.; Balach, J.; Jaumann, T.; Stoeck, U.; Eckert, J.; Giebeler, L. Hierarchically nanostructured hollow carbon nanospheres for ultra-fast and long-life energy storage. Carbon 2016, 106, 306-313. [CrossRef]

109. Young, C.; Kim, J.; Kaneti, Y.V.; Yamauchi, Y. One-Step Synthetic Strategy of Hybrid Materials from Bimetallic Metal-Organic Frameworks for Supercapacitor Applications. ACS Appl. Energy Mater. 2018, 1, 2007-2015. [CrossRef]

110. Qiu, J.; Dai, E.; Xu, J.; Liu, S.; Liu, Y. Functionalized MOFs-controlled formation of novel Ni-Co nanoheterostructure@carbon hybrid as the electrodes for supercapacitor. Mater. Lett. 2018, 216, 207-211. [CrossRef]

111. Salunkhe, R.R.; Tang, J.; Kamachi, Y.; Nakato, T.; Kim, J.H.; Yamauchi, Y. ASSCs Using 3D Nanoporous Carbon and Cobalt Oxide Electrodes Synthesized from a Single Metal-Organic Framework. ACS Nano 2015, 9, 6288-6296. [CrossRef] [PubMed]

112. Yang, H.; Zhao, D.; Meng, W.; Zhao, M.; Duan, Y.; Han, X.; Tian, X. Nickel NPs incorporated into N-doped porous carbon derived from $\mathrm{N}$-containing nickel-MOF for high-performance supercapacitors. J. Alloys Compd. 2019, 782, 905-914. [CrossRef]

113. Wen, P.; Li, Z.; Gong, P.; Sun, J.; Wang, J.; Yang, S. Design and fabrication of carbonized rGO/CMOF-5 hybrids for supercapacitor applications. RSC Adv. 2016, 6, 13264-13271. [CrossRef]

114. Wang, L.; Wei, T.; Sheng, L.; Jiang, L.; Wu, X.; Zhou, Q.; Yuan, B.; Yue, J.; Liu, Z.; Fan, Z. “Brick-and-mortar" sandwiched porous carbon building constructed by metal-organic framework and graphene: Ultrafast charge/discharge rate up to $2 \mathrm{~V} \mathrm{~s}^{-1}$ for supercapacitors. Nano Energy 2016, 30, 84-92. [CrossRef]

115. Li, C.; Hu, C.; Zhao, Y.; Song, L.; Zhang, J.; Huang, R.; Qu, L. Decoration of graphene network with metal-organic frameworks for enhanced electrochemical capacitive behavior. Carbon 2014, 78, 231-242. [CrossRef]

116. Zhu, Y.; Tao, Y. Constructing nitrogen-doped nanoporous carbon/graphene networks as promising electrode materials for supercapacitive energy storage. RSC Adv. 2016, 6, 28451-28457. [CrossRef]

117. Jiang, X.; Sun, L.; Xu, F. ZIF-8 Derived Graphene-Based Nitrogen-Doped Porous Carbonas Highly Efficient Supercapacitor Electrodes. Mater. Sci. Forum 2016, 852, 829-834. [CrossRef]

118. Xin, L.; Liu, Q.; Liu, J.; Chen, R.; Li, R.; Li, Z.; Wang, J. Hierarchical metal-organic framework derived nitrogen-doped porous carbon/graphene composite for high performance supercapacitors. Electrochim. Acta 2017, 248, 215-224. [CrossRef]

119. Martín-Jimeno, F.J.; Suárez-García, F.; Paredes, J.I.; Enterría, M.; Pereira, M.F.R.; Martins, J.I.; Figueiredo, J.L.; Martínez-Alonso, A.; Tascón, J.M.D. A “Nanopore Lithography” Strategy for Synthesizing Hierarchically Micro/Mesoporous Carbons from ZIF-8/Graphene Oxide Hybrids for Electrochemical Energy Storage. ACS Appl. Mater. Interfaces 2017, 9, 44740-44755. [CrossRef]

120. Wang, L.; Wang, C.; Wang, H.; Jiao, X.; Ouyang, Y.; Xia, X.; Lei, W.; Hao, Q. ZIF-8 nanocrystals derived $\mathrm{N}$-doped carbon decorated graphene sheets for SSCs. Electrochim. Acta 2018, 289, 494-502. 
121. Liu, W.; Wang, K.; Li, C.; Zhang, X.; Sun, X.; Han, J.; Wu, X.-L.; Li, F.; Ma, Y. Boosting solid-state flexible supercapacitors by employing tailored hierarchical carbon electrodes and a high-voltage organic gel electrolyte. J. Mater. Chem. A 2018, 6, 24979-24987. [CrossRef]

122. Lu, H.; Liu, S.; Zhang, Y.; Huang, Y.; Zhang, C.; Liu, T. Nitrogen-Doped Carbon Polyhedra Nanopapers: An Advanced Binder-Free Electrode for High-Performance Supercapacitors. ACS Sustain. Chem. Eng. 2019, 7, 5240-5248. [CrossRef]

123. Yu, H.; Zhu, W.; Zhou, H.; Liu, J.; Yang, Z.; Hu, X.; Yuan, A. Porous carbon derived from metal-organic framework@graphene quantum dots as electrode materials for supercapacitors and lithium-ion batteries. RSC Adv. 2019, 9, 9577-9583. [CrossRef]

124. Xu, X.; Wang, M.; Liu, Y.; Lu, T.; Pan, L. Metal-organic framework-engaged formation of a hierarchical hybrid with carbon nanotube inserted porous carbon polyhedra for highly efficient capacitive deionization. J. Mater. Chem. A 2016, 4, 5467-5473. [CrossRef]

125. Wang, Y.; Chen, B.; Zhang, Y.; Fu, L.; Zhu, Y.; Zhang, L.; Wu, Y. ZIF-8@MWCNT-derived carbon composite as electrode of high performance for supercapacitor. Electrochim. Acta 2016, 213, 260-269. [CrossRef]

126. Xu, X.; Wang, M.; Liu, Y.; Li, Y.; Lu, T.; Pan, L. In situ construction of carbon nanotubes/nitrogen-doped carbon polyhedral hybrids for supercapacitors. Energy Storage Mater. 2016, 5, 132-138. [CrossRef]

127. Li, X.; Hao, C.; Tang, B.; Wang, Y.; Liu, M.; Wang, Y.; Zhu, Y.; Lu, C.; Tang, Z. Supercapacitor electrode materials with hierarchically structured pores from carbonization of MWCNTs and ZIF-8 composites. Nanoscale 2017, 9, 2178-2187. [CrossRef]

128. Liu, Y.; Li, G.; Chen, Z.; Peng, X. CNT-threaded N-doped porous carbon film as binder-free electrode for high-capacity supercapacitor and Li-S battery. J. Mater. Chem. A 2017, 5, 9775-9784. [CrossRef]

129. Wan, L.; Shamsaei, E.; Easton, C.; Yu, D.; Liang, Y.; Chen, X.; Abbasi, Z.; Akbari, A.; Zhang, X.; Wang, H. ZIF-8 derived nitrogen-doped porous carbon/carbon nanotube composite for high-performance supercapacitor. Carbon 2017, 121, 330-336. [CrossRef]

130. Tang, Z.; Zhang, G.; Zhang, H.; Wang, L.; Shi, H.; Wei, D.; Duan, H. MOF-derived N-doped carbon bubbles on carbon tube arrays for flexible high-rate supercapacitors. Energy Storage Mater. 2018, 10, 75-84. [CrossRef]

131. Cai, C.; Zou, Y.; Xiang, C.; Chu, H.; Qiu, S.; Sui, Q.; Xu, F.; Sun, L.; Shah, A. Broccoli-like porous carbon nitride from ZIF-8 and melamine for high performance supercapacitors. Appl. Surf. Sci. 2018, 440, 47-54. [CrossRef]

132. Kong, L.; Chen, Q.; Shena, X.; Xu, Z.; Xu, C.; Ji, Z.; Zhu, J. MOF derived nitrogen-doped carbon polyhedrons decorated on graphitic carbon nitride sheets with enhanced electrochemical capacitive energy storage performance. Electrochim. Acta 2018, 265, 651-661. [CrossRef]

133. Lu, C.; Wang, N.; Zhao, J.; Han, S.; Chen, W. A Continuous Carbon Nitride Polyhedron Assembly for High-Performance Flexible Supercapacitors. Adv. Funct. Mater. 2017, 27, 1606219. [CrossRef]

134. Jiang, M.; Cao, X.; Zhu, D.; Duan, Y.; Zhang, J.-M. Hierarchically Porous N-doped Carbon Derived from ZIF-8 Nanocomposites for Electrochemical Applications. Electrochim. Acta 2016, 196, 699-707. [CrossRef]

135. Li, Z.; Mi, H.; Liu, L.; Bai, Z.; Zhang, J.; Zhang, Q.; Qiu, J. Nano-sized ZIF-8 anchored polyelectrolyte-decorated silica for Nitrogen-Rich Hollow Carbon Shell Frameworks toward alkaline and neutral supercapacitors. Carbon 2018, 136, 176-186. [CrossRef]

136. Li, Z.; Liu, X.; Wang, L.; Bu, F.; Wei, J.; Pan, D.; Wu, M. Hierarchical 3D All-Carbon Composite Structure Modified with N-Doped Graphene Quantum Dots for High-Performance Flexible Supercapacitors. Small 2018, 14, 1801498. [CrossRef]

137. Xia, W.; Qu, C.; Liang, Z.; Zhao, B.; Dai, S.; Qiu, B.; Jiao, Y.; Zhang, Q.; Huang, X.; Guo, W.; et al. High-Performance Energy Storage and Conversion Materials Derived from a Single Metal-Organic Framework/Graphene Aerogel Composite. Nano Lett. 2017, 17, 2788-2795. [CrossRef]

138. Liu, Y.; Li, G.; Guo, Y.; Ying, Y.; Peng, X. Flexible and Binder-Free Hierarchical Porous Carbon Film for Supercapacitor Electrodes Derived from MOFs/CNT. ACS Appl. Mater. Interfaces 2017, 9, 14043-14050. [CrossRef]

139. Mao, M.L.; Sun, L.; Xu, F. Metal-Organic Frameworks/Carboxyl Graphene Derived Porous Carbon as a Promising Supercapacitor Electrode Material. Key Eng. Mater. 2017, 727, 756-763. [CrossRef]

140. Wan, L.; Wei, J.; Liang, Y.; Hu, Y.; Chen, X.; Shamsaei, E.; Ou, R.; Zhang, X.; Wang, H. ZIF-derived nitrogen-doped carbon/3D graphene frameworks for all-solid-state supercapacitors. RSC Adv. 2016, 6, 76575-76581. [CrossRef] 
141. Tang, J.; Salunkhe, R.; Liu, J.; Torad, N.L.; Imura, M.; Furukawa, S.; Yamauchi, Y. Thermal Conversion of Core-Shell Metal-Organic Frameworks: A New Method for Selectively Functionalized Nanoporous Hybrid Carbon. J. Am. Chem. Soc. 2015, 137, 1572-1580. [CrossRef]

142. Kim, J.; Young, C.; Lee, J.; Park, M.-S.; Shahabuddin, M.; Yamauchi, Y.; Kim, J.H. CNTs grown on nanoporous carbon from zeolitic imidazolate frameworks for supercapacitors. Chem. Commun. 2016, 52, 13016-13019. [CrossRef] [PubMed]

143. Meng, X.; Wan, C.; Jiang, X.; Ju, X. Rodlike $\mathrm{CeO}_{2}$ /carbon nanocomposite derived from metal-organic frameworks for enhanced supercapacitor applications. J. Mater. Sci. 2018, 53, 13966-13975. [CrossRef]

144. Zhang, C.; Xiao, J.; Lv, X.; Qian, L.; Yuan, S.; Wang, S.; Lei, P. Hierarchically porous $\mathrm{Co}_{3} \mathrm{O}_{4} / \mathrm{C}$ nanowire arrays derived from a metal-organic framework for high performance supercapacitors and the oxygen evolution reaction. J. Mater. Chem. A 2016, 4, 16516-16523. [CrossRef]

145. Young, C.; Wang, J.; Kim, J.; Sugahara, Y.; Henzie, J.; Yamauchi, Y. Controlled Chemical Vapor Deposition for Synthesis of Nanowire Arrays of Metal-Organic Frameworks and Their Thermal Conversion to Carbon/Metal Oxide Hybrid Materials. Chem. Mater. 2018, 30, 3379-3386. [CrossRef]

146. Azad, U.P.; Ghosh, S.; Verma, C.J.; Singh, A.K.; Singh, A.K.; Prakash, R. Study of the Capacitive Behavior of MOF-Derived Nanocarbon Polyhedra. ChemistrySelect 2018, 3, 6107-6111. [CrossRef]

147. Khan, I.A.; Badshah, A.; Nadeem, M.A.; Haider, N.; Nadeem, M.A. A copper based metal-organic framework as single source for the synthesis of electrode materials for high-performance supercapacitors and glucose sensing applications. Int. J. Hydrog. Energy 2014, 39, 19609-19620. [CrossRef]

148. Meng, W.; Chen, W.; Zhao, L.; Huang, Y.; Zhu, M.; Huang, Y.; Fu, Y.; Geng, F.; Yu, J.; Chen, X.; et al. Porous $\mathrm{Fe}_{3} \mathrm{O}_{4}$ /carbon composite electrode material prepared from metal-organic framework template and effect of temperature on its capacitance. Nano Energy 2014, 8, 133-140. [CrossRef]

149. Sui, Y.; Zhang, D.; Han, Y.; Sun, Z.; Qi, J.; Wei, F.; He, Y.; Meng, Q. Effects of Carbonization Temperature on Nature of Nanostructured Electrode Materials Derived from Fe-MOF for Supercapacitors. Electron. Mater. Lett. 2018, 14, 548-555. [CrossRef]

150. Wang, K.; Lu, A.; Zhang, Z.; Shi, X.; Ma, X. High nitrogen-doped carbon/ $\mathrm{Mn}_{3} \mathrm{O}_{4}$ hybrids synthesized from nitrogen-rich coordination polymer particles as supercapacitor electrodes. Dalton Trans. 2015, 44, 151-157. [CrossRef]

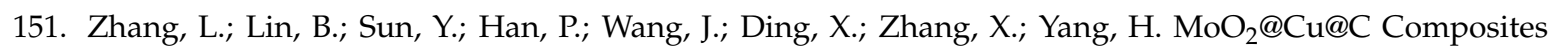
Prepared by Using Polyoxometalates@Metal-Organic Frameworks as Template for All-Solid-State Flexible Supercapacitor. Electrochim. Acta 2016, 188, 490-498. [CrossRef]

152. Zhang, Q.; Zhong-Ai, H.; Yang, Y.; Zhang, Z.; Wang, X.; Yang, X.; An, Y.; Guo, B. Metal organic frameworks-derived porous carbons/ruthenium oxide composite and its application in supercapacitor. J. Alloy. Compd. 2018, 735, 1673-1681. [CrossRef]

153. Wang, J.; Luo, X.; Young, C.; Kim, J.; Kaneti, Y.V.; You, J.; Kang, Y.-M.; Yamauchi, Y.; Wu, K.C.-W. A Glucose-Assisted Hydrothermal Reaction for Directly Transforming Metal-Organic Frameworks into Hollow Carbonaceous Materials. Chem. Mater. 2018, 30, 4401-4408. [CrossRef]

154. Guo, W.; Xiang, Y.; Xing, Y.; Li, S.; Li, J.; Tang, H. $\left(\mathrm{Co}_{0.94} \mathrm{Fe}_{0.06}\right)_{3} \mathrm{O}_{4} \mathrm{NPs}$ Embedded Porous Hollow Carbon Nanowire Derived from Co-based metal-organic Frameworks and Its Capacitive Behavior. Int. J. Electrochem. Sci. 2016, 11, 9216-9227. [CrossRef]

155. Zhu, Z.; Wang, Z.; Yan, Z.; Zhou, R.; Wang, Z.; Chen, C. Facile synthesis of MOF-derived porous spinel zinc manganese oxide/carbon nanorods hybrid materials for supercapacitor application. Ceram. Int. 2018, 44, 20163-20169. [CrossRef]

156. Qian, J.; Wang, X.; Chai, L.; Liang, L.-F.; Li, T.-T.; Hu, Y.; Huang, S. Robust Cage-Based Zinc-Organic Frameworks Derived Dual-Doped Carbon Materials for Supercapacitor. Cryst. Growth Des. 2018, 18, 2358-2364. [CrossRef]

157. Wang, Y.C.; Li, W.B.; Zhao, L.; Xu, B.Q. MOF-derived binary mixed metal/metal oxide@carbon nanoporous materials and their novel supercapacitive performances. Phys. Chem. Chem. Phys. 2016, 18, 17941-17948. [CrossRef]

158. Zeng, W.; Wang, L.; Shi, H.; Zhang, G.; Zhang, K.; Gong, F.; Wang, T.; Duan, H. Metal-organic-framework-derived $\mathrm{ZnO} @ \mathrm{C} @ \mathrm{NiCo}_{2} \mathrm{O}_{4}$ core-shell structures as an advanced electrode for high-performance supercapacitors. J. Mater. Chem. A 2016, 4, 8233-8241. [CrossRef] 
159. Cao, F.; Zhao, M.; Yu, Y.; Chen, B.; Huang, Y.; Yang, J.; Cao, X.; Lu, Q.; Zhang, X.; Zhang, Z.; et al. Synthesis of Two-Dimensional $\operatorname{CoS}_{1.097} /$ Nitrogen-Doped Carbon Nanocomposites Using Metal-Organic Framework Nanosheets as Precursors for Supercapacitor Application. J. Am. Chem. Soc. 2016, 138, 6924-6927. [CrossRef]

160. Zou, K.-Y.; Liu, Y.-C.; Jiang, Y.-F.; Yu, C.-Y.; Yue, M.-L.; Li, Z.-X. Benzoate Acid-Dependent Lattice Dimension of Co-MOFs and MOF-Derived $\mathrm{CoS}_{2} @ \mathrm{CNTs}$ with Tunable Pore Diameters for Supercapacitors. Inorg. Chem. 2017, 56, 6184-6196. [CrossRef]

161. Liu, S.; Tong, M.; Liu, G.; Zhang, H.; Wang, Z.; Wang, G.; Cai, W.; Zhang, H.; Zhao, H. S,N-Containing Co-MOF derived $\mathrm{Co}_{9} \mathrm{~S}_{8} @ \mathrm{~S}, \mathrm{~N}$-doped carbon materials as efficient oxygen electrocatalysts and supercapacitor electrode materials. Inorg. Chem. Front. 2017, 4, 491-498. [CrossRef]

162. Wu, R.; Wang, D.P.; Kumar, V.; Zhou, K.; Law, A.W.K.; Lee, P.S.; Lou, J.; Chen, Z. MOFs-derived copper sulfides embedded within porous carbon octahedra for electrochemical capacitor applications. Chem. Commun. 2015, 51, 3109-3112. [CrossRef]

163. Li, L.; Liu, Y.; Han, Y.; Qi, X.; Li, X.; Fan, H.; Meng, L. Metal-organic framework-derived carbon coated copper sulfide nanocomposites as a battery-type electrode for electrochemical capacitors. Mater. Lett. 2019, 236, 131-134. [CrossRef]

164. Choi, I.-H.; Jang, S.-Y.; Kim, H.C.; Huh, S. $\operatorname{In}_{6} \mathrm{~S}_{7}$ nanoparticle-embedded and sulfur and nitrogen co-doped microporous carbons derived from In(tdc) 2 metal-organic framework. Dalton Trans. 2018, 47, 1140-1150. [CrossRef]

165. Weng, Q.; Wang, X.; Wang, X.-B.; Zhang, C.; Jiang, X.; Bando, Y.; Golberg, D. Supercapacitive energy storage performance of molybdenum disulfide nanosheets wrapped with microporous carbons. J. Mater. Chem. A 2015, 3, 3097-3102. [CrossRef]

166. Li, Z.-X.; Yang, B.-L.; Jiang, Y.-F.; Yu, C.-Y.; Zhang, L. Metal-Directed Assembly of Five 4-Connected MOFs: One-Pot Syntheses of MOF-Derived $\mathrm{M}_{\mathrm{x}} \mathrm{S}_{\mathrm{y}} @ \mathrm{C}$ Composites for Photocatalytic Degradation and Supercapacitors. Cryst. Growth Des. 2018, 18, 979-992. [CrossRef]

167. Guo, S.; Zhu, Y.; Yan, Y.; Min, Y.; Fan, J.; Xu, Q.; Yun, H. (Metal-Organic Framework)-Polyaniline sandwich structure composites as novel hybrid electrode materials for high-performance supercapacitor. J. Power Sources 2016, 316, 176-182. [CrossRef]

168. Salunkhe, R.; Tang, J.; Kobayashi, N.; Kim, J.; Ide, Y.; Tominaka, S.; Kim, J.H.; Yamauchi, Y. Ultrahigh performance supercapacitors utilizing core-shell nanoarchitectures from a metal-organic framework-derived nanoporous carbon and a conducting polymer. Chem. Sci. 2016, 7, 5704-5713. [CrossRef]

169. Guo, S.; Shen, H.; Tie, Z.; Zhu, S.; Shi, P.; Fan, J.; Xu, Q.; Min, Y. Three-dimensional cross-linked Polyaniline fiber/N-doped porous carbon with enhanced electrochemical performance for high-performance supercapacitor. J. Power Sources 2017, 359, 285-294. [CrossRef]

170. Li, Y.; Kim, J.; Wang, J.; Liu, N.-L.; Bando, Y.; AlShehri, A.A.; Yamauchi, Y.; Hou, C.-H.; Wu, K.C.-W. High performance capacitive deionization using modified ZIF-8-derived, N-doped porous carbon with improved conductivity. Nanoscale 2018, 10, 14852-14859. [CrossRef]

171. Han, B.; Cheng, G.; Zhang, E.; Zhang, L.; Wang, X. Three dimensional hierarchically porous ZIF-8 derived carbon/LDH core-shell composite for high performance supercapacitors. Electrochim. Acta 2018, 263, 391-399. [CrossRef]

172. Wang, B.; Tan, W.; Fu, R.; Mao, H.; Kong, Y.; Qin, Y.; Tao, Y. Hierarchical mesoporous $\mathrm{Co}_{3} \mathrm{O}_{4} / \mathrm{C} \mathrm{MoS}_{2}$ core-shell structured materials for electrochemical energy storage with high supercapacitive performance. Synth. Met. 2017, 233, 101-110. [CrossRef]

173. Xu, X.; Shi, W.; Liu, W.; Ye, S.; Yin, R.; Zhang, L.; Xu, L.; Chen, M.; Zhong, M.; Cao, X.; et al. Preparation of two-dimensional assembled Ni-Mn-C ternary composites for high-performance all-solid-state flexible supercapacitors. J. Mater. Chem. A 2018, 6, 24086-24091. [CrossRef]

174. Kim, J.; Young, C.; Lee, J.; Heo, Y.-U.; Park, M.-S.; Hossain, S.A.; Yamauchi, Y.; Kim, J.H. Nanoarchitecture of MOF-derived nanoporous functional composites for hybrid supercapacitors. J. Mater. Chem. A 2017, 5, 15065-15072. [CrossRef]

175. Li, D.-J.; Lei, S.; Wang, Y.-Y.; Chen, S.; Kang, Y.; Gu, Z.-G.; Zhang, J. Helical carbon tubes derived from epitaxial Cu-MOF coating on textile for enhanced supercapacitor performance. Dalton Trans. 2018, 47, 5558-5563. [CrossRef] 
176. Zhao, K.; Lyu, K.; Gan, Q.; Liu, S.; Zhou, Z.; He, Z. Ordered porous $\mathrm{Mn}_{3} \mathrm{O}_{4} @ \mathrm{~N}-$ doped carbon/graphene hybrids derived from metal-organic frameworks for supercapacitor electrodes. J. Mater. Sci. 2016, 52, 446-457. [CrossRef]

177. Yao, M.; Zhao, X.; Zhang, J.; Tan, W.; Luo, J.; Dong, J.; Zhang, Q. Flexible all-solid-state supercapacitors of polyaniline nanowire arrays deposited on electrospun carbon nanofibers decorated with MOFs. Nanotechnology 2018, 30, 085404. [CrossRef]

178. He, L.; Liu, J.; Yang, L.; Song, Y.; Wang, M.; Peng, D.; Zhang, Z.; Fang, S. Copper metal-organic framework-derived $\mathrm{CuO}_{\mathrm{x}}$-coated three-dimensional reduced graphene oxide and polyaniline composite: Excellent candidate free-standing electrodes for high-performance supercapacitors. Electrochim. Acta 2018, 275, 133-144. [CrossRef]

179. Niu, H.; Zhang, Y.; Liu, Y.; Xin, N.; Shi, W. NiCo-layered double-hydroxide and carbon nanosheets microarray derived from MOFs for high performance hybrid supercapacitors. J. Colloid Interface Sci. 2019, 539, 545-552. [CrossRef]

180. Guo, B.; Yang, Y.; Hu, Z.; An, Y.; Zhang, Q.; Yang, X.; Wang, X.; Wu, H. Redox-active organic molecules functionalized nitrogen-doped porous carbon derived from metal-organic framework as electrode materials for supercapacitor. Electrochim. Acta 2017, 223, 74-84. [CrossRef]

181. Long, J.Y.; Yan, Z.S.; Gong, Y.; Lin, J.H. MOF-derived Cl/O-doped C/CoO and C NPs for high performance supercapacitor. Appl. Surf. Sci. 2018, 448, 50-63. [CrossRef]

182. Dai, E.; Xu, J.; Qiu, J.; Liu, S.; Chen, P.; Liu, Y. Co@Carbon and $\mathrm{Co}_{3} \mathrm{O}_{4} @$ Carbon nanocomposites derived from a single MOF for supercapacitors. Sci. Rep. 2017, 7, 12588. [CrossRef] [PubMed]

183. Song, Y.; Zhang, M.; Liu, T.; Li, T.; Guo, D.; Liu, X.-X. Cobalt-Containing Nanoporous Nitrogen-Doped Carbon Nanocuboids from Zeolite Imidazole Frameworks for Supercapacitors. Nanomaterials 2019, 9, 1110. [CrossRef] [PubMed]

184. Mahmood, A.; Zou, R.; Wang, Q.; Xia, W.; Tabassum, H.; Qiu, B.; Zhao, R. Nanostructured Electrode Materials Derived from Metal-Organic Framework Xerogels for High-Energy-Density ASSC. ACS Appl. Mater. Interfaces 2016, 8, 2148-2157. [CrossRef] [PubMed]

185. Zhou, Z.; Zhang, Q.; Sun, J.; He, B.; Guo, J.; Li, Q.; Li, C.; Xie, L.; Yao, Y. Metal-Organic Framework Derived Spindlelike Carbon Incorporated $\alpha-\mathrm{Fe}_{2} \mathrm{O}_{3}$ Grown on Carbon Nanotube Fiber as Anodes for High-Performance Wearable ASSCs. ACS Nano 2018, 12, 9333-9341. [CrossRef] [PubMed]

186. Yang, Q.; Liu, Y.; Yan, M.; Lei, Y.; Shi, W. MOF-derived hierarchical nanosheet arrays constructed by interconnected NiCo-alloy@NiCo-sulfide core-shell NPs for high-performance aSSCs. Chem. Eng. J. 2019, 370, 666-676. [CrossRef]

187. Chen, S.; Cai, D.; Yang, X.; Chen, Q.; Zhan, H.; Qu, B.; Wang, T. Metal-Organic Frameworks Derived Nanocomposites of Mixed-Valent MnOx NPs In-Situ Grown on Ultrathin Carbon Sheets for High-Performance Supercapacitors and Lithium-Ion Batteries. Electrochim. Acta 2017, 256, 63-72. [CrossRef]

188. Yao, M.; Zhao, X.; Jin, L.; Zhao, F.; Zhang, J.; Dong, J.; Zhang, Q. High energy density aSSCs based on MOF-derived nanoporous carbon/manganese dioxide hybrids. Chem. Eng. J. 2017, 322, 582-589. [CrossRef]

189. Nagamuthu, S.; Ryu, K. MOF-derived microstructural interconnected network porous $\mathrm{Mn}_{2} \mathrm{O}_{3} / \mathrm{C}$ as negative electrode material for aSSC device. CrystEngComm 2019, 21, 1442-1451. [CrossRef]

190. Dubal, D.P.; Jayaramulu, K.; Sunil, J.; Kment, Š.; Gomez-Romero, P.; Narayana, C.; Zboril, R.; Fischer, R.A. Metal-Organic Framework (MOF) Derived Electrodes with Robust and Fast Lithium Storage for Li-Ion Hybrid Capacitors. Adv. Funct. Mater. 2019, 29. [CrossRef]

191. Liu, S.; Zhou, J.; Cai, Z.; Fang, G.; Cai, Y.; Pan, A.; Liang, S. $\mathrm{Nb}_{2} \mathrm{O}_{5}$ quantum dots embedded in MOF derived nitrogen-doped porous carbon for advanced hybrid supercapacitor applications. J. Mater. Chem. A 2016, 4, 17838-17847. [CrossRef]

192. Young, C.; Salunkhe, R.; AlShehri, S.M.; Ahamad, T.; Huang, Z.-G.; Henzie, J.; Yamauchi, Y. High energy density supercapacitors composed of nickel cobalt oxide nanosheets on nanoporous carbon nanoarchitectures. J. Mater. Chem. A 2017, 5, 11834-11839. [CrossRef]

193. Farisabadi, A.; Moradi, M.; Hajati, S.; Kiani, M.A.; Espinos, J.P. Controlled thermolysis of MIL-101(Fe, Cr) for synthesis of $\mathrm{Fe}_{\mathrm{x}} \mathrm{O}_{\mathrm{y}}$ /porous carbon as negative electrode and $\mathrm{Cr}_{2} \mathrm{O}_{3}$ /porous carbon as positive electrode of supercapacitor. Appl. Surf. Sci. 2019, 469, 192-203. [CrossRef] 
194. Tong, M.; Liu, S.; Zhang, X.; Wu, T.; Zhang, H.; Wang, G.; Zhang, Y.; Zhu, X.; Zhao, H. Two-dimensional CoNi nanoparticles@S,N-doped carbon composites derived from S,N-containing Co/Ni MOFs for high performance supercapacitors. J. Mater. Chem. A 2017, 5, 9873-9881. [CrossRef]

195. Zhang, S.; Li, D.; Chen, S.; Yang, X.; Zhao, X.; Zhao, Q.; Komarneni, S.; Yang, D. Highly stable supercapacitors with MOF-derived $\mathrm{Co}_{9} \mathrm{~S}_{8} /$ carbon electrodes for high rate electrochemical energy storage. J. Mater. Chem. A 2017, 5, 12453-12461. [CrossRef]

196. Sun, S.; Luo, J.; Qian, Y.; Jin, Y.; Liu, Y.; Qiu, Y.; Li, X.; Fang, C.; Huang, Y.; Huang, Y. Metal-Organic Framework Derived Honeycomb $\mathrm{Co}_{9} \mathrm{~S}_{8} @ \mathrm{C}$ Composites for High-Performance Supercapacitors. Adv. Energy Mater. 2018, 8, 1801080. [CrossRef]

197. Qiu, J.; Bai, Z.; Liu, S.; Liu, Y. Formation of nickel-cobalt sulphide@graphene composites with enhanced electrochemical capacitive properties. RSC Adv. 2019, 9, 6946-6955. [CrossRef]

198. Yi, M.; Zhang, C.; Cao, C.; Xu, C.; Sa, B.; Cai, D.; Zhan, H. MOF-Derived Hybrid Hollow Submicrospheres of Nitrogen-Doped Carbon-Encapsulated Bimetallic Ni-Co-S NPs for Supercapacitors and Lithium Ion Batteries. Inorg. Chem. 2019, 58, 3916-3924. [CrossRef]

199. Wang, Y.; Huang, J.; Xiao, Y.; Peng, Z.; Yuan, K.; Tan, L.; Chen, Y. Hierarchical nickel cobalt sulfide nanosheet on MOF-derived carbon nanowall arrays with remarkable supercapacitive performance. Carbon 2019, 147, 146-153. [CrossRef]

200. Yan, Y.; Li, A.; Lu, C.; Zhai, T.; Lu, S.; Li, W.; Zhou, W. Double-layered yolk-shell microspheres with $\mathrm{NiCo}_{2} \mathrm{~S}_{4}-\mathrm{Ni}_{9} \mathrm{~S}_{8}-\mathrm{C}$ hetero-interfaces as advanced battery-type electrode for hybrid supercapacitors. Chem. Eng. J. 2020, 396, 125316. [CrossRef]

201. Yan, Z.S.; Long, J.Y.; Zhou, Q.F.; Gong, Y.; Lin, J.H. One-step synthesis of $\mathrm{MnS} / \mathrm{MoS}_{2} / \mathrm{C}$ through the calcination and sulfurization of a bi-metal-organic framework for a high-performance supercapacitor and its photocurrent investigation. Dalton Trans. 2018, 47, 5390-5405. [CrossRef] [PubMed]

202. Li, X.; Qiao, Y.; Wang, C.; Shen, T.; Zhang, X.; Wang, H.; Li, Y.; Gao, W. MOF-derived Co/C nanocomposites encapsulated by $\mathrm{Ni}(\mathrm{OH})_{2}$ ultrathin nanosheets shell for high performance supercapacitors. J. Alloy Compd. 2019, 770, 803-812. [CrossRef]

203. Zhang, Y.; Lin, B.; Wang, J.; Tian, J.; Sun, Y.; Zhang, X.; Yang, H. All-solid-state aSSCs based on ZnO quantum dots/carbon/CNT and porous Ndoped carbon/CNT electrodes derived from a single ZIF-8/CNT template. J. Mater. Chem. A 2016, 4, 10282-10293. [CrossRef]

204. Yang, Q.; Li, Z.; Zhang, R.; Zhou, L.; Shao, M.; Wei, M. Carbon modified transition metal oxides/hydroxides nanoarrays toward high-performance flexible all-solid-state supercapacitors. Nano Energy 2017, 41, 408-416. [CrossRef]

205. Yilmaz, G.; Yam, K.M.; Zhang, C.; Fan, H.J.; Ho, G.W. In Situ Transformation of MOFs into Layered Double Hydroxide Embedded Metal Sulfides for Improved Electrocatalytic and Supercapacitive Performance. Adv. Mater. 2017, 29, 1606814. [CrossRef] [PubMed]

(C) 2020 by the authors. Licensee MDPI, Basel, Switzerland. This article is an open access article distributed under the terms and conditions of the Creative Commons Attribution (CC BY) license (http://creativecommons.org/licenses/by/4.0/). 